\title{
Phasengleichgewichte beim Ausfällen von Proteinen aus wässrigen Lösungen
}

\author{
vom Fachbereich Maschinenbau und Verfahrenstechnik \\ der Technischen Universität Kaiserslautern \\ zur Erlangung des akademischen Grades \\ Doktor-Ingenieur (Dr.-Ing.) \\ genehmigte Dissertation \\ vorgelegt von \\ Dipl.-Chem. Ekaterina Popova \\ aus Sankt Petersburg, Russische Föderation
}

D 386

Kaiserslautern 2007 



\title{
Phasengleichgewichte beim Ausfällen von Proteinen aus wässrigen Lösungen
}

\author{
vom Fachbereich Maschinenbau und Verfahrenstechnik \\ der Technischen Universität Kaiserslautern \\ zur Erlangung des akademischen Grades \\ Doktor-Ingenieur (Dr.-Ing.) \\ genehmigte Dissertation \\ vorgelegt von \\ Dipl.-Chem. Ekaterina Popova \\ aus Sankt Petersburg, Russische Föderation
}

Eingereicht am: $\quad 10.01 .2007$

Mündliche Prüfung am: $\quad$ 11.05.2007

Promotionskomission:

Vorsitzender:

Prof. Dipl.-Ing. Dr. techn. H.-J. Bart

Referenten:

Prof. Dr.-Ing. G. Maurer

Prof. Dr. G. Sadowski

Dekan:

Prof. Dr.-Ing. J. Aurich

D 386

Kaiserslautern 2007 



\section{Vorwort}

Die vorliegende Arbeit entstand in der Zeit von 2002 bis 2006 während meiner Tätigkeit als wissenschaftliche Mitarbeiterin am Lehrstuhl für Technische Thermodynamik der Technischen Universität Kaiserslautern. Herr Prof. Dr.-Ing. G. Maurer hat diese Arbeit angeregt, stets engagiert betreut und mich tatkräftig unterstützt. Für die zahlreichen Diskussionen und die vielen hilfreichen Ratschläge danke ich ihm aufrichtig.

Frau Prof. Dr. G. Sadowski danke ich für die Übernahme des Koreferates und das meiner Arbeit entgegenbrachte grosse Interesse. Herrn Prof. Dipl.-Ing. Dr. techn. H.-J. Bart danke ich für die Übernahme des Vorsitzes der Prüfungskomission.

Bei allen Mitarbeitern des Lehrstuhls für Technische Thermodynamik bedanke ich mich für ein angenehmes Arbeitsklima und eine unkomplizierte Zusammenarbeit. Ein besonderes Dankeschön für die freundliche Unterstützung im Lehrstuhlsalltag und für das Korrekturlesen dieser Arbeit gilt Frau Monika Reim.

Der Deutschen Forschungsgemeinschaft, Bonn-Bad Godesberg danke ich für die finanzielle Unterstützung.

Von ganzem Herzen bedanke ich bei meinen Eltern und meinem Freund Martin, die mich mit ihrer Hilfsbereitschaft und ihrem Verständnis stets liebevoll unterstützt und damit auch zum Gelingen dieser Arbeit beigetragen haben.

Neustadt an der Weinstrasse, im Mai 2007 



\section{Summary}

Salting-out is a widely used method for the isolation and purification of proteins on both the laboratory and the industrial scales. In a salting-out step an aqueous protein solution is forced to undergo a phase separation by adding an appropriate salt solution. The solution is thus separated into a protein lean liquid phase and a protein rich phase. The structure of the protein rich phase may depend on various parameters as, e.g., the initial protein concentration, the amount of added salt, the $\mathrm{pH}$ of solution and the temperature. Caused by kinetically controlled processes, the precipitating protein might not be in thermodynamic equilibrium but in a metastable state.

In the present work, the results of a systematic experimental study on the phase behaviour of aqueous systems of a protein and a single salt are presented. The precipitation of lysozyme, bovine serum albumin, ovalbumin and trypsin by sodium sulphate, ammonium sulphate as well as volatile salts (ammonium carbamat and ammonium bicarbonate) was investigated. Three types of experiments were performed without $\mathrm{pH}$-adjustment of the aqueous solutions at room temperature: cloud point measurements, phase equilibrium measurements with an analysis of the compositions of the coexisting phases and light microscopy of the precipitated phases.

The appearance of a cloud point in aqueous (protein + salt + water) systems implies the start of phase separation. However, it does not say anything about the structure and the thermodynamical stability of the coexisting phases. It was shown, that by cloud point measurements the boundary between one-phase and two-phase regions (solid-liquid boundary) is overpassed. But it was also shown, that cloud point may occur in a one phase region. In such cases it is suggested, that a macromolecular impurity precipitates. The measured cloud point curves cover salt concentrations up to $40 \mathrm{wt} \%$ (depending on salt solubility) at protein concentrations up to $25 \mathrm{wt} \%$. The salt concentration required to turn the solution cloudy increases rapidly with decreasing protein concentration.

The experimental results for the cloud points in (lysozyme + sodium sulphate (ammonium sulphate) + water) are in good agreement with literature data for amorphous lysozyme. About $15 \mathrm{wt} \%$ of sodium sulphate, or $20 \mathrm{wt} \%$ ammonium sulphate, or $9 \mathrm{wt} \%$ ammonium carbamate 
or $6 \mathrm{wt} \%$ ammonium bicarbonate are required to cause the appearance of a cloud point in a one weight percent solution of lysozyme.

Aqueous solutions of bovine serum albumin and ovalbumin could be turned cloudy with aqueous solutions of ammonium sulphate. In both cases the concentration of about $30 \mathrm{wt} \%$ salt is required to turn a one weight percent protein solution cloudy. The addition of saturated sodium sulphate solution results in phase separation neither with bovine serum albumin solutions nor with ovalbumin solutions. The addition of saturated solutions of the volatile salts to aqueous bovine serum albumin (ovalbumin) solution results in the formation of gas.

The phase equilibrium measurements gave the coexisting protein lean and protein rich phases. In systems (bovine serum albumin (ovalbumin) +sodium sulphate + water) a three-phase equilibrium was observed. In nearly all experiments the supernatant protein lean phase was homogenous whereas the protein rich precipitate was in all cases a mixture of the "true" precipitate and the protein lean liquid phase as a complete phase separation could not be achieved.

In all (lysozyme + salt + water) systems the formation of lysozyme crystals was observed. At low salt concentration salt free lysozyme crystals are formed. The composition of these crystals is about $16 \mathrm{wt} \%$ water and $84 \mathrm{wt} \%$ lysozyme. This observation is in good agreement with literature data. The crystals which form at high salt concentration may contain up to 15 $w t \%$ of salt.

In further work the influence of $\mathrm{pH}$ on phase behaviour (lysozyme + sodium sulphate (ammonium sulphate) + water) systems was investigated. The composition of salt free lysozyme crystals remained the same over a wide range of $\mathrm{pH}$.

The protein lean phase coexisting with lysozyme crystals may content up to $12 \mathrm{wt} \%$ of protein. The lysozyme solubility is significantly reduced by volatile salts. This can be used in the treatment of aqueous protein solutions. Moreover, both the protein lean and protein rich phases can be easily desalted when volatile salts are used as precipitating agent.

The salting-out of bovine serum albumin as well as of ovalbumin with ammonium sulphate results in the precipitation of an amorphous water-soluble phase. No protein crystals were 
observed. The amorphous protein rich phase may contain up to $20 \mathrm{wt} \%$ of the salt. The solubility of bovine serum albumin as well as ovalbumin is higher than that of lysozyme.

A metastable equilibrium between a liquid protein lean phase and an amorphous protein rich phase was observed by salting-out of these proteins with sodium sulphate. The protein concentration in the protein lean phase is very small and seems to be independent of the salt concentration. In case of stable three-phase equilibrium a protein lean supernatant phase coexists with a sodium sulphate decahydrate crystals and a very viscous protein rich phase.

In the system (trypsin + ammonium sulphate + water) a two-phase equilibrium between an amorphous precipitate and a liquid protein lean phase was observed. The stability of trypsin should be taken into account when choosing the precipitating salt, as trypsin is only stable at low $\mathrm{pH}$.

The present work contributes to the understanding of phase behaviour of (protein + salt + water) mixtures. Some model systems with sodium sulphate and ammonium sulphate were investigated. It was shown, that volatile salts (i.e. salts from ammonia and carbon dioxide) can be successfully used for precipitating of proteins from aqueous solutions. The experimental results of this work provide a basis for modelling the phase behaviour of (protein + salt + water) systems, e.g. protein salting-out and protein crystallisation. 


\section{Inhaltsverzeichnis}

SUMMARY I

FORMELZEICHEN UND INDIZES VIII

1 EINLEITUNG 1

2 STAND DES WISSENS 3

2.1 Physikalisch-chemische Eigenschaften der Proteine 3

2.1.1 Aufbau der Proteine 3

2.1.2 Löslichkeit von Proteinen in wässrigen Lösungen 5

2.1.3 Einfluss von $\mathrm{pH}$ und Einfluss eines Salzes auf die Löslichkeit 6

2.2 Phasenverhalten wässriger, proteinhaltiger Systeme 8

2.2.1 Spontanes Ausfällen durch Salzzugabe: Salting Out 9

2.2.2 Kristallisation eines Proteins 12

2.2.3 Metastabiles Flüssig-Flüssig-Gleichgewicht 14

2.2.4 Komplette Phasendiagramme 16

2.2.5 Molekulare Thermodynamik proteinhaltiger Lösungen 19

3 EXPERIMENTELLE UNTERSUCHUNGEN 22

$\begin{array}{lll}3.1 & \text { Einführung } & 22\end{array}$

$\begin{array}{lll}3.2 & \text { Verwendete Materialien } & 23\end{array}$

3.3 Eigenschaften der reinen Komponenten 24

$\begin{array}{llr}3.4 & \text { Trübungskurve } & 26\end{array}$

3.4.1 Experimentelle Vorgehensweise 26

$\begin{array}{lll}3.4 .2 & \text { Anmerkungen } & 27\end{array}$

$\begin{array}{lll}3.5 & \text { Phasengleichgewicht } & 28\end{array}$

3.5.1 Experimentelle Vorgehensweise 28

3.5.2 Überblick über Messmethoden 29 
3.5.3 UV/VIS Spektrophotometrie 30

3.5.4 Ionenchromatographie 33

3.5.5 Gefriertrocknung 34

3.5.6 Analyse von Natriumsulfat in der proteinreichen Phase 34

3.5.7 Karl-Fischer Titration $\quad 35$

$\begin{array}{lll}3.6 & \text { pH-Wert-Messungen } & 35\end{array}$

$\begin{array}{lll}3.7 & \text { Mikroskopische Untersuchungen } & 36\end{array}$

$4 \quad$ ERGEBNISSE UND DISKUSSION

$\begin{array}{lll}4.1 & \text { Lysozym } & 37\end{array}$

4.1.1 Lysozym $-\mathrm{Na}_{2} \mathrm{SO}_{4}-\mathrm{H}_{2} \mathrm{O}$

4.1.2 Lysozym - $\left(\mathrm{NH}_{4}\right)_{2} \mathrm{SO}_{4}-\mathrm{H}_{2} \mathrm{O}$

4.1.3 Lysozym - Flüchtiges $\mathrm{Salz}-\mathrm{H}_{2} \mathrm{O}$

$\begin{array}{llr}4.2 & \text { Bovin Serum Albumin } & 58\end{array}$

4.2.1 $\mathrm{BSA}-\left(\mathrm{NH}_{4}\right)_{2} \mathrm{SO}_{4}-\mathrm{H}_{2} \mathrm{O} \quad 58$

4.2.2 $\mathrm{BSA}-\mathrm{Na}_{2} \mathrm{SO}_{4}-\mathrm{H}_{2} \mathrm{O}$

$\begin{array}{lll}4.3 & \text { Ovalbumin } & 70\end{array}$

4.3.1 Ovalbumin $-\left(\mathrm{NH}_{4}\right)_{2} \mathrm{SO}_{4}-\mathrm{H}_{2} \mathrm{O} \quad 70$

4.3.2 Ovalbumin $-\mathrm{Na}_{2} \mathrm{SO}_{4}-\mathrm{H}_{2} \mathrm{O} \quad 75$

$\begin{array}{llr}4.4 & \text { Trypsin } & 82\end{array}$

4.4.1 Trypsin $-\left(\mathrm{NH}_{4}\right)_{2} \mathrm{SO}_{4}-\mathrm{H}_{2} \mathrm{O} \quad 82$

5 ZUSAMMENFASSUNG $\quad 87$

$\begin{array}{ll}\text { LITERATURVERZEICHNIS } & 90\end{array}$

$\begin{array}{ll}\text { ANHANG } & 97\end{array}$

$\begin{array}{lll}\text { A Versuchsapparatur } & 97\end{array}$

B Ergebnisse der experimentellen Untersuchungen zur Bestimmung der Trübungskurven 
D Mikroskopische Aufnahmen und Zusammensetzungen der Feedlösungen

D.1 Lysozym $-\mathrm{Na}_{2} \mathrm{SO}_{4}-\mathrm{H}_{2} \mathrm{O}$

D.2 Lysozym - $\left(\mathrm{NH}_{4}\right)_{2} \mathrm{SO}_{4}-\mathrm{H}_{2} \mathrm{O}$

D.3 Lysozym $-\mathrm{NH}_{2} \mathrm{COONH}_{4}-\mathrm{H}_{2} \mathrm{O}$

D.4 Lysozym $-\mathrm{NH}_{4} \mathrm{HCO}_{3}-\mathrm{H}_{2} \mathrm{O}$

D.5 Bovin Serum Albumin - $\left(\mathrm{NH}_{4}\right)_{2} \mathrm{SO}_{4}-\mathrm{H}_{2} \mathrm{O}$

D.6 Bovin Serum Albumin - $\mathrm{Na}_{2} \mathrm{SO}_{4}-\mathrm{H}_{2} \mathrm{O}$

D.7 Ovalbumin - $\left(\mathrm{NH}_{4}\right)_{2} \mathrm{SO}_{4}-\mathrm{H}_{2} \mathrm{O}$

D.8 Ovalbumin $-\mathrm{Na}_{2} \mathrm{SO}_{4}-\mathrm{H}_{2} \mathrm{O}$

D.9 Trypsin $-\left(\mathrm{NH}_{4}\right)_{2} \mathrm{SO}_{4}-\mathrm{H}_{2} \mathrm{O}$ 


\title{
Formelzeichen und Indizes
}

\author{
Formelzeichen / Abkürzungen
}

a

A

A

$\mathrm{B}_{22}$

BSA

c

DLVO-Theorie

F

$I_{m}$

$I$

$k$

$K_{s}$

1

$l$

$m$

M

$\mathrm{N}_{\mathrm{A}}$

$p$

$\mathrm{pH}$

pI

r

$\mathrm{R}$

S

$\mathrm{t}$

$\mathrm{T}$

$W(r)$

Z

Faktor in der chromatographischen Kalibrierung

Absorption der UV-Licht

Peakfläche einer Komponente

Zweite osmotische Virialkoeffizient

Bovin Serum Albumin

Konzentration in Masse pro Volumen

Derjaguin-Landau-Verwey-Overbeek Theorie

Zwischenmolekulare Kraft

Ionenstärke, $I=\frac{1}{2} \sum_{i=1}^{N} m_{i} z_{i}^{2}$

Intensität der Strahlung

Boltzmann-Konstante

Aussalzkonstante

Liter

Schichtdicke

Molalität in $\frac{m o l}{1000 g(\text { Wasser })}$

Molmasse in $\mathrm{g} / \mathrm{mol}$

Avogadrozahl

Druck

pH-Wert; entspricht dem negativen dekadischen Logarithmus der $\mathrm{H}_{3} \mathrm{O}^{+}$-Ionen-Aktivität

isoelektrischer Punkt des Dissoziationsgleichgewichtes

Abstand

universelle Gaskonstante

Löslichkeit eines Proteins, mg/g $\mathrm{H}_{2} \mathrm{O}$ bzw. mg/ml

Temperatur in Celsius

Temperatur in Kelvin

„Potential of mean force“, PMF

Ladungszahl eines Ions 
$\beta$

$\varepsilon$

$\pi$

$\sum$

$\xi$

\section{Indizes}

disp

el

hs

$i$

$\mathrm{P}$

$\mathrm{S}$

W
Beta-Parameter in der Cohn Gleichung

Extinktionskoeffizient

osmotischer Druck

Summenzeichen

Massenanteil einer Komponente

Dispersionskräfte

elektrostatische Kräfte

"hard-sphere" (harte Kugel) Wechselwirkungen

Komponente $i$

Protein

Salz

Wasser 


\section{Einleitung}

Der wachsende Bedarf an Enzymen bzw. Proteinen für z. B. medizinische, zunehmend aber auch technische Zwecke, ist nur durch deren biotechnologische Herstellung zu decken. Häufig werden dafür gentechnisch veränderte Hefen oder Bakterien eingesetzt, die aus dem ihnen zugeführten Substrat (unter anderem) das gewünschte Protein metabolisieren. Auf diese Weise gewonnene Proteine müssen aus wässrigen Lösungen abgetrennt und gereinigt werden. $\mathrm{Zu}$ den häufig verwendeten Grobreinigungsverfahren gehören das isoelektrische Ausfällen und das Ausfällen mit Hilfe von Salzen, organischen Lösungsmitteln und Polymeren [1].

Die Fällung mit Hilfe von Salzen (z. B. Ammoniumsulfat) ist ein unkompliziertes und verbreitetes Verfahren, bei dem die biologischen Eigenschaften eines Proteins erhalten bleiben. Dieses Verfahren basiert auf dem Aussalzeffekt, d. h. dem Verringern der Löslichkeit eines Proteins mit steigender Salzkonzentration. Das Phasenverhalten eines proteinhaltigen Systems wird durch eine Vielzahl von Parametern, z. B. Art und Konzentration der Stoffe, Temperatur, pH-Wert und Ionenstärke, beeinflusst. Beim Ausfällen der Proteine können sowohl stabile als auch metastabile Phasengleichgewichte auftreten. Trotz der großen Bedeutung dieses Phänomens bei der biotechnologischen Herstellung von Proteinen sind die das Ausfällen verursachenden physikalisch-chemischen Effekte weitgehend ungeklärt. Deshalb wird die Thermodynamik solcher Phasengleichgewichte intensiv untersucht. Dabei stehen Arbeiten zur Bestimmung der Trübungskurven in wässrigen Proteinlösungen [2-8], der Löslichkeit von amorphen Proteinen in wässrigen Salzlösungen [9-14] sowie der Kristallisation von Proteinen [15-18] im Vordergrund des Interesses. Die Untersuchungen konzentrieren sich meistens auf eines der beschriebenen Phänomene. Über allgemeine thermodynamische Forschungen auf diesem Gebiet wird in der Literatur selten berichtet $[10,19,20]$.

Für die Auslegung und Optimierung des Reinigungsverfahrens eines Proteins ist die Kenntnis aller Phasengleichgewichte in einem System aus Protein, Salz und Wasser und deren Beeinflussung durch Verfahrensparameter erforderlich. In diesem Zusammenhang muss die Verteilung aller Komponenten auf die koexistierenden Phasen untersucht werden.

Die vorliegende Arbeit ist Teil eines Projektes am Lehrstuhl für Technische Thermodynamik der Technischen Universität Kaiserslautern, das in Zusammenarbeit mit den Arbeitsgruppen von Prof. P. A. Pessôa Filho von der Faculty of Chemical Engineering der Escola Politecnica, São Paulo / Brasilien und Prof. E. Miranda vom Department of Biotechnological Processes der Universidade Estadual de Campinas - UNICAMP, Campinas / Brasilien, mit 
Unterstützung durch die Deutsche Forschungsgemeinschaft durchgeführt wird. Ziel dieser Arbeiten ist es, das Phasenverhalten ternärer Systeme Protein - Salz - Wasser zu bestimmen und die das Ausfällen verursachenden physikalisch-chemischen Effekte zu modellieren. In diesem Zusammenhang wurde in der vorliegenden Arbeit das Phasenverhalten solcher ternärer Systeme bei Umgebungstemperatur experimentell untersucht.

Bei der Auswahl der verwendeten Proteine war zu beachten, dass diese in ausreichender Reinheit erhältlich und über einen hinreichenden langen Zeitraum in den zu untersuchenden ternären Systemen stabil sind. In der vorliegenden Arbeit wurden mehrere Proteine untersucht. Lysozym ist ein in fast allen tierischen Körperflüssigkeiten vorkommendes Enzym, das gegen Bakterien wirkt, indem es deren Zellwand abbaut. Therapeutisch verwendetes Lysozym wird aus Hühnereiern gewonnen (Hühnereiweiß-Lysozym). Lysozym aus Hühnereiweiß ist das am gründlichsten untersuchte Lysozym, deshalb wurde es als Modellprotein für die Versuche ausgewählt. Ein weiteres hier verwendetes Protein ist das aus Rinderblut gewonnenes Bovin Serum Albumin (BSA). Genauso wie Ovalbumin (Albumin aus Eiweiß) ist es gut in Wasser löslich und in einem breiten $\mathrm{pH}$ - und Konzentrationsbereich stabil. Trypsin gehört zu den wichtigsten Verdauungsenzymen (Proteasen). Diese in der Medizin (Enzym-Therapie) eingesetzten Enzyme werden aus tierischen Quellen gewonnen. Als „Standardsalze“ für die experimentellen Untersuchungen wurden Natriumsulfat und Ammoniumsulfat gewählt. In weiteren Untersuchungen wurden sogenannte „flüchtige“ Salze (auf der Basis von Ammoniak und Kohlendioxid) eingesetzt. Solche Salze haben den Vorteil, dass die nach einer Abtrennung der Proteine verbleibenden Salzlösungen durch Erwärmung weitgehend entsalzt und die dabei zurückgewonnenen Gase (Ammoniak und Kohlendioxid) zurückgeführt werden können. Die Ergebnisse der experimentellen Untersuchungen sollen die Grundlagen für eine in weiterführenden Arbeiten vorgesehene Modellierung liefern. 


\section{Stand des Wissens}

\subsection{Physikalisch-chemische Eigenschaften der Proteine}

\subsubsection{Aufbau der Proteine}

Proteine sind Makromoleküle aus Aminosäuren. Die Aminosäuren sind ausschließlich durch Peptidbindungen verbunden. Eine Peptidbindung entsteht zwischen einer sauren Carboxylgruppe und einer basischen Aminogruppe zweier Aminosäuren unter Abspaltung eines Wassermoleküls (Abb. 2.1). Diese starke kovalente Bindung kann nur durch konzentrierte Säuren oder Basen, hohe Temperaturen oder proteolytische Enzyme (andere Proteine, sogenannte Proteasen) zerstört werden. Natürliche Proteine enthalten nur 20 von über 80 bekannten Aminosäuren. Die Seitenketten R, die diese 20 Aminosäuren unterscheiden, bestehen aus Kohlenwasserstoffgruppen, die z. B. aromatische Ringe, Aminound Carboxylgruppen, sowie Schwefelwasserstoffgruppen enthalten können. Einige Proteine besitzen „nicht natürliche“ Aminosäuren. Solche Proteine entstehen z. B. durch chemische Modifikation nach der Synthese oder durch Eingriffe in den Synthesevorgang.

a)<smiles>[R]C(N)C(=O)N[NH2+][14CH2][14C]([R])[14C](=O)[14C](=O)O</smiles><smiles>[R]C(N)C(=O)NC([R])C(=O)O</smiles>

b)<smiles>[R]C(NN)C(=O)O</smiles>

Abb. 2.1 Primärstruktur des Proteins: a) Bildung der Peptidbindung zwischen zwei Aminosäuren mit unterschiedlichen Seitenketten R; b) generelle Formel einer Polypeptidkette mit $R_{i}$

Die Vielfalt der chemischen Eigenschaften der Aminosäuren ermöglicht den Einsatz von Proteinen beispielsweise als strukturelle Proteine (z. B. Membranproteine), katalytische Proteine (Enzyme), Transport- und Speicherproteine (z. B. Hämoglobin), Regulationsproteine (z. B. Hormone) und Immunsystemproteine (z. B. Immunoglobuline). 
Die Anzahl der Aminosäuren in einem Proteinmolekül variiert zwischen etwa 100 und 27000. Die Aminosäuresequenz bestimmt die Primärstruktur eines Proteins (Abb. 2.2a). Von über 40000 Proteinen ist die Primärstruktur aufgeklärt.

Die Aminosäurenkette ist $\mathrm{zu}$ einer Sekundärstruktur (Abb. 2.2b) gefaltet. Unter der Sekundärstruktur eines Proteins versteht man eine übergeordnete Struktur, die sich einstellt, wenn nicht benachbarte Aminosäuren der Primärstruktur miteinander in Wechselwirkungen treten, z. B. durch Wasserstoffbrücken, elektrostatische Anziehungskräfte, etc. Drei Sekundärstrukturen (wie $\alpha$-Helix, $\beta$-Faltblätter und Loops) sind bekannt. Bei einer $\alpha$-HelixStruktur faltet sich eine Polypeptidkette zu einer zylinderartigen Struktur, welche eine durchschnittliche Länge von 10 Aminosäuren besitzt und alle Seitenketten nach außen gerichtet hat. Bei einer $\beta$-Faltblatt-Struktur werden Wasserstoffbrücken zwischen zwei nebeneinander liegenden Peptidketten, welche völlig ausgestreckt sind, gebildet. Loops bestehen zum Großteil aus hydrophilen Aminosäuren und sind dadurch recht häufig an der Oberfläche von Proteinen anzutreffen. Wie aus dem Namen schon ersichtlich ist, ermöglichen sie es der Polypeptidkette, innerhalb von wenigen Aminosäuren ihre Richtung zu ändern.

a)

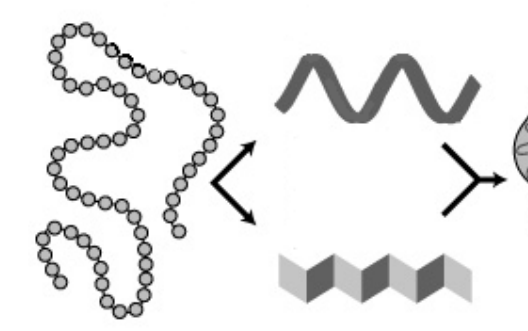

c)

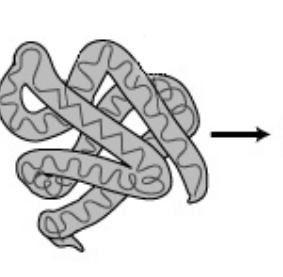

d)

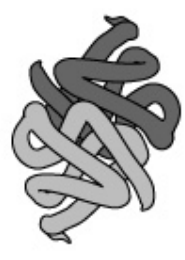

Abb. 2.2 Räumliche Struktur des Proteins: a) Primärstruktur, b) Sekundärstruktur $\alpha$ Helix und $\beta$-Faltblatt; c) Tertiärstruktur und d) quaternäre Struktur

Als Tertiärstruktur bezeichnet man die räumliche Anordnung, die das Protein in einer wässrigen Lösung unter bestimmten Bedingungen (z. B. Temperatur und pH-Wert), einnimmt. Die Tertiärstruktur (Abb. 2.2c) kann sich aus verschiedenen Sekundärstrukturen zusammensetzen. Die Tertiärstruktur eines Proteins hängt von zwei wichtigen Faktoren ab: von der Primärstruktur und von den physikalisch-chemischen Bedingungen, die von der Umgebung aufgeprägt werden. So brechen bei Temperaturerhöhung einige der schwachen intramolekularen Bindungen (meistens Dipol-Dipol Wechselwirkungen) auf, so dass sich die Tertiärstruktur ändert. Verändert sich der pH-Wert des Mediums, so verlieren einige saure 
oder basische Seitenketten ihre negativen bzw. positiven Ladungen, und darauf basierende Bindungen werden aufgelöst, das wirkt sich wiederum auf die Tertiärstruktur aus. Die biochemischen Eigenschaften eines Proteins hängen von der Tertiärstruktur ab. Wird beispielsweise die Tertiärstruktur eines Enzyms verändert, so ändern sich seine katalytischen Eigenschaften; im Extremfall verliert das Enzym seine katalytische Wirkung.

Viele Proteine besitzen eine so genannte quaternäre Struktur (Abb. 2.2d). Sie entsteht dadurch, dass zwei oder mehrere räumlich gefaltete Polypeptidketten durch nichtkovalente Wechselwirkungen zusammengehalten werden.

Man unterscheidet zwei Hauptgruppen von Proteinen: globulare und fibrillare Proteine. Die globularen Proteine, deren Tertiär- oder Quaternärstruktur einer Kugel oder einer Birnenform ähnelt, sind meist in Wasser (Albumine) oder in wässrigen Salzlösungen (Globuline) gut löslich (s. Abschnitt 2.1.2). Die fibrillaren Proteine weisen eine fadenförmige Struktur auf und sind in Wasser unlöslich (z. B. Keratin oder Kollagen).

\subsubsection{Löslichkeit von Proteinen in wässrigen Lösungen}

Durch Aminosäurereste und unpolare bzw. polare Gruppen der seitlichen Ketten des Proteinmoleküls, die sich auf der Proteinoberfläche befinden, besitzen die Proteinmoleküle sowohl hydrophobe als auch hydrophile Oberflächen. Die Verteilung der hydrophoben und hydrophilen Oberflächen bestimmt die Löslichkeit eines Proteins in Wasser (vgl. Abb. 2.3).
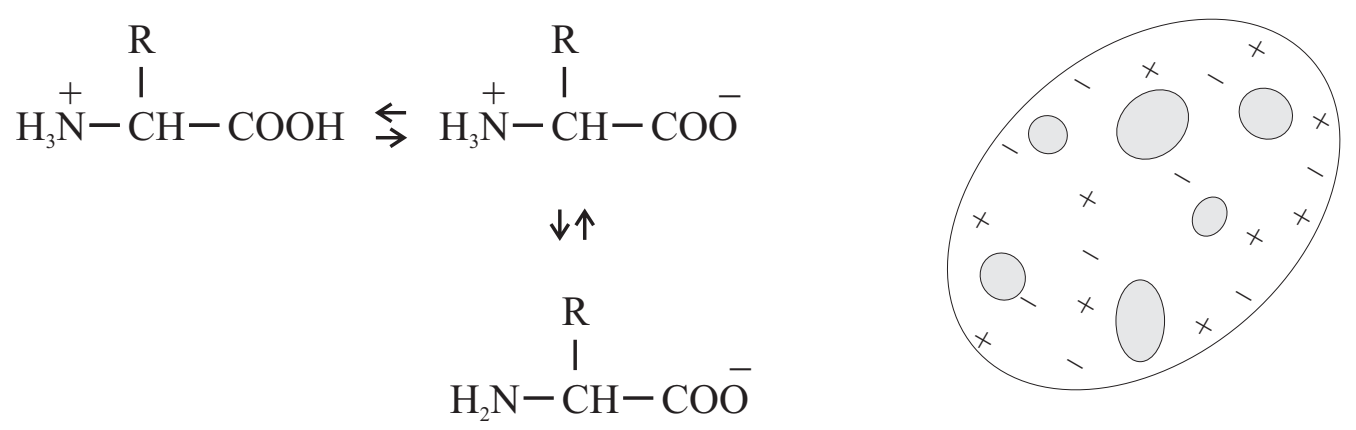

Abb. 2.3 Löslichkeit der Proteine: links - Säure-Base-Gleichgewicht einer Aminosäure; rechts - Verteilung der Ladungen und hydrophoben Oberflächen eines Proteinmoleküls.

Basierend auf dem Löslichkeitsverhalten werden die globularen Proteine in Albumine und Globuline unterteilt. Albumine sind gut in Wasser sowie in verdünnten wässrigen 
Salzlösungen löslich. Globuline dagegen sind ausschließlich in wässrigen Salzlösungen löslich.

Das Löslichkeitsverhalten der Proteine in wässrigen Lösungen resultiert aus verschiedenen Arten von Wechselwirkungen (s. Tabelle 1). In der Lösung lagern sich Wassermoleküle an das Protein an. Sie bilden eine Hydrathülle, wobei die hydrophilen und hydrophoben Oberflächen von Wassermolekülen ,geschützt“ werden. Sind in der Lösung ionische Komponenten vorhanden, so können sie zur Löslichkeit des Proteins beitragen. Kationen und Anionen können auf unterschiedliche Weise mit einem Proteinmolekül in Wechselwirkung treten. Dabei unterscheidet man zwischen nicht spezifischer (elektrostatischer) und spezifischer (chemischer) Bindung. Die Aggregation der Proteinmoleküle (und als Folge das Verringern der Löslichkeit) wird durch Protein-Protein-Wechselwirkungen bedingt.

Tabelle $1 \quad$ Wechselwirkungen zwischen einem Proteinmolekül und seiner Umgebung

\begin{tabular}{|c|c|}
\hline \multicolumn{2}{|c|}{ Proteinmolekül } \\
\hline Hydrophobe Oberflächen & Hydrophyle Oberflächen \\
\hline Protein-Protein-Wechselwirkungen & $\begin{array}{c}\text { Elektrostatische Wechselwirkungen } \\
\text { (Abschirmen) }\end{array}$ \\
\cline { 2 - 3 } & $\begin{array}{c}\text { chemische Bindung Ion-Protein } \\
\text { (Bindung mit } \mathrm{H}^{+}, \mathrm{OH}^{-}, \text {Gegenionen) }\end{array}$ \\
\hline \hline
\end{tabular}

Aufgrund der Vielfalt physikalisch-chemischer Wechselwirkungen zwischen den Komponenten einer wässrigen Proteinlösung wird die Löslichkeit eines Proteins von vielen Parametern beeinflusst.

\subsubsection{Einfluss von pH und Einfluss eines Salzes auf die Löslichkeit}

Je nach pH-Wert ist das Säure-Base-Gleichgewicht der restlichen Amino- und Carboxylgruppen in einem Proteinmolekül (Abb. 2.3a) verschoben. Die Gesamtmenge der Ladungen aller Gruppen legt die Nettoladung eines Proteins fest. Die Nettoladung wird deshalb vom pH-Wert der umgebenden Lösung (Abb. 2.4a) bestimmt. Der pH-Wert, bei dem sich die positiven und negativen Ladungen des Proteinmoleküls gegenseitig aufheben (die Nettoladung also Null wird), nennt man den isoelektrischen Punkt. Dieser pH-Wert wird 
durch pI gekennzeichnet. Die Löslichkeit eines Proteins ist am isoelektrischen Punkt am geringsten (Abb. 2.4b). Ober- oder unterhalb des isoelektrischen Punktes tragen die Proteinmoleküle Ladungen mit gleichen Vorzeichen (positiv oder negativ) und stoßen sich ab. Eine Zusammenballung zu unlöslichen Aggregaten wird dadurch vermindert und die Proteinmoleküle bleiben in Lösung. So ist z. B. die Löslichkeit von Lactalbumin bei pH 5,2 bis 5,3 am geringsten, ober- oder unterhalb dieses $\mathrm{pH}$-Wertes steigt die Löslichkeit des Proteins stark an. Dieses Verhalten ist typisch für globulare Proteine, wobei der pH Wert, bei dem das Löslichkeitsminimum auftritt, von Protein zu Protein verschieden ist.

Da die Nettoladung eines Proteins sich auch auf dessen Tertiärstruktur auswirken kann, sind viele Proteine nur in einem bestimmten $\mathrm{pH}$-Bereich stabil. Verlässt man diesen $\mathrm{pH}$-Bereich, kommt es in der Regel zu irreversiblen Veränderungen der räumlichen Struktur des Proteins. Diese Erscheinung nennt man Denaturieren [1].

a)

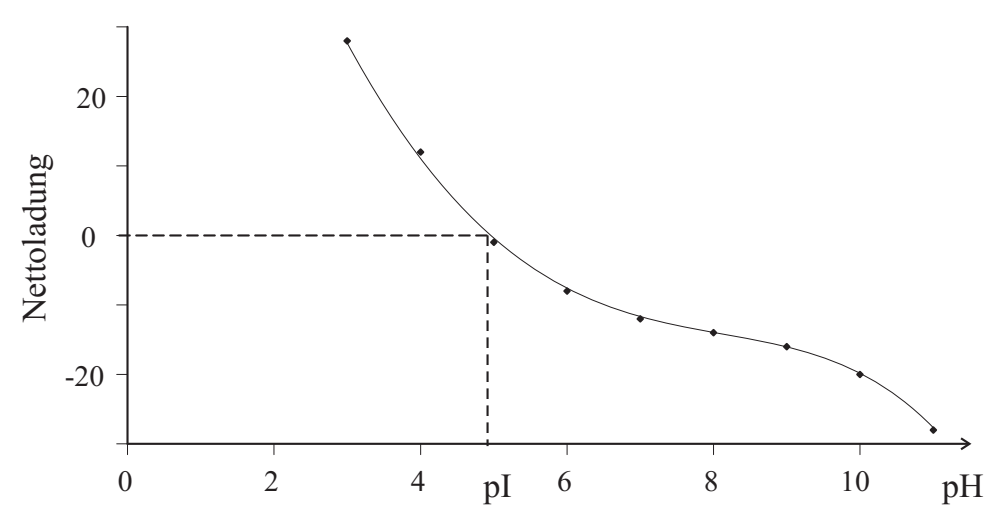

b)

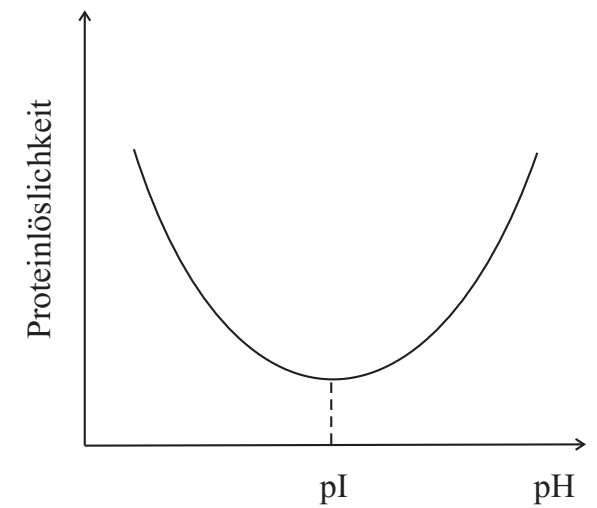

Abb. 2.4 Einfluss des pH-Wertes auf die Proteinlöslichkeit: a) Abhängigkeit der Nettoladung von Ovalbumin vom pH-Wert der Lösung [21]; b) Löslichkeit eines globularen Proteins

Durch Erhöhung der Konzentration eines Salzes kann die Löslichkeit eines Proteins sowohl erhöht als auch erniedrigt werden.

Die Zunahme der Proteinlöslichkeit wird „Salting-In“ (Einsalzen) genannt. Dieser Effekt wird überwiegend bei niedriger Ionenstärke (unter $0,5 \mathrm{M}$ ) beobachtet und kann durch nicht spezifische elektrostatische Wechselwirkungen zwischen geladenem Protein und Salzionen, z. B. mit der Debye-Hückel-Theorie, erklärt werden [22].

Die Erniedrigung der Löslichkeit bei Zugabe eines Salzes wird „Salting-Out“ (Aussalzen) genannt. Aussalzen wird insbesondere bei höherer Ionenstärke beobachtet. Dieser Effekt 
beruht vor allem auf der Konkurrenz von Protein und Salzionen um die Wassermoleküle der Hydrathülle. Bei hoher Ionenkonzentration stehen nicht mehr genügend Wassermoleküle zur Hydratisierung der Proteine zur Verfügung. Die hydrophoben Wechselwirkungen zwischen Proteinmolekülen werden dadurch verstärkt, dies führt zur Aggregation. Aus diesen Erläuterungen erkennt man, dass am isoelektrischen Punkt die Auswirkung einer Änderung der Konzentration eines Salzes gering ist [23,24].

\subsection{Phasenverhalten wässriger, proteinhaltiger Systeme}

Ein Phasendiagramm zeigt die Gleichgewichtszusammensetzungen als Funktion der Einflussgrößen, z. B. Temperatur und Konzentration. Wässrige Proteinlösungen sind in der Regel sehr komplex. Dies resultiert daraus, dass Proteine selten hochrein vorliegen, sondern als mehr oder weniger verunreinigte Stoffe. Als Verunreinigungen treten häufig Salze oder andere makromolekulare Verbindungen (z. B. andere Proteine oder Fettsäuren) auf. In Systemen aus Protein, Salz und Wasser untersucht man üblicherweise den Einfluss der Temperatur oder der Konzentration eines oder mehrerer Salze auf die Proteinlöslichkeit.

Die beim Annähern oder Überschreiten einer Phasengrenze auftretenden thermodynamischen Phänomene sind in wässrigen Proteinlösungen die gleichen wie in wässrigen Lösungen niedermolekularer Stoffe. Allerdings verursacht die komplexe Struktur der in Wasser gelösten Proteine einige Besonderheiten, die überwiegend auf kinetischen Effekten beruhen. Aus diesem Grund werden oft metastabile Zustände (Übersättigung) beobachtet, die zur Nukleation und zum Phasenübergang (z. B. Kristallisation) führen. Ein Schema eines solchen Phasendiagramms für eine konstante Temperatur ist in der Abb. 2.5 dargestellt.

Die Löslichkeitskurve bildet die Grenze zwischen „ungesättigten“ und „übersättigten“ Lösungen. In ungesättigter Lösung befindet sich das System in einem thermodynamisch stabilen Zustand. Dort findet kein Phasenzerfall statt. Unmittelbar an die Löslichkeitskurve grenzt der Bereich der metastabilen Lösung an. In diesem Bereich ist die Lösung stabil gegen kleine Einwirkungen von außen und kann lange einphasig bleiben. Bei noch höheren Salzbzw. Proteinkonzentrationen wird die Stabilitätsgrenze erreicht, bei deren Überschreiten ein Phasenzerfall eintreten muss. Die dabei ausfallende proteinreiche Phase kann eine stabile (kristalline) Phase oder eine metastabile (z. B. flüssige oder amorphe) Phase sein. Diese Phase koexistiert mit einer proteinarmen Lösung. Die Zusammensetzung dieser Lösung stellt die Proteinlöslichkeit, die bei konstanter Temperatur vom Salzgehalt und der Ionenstärke abhängt, dar. 


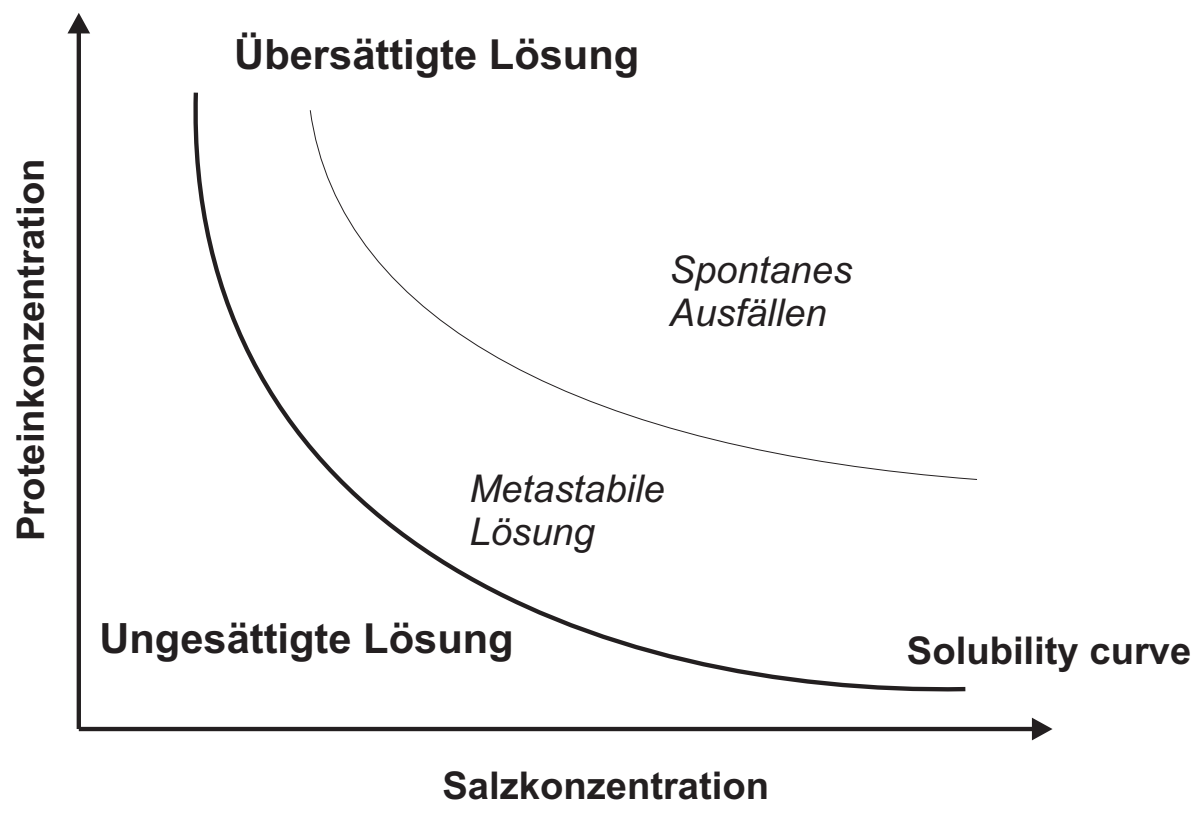

Abb. $2.5 \quad$ Phasenverhalten proteinhaltiger Lösungen

Die Grenzen zwischen einer metastabilen und einer stabilen Phase ist im Experiment in der Regel nicht exakt zu bestimmen, da kinetische Effekte sich entscheidend bemerkbar machen. Das bedeutet auch, dass bei experimentellen Untersuchungen das thermodynamisch stabile Gleichgewicht in der Regel nicht erreicht wird. Aus diesem Grund wird zwischen den Proteinlöslichkeiten in Präsenz von Proteinkristallen und einem amorphen Niederschlag unterschieden.

In den folgenden Abschnitten werden die in proteinhaltigen, wässrigen Systemen auftretenden Phasengleichgewichte diskutiert. Die Darstellung dieser Phasengleichgewichte z. B. in Temperatur-Konzentration Diagrammen wird im Abschnitt 2.2.4 beschrieben. Ein Ansatz der molekularen Thermodynamik zum Beschreiben des Phasenverhaltens proteinhaltiger Lösungen wird im Abschnitt 2.2.5 vorgestellt.

\subsubsection{Spontanes Ausfällen durch Salzzugabe: Salting Out}

Nach der von Melander und Horvath vorgeschlagenen Theorie der hydrophoben Wechselwirkungen [22] dominieren beim Aussalzen zwei Faktoren: die Bildung einer Hydrathülle und die elektrostatischen Wechselwirkungen. Die Zugabe eines Salzes zu einer proteinhaltigen Lösung führt bei ausreichend hoher Salzkonzentration zur Zerstörung der Hydrathülle des Proteinmoleküls durch Veränderungen in der Struktur des Wassers. Dies 
verstärkt die hydrophoben Wechselwirkungen zwischen den Proteinmolekülen und die Proteinmoleküle lagern sich zusammen. In der Regel sind diese Anziehungskräfte so stark, dass das Protein in einem amorphen Zustand ausfällt.

Elektrostatische Wechselwirkungen spielen dabei eine wichtige Rolle: einerseits treten nichtspezifische elektrostatische Wechselwirkungen und andererseits spezifische Bindungen zwischen Salz und Protein auf. Untersuchungen zu Protein-Salz-Wechselwirkungen wurden von Timasheff und Mitarbeitern durchgeführt [25-29]. Dabei zeigte sich, dass die Eigenschaften der Salzionen $\mathrm{zu}$ den Wechselwirkungen beitragen. Salze, die an das Proteinmolekül chemisch gebunden sind, destabilisieren das Protein. Optimal für das Ausfällen sind Salze, die das Hydratisieren von polaren Stellen und das Dehydratisieren von hydrophoben Stellen fördern, ohne sich dabei an das Protein zu binden. Dieser Einfluss wird durch die empirisch gefundene Hofmeister-Reihe [30-32] beschrieben. Für eine Reihe wichtiger Anionen und Kationen ist die Hofmeister-Reihe in der Tabelle 2 angegeben. Die Effektivität der Ionen beim Aussalzen nimmt dabei von links nach rechts ab. So wird, um ein Protein mit einem Sulfatsalz zum Ausfällen zu bringen, eine geringere Menge als mit dem entsprechenden Chloridsalz benötigt.

Tabelle 2 Hofmeister-Reihe für Anionen und Kationen

\begin{tabular}{|l|l|}
\hline Anionen & $\mathrm{PO}_{4}^{3-}>\mathrm{SO}_{4}^{2-}>\mathrm{CH}_{3} \mathrm{COO}^{-}>\mathrm{Cl}^{-}>\mathrm{NO}_{3}^{-}>\mathrm{SCN}^{-}$ \\
\hline Kationen & $\mathrm{NH}_{4}^{+}>\mathrm{K}^{+}>\mathrm{Na}^{+}$ \\
\hline
\end{tabular}

Die Proteinlöslichkeit in salzhaltiger wässriger Lösung wird häufig mit der Cohn Gleichung beschrieben [33]:

$$
\log S=\beta-K_{s} I
$$

Darin ist $S$ die Proteinlöslichkeit (üblicherweise in $\mathrm{mg} / \mathrm{g} \mathrm{H}_{2} \mathrm{O}$ ) und $I$ die Ionenstärke der Lösung (üblicherweise mit der Molalitätsskala beschrieben). $K_{s}$ ist die Aussalzkonstante, die von Protein und Salz abhängt. Der Parameter $\beta$ hängt von der Temperatur und dem Protein ab $[34,35]$. Die Cohn Gleichung wird ebenfalls benutzt, um den Einfluss eines Salzes auf die Löslichkeit organischer Substanzen und Gase in Wasser zu beschreiben.

Die Abbildung 2.6a zeigt ein Schema eines Phasengleichgewichts in einer wässrigen Lösung eines Proteins mit einem Salz. Im Bereich geringer Ionenstärke (d. h. niedrigen Salzgehalts) nimmt die Löslichkeit mit steigender Salzkonzentration zu (Einsalzen). Nachdem ein 
Maximalwert überschritten ist, beobachtet man das Phänomen des Aussalzens. Dabei folgt der Verlauf der Löslichkeit S in Abhängigkeit von der Ionenstärke $I$ der Gleichung (1).

In der Literatur gibt es mehrere Angaben zur Proteinlöslichkeit (in Form eines amorphen Niederschlags), z. B. für Lysozym [10,19,34] sowie für verschiedene Serum Albumine [14]. In der Abbildung 2.6b sind die Messergebnisse von Shih et al. [10] für die Löslichkeit von Lysozym in wässrigen Lösungen von Natriumchlorid in einer der Gleichung (1) entsprechenden Darstellung gezeigt. Dabei wird als weiterer Parameter der $\mathrm{pH}-\mathrm{Wert}$ der Lösung betrachtet. Die Messergebnisse überdecken ausschließlich den „Salting-Out“ Bereich. Die Löslichkeit von Lysozym nimmt im mittleren $\mathrm{pH}$-Bereich mit steigendem $\mathrm{pH}-\mathrm{Wert} \mathrm{ab}$, eine Erklärung hierfür ist die Lage des isoelektrischen Punktes ( $\mathrm{pI}=11)$.

a)

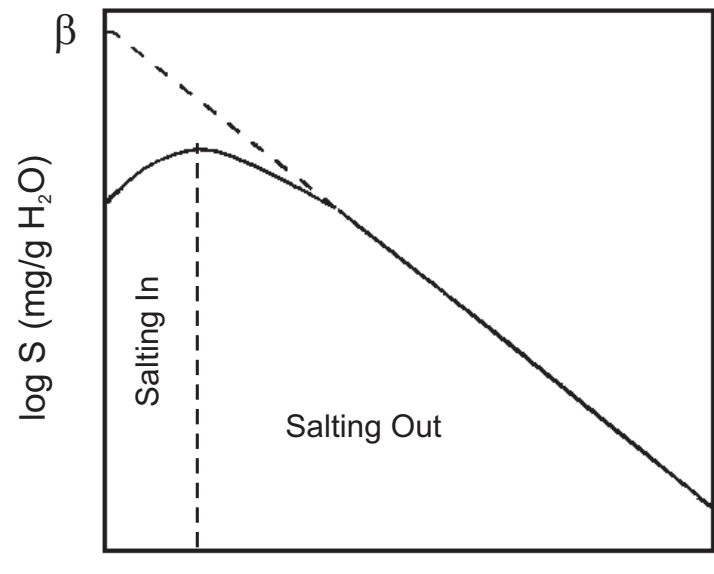

Ionenstärke, m b)

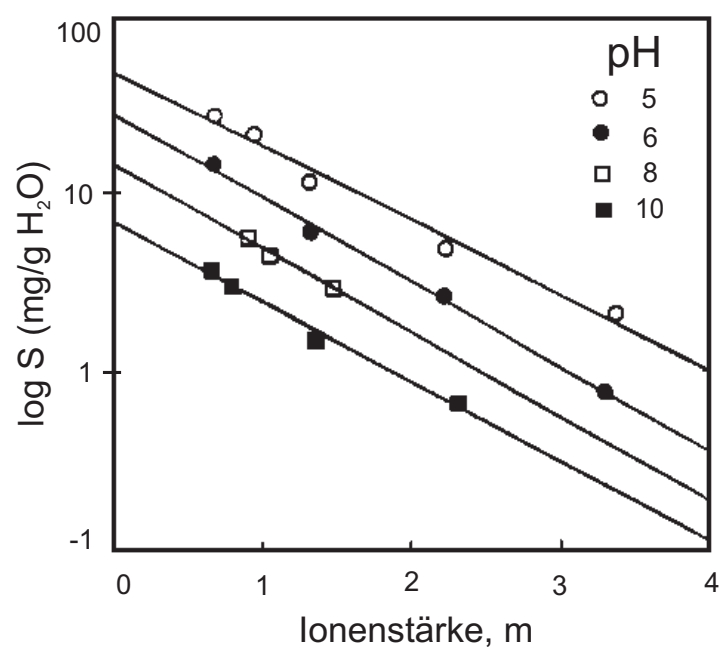

Abb.2.6 Proteinlöslichkeit: a) Einfluss eines Salzes auf das Löslichkeitsverhalten eines Proteins; b) Literaturdaten von Shih et al. [10] für die Löslichkeit von Lysozym in wässrigen Lösungen von $\mathrm{NaCl}$ bei $25^{\circ} \mathrm{C}$.

Die experimentellen Untersuchungen zeigen einen Einfluss der Ladung sowohl der Anionen als auch der Kationen eines Salzes auf die Steigung der Löslichkeitskurve (Faktor $\mathrm{K}_{\mathrm{s}}$ in Gleichung 1), wobei der Einfluss von Anionen und Kationen gegenläufig ist. Der Betrag von $K_{s}$ nimmt mit steigender Ladungszahl der Kationen und mit abnehmender Ladungszahl der Anionen ab [22,26,27]. Salze aus monovalenten Kationen und polyvalenten Anionen (z. B. Natriumsulfat und Ammoniumsulfat) beeinflussen deshalb die Löslichkeit von Proteinen am stärksten. 


\subsubsection{Kristallisation eines Proteins}

Proteinkristalle werden u. a. zur Analyse der räumlichen Struktur eines Proteins benötigt. Die Forschung auf dem Gebiet der Proteinkristallisation befasst sich mit physikalisch-chemischen Grundlagen und experimentellen Methoden, um für eine Röntgenstrukturanalyse geeignete Kristalle zu erzeugen. In der pharmazeutischen Technik ist die Proteinkristallisation ein wichtiger Schritt bei der Feinreinigung und Formulierung der Wirkstoffe. Es wurden mehrere experimentelle Methoden zur Proteinkristallisation entwickelt [36-39]. Obwohl Proteine schon vor 150 Jahren kristallisiert wurden [40-41], sind die Mechanismen der Kristallisation biologischer Makromoleküle nicht vollständig bekannt.

Die Kristallisation eines biologischen Makromoleküls ist aus mehreren Gründen komplizierter als die Kristallisation einer niedrigmolekularen Verbindung. Protein-ProteinWechselwirkungen ähneln den Wechselwirkungen zwischen kleinen Molekülen. Allerdings sind die Kräfte, die einen Kristall zusammenhalten, antiproportional dem Molekulargewicht und wirken in einem Kristall aus Makromolekülen viel schwächer. Ein Proteinmolekül besitzt mehrere Konformationen, mit Auswirkung auf die Kristallstruktur. Die Vielfalt der chemischen Gruppen in einem Proteinmolekül führt dazu, dass schon kleine Veränderungen von pH-Wert, Ionenstärke oder Temperatur die Kristallisation deutlich beeinflussen können. Die physikalisch-chemischen Grundlagen der Proteinkristallisation wurden in Übersichten z. B. von Durbin und Feher [18] und von Rosenberger [16,17] diskutiert. Eine Datensammlung über bereits kristallisierte Proteine wurde von Gilliland [42] vorgestellt.

Für eine Kristallbildung müssen hydrophobe Wechselwirkungen zwischen Proteinmolekülen, die beispielsweise in der Nähe des isoelektrischen Punktes stärker wirken, reduziert werden. Dies wird in der Regel (nach einer Einstellung des $\mathrm{pH}$ auf $\mathrm{pH} \neq \mathrm{pI}$ ) durch die Zugabe von Salzen ( $\mathrm{NaCl}, \mathrm{NH}_{4} \mathrm{NO}_{3}$ usw.) erreicht. Günstige Kristallisationsbedingungen werden dann erreicht, wenn alle Ladungen des Proteinmoleküls abgeschirmt sind [43]. Das geschieht üblicherweise bei Salzkonzentrationen zwischen 0,5 und 1,0 mol/1.

Die Proteine bilden Kristalle, die große Hohlräume (bis zu $85 \%$ des Volumens) aufweisen. Die Hohlräume sind mit Lösung gefüllt und mit Wassermolekülen (sogennantem gebundenem Wasser [44]) „gefüttert“. Es wird oft behauptet, dass die Lösung in den Räumen des Proteinkristalls die gleiche Zusammensetzung, wie die umgebende Lösung, aufweist. Diese Behauptung wird jedoch in Frage gestellt [18]. 
In der Regel beträgt der Wassergehalt in einem Proteinkristall zwischen 13 und 43 Massen-\% [45]. Er kann mittels analytischer Methoden [19] sowie durch Röntgenstrukturanalyse [45-47] bestimmt werden.

Es wurde bereits erwähnt, dass die Löslichkeit eines Proteins davon abhängt, in welcher Form es aus der Lösung ausfällt. Die Löslichkeit von kristallinem Lysozym [34,48-58], Hemoglobin [59,60], Ovalbumin [61], Canavalin [62], Rennin [63], Collagenase [64], Concanavalin A [65] und Aprotinin [66] wurde in wässrigen Salzlösungen experimentell bestimmt.

Die Abbildung 2.7 zeigt den Einfluss verschiedener Parameter auf die Löslichkeit von Lysozymkristallen [34].

a)

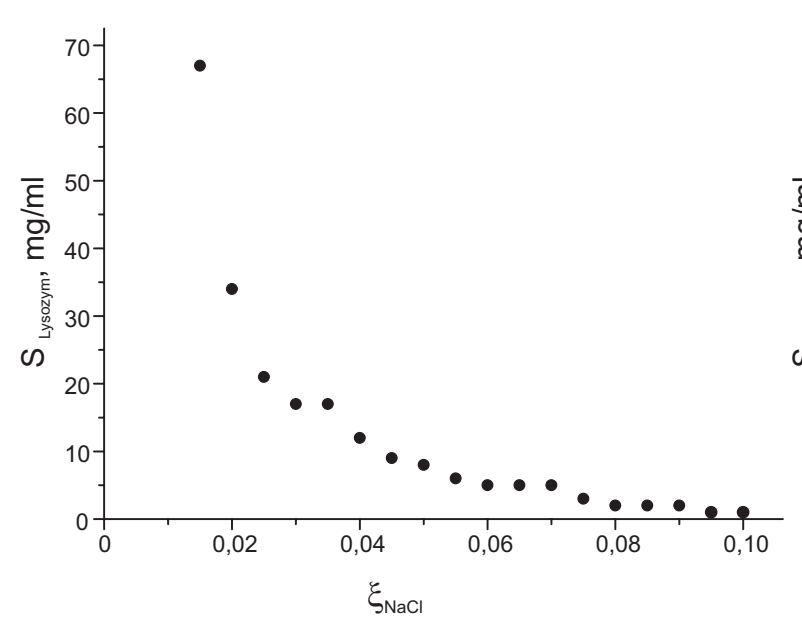

b)

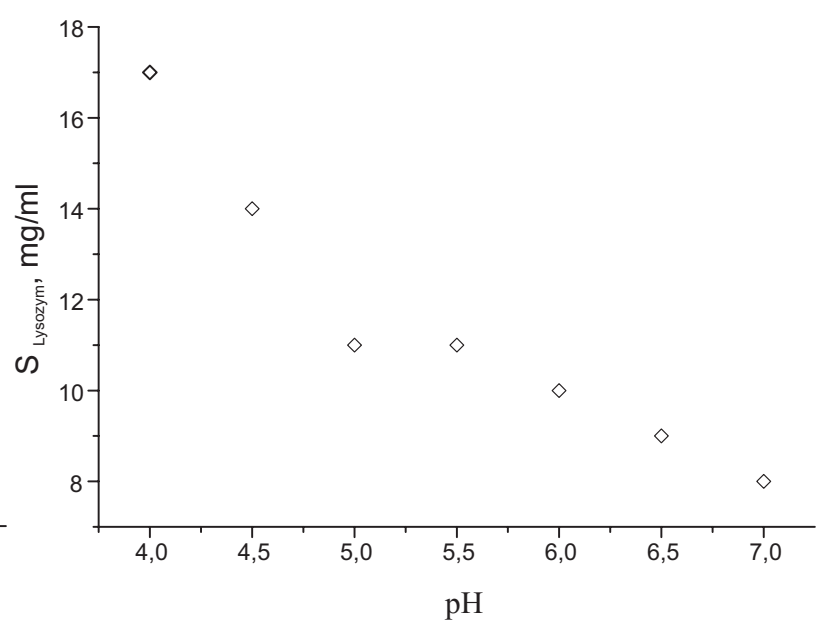

Abb. 2.7 Experimentelle Ergebnisse für die Löslichkeit von Lysozym in wässrigen Lösungen von $\mathrm{NaCl}$ bei $25^{\circ} \mathrm{C}$ : a) Einfluss der Salzkonzentration bei $\mathrm{pH}=5,0$ [34]; b) Einfluss des pH-Wertes bei festgehaltener Salzkonzentration, $\xi_{\mathrm{NaCl}}=3,5$ Massen-\% [34]

Im linken Teil der Abbildung ist der Einfluss der Salzkonzentration auf die Proteinlöslichkeit dargestellt. Die Proteinkonzentration in der proteinarmen Lösung, die sich im Gleichgewicht mit Proteinkristallen befindet, nimmt mit steigender Salzkonzentration ab (Aussalzen). Retailleau et al. [24] haben festgestellt, dass bei der Kristallbildung kein Einsalzen, wie z. B. im Fall des Auflösens eines amorphen Niederschlags, auftritt. Der Einfluss der Temperatur auf die Löslichkeit von kristallinem Protein wurde z. B. in Systemen mit Lysozym [34,54] und Ovalbumin [61] untersucht. In der Regel nimmt die Proteinlöslichkeit mit steigender Temperatur zu. 
Es ist nicht unüblich, dass Proteine mehrere Kristallstrukturen bilden (sog. Polymorphie). Lysozym wurde beispielsweise in mehr als 4 unterschiedlichen kristallographischen Formen kristallisiert [66]. Die Eigenschaften dieser verschiedenen Kristallformen, wie z. B. Löslichkeit $[53,54,56]$ oder Wärmekapazität, unterscheiden sich erheblich.

\subsubsection{Metastabiles Flüssig-Flüssig-Gleichgewicht}

Bei einer Veränderung der Umgebungsbedingungen, wie Temperatur, $\mathrm{pH}-$ Wert oder Konzentration von Komponenten, wird in proteinhaltigen wässrigen Lösungen manchmal die Bildung einer zweiten Flüssigkeit beobachtet (Abb. 2.8a). Die Tropfen dieser Flüssigkeit, die als Koazervat bezeichnet werden, enthalten das Protein in hoher Konzentration.

Ein solches Phasenverhalten wird in der Regel bei Temperaturen unterhalb der Löslichkeitsgrenze Flüssig-Fest beobachtet. Daher handelt es sich um ein metastabiles Flüssig-Flüssig-Gleichgewicht. Insbesondere für kleine Proteine kann sich das FlüssigFlüssig-Gleichgewicht zu höheren Temperaturen hin verlagern, so dass es auch zu einer Überlagerung von stabilen Flüssig-Fest- und Flüssig-Flüssig-Gleichgewichten kommen kann. Aus diesem Grund hat das metastabile Gebiet der Flüssig-Flüssig-Entmischung Konsequenzen sowohl für das Kristallisationsverhalten von Proteinen als auch für die Morphologie der gebildeten Kristalle. 
a)

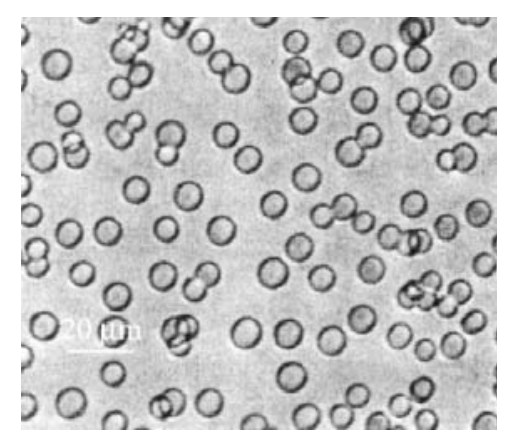

b)

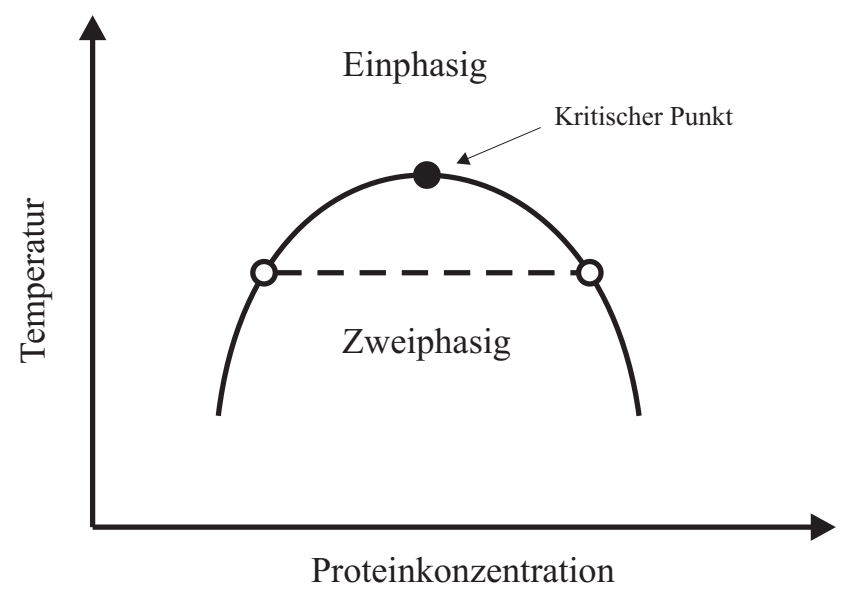

Abb. 2.8 Flüssig-Flüssig-Gleichgewicht: a) Bildung von Koazervat im System Bovin $\gamma E$ Crystallin - Natriumphosphat - Wasser bei $p H=7,1$ [3]; b) schematische Darstellung des Flüssig-Flüssig-Gleichgewichts.

In der Abbildung 2.8b ist ein solches Flüssig-Flüssig-Gleichgewicht schematisch in einem Diagramm dargestellt, in dem die Temperatur über der Proteinkonzentration aufgetragen ist. Die eingetragene Kurve bildet die Grenze zwischen dem ein- und dem zweiphasigen Bereich. Die Punkte kennzeichnen die Zusammensetzungen zweier koexistierender flüssiger Phasen. Dabei wird angenommen, dass sich lediglich die Konzentration des Proteins in beiden Phasen unterscheidet, d. h. der Konzentrationsunterschied des Salzes in beiden Phasen gering ist. Oberhalb der kritischen Temperatur ist die Lösung einphasig.

Die Trübungskurven wurden bereits für mehrere Proteine in salzhaltigen Lösungen gemessen, z. B. für $\gamma$-Crystallin [3,4], Lysozym [2,7,68] und Immunoglobulin [69]. In der Abbildung 2.9 ist die Abhängigkeit der Trübungstemperatur von der Ionenstärke der Lösung im System Lysozym - Natriumchlorid - Wasser dargestellt [2]. Dabei wurden wässrige Lösungen mit einem konstanten Lysozymgehalt $(87 \mathrm{mg} / \mathrm{ml})$ sowie verschiedener Salzkonzentration hergestellt und langsam abgekühlt, bis eine Trübung durch Bildung einer zweiten flüssigen Phase beobachtet wurde. 


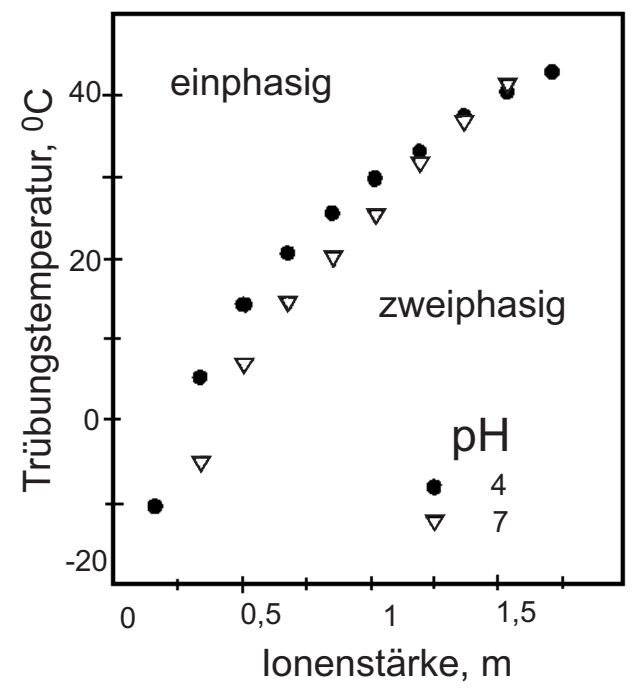

Abb. 2.9 Flüssig-Flüssig-Gleichgewicht im System Lysozym - Natriumchlorid - Wasser bei $\mathrm{pH}$-Werten von 4 und 7 [2]

\subsubsection{Komplette Phasendiagramme}

Das Phasendiagramm einer proteinhaltigen Lösung dient dazu, die physikalisch-chemischen Eigenschaften und das Verhalten der Proteine zu verstehen. Das Phasenverhalten eines proteinhaltigen Systems muss unter Einbeziehung aller Einflussparameter (z. B. Temperatur, pH-Wert und Salzkonzentration) aufgeklärt werden.

In verschiedenen Publikationen z. B. von Broide et al. [3], Muschol und Rosenberger [7] wurden die Phasendiagramme in Systemen mit $\gamma$-Crystallin und Lysozym untersucht.

In der Abbildung 2.10a ist das Phasendiagramm des Systems Lysozym - Natriumchlorid Wasser dargestellt [7]. Die schwarzen Punkte kennzeichnen die Trübungskurve. Diese Trübungskurve entspricht dem Phänomen der Flüssig-Flüssig-Entmischung (s. 2.2.3). Die Konzentration von Natriumchlorid ist in den beiden flüssigen Phasen gleich. Der kritische Punkt liegt bei etwa $20{ }^{\circ} \mathrm{C}$ und einer Lysozymkonzentration von $\approx 260 \mathrm{mg} / \mathrm{ml}$. Bei geringerer Proteinkonzentration und bei Temperaturen unter $25{ }^{\circ} \mathrm{C}$ wurde die Bildung von tetragonalen Kristallen beobachtet. Orthorhombische Kristalle wurden bei Temperaturen über $25{ }^{\circ} \mathrm{C}$ beobachtet [59]. 
a)

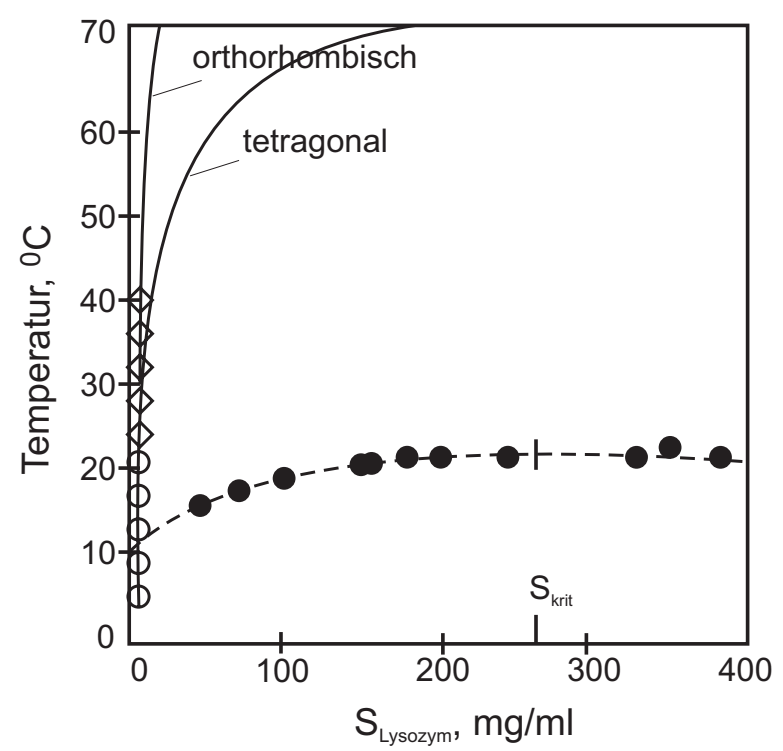

b)

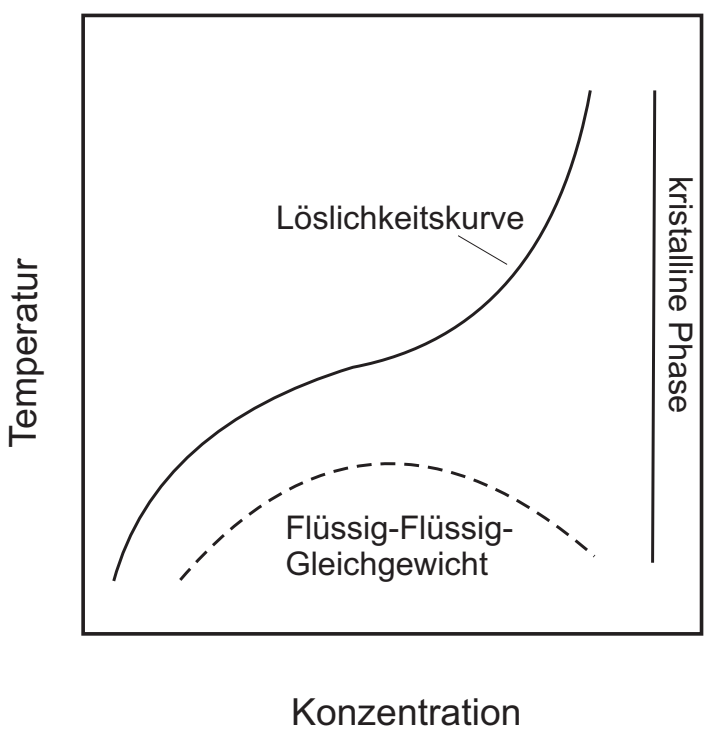

Abb. 2.10 Phasenverhalten proteinhaltiger Systeme: a) Phasendiagramm des Systems Lysozym - Natriumchlorid - Wasser, $\xi_{S}=5$ Massen- $\%, p H=4,5(0,1 \mathrm{M}$ Natriumazetat-Puffer) [7]; b) allgemeines Temperatur-Konzentration Phasendiagramm

In der Abbildung 2.10b ist das generelle Phasenverhalten eines proteinhaltigen Systems in einem Temperatur - Konzentration Diagramm gezeigt. Ein solches Phasendiagramm weist ein breites Fest-Flüssig-Gebiet auf. Die Löslichkeitskurve bezeichnet die Löslichkeit von Kristallen. Wenn ein Protein (z. B. Lysozym) unterschiedliche Kristallformen bildet, können mehrere Löslichkeitskurven auftreten. Innerhalb des Fest-Flüssig-Gebietes befindet sich ein metastabiles Flüssig-Flüssig-Gleichgewicht.

In einem Dreiecksdiagramm, in dem die Ecken die reinen Komponenten darstellen, wird die Zusammensetzung koexistierender Phasen bei einer konstanten Temperatur aufgetragen.

Von Moretti et al. [19] wurde das Phasenverhalten des Systems Lysozym - Ammoniumsulfat - Wasser bei Umgebungstemperatur untersucht. Je nach Konzentration des Proteins und des Salzes wird Kristallisation, ein Ausfällen oder die Bildung eines Gels beobachtet. In der Abb. 2.11 sind die Ergebnisse dieser Untersuchungen bei $\mathrm{pH}=8$ gezeigt. Bei höheren Salzkonzentrationen (über 20 Massen-\%) wurde das Ausfällen einer amorphen Phase beobachtet. Die gefüllten bzw. offenen Kreise kennzeichnen entsprechend die Zusammensetzungen der proteinarmen und proteinreichen Phasen. Bei niedrigeren Salz- und Proteinkonzentrationen wurde die Bildung von Proteinkristallen beobachtet. Die Zusammensetzung dieser Kristalle beträgt 16 Massen-\% Lysozym und 84 Massen-\% Wasser. 
In Rahmen der Messgenauigkeit konnte in diesen Kristallen kein Ammoniumsulfat nachgewiesen werden.

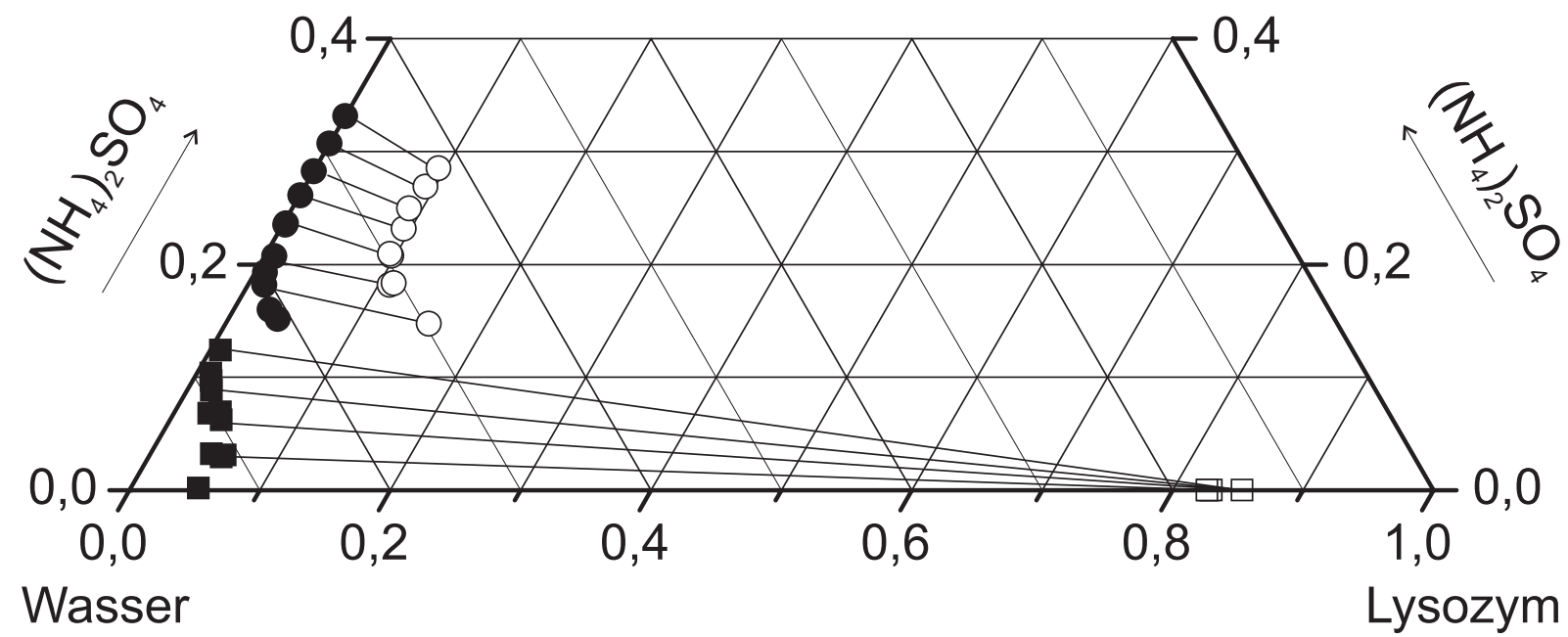

Abb. 2.11 Phasengleichgewichte im System Lysozym - Ammoniumsulfat - Wasser bei Umgebungstemperatur und $p H=8$ (Moretti et al. [19])

Nach der Abtrennung der proteinreichen amorphen Phase blieb die proteinarme Phase übersättigt und es wurde eine Kristallbildung beobachtet. In dem Gebiet mit Proteinkonzentrationen bis zu 10 Massen-\% und Salzkonzentrationen von etwa 2 Massen-\% bildete sich eine Gelphase aus. 


\subsubsection{Molekulare Thermodynamik proteinhaltiger Lösungen}

Die Protein-Protein- und Protein-Salz-Wechselwirkungen bestimmen die thermodynamischen Eigenschaften wässriger proteinhaltiger Lösungen auf molekularer Ebene. Sowohl experimentelle als auch theoretische Untersuchungen tragen $\mathrm{zu}$ Aufklärung dieser Wechselwirkungen bei. Die Ergebnisse experimenteller Untersuchungen sind für die Entwicklung molekularer, thermodynamischer Modelle unabdingbar. Die Modelle können dann zu Vorhersagen für das Phasenverhalten, die Proteinkristallisation sowie die Proteinaggregation [70,71] verwendet werden. Erste theoretische Untersuchungen des Aussalzens wurden von Melander und Horvath durchgeführt [22]. Ihre Theorie der hydrophoben Wechselwirkungen behandelt den Einfluss des Salzes auf die freie Energie des Proteins.

Um eine quantitative Beschreibung des Phasenverhaltens proteinhaltiger Lösung zu ermöglichen, werden zwei Informationen benötigt. Zunächst braucht man eine Beziehung zwischen dem chemischen Potential des Proteins und der Temperatur, der Konzentration weiterer Komponente und dem pH-Wert der Lösung. Diese Zusammenhänge ermittelt z. B. die statistische Thermodynamik. Als Zweites benötigt man quantitative Angaben zu den intermolekularen Wechselwirkungen zwischen den gelösten Proteinmolekülen. Diese Angabe bezeichnet man häufig als ,potential of mean force“ (PMF) $W(r) . W(r)$ ist die zwischenmolekulare Energie der Wechselwirkungen zweier Teilchen, aus der die zwischen den beiden Molekülen wirkende $\operatorname{Kraft} F$ folgt:

$$
F=\frac{-d W(r)}{d r}
$$

Das PMF bestimmt das Phasenverhalten eines Systems und kann sowohl aus theoretischen als auch aus experimentellen Untersuchungen bestimmt werden [21].

Molekulare Simulationen, die vereinfachte Darstellungen für $W(r)$ verwenden [72] (z. B. „square-well potential“), zeigen, dass wässrige Proteinlösungen ein metastabiles FlüssigFlüssig-Gleichgewicht aufweisen. Ein von ten Wolde und Frenkel [73-78] berechnetes Phasendiagramm ähnelt den experimentell bestimmten Diagrammen [3-7] (vgl. Abb. 2.10).

Da wässrige Proteinlösungen auch als kolloidale Systeme bezeichnet werden können, benutzen manche Modelle [5] die Grundlagen der kolloidalen Chemie, z. B. so genannte Derjaguin-Landau-Verwey-Overbeek Theorie (DLVO). Die DLVO Theorie [79] betrachtet die Proteinmoleküle als geladene dielektrische Kugeln. 
Die PMF wird durch drei Beiträge definiert:

$$
W(r)=W(r)_{h s}+W(r)_{e l}+W(r)_{d i s p}
$$

Der erste Beitrag $W(r)_{h s}$ entspricht dem Potential zwischen zwei harten Kugeln. $W(r)_{e l}$ steht für elektrostatische Wechselwirkungen zwischen geladenen Partikeln und kann z. B. mit Hilfe der Debye-Hückel Theorie approximiert werden. $W(r)_{\text {disp }}$ resultiert aus anziehenden Dispersionskräften und kann mit Hilfe der Hamaker Theorie abgeschätzt werden.

Eine andere Gruppe von Modellen basiert auf der McMillan-Mayer Theorie [80]. Danach besteht zwischen dem Proteinmassenbruch in der Lösung $\xi_{P}$ und dem osmotischen Druck $\pi$ einer Proteinlösung folgende Beziehung (,osmotische Virialgleichung“"):

$$
\frac{\pi}{\xi_{p} R T}=\frac{1}{M_{p}}+B_{22} \xi_{p}+\ldots
$$

$M_{p}$ ist die Molmasse des Proteins. $\mathrm{B}_{22}$ ist der zweite osmotische Virialkoeffizient des gelösten Proteins. Er ist ein Maß für die intermolekularen Wechselwirkungen zwischen zwei Proteinmolekülen im Lösungsmittel. Wegen der in der Regel unbekannten Virialkoeffizienten höherer Ordnung ist diese Gleichung jedoch nur für den hochverdünnten Bereich und nicht zur Beschreibung von Flüssig-Flüssig- oder Flüssig-Fest-Gleichgewichten geeignet. Der Vorteil der Beschreibung mit Hilfe der osmotischen Virialgleichung besteht darin, dass der zweite Virialkoeffizient experimentell zugänglich ist. Er kann z. B. aus Lichtstreumessungen verdünnter Proteinlösungen [81,82] oder aus Messungen des osmotischen Druckes [83] wässriger Lösungen mit höherer Proteinkonzentration (und Extrapolation in den Bereich der unendlichen Verdünnung) bestimmt werden.

Die Bedeutung des zweiten osmotischen Virialkoeffizienten als Maß für Protein-ProteinWechselwirkungen wurde von Georg und Wilson [84] beschrieben. Sie ermittelten experimentell, dass eine erfolgreiche Proteinkristallisation nur möglich ist, wenn die Zahlenwerte von $\mathrm{B}_{22}$ innerhalb eines „Kristallisationsfensters“ liegen: positive Werte von $\mathrm{B}_{22}$ deuten auf eine abstoßende Wechselwirkung zwischen den Proteinen hin; es kommt nicht zur Kristallisation. Bei stark negativen Werten von $\mathrm{B}_{22}$ sind die anziehenden Wechselwirkungen zwischen den Proteinmolekülen so stark, dass die Zeit zur Kristallbildung nicht ausreicht, sondern amorphe Agglomerate gebildet werden. Kristalle werden in der Regel nur gebildet, wenn $\mathrm{B}_{22}$ leicht negative Werte annimmt (Abb. 2.12).

Diese zunächst rein empirisch gefundenen Zusammenhänge werden durch die Arbeiten weiterer Autoren gestützt [85-87]. Damit ist die Möglichkeit gegeben, mit Hilfe des experimentell zugänglichen zweiten Virialkoeffizienten eine qualitative Abschätzung des Kristallisationsverhaltens von Proteinen zu treffen. 


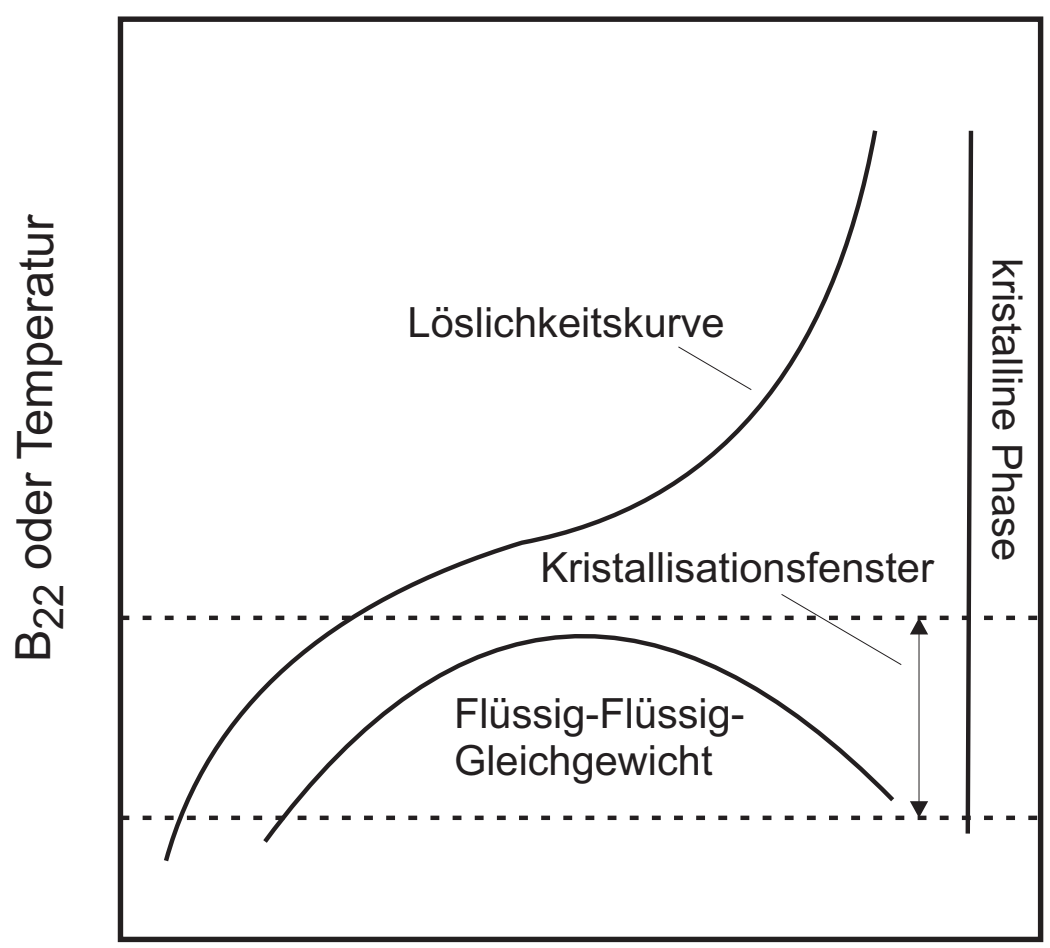

Proteinkonzentration

Abb. 2.12 Die Lage eines Kristallisationsfensters in einem Phasendiagramm

Den Zusammenhang zwischen dem zweiten osmotischen Virialkoeffizient $\mathrm{B}_{22}$ und der PMF $W(r)$ liefert die statistische Mechanik:

$$
B_{22}=-\frac{N_{A}}{2 M_{p}^{2}} \int_{0}^{\infty}\left[\exp \left(-\frac{W(r)}{k T}\right)-1\right] 4 \pi r^{2} d r
$$

Die Gleichung (5) erlaubt „rückwärts“ auch die Abschätzung der PMF aus experimentell bestimmten zweiten osmotischen Virialkoeffizienten. Derartige Berechnungen für Modellsysteme wurden von verschiedenen Autoren durchgeführt [88-90]. 


\section{Experimentelle Untersuchungen}

\subsection{Einführung}

Ziel der experimentellen Arbeiten war die Bestimmung des Phasenverhaltens ternärer Systeme vom Typ Protein - Salz - Wasser bei Umgebungstemperatur. In solchen Systemen ist der experimentell zugängliche Konzentrationsbereich aufgrund der hohen Viskosität konzentrierter Proteinlösungen auf Lösungen mit einem Proteingehalt von in der Regel unter 20 bis 30 Massen-\% beschränkt.

Die Beschreibung des Phasengleichgewichts erfolgt durch die Bestimmung der Zusammensetzung der koexistierenden Phasen sowie der Struktur eventuell auftretender koexistierender Phasen. Die experimentellen Untersuchungen erfolgten in zwei Stufen. Zunächst wurden die Trübungskurven bestimmt und danach - in getrennten Versuchen - die Zusammensetzung der koexistierenden Phasen ermittelt. Die Vorgehensweise zur Bestimmung der Trübungskurven wird im Kapitel 3.4 beschrieben. Die experimentelle Vorgehensweise zur Bestimmung der Zusammensetzung koexistierender Phasen einschließlich der Analysemethoden wird im Kapitel 3.5 beschrieben.

Die experimentellen Untersuchungen wurden ohne Einstellung des pH-Wertes durchgeführt. In weitergehenden Arbeiten ist vorgesehen, den Einfluss des pH-Wertes zu untersuchen.

Die Tabelle 3 gibt einen Überblick über die untersuchten Systeme.

Tabelle $3 \quad$ Untersuchte Systeme bei $25^{\circ} \mathrm{C}$ und $p H=5,5-9,5$

\begin{tabular}{|l|c|c|c|c|}
\hline Protein Salz & $\mathrm{Na}_{2} \mathrm{SO}_{4}$ & $\left(\mathrm{NH}_{4}\right)_{2} \mathrm{SO}_{4}$ & $\mathrm{NH}_{2} \mathrm{COONH}_{4}$ & $\mathrm{NH}_{4} \mathrm{HCO}_{3}$ \\
\hline Lysozym & + & + & + & + \\
\hline $\begin{array}{l}\text { Bovin Serum } \\
\text { Albumin }\end{array}$ & + & + & + & + \\
\hline Ovalbumin & + & + & + & \\
\hline Trypsin & & + & & \\
\hline
\end{tabular}




\subsection{Verwendete Materialien}

Die Tabellen 4 und 5 geben einen Überblick über die in der vorliegenden Arbeit verwendeten Proteine, Salze und die weiteren Chemikalien.

Die Reinheit des verwendeten Lysozyms betrug nach Herstellerangaben über 95 Massen-\% (die Verunreinigungen bestehen vor allem aus Salzen, wie Natriumacetat und Natriumchlorid). Die Reinheit der Proteine Bovin Serum Albumin und Ovalbumin betrug nach Herstellerangabe 98 Massen-\% (ohne Angaben zu den Nebenkomponenten). Trypsin enthält nach Angaben des Lieferanten Spuren von Chymotrypsin, Elastase und Laktose (ohne zahlenmäßige Angabe). Die Proteine Lysozym, Trypsin und Chymotrypsin wurden bei $-18{ }^{\circ} \mathrm{C}$ gelagert. Bovin Serum Albumin und Ovalbumin wurden bei $4{ }^{\circ} \mathrm{C}$ aufbewahrt.

Die nichtflüchtigen Salze wurden vor der Verwendung mehrere Tage im Vakuumschrank bei $60{ }^{\circ} \mathrm{C}$ getrocknet. Die flüchtigen Salze wurden im Kühlschrank bei $4{ }^{\circ} \mathrm{C}$ in dicht verschlossenen Gläsern aufbewahrt.

\section{Tabelle $4 a \quad$ Untersuchte Proteine}

\begin{tabular}{|l|l|c|c|c|}
\hline Protein & Herkunft / Organismus & Lieferant & Art. Nr. & EC Nr. \\
\hline Lysozym & Hühnereiweiß & Sigma & L6876 & 3.2 .1 .17 \\
\hline $\begin{array}{l}\text { Bovin Serum } \\
\text { Albumin }\end{array}$ & Rinderserum & Sigma & A7906 & - \\
\hline Ovalbumin & Hühnereiweiß & Sigma & A5503 & - \\
\hline Trypsin & Pankreas vom Schwein & Sigma & T4799 & 3.4 .24 .4 \\
\hline
\end{tabular}

Tabelle $4 b \quad$ Verwendete Salze

\begin{tabular}{|l|c|c|c|}
\hline Name & Lieferant & Art. Nr. & Molmasse \\
\hline Natriumsulfat $\mathrm{Na}_{2} \mathrm{SO}_{4}$ p.a. & Merck & 106649 & 142,04 \\
\hline Ammoniumsulfat $\left(\mathrm{NH}_{4}\right)_{2} \mathrm{SO}_{4}$ p.a. & Merck & 101217 & 132,14 \\
\hline Ammoniumcarbamat p.a. & Fluka & 09699 & 78,07 \\
\hline Ammoniumhydrogenkarbonat p.a. & Riedel-de-Haën & 11213 & 79,02 \\
\hline
\end{tabular}


Tabelle $5 \quad$ Sonstige verwendete Chemikalien

\begin{tabular}{|c|c|c|c|}
\hline Name & Lieferant & $\begin{array}{l}\text { Kennzeichen } \\
\text { bzw. Art. Nr. }\end{array}$ & $\begin{array}{c}\text { Bemerkung bzw. } \\
\text { Molmasse }\end{array}$ \\
\hline Natriumnitrat $\mathrm{NaNO}_{3}$ p.a. & Merck & 106537 & 84,99 \\
\hline Ammoniumnitrat $\mathrm{NH}_{4} \mathrm{NO}_{3}$ p.a. & Merck & 101188 & 80,04 \\
\hline Kaliumchlorid - Lösung & Merck & 108164 & $3 \mathrm{~mol} / \mathrm{l}$ \\
\hline 2-Propanol p.a. & Merck & 100993 & 60,10 \\
\hline Phthalsäure $\mathrm{C}_{6} \mathrm{H}_{4}(\mathrm{COOH})_{2}$ p.a. & Merck & 109611 & 166,13 \\
\hline $\begin{array}{l}\text { Tris(hydroxymethyl)- } \\
\text { aminomethan } \mathrm{C}_{4} \mathrm{H}_{11} \mathrm{NO}_{3} \text { p.a. }\end{array}$ & Merck & 108382 & 121,14 \\
\hline Borsäure $\mathrm{H}_{3} \mathrm{BO}_{3}$ p.a. & Merck & 100165 & 61,83 \\
\hline Pufferlösung $\mathrm{pH}=4$ & Metrohm & & Biphthalat \\
\hline Pufferlösung $\mathrm{pH}=7$ & Metrohm & & Phosphat \\
\hline Pufferlösung $\mathrm{pH}=9$ & Metrohm & & Borat \\
\hline Coomasie Brilliant Blau & Fluka & 27815 & G 250 \\
\hline $\begin{array}{l}\text { Phenylmethansulfonylfluorid } \\
\mathrm{C}_{7} \mathrm{H}_{7} \mathrm{FO}_{2} \mathrm{~S}\end{array}$ & Fluka & 78830 & 174,20 \\
\hline Titrant Hydranal-Composite $5 \mathrm{~K}$ & Riedel-de-Haën & & Karl-Fischer-Reagent \\
\hline Solvent K & Riedel-de-Haën & & $\begin{array}{l}\text { Karl-Fischer- } \\
\text { Lösungsmittel }\end{array}$ \\
\hline
\end{tabular}

\subsection{Eigenschaften der reinen Komponenten}

Die Löslichkeit der Proteine und Salze in Wasser bei $25{ }^{\circ} \mathrm{C}$ ist in den Tabellen $6 \mathrm{a}$ und $6 \mathrm{~b}$ zusammengestellt.

Die Löslichkeiten von Bovin Serum Albumin und Ovalbumin wurden aus der Literatur entnommen. Die Löslichkeiten von Lysozym, Trypsin und Chymotrypsin in reinem Wasser wurden in der vorliegenden Arbeit experimentell bestimmt. Die Löslichkeit der untersuchten Proteine in reinem Wasser liegt im Bereich zwischen etwa 30 und 56 Massen-\%. In der vorliegenden Arbeit wird davon ausgegangen, dass ein Protein näherungsweise wie ein reiner Stoff behandelt werden kann. Die Löslichkeitsgrenze gilt also für „pseudoreine“ Proteine. 
Diese Bezeichnung wurde gewählt, um auszudrücken, dass eine Verunreinigung die Löslichkeit beeinflussen kann.

Zur Bestimmung der Trübungskurven und der Zusammensetzung der koexistierenden Phasen wurden wässrige Stammlösungen von Proteinen bzw. Salzen verwendet. Da die experimentellen Untersuchungen ohne Einstellung des $\mathrm{pH}$-Wertes durchgeführt wurden, wurden zusätzlich die pH-Werte der wässrigen Stammlösungen gemessen.

Der pH-Wert der wässrigen Lösung eines Elektrolyten sowie eines Proteins hängt von der Konzentration des Stoffes ab. In den Tabellen 6a und $6 \mathrm{~b}$ sind die gemessenen $\mathrm{pH}-\mathrm{Werte}$ und die Konzentrationen, bei denen der pH-Wert bestimmt wurde, angegeben.

Tabelle 6a Eigenschaften der untersuchten Proteine

\begin{tabular}{|l|c|c|c|c|c|}
\hline \multirow{2}{*}{ Protein } & $\mathrm{M}_{\mathrm{p}}$ & $\mathrm{pI}$ & $\begin{array}{c}\text { Löslichkeit in Wasser } \\
\text { bei } 25{ }^{\circ} \mathrm{C}, \mathrm{g} / \mathrm{g}\end{array}$ & \multicolumn{2}{c|}{$\begin{array}{c}\mathrm{pH} \text {-Wert der Lösung } \\
\text { [eigene Messungen] }\end{array}$} \\
\cline { 5 - 7 } & & & & $\mathrm{pH}$ & $\xi_{P}$ \\
\hline Lysozym & 14388 & $10,5[23]$ & 0,28 & 6,90 & 0,07 \\
\hline BSA & 66430 & $5,7[98]$ & $0,56[92]$ & 7,60 & 0,30 \\
\hline Ovalbumin & 44287 & $4,6[21]$ & $0,56[93]$ & 7,20 & 0,25 \\
\hline Trypsin & 23800 & $10,5[99]$ & $\begin{array}{c}0,41 \\
{[\text { eigene Messungen] }}\end{array}$ & 4,60 & 0,30 \\
\hline
\end{tabular}

Tabelle $6 b \quad$ Eigenschaften der verwendeten Salze

\begin{tabular}{|l|c|c|c|}
\hline \multirow{2}{*}{ Salz } & \multirow{2}{*}{$\begin{array}{c}\text { Löslichkeit in Wasser } \\
\text { bei } 25^{\circ} \mathrm{C}, \mathrm{g} / \mathrm{g}\end{array}$} & \multicolumn{2}{|c|}{$\begin{array}{c}\mathrm{pH} \text {-Wert der Lösung } \\
\text { [eigene Messungen] }\end{array}$} \\
\cline { 3 - 4 } & & $\mathrm{pH}$ & $\xi_{S}$ \\
\hline \multirow{2}{*}{$\mathrm{Na}_{2} \mathrm{SO}_{4}$} & $0,218[91]$ & 7,0 & 0,05 \\
\cline { 3 - 4 } & $0,435[91]$ & 6,8 & 0,15 \\
\hline$\left(\mathrm{NH}_{4}\right)_{2} \mathrm{SO}_{4}$ & $0,441[91]$ & 5,6 & 0,20 \\
\hline $\mathrm{NH}_{2} \mathrm{COONH}_{4}$ & $0,199[91]$ & 5,2 & 0,40 \\
\hline $\mathrm{NH}_{4} \mathrm{HCO}_{3}$ & & 9,1 & 0,20 \\
\hline
\end{tabular}




\subsection{Trübungskurve}

\subsubsection{Experimentelle Vorgehensweise}

Das experimentelle Vorgehen zur Bestimmung der Trübungskurven ist in der Abb. 3.1 skizziert. In einem verschließbaren, thermostatisierten Zentrifugenglas (Volumen ca. $12 \mathrm{~cm}^{3}$ ) werden ca. $3 \mathrm{~g}$ einer Lösung eines Proteins mit vorgegebener Konzentration in Wasser vorgelegt. Die Zusammensetzung dieser wässrigen Lösung ist in der Abb. 3.1 durch den Punkt B gekennzeichnet. Zu dieser Lösung wird mit einer Spritze unter Rühren tropfenweise (Masse eines Tropfens ca. 0,04 g) eine wässrige Lösung des Salzes zugegeben. Die Salzkonzentration in dieser Lösung ist durch den Punkt A gekennzeichnet. Nach jeder Zugabe werden die Zentrifugengläser fest verschlossen. Zwischen je zwei Zugaben wird die Probe in einem Rührbehälter thermostatisiert und unter Verwendung eines Magnetrührers gerührt. Durch diese Zugabe ändert sich die Zusammensetzung der Lösung ausgehend von Punkt B entlang der Bilanzlinie BA. Liegt der Mischungspunkt innerhalb der Mischungslücke, so zeigt sich dies an einer bleibenden Trübung. Die Trübung wird visuell festgestellt. Sobald sich eine Trübung eingestellt hat, wird die weitere Zugabe der Salzlösung beendet.

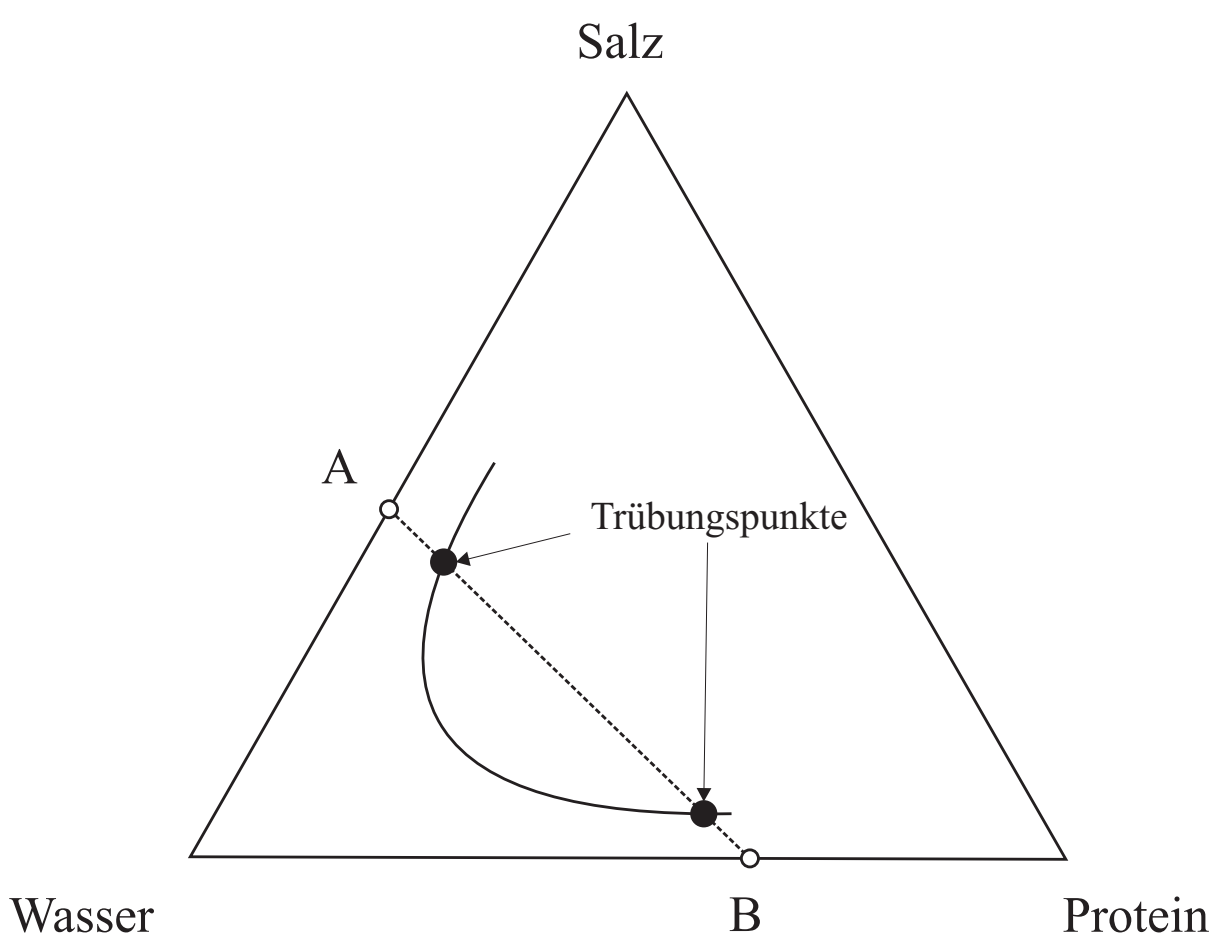

Abb.3.1 Schematische Vorgehensweise zur Bestimmung der Trübungskurve 
Zur Kontrolle wird die Probe noch bis zu 5 Stunden im thermostatisierten Behälter aufbewahrt. Ist sie nach diesem Zeitraum immer noch trübe, wird davon ausgegangen, dass die Grenze zwischen ein- und mehrphasigem Bereich überschritten ist. Wird die Probe im Laufe dieser Zeit wieder klar, d. h. einphasig, wird bis zu erneuter Eintrübung wieder tropfenweise die entsprechende Salzlösung zugegeben. Aus den Massen der Komponenten in der Ausgangslösung und der gesamten Masse der zugegebenen Salzlösung wird die Zusammensetzung der Probe (Punkt auf der Trübungskurve) berechnet. Zur Bestimmung der Trübungskurve wird dieses Vorgehen wiederholt, wobei Ausgangslösung und zugegebene Lösung vertauscht werden.

Proteine und Salze wurden ohne Zugabe von Puffer im Wasser gelöst. Die pH-Werte der eingetrübten Lösungen wurden gemessen.

Die Ergebnisse für die Vielzahl der Trübungspunkte sind im Anhang B tabelliert.

\subsubsection{Anmerkungen}

Aufgrund der Existenz metastabiler Zustände kann die Trübung - trotz ständigen Rührens manchmal erst nach deutlichem Überschreiten der Löslichkeitskurve, d. h. teilweise weit im zweiphasigen Bereich, auftreten. Die im Rahmen der vorliegenden Arbeit untersuchten Proteine enthalten bis zu 5 Massen-\% Verunreinigungen. Es kann deshalb nicht ausgeschlossen werden, dass in manchen Experimenten die Trübung wesentlich durch das Ausfällen der Nebenkomponenten verursacht wurde. 


\subsection{Phasengleichgewicht}

\subsubsection{Experimentelle Vorgehensweise}

Zur Herstellung der Protein - Salz - Wasser Systeme wurden zunächst Stammlösungen des Proteins und des Salzes angesetzt. Lediglich Natriumsulfat wurde bei einigen Versuchen direkt eingewogen. Pro System wurden 6 bis 10 Feedlösungen (Masse je ca. 6 g) unterschiedlicher Zusammensetzung vorbereitet. Dabei wurden ungepufferte wässrige Stammlösungen in verschließbare Zentrifugengläser mit Magnetrührstäbchen mit einer Präzisionswaage (Typ AG 204, Fa. Mettler Toledo GmbH, Gießen, Deutschland) eingewogen.

Die Zusammensetzungen der Feedlösungen wurden zunächst so gewählt, dass sie sich innerhalb der Trübungskurve befanden. In der Regel wurde dann ein sofortiger Phasenzerfall beobachtet. Ein Phasenzerfall wurde ebenfalls bei Proben beobachtet, deren Zusammensetzung außerhalb der Trübungskurve lag. Bei diesen Proben trat der Phasenzerfall in der Regel erst nach einigen Stunden auf.

Die Proben wurden gründlich durchmischt, bevor sie zur Gleichgewichtseinstellung für 5 bis 12 Stunden in einem thermostatisierten Rührbehälter aufbewahrt wurden. Danach wurden die trüben Mischungen in einer auf $25{ }^{\circ} \mathrm{C}$ thermostatisierten Laborzentrifuge (Typ Labofuge A. Fa. Heraeus Sepatech GmbH, Berlin, Deutschland) bei 4000 U/min aufgetrennt (Dauer 3-4 h). Mittels einer Spritze (mit Kanüle und aufgesetztem Filter) wurde die proteinarme, transparente Phase so weit wie möglich entfernt und ihre Masse (aus der Massendifferenz vor und nach dem Entfernen) bestimmt. Dabei wurde darauf geachtet, dass die Phasen nicht wieder vermischt wurden. Beide Phasen wurden gegebenenfalls mit destilliertem Wasser verdünnt und anschließend analysiert.

Bei den Versuchen wird davon ausgegangen, dass der pH-Wert aller Feedlösungen etwa gleich ist. Als pH-Wert im Gleichgewicht wurde der Mittelwert über verschiedene Ausgangszusammensetzungen bestimmt. Die einzelnen gemessenen Werte unterscheiden sich um $\pm 0,5 \mathrm{pH}$-Einheiten.

Die experimentellen Ergebnisse der Phasengleichgewichtsmessungen sind im Anhang C zusammengestellt. 


\subsection{2 Überblick über Messmethoden}

Zur Bestimmung der Zusammensetzung einer ternären Mischung müssen mindestens die Konzentrationen von zwei der drei Komponenten gemessen werden. Zu Minimierung der experimentellen Unsicherheit ist es in der Regel empfehlenswert, die Konzentrationen derjenigen Komponenten zu messen, die in geringerer Konzentration vorliegen.

Für proteinarme (und salzreiche) Phasen wurde in den meisten Fällen die Konzentration von Protein und Salz bestimmt. Die Proteinkonzentration lag dabei unter 5 Massen-\%. Bei den Untersuchungen von Systemen mit „flüchtigen“ Salzen wurden die Konzentrationen von Protein und Wasser in der proteinarmen Phase gemessen.

Die Analyse der Proteinkonzentration erfolgte mittels UV/VIS Spektrophotometrie (s. 3.5.3). Die Salzkonzentration in der proteinarmen Phase wurde mit Hilfe der Ionenchromatographie (s. 3.5.4) gemessen. Die Analyse des Wassergehalts sowohl der proteinarmen als auch der proteinreichen Phasen erfolgte mittels Karl-Fischer-Titration (s. 3.5.7) bzw. Gefriertrocknung (s. 3.5.5).

Die proteinreiche Phase war in den meisten Fällen nicht einphasig, sondern in der Regel mehrphasig und sehr viskos. Diese Phase enthielt außer dem ausgefallenen Stoff viel Wasser und trocknete an der Luft schnell aus. Aus diesen Gründen war die bei einer flüssigen Phase übliche Probennahme nicht möglich. Für die Analyse wurde die proteinreiche Phase, die als Rest im Zentrifugenglas vorlag, mit einer bekannten Menge destillierten Wassers in eine Aluschale für die Gefriertrocknung gespült.

Bei Verwendung eines nicht flüchtigen Salzes liegt nach der Gefriertrocknung eine wasserfreie Mischung aus Protein und Salz vor. Im Fall der Verwendung von Ammoniumsulfat wurde der Proteingehalt dieser Mischung analysiert, in Systemen mit Natriumsulfat wurde der Salzgehalt analysiert (s. 3.5.6).

Bei Verwendung eines „flüchtigen“ Salzes liegt nach der Gefriertrocknung der proteinreichen Phase „reines“ Protein vor. Dadurch wurde in Systemen mit „flüchtigen“ Salzen der Proteingehalt ermittelt. Die Zusammensetzung der proteinreichen Phase wurde aus der Zusammensetzung der proteinarmen Phase und dem Proteingehalt der proteinreichen Phase berechnet.

Zusätzlich wurden Proben der proteinreichen Phasen unter dem Mikroskop untersucht, um die Struktur der Phase aufzuklären (s. 3.6). 


\subsubsection{UV/VIS Spektrophotometrie}

Die spektroskopische Analyse der Proteinkonzentration ist unkompliziert, schnell und zuverlässig. Proteine absorbieren UV-Licht mit zwei Maxima bei ca. 205 und $280 \mathrm{~nm}$.

Bei $280 \mathrm{~nm}$ werden die Elektronen in aromatischen Ringen angeregt. Die Elektronenanregungszustände in einem Proteinmolekül werden durch intramolekulare Wechselwirkungen stabilisiert, wobei die Tertiärstruktur des Proteins eine große Rolle spielt. Dementsprechend beeinflussen alle Faktoren, die die Tertiärstruktur des Proteins ändern (z. B. pH-Wert und Ionenstärke), das Analysenergebnis. Die Stärke der Lichtabsorption bei $280 \mathrm{~nm}$ unterscheidet sich stark von Protein zu Protein.

Peptidbindungen sind im Wellenlängenbereich unter $210 \mathrm{~nm}$ UV-aktiv. Da die Anzahl der Peptidbindungen in einem Proteinmolekül hoch ist, ist dieser Spektralbereich sehr empfindlich. Die Unterschiede zwischen verschiedenen Proteinen sind weniger ausgeprägt. Viele chemische Verbindungen sind in diesem Bereich auch UV-aktiv, insbesondere Stoffe, die $\mathrm{C}=\mathrm{C}$ oder $\mathrm{C}=\mathrm{O}$ Bindungen besitzen.

Der Konzentrationsbereich in dem die UV-Analysen durchgeführt wurden, lag zwischen 20 bis $3000 \mu \mathrm{g} / \mathrm{g} \mathrm{H}_{2} \mathrm{O}$ bei $280 \mathrm{~nm}$ und 1 bis $100 \mu \mathrm{g} / \mathrm{g} \mathrm{H} \mathrm{H}_{2} \mathrm{O}$ bei $205 \mathrm{~nm}$.

Die Absorption folgt für verdünnte Lösungen und monochromatisches Licht dem Lambert Beerschen Gesetz:

$$
A=-\lg \frac{I}{I_{0}}=\varepsilon \cdot c \cdot l
$$

Die Absorption $A$ ist der Konzentration des Stoffes $c$, der Schichtdicke $l$ und dem Extinktionskoeffizienten $\varepsilon$ proportional. Der Extinktionskoeffizient ist die charakteristische Stoffkonstante.

Für die UV-Analyse wurde ein Einstrahl - Spektrometer (Model 8452A, Fa. Hewlett Packard, Palo Alto, USA) benutzt. Im Einstrahl - Spektrometer wird nur ein Lichtstrahl eingesetzt (vgl. Abb. A.2 im Anhang A). Die Strahlungsintensität $\mathrm{I}_{0}$ wird deshalb zu Beginn der Analyse mit einer Referenzlösung bestimmt. In dieser Arbeit wurde destilliertes Wasser als Referenz verwendet.

Für jedes Protein wurden Kalibrierungen durchgeführt. Die entsprechenden Extinktionskoeffizienten und Konzentrationsbereiche sind in der Tabelle 7 zusammengestellt. 
Tabelle $7 \quad$ Extinktionskoeffizienten der untersuchten Proteine in wässriger Lösung

\begin{tabular}{|l|c|c|c|}
\hline Komponente & $v, n m$ & $\varepsilon, g_{\mathrm{H}_{2} \mathrm{O}} / m g \cdot \mathrm{cm}$ & $\mathrm{S}_{\text {Protein }}, m g / g_{\mathrm{H}_{2} \mathrm{O}}$ \\
\hline \multirow{2}{*}{ Lysozym } & 205 & 35,5 & $0,01-0,04$ \\
\cline { 2 - 4 } & 285 & 1,98 & $0,1-0,6$ \\
\hline \multirow{2}{*}{ Albumin (BSA) } & 205 & 28,1 & $0,01-0,05$ \\
\cline { 2 - 4 } & 281 & 0,612 & $0,1-2,0$ \\
\hline \multirow{2}{*}{ Ovalbumin } & 205 & 10,7 & $0,01-0,1$ \\
\cline { 2 - 4 } & 278 & 1,69 & $0,1-0,7$ \\
\hline \multirow{2}{*}{ Trypsin } & 280 & 0,206 & $1,0-6,0$ \\
\hline
\end{tabular}

Sind in einer zu analysierenden wässrigen Proteinlösung weitere Komponenten (z. B. Salze) vorhanden, können diese die UV-Analyse beeinflussen. Die Absorption setzt sich dann aus den Absorptionen aller Komponenten zusammen. Um den Einfluss eines Salzes bei der UVAnalyse auszuschließen, wurde die Kalibrierung mit salzhaltigen Proteinlösungen wiederholt. Die Abb. 3.2 zeigt den Vergleich der Kalibrierkurven „mit“ und „ohne“ Salz bei $280 \mathrm{~nm}$. Bei Salzkonzentrationen unter 5 Massen-\% konnte im Rahmen der Messgenauigkeit kein Einfluss des Salzes festgestellt werden. 


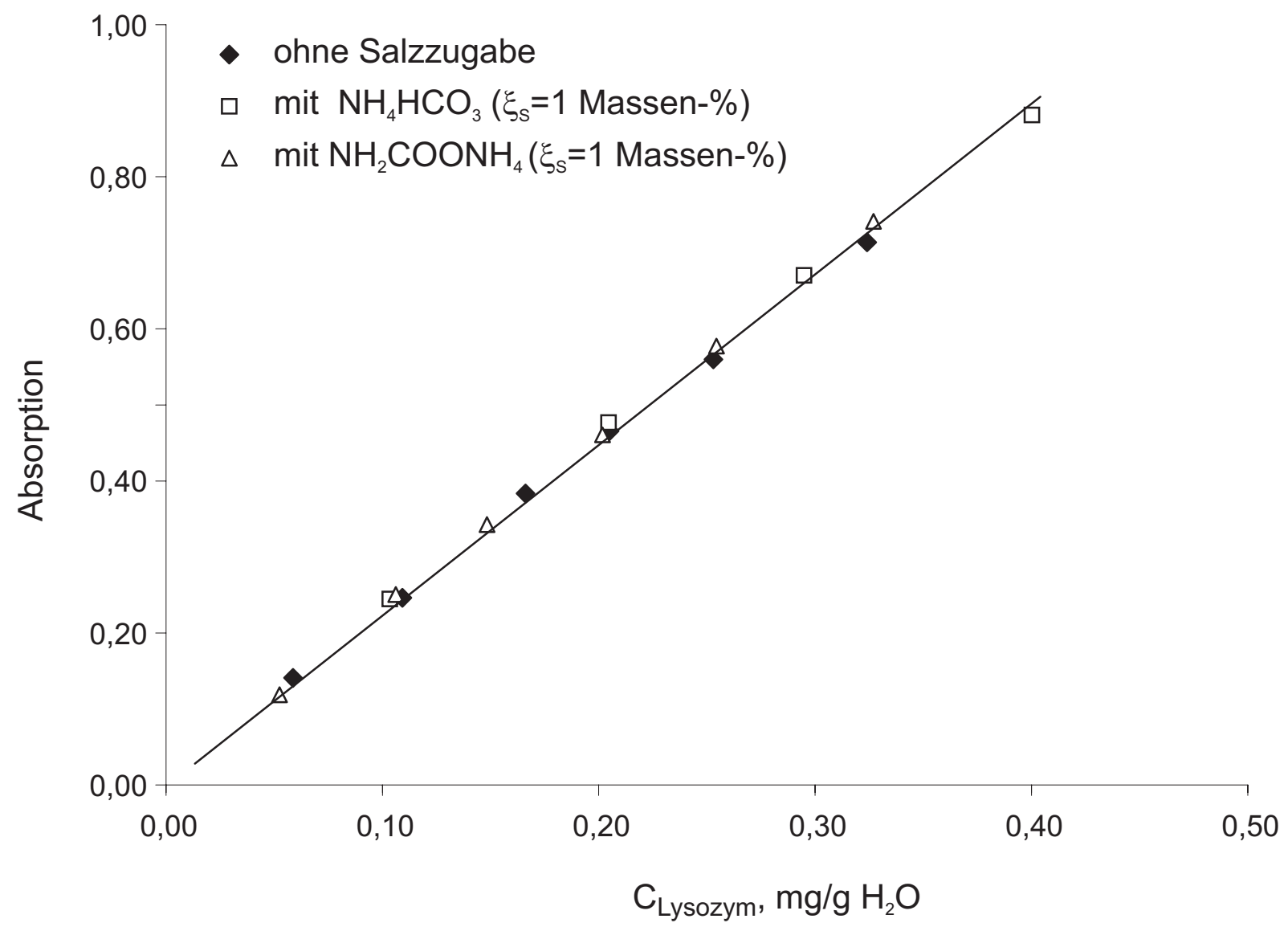

Abb. 3.2 Kalibrierkurve für die UV-Analyse von Lysozym bei $280 \mathrm{~nm}$ „,mit“ und „ohne“ Salz.

Lediglich bei Verwendung von Ammoniumcarbamat (bei $205 \mathrm{~nm}$ ) zeigt sich ein Einfluss auf die Kalibrierkurve des Proteins. Deshalb wurden Eichungen für mehrere Salzkonzentrationen vorgenommen. Die Auswertung der UV-Analyse zur Bestimmung der Proteinkonzentration erfolgte mit entsprechend (für Ammoniumcarbamat) korrigierten Kalibrierkurven bzw. nach Abzug der von Ammoniumcarbamat verursachten Absorption von der Gesamtabsorption.

Für die Analyse wurden Proben der proteinarmen Phase (etwa 2 g) so mit Wasser verdünnt, dass die gemessene Absorption im linearen Bereich der Eichkurve lag und der Salzeinfluss ausgeschlossen ist. Bei der Bestimmung der Proteinkonzentration in den proteinreichen Phasen nach der Gefriertrocknung wurde der Feststoff bis zu einer Konzentration von etwa 0,3 mg Protein/( $\left.\mathrm{g} \mathrm{H}_{2} \mathrm{O}\right)$ verdünnt. Die Lösungen wurden anschließend filtriert, um eventuell vorhandene Partikel zu entfernen, die durch Streuung des UV-Lichts einen Fehler verursachen können.

Die relative Unsicherheit der durch UV-Analyse ermittelten Proteinkonzentration ist kleiner als $\pm 2 \%$. Lediglich in den Fällen, in denen eine Phase nur sehr wenig Protein (unter 0,5 
Massen-\%) enthält, wird diese Fehlergrenze deutlich überschritten. In diesem Fall wurde der Fehler aus der Streuung der experimentellen Ergebnisse abgeschätzt.

\subsubsection{Ionenchromatographie}

Für die quantitative Analyse der Sulfationen wurde die Ionenaustausch - Chromatographie mit einer Anionensäule Shodex IC (Typ I-524A, Techlab GmbH, Erkerode, Deutschland) in einer HPLC-Anlage (Einzelteile vgl. Anhang A) verwendet. Als Eluent wurde eine vom

Trennsäulenhersteller empfohlene Lösung von Borsäure, Phtalsäure und Tris(hydroxymethyl)aminomethan in chromatographischem Wasser eingesetzt. Zur Detektion wurde ein Leitfähigkeitsdetektor verwendet. Die Beschreibung der Versuchsapparatur sowie die Analysebedingungen befinden sich im Anhang A.

Da bei der Messung der Salzkonzentration das Injektionsvolumen des Autosamplers nicht exakt reproduzierbar war, wurde bei der Analyse die vom Injektionsvolumen unabhängige Methode des ,internen Standards“ gewählt. Dabei wird einer zu analysierenden Probe eine Standardsubstanz in bekannter Konzentration zugesetzt. Als Standardsalz zur Analyse von Sulfat wurde Nitrat verwendet.

Die Abhängigkeit des Verhältnisses der Peakfläche der zu analysierenden Substanz $A_{i}$ zu der Peakfläche der Standardsubstanz $A_{j}$ vom Konzentrationsverhältnis $c_{i} / c_{j}$ ist linear:

$$
\frac{A_{i}}{A_{j}}=a \cdot \frac{c_{i}}{c_{j}}
$$

$c_{i}$ ist aus der Einwaage bekannt, $A_{i} / A_{j}$ aus der Ergebnissen der IC-Analyse, der Faktor $a$ wird bei einer Kalibrierung ermittelt. Für jede Salzkombination (Natriumsulfat/Natriumnitrat und Ammoniumsulfat/Ammoniumnitrat) wurde die Kalibrierung bei den gleichen Bedingungen wie bei der Analyse der proteinarmen Phase, durchgeführt.

Für die Analyse wurden etwa $0,7 \mathrm{~g}$ der zu analysierenden verdünnten Phase und etwa 0,8 $\mathrm{g}$ der wässrigen Standardlösung in ein verschließbares Probenglas eingewogen. Die Salzkonzentration wurde dann aus dem Peakflächenverhältnis, der Konzentration des Nitrates und dem Kalibrierungsfaktor berechnet. Der relative Fehler der Analyse wurde aus der Streuung der experimentellen Ergebnisse zu kleiner als $\pm 0,5 \%$ abgeschätzt. 


\subsubsection{Gefriertrocknung}

Für die Bestimmung des Wassergehalts wurde die gesamte proteinreiche Phase (ca. 1,5 bis $3 \mathrm{~g}$ ) nach einer genauen Wägung mit etwa $30 \mathrm{~g}$ Wasser verdünnt und in eine Aluminiumschale gegeben. Durch die Verdünnung wird zum einen die Gefrierpunktserniedrigung der Lösung verringert, zum anderen wird sichergestellt, dass beim Gefriertrocknen ein faseriges, großporiges Produkt ohne Wassereinschlüsse anfällt. Die verdünnten Proben wurden in einem Gefrierschrank bei $-18{ }^{\circ} \mathrm{C}$ eingefroren und anschließend mit flüssigem Stickstoff auf ca. $-190{ }^{\circ} \mathrm{C}$ abgekühlt. Danach wurden die Proben in einem Gefriertrockner (Typ Lyovac GT2, Fa. Amsco/Finn-Aqua, Hürth, Deutschland) bei einem Druck von $51 \mathrm{~Pa}$ (entsprechend einer Sublimationstemperatur von $-30{ }^{\circ} \mathrm{C}$ ) etwa 72 Stunden getrocknet. Das Ende des Trocknungsvorgangs ist an einem deutlichen Anstieg der Temperatur im Kondensatorraum zu erkennen. Die getrockneten Proben wurden entnommen und mit einer Analysewaage gewogen.

Aus den Massen des getrockneten Restes und der Masse der Probe vor der Verdünnung mit Wasser wurde der Wasserverlust beim Trocknen und daraus der Wassergehalt der Probe berechnet. Anschließend wurde die trockene Mischung auf Protein gegebenenfalls auch auf Salz analysiert. Die relative experimentelle Unsicherheit bei der Bestimmung des Wassergehalts wird auf etwa $\pm 3 \%$ geschätzt.

\subsubsection{Analyse von Natriumsulfat in der proteinreichen Phase}

Die trockene Mischung aus Protein und Salz aus der Gefriertrocknung wurde in einen Tiegel eingewogen und bei $700{ }^{\circ} \mathrm{C}$ in einem Muffelofen (Model T16A, Fa. Heraeus, Berlin, Deutschland) verbrannt. Nach der Verbrennung bleibt im Tiegel reines Natriumsulfat (Schmelzpunkt: $884{ }^{\circ} \mathrm{C}$ [94]). Aus der Massen der Probe vor und nach der Verbrennung wurde der Salzgehalt der trockenen Mischung ermittelt. In der Regel lag der Salzgehalt in der proteinreichen Phase zwischen 5 und 23 Massen-\%. Die relative experimentelle Unsicherheit bei der Analyse betrug weniger als $\pm 3 \%$. 


\subsubsection{Karl-Fischer Titration}

Der Wassergehalt der proteinarmen Phase in Systemen mit einem flüchtigen Salz wurde mit Hilfe der Karl-Fischer Titration bestimmt. Die Methode beruht auf einer Reaktion, bei der Jod mit Schwefeldioxid und Wasser zu Jodwasserstoff und Schwefelsäure umgesetzt wird:

$$
\mathrm{J}_{2}+\mathrm{SO}_{2}+2 \mathrm{H}_{2} \mathrm{O} \rightarrow 2 \mathrm{HJ}+\mathrm{H}_{2} \mathrm{SO}_{4}
$$

Ist das in der Probe vorhandene Wasser vollständig verbraucht, bleibt freies Jod in der Mischung zurück. Dies wird zur Bestimmung des Titrationsendpunktes verwendet, da freies Jod die elektrische Leitfähigkeit der Mischung stark beeinflusst.

Zur Analyse einer Probe der proteinarmen Phase wurden Solvent K und Titrant HydranalComposite 5K verwendet (s. Tabelle 5). Die Proben wurden in eine geschlossene Titrierzelle eingewogen, die ungefähr $30 \mathrm{~cm}^{3}$ Solvent enthielt. Die Probenmenge wurde so gewählt, dass etwa $4 \mathrm{ml}$ Titrant zudosiert werden musste (etwa 0,02 g), bis das Wasser in der Probe vollständig verbraucht war. Aus dem zudosierten Titervolumen wurde die Wassermasse in der Probe ermittelt.

\section{6 pH-Wert-Messungen}

Die Messung des pH-Wertes erfolgte mit einem pH/ION Meter (Typ pMX 3000, WTW, Weilheim, Deutschland) in Verbindung mit einer kombinierten Glaselektrode (Typ 6.0224.100, Metrohm, Filderstadt, Deutschland). Die Kalibrierung des pH-Meters, die vor jeder Messreihe vorgenommen wurde, erfolgte mit gebrauchsfertigen Pufferlösungen $(\mathrm{pH}=4,0 ; 7,0$ und 9,0$)$ bei $25^{\circ} \mathrm{C}$. Die Messung des $\mathrm{pH}$-Wertes wurde unmittelbar nach der Lösungsvorbereitung bzw. nach Ende der Trübungskurvenmessungen durchgeführt, um einen Einfluss von $\mathrm{CO}_{2}$ aus der Atmosphäre zu minimieren.

Die Unsicherheit der experimentell ermittelten $\mathrm{pH}$-Werte wird $\mathrm{zu} \pm 0,05 \mathrm{pH}$-Einheiten abgeschätzt. 


\subsection{Mikroskopische Untersuchungen}

Die Lichtmikroskopie eignet sich zur Untersuchung von Gewebestrukturen, Zellen und Organellen. Man unterscheidet die Durchlichtmikroskopie, bei der das Objekt transparent oder sehr dünn ist und von der dem Objektiv des Mikroskops abgewandten Seite beleuchtet wird, und die Auflichtmikroskopie, bei der durch Beleuchtung der dem Objektiv zugewandten Seite die Oberfläche des Objekts untersucht wird. In der vorliegenden Arbeit wurde für die Untersuchung der Struktur der proteinreichen Phase die Durchlichtmikroskopie im Hellfeld eingesetzt, da bei dieser Methode die besten Abbildungen erhalten wurden.

Die Probe der proteinreichen Phase wurde auf ein Trägerglas so dünn wie möglich aufgetragen, mit einem Deckglas bedeckt (um das Verdunsten von Wasser zu vermeiden) und unter einem Lichtmikroskop (Model Leitz Orthoplan, Ernst Leitz GmbH, Wetzlar, Deutschland) untersucht. Die Aufnahmen erfolgten mit Hilfe einer Spiegelreflexkamera bzw. einer Digitalkamera. Die Gesamtvergrößerung des Mikroskops betrug je nach Probe 400 oder 1000.

Um Proteinaggregate bzw. Proteinkristalle besser von Salzkristallen unterscheiden zu können, wurden manche Proben mit „Coomasie Brilliant Blau“ gefärbt. Diese Substanz wird an freie Aminosäurenreste eines Proteins gebunden und verleiht dem Protein eine intensive, blaue Farbe, die im Mikroskop deutlich zu sehen ist.

Die Rasterelektronenmikroskopie (REM) liefert Abbildungen mit einer Vergrößerung bis zu 900000. Die REM kann zur Abbildung von Oberflächen und Bruchflächen von Feststoffen, z. B. Membranen, Werkstoffen oder medizinischen und biologischen Präparaten eingesetzt werden. Allerdings eignet sich diese Methode nur zur Untersuchung fester, nicht flüchtiger und wasserfreier Materialen. Dazu wird die zu untersuchende Probe mit einem Metallfilm (z. B. Goldfilm) beschichtet, da nur die leitenden Oberflächen dargestellt werden können. Da die Struktur der proteinhaltigen Aggregate bzw. Proteinkristalle dabei leicht zerstört werden kann, wurde nur eine Probe der proteinreichen Phase untersucht. Diese Untersuchung erfolgte am Rasterelektronenmikroskop (Modell JEOL JSM-6400F, JEOL GmbH, Eching, Deutschland).

Die mikroskopischen Aufnahmen sowie die Zusammensetzungen der untersuchten Proben sind im Anhang D zu finden. 


\section{Ergebnisse und Diskussion}

\subsection{Lysozym}

\subsubsection{Lysozym $-\mathrm{Na}_{2} \mathrm{SO}_{4}-\mathrm{H}_{2} \mathrm{O}$}

Die Abbildung 4.1 zeigt die experimentellen Ergebnisse der Trübungskurvenmessungen für das System Lysozym $-\mathrm{Na}_{2} \mathrm{SO}_{4}-$ Wasser bei $25^{\circ} \mathrm{C}$ und $\mathrm{pH}=7$.

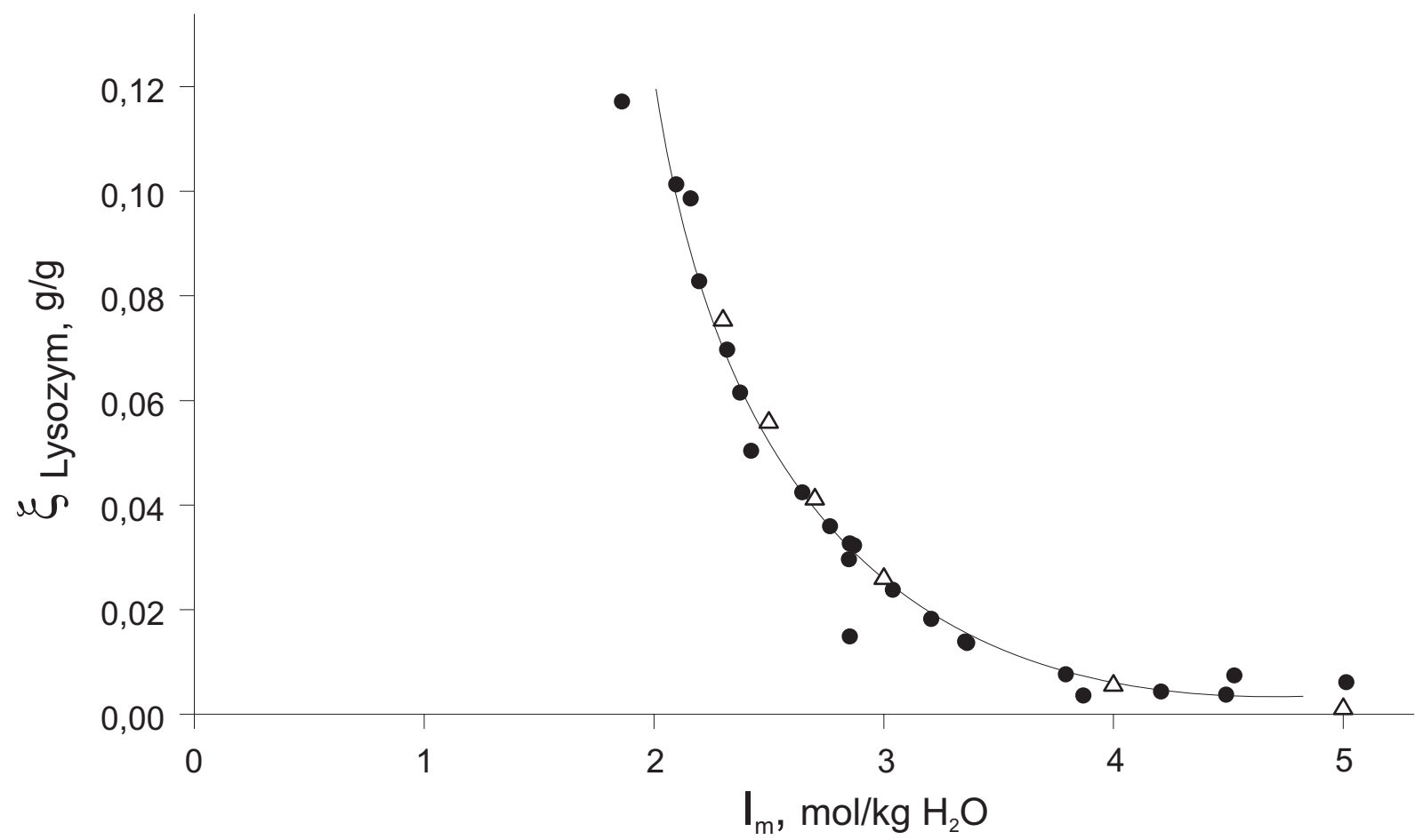

Abb.4.1 Experimentelle Ergebnisse für das System Lysozym - $\mathrm{Na}_{2} \mathrm{SO}_{4}-$ Wasser bei $25^{\circ} \mathrm{C}$ und $\mathrm{pH}=7$ :

- Trübungskurvenmessungen (diese Arbeit); $\triangle$ - Löslichkeit von amorphem Lysozym [10]

Dabei ist der Massenanteil von Lysozym in Abhängigkeit von der Ionenstärke der Lösung aufgetragen. Die Ionenstärke wird stets allein aus der Salzkonzentration berechnet. Die Ionenstärke ist in der Konzentrationseinheit Molalität dargestellt $\left(I_{m}\right)$. Die gefüllten Punkte markieren die experimentell bestimmten Trübungspunkte. Die Größe der Symbole entspricht ungefähr der Messgenauigkeit.

Die Konzentrationen der Stammlösungen von Lysozym bei diesen Untersuchungen lagen zwischen 1 und 18 Massen-\%. Stammlösungen mit höherem Lysozymgehalt wurden nicht 
verwendet, da die erhöhte Viskosität der Lösung die Einstellung der Trübung stark verzögert. Wegen der geringen Löslichkeit von $\mathrm{Na}_{2} \mathrm{SO}_{4}$ in Wasser wurden die Messungen auf Salzkonzentrationen bis etwa 20 Massen-\% beschränkt. Die experimentell bestimmte Trübungskurve überdeckt deshalb den Konzentrationsbereich bis etwa 10 Massen-\% Lysozym und bis 20 Massen-\% Natriumsulfat. Zum Beispiel werden etwa 8 Massen-\% Natriumsulfat benötigt, um eine Trübung bei der höchsten untersuchten Lysozymkonzentration (etwa 10 Massen-\%) zu verursachen. Die für eine Trübung benötigte Konzentration von Natriumsulfat beträgt bei einem Massen-\% Lysozym ungefähr 15 Massen-\%.

Die Abb. 4.1 zeigt die Ergebnisse von Shih et al. [10] für das gleiche System bei pH=7. Die leeren Dreiecke kennzeichnen die von Shih et al. angegebene Zusammensetzung der proteinarmen Phase, die zusammen mit einem amorphen, proteinreichen Niederschlag vorliegt. Man erkennt eine gute Übereinstimmung mit den Ergebnissen der vorliegenden Arbeit. Basierend auf den Ergebnissen für die Trübungskurve kann man keine Aussagen über die Struktur oder die Stabilität der ausgefällten Phase machen. Der thermodynamische Zustand (stabil oder metastabil) der proteinarmen Phase ist nicht bekannt.

Die in Phasengleichgewichtsmessungen bestimmten Zusammensetzungen der koexistierenden Phasen im System Lysozym $-\mathrm{Na}_{2} \mathrm{SO}_{4}$ - Wasser bei $25{ }^{\circ} \mathrm{C}$ und $\mathrm{pH}=7$ sind in der Abb. 4.2 dargestellt. Die entsprechenden Zahlenwerte sind im Anhang C tabelliert.

Die mit Lysozym angereicherte Phase bildet die Unterphase, die proteinarme Phase die Oberphase. Die Unterphasen sind durch leere Quadrate und die Oberphasen durch leere Kreise gekennzeichnet. Die Zusammensetzungen der Feedlösungen liegen auf der Linie, welche die beiden Phasen verbindet (Erfüllung der Massenbilanz), der Konode. Die Feedpunkte sind zum besseren Überblick in der Abb. 4.2 nicht gezeigt. Die gefüllten Kreise markieren Punkte auf der Trübungskurve. 


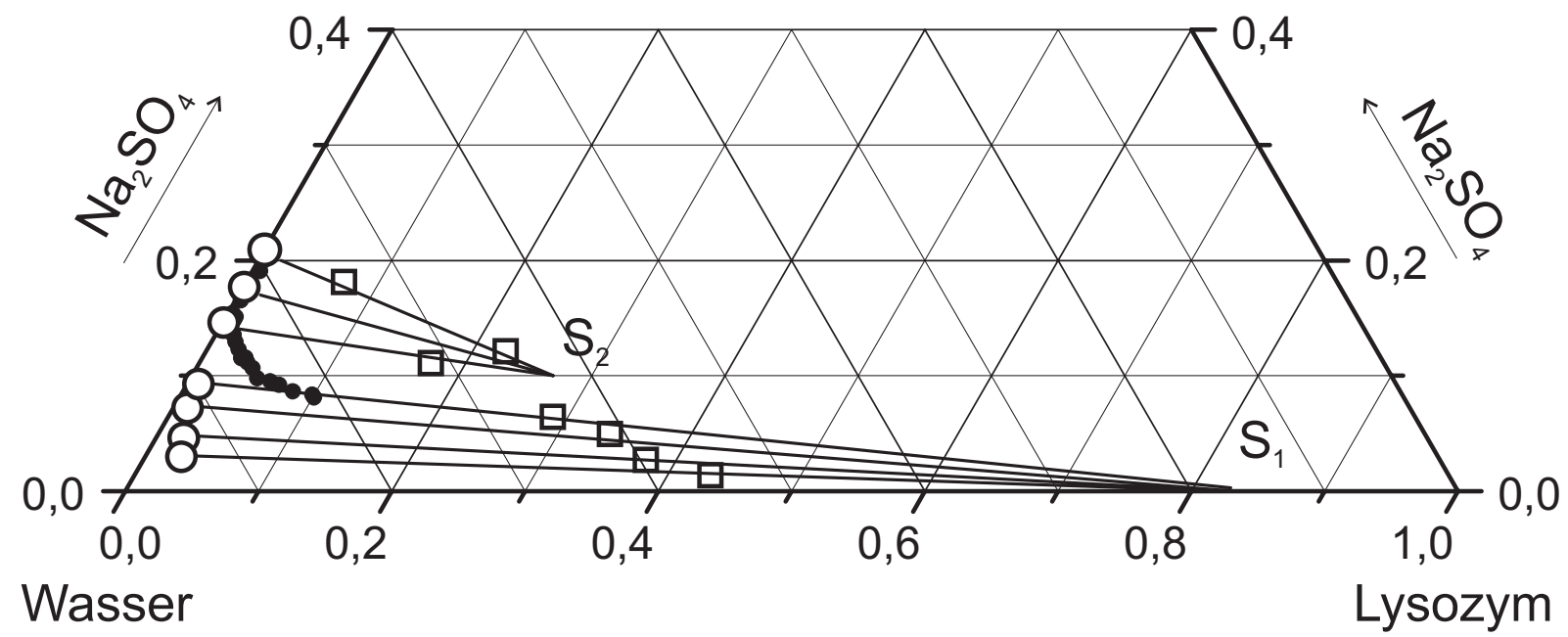

Abb.4.2 Experimentelle Ergebnisse für das Phasengleichgewicht des Systems Lysozym - $\mathrm{Na}_{2} \mathrm{SO}_{4}-$ Wasser bei $25^{\circ} \mathrm{C}$ und $\mathrm{pH}=7$ :

- - Trübungskurve; $\bigcirc$ - Zusammensetzung der proteinarmen Phase;

$\square$ - Zusammensetzung der proteinreichen Phase

Es wurde festgestellt, dass durch Zentrifugieren keine vollständige Trennung der Phasen erreicht wird. Die Unterphase stellt eine Mischung aus der proteinreichen und der proteinarmen Phase dar. Bei einer Verlängerung der Konoden werden zwei Schnittpunkte $S_{1}$ und $\mathrm{S}_{2}$ beobachtet. Der Punkt $\mathrm{S}_{1}$ liegt bei etwa 83 Massen-\% Lysozym und enthält kein Salz. Der Punkt $\mathrm{S}_{2}$ liegt bei etwa 27 Massen-\% Lysozym und etwa 10 Massen-\% Salz. Dieses Ergebnis wird so interpretiert, dass sich immer eine proteinreiche Phase ausbildet (entweder $\mathrm{S}_{1}$ oder $\mathrm{S}_{2}$ ), die mit einer proteinarmen Lösung koexistiert. Wenn die Phasen nicht komplett getrennt werden können, liegt die gemessene Zusammensetzung der „Unterphase“ auf der Linie, welche den jeweiligen Schnittpunkt $S_{1}$ bzw. $S_{2}$ mit der Oberphase verbindet.

Die mikroskopischen Untersuchungen haben gezeigt, dass die proteinreiche Phase eine kristalline Struktur aufweist. Für diese Untersuchungen wurden die Proben genauso wie für die Versuche zur Bestimmung der Zusammensetzung der koexistierenden Phasen hergestellt und separiert. Die proteinreiche Phase wurde unter dem Lichtmikroskop untersucht (s. Abschnitt 3.7). Die Abbildung 4.3 zeigt fotographische Aufnahmen der untersuchten Proben. 
a)

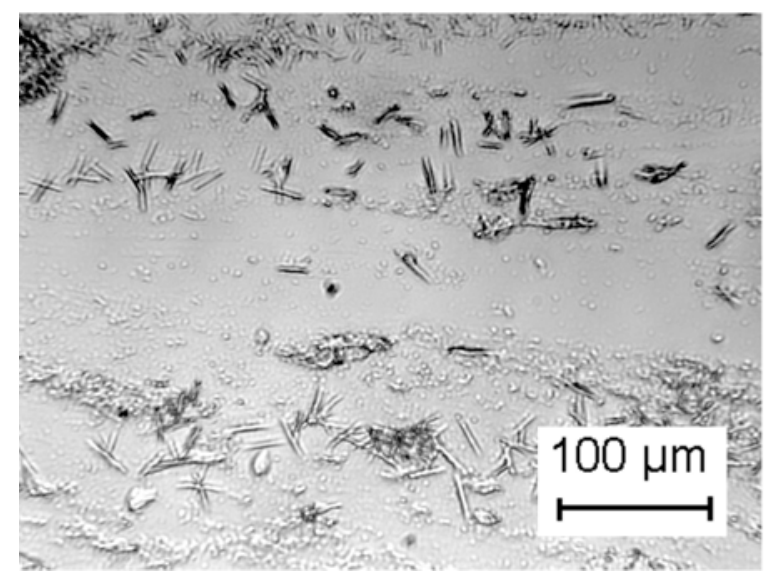

b)

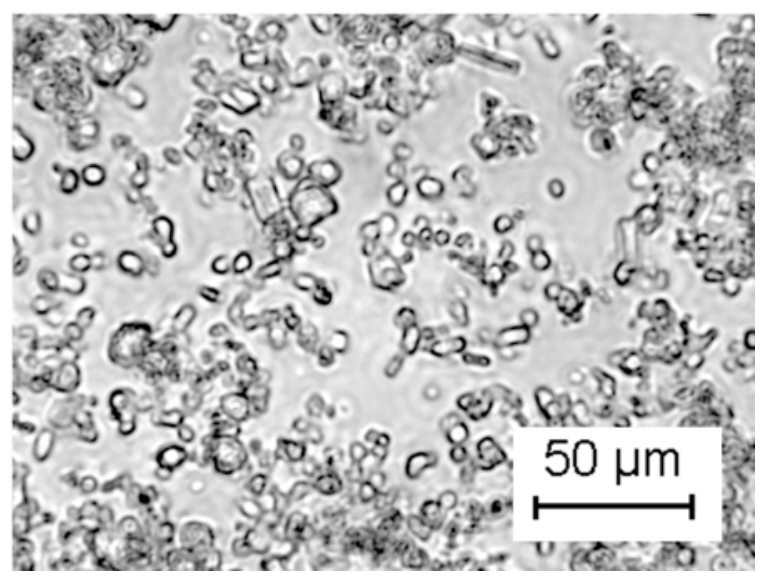

Abb. 4.3 System Lysozym $-\mathrm{Na}_{2} \mathrm{SO}_{4}-$ Wasser bei $25{ }^{\circ} \mathrm{C}$ und $\mathrm{pH}=7$. Mikroskopische Aufnahmen von Proben der Unterphase:

a) Zusammensetzung der Feedlösung ( $\left.\xi_{P}=0,0563 ; \xi_{S}=0,1379 ; \xi_{W}=0,8059\right)$;

b) Zusammensetzung der Feedlösung ( $\left.\xi_{P}=0,1302 ; \xi_{S}=0,0261 ; \xi_{W}=0,8437\right)$.

Im linken Teil der Abbildung 4.3 sind stäbchenformige Lysozymkristalle zu erkennen. Die Feedlösung der untersuchen Probe enthielt etwa 6 Massen-\% Lysozym und 14 Massen-\% Natriumsulfat, d. h. der Mischungspunkt liegt in jenem Konzentrationsbereich, aus dem der Schnittpunkt $\mathrm{S}_{2}$ resultiert. Die Größe der Kristalle beträgt ungefähr $50 \mu \mathrm{m}$. Bei Salzkonzentrationen unter 10 Massen-\% und vergleichbar großer Lysozymkonzentration (die Feedlösung im linken Teil der Abb. 4.3 enthielt etwa 13 Massen-\% Lysozym und 3 Massen-\% Natriumsulfat) bilden sich mehreckige Kristalle (Abb. 4.3b). Aus diesem Bereich kristallisiert salzfreies, wasserhaltiges Lysozym aus.

Wie aus der Abb. 4.2 zu erkennen ist, stimmt die gemessene Trübungskurve mit der Linie, die die Zusammensetzungen der Oberphase verbindet, nicht überein. Das bedeutet, dass bei der Trübungskurvenbestimmung die Löslichkeitsgrenze von kristallinem Lysozym überschritten wurde. Man befindet sich dann in einem metastabilen Bereich. In der Abbildung 4.4 ist zur besseren Übersicht die Zusammensetzung der proteinarmen Phase (die Löslichkeitsgrenze) zusammen mit der Trübungskurve aufgetragen. 


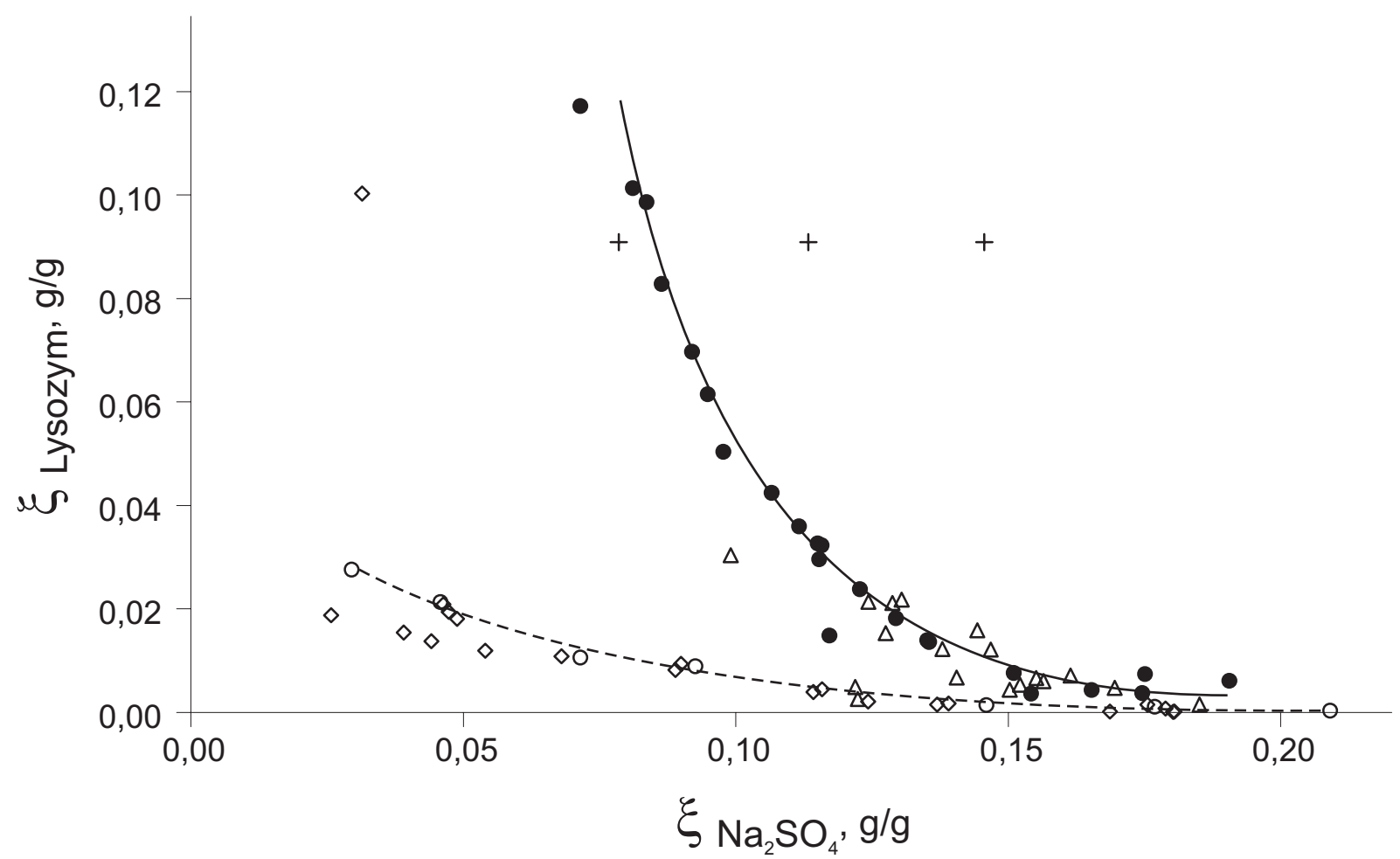

Abb.4.4 Vergleich der Löslichkeitsgrenze und der Trübungskurve in System Lysozym $\mathrm{Na}_{2} \mathrm{SO}_{4}$ - Wasser bei $25^{\circ} \mathrm{C}$ und $\mathrm{pH}=7$ : - Trübungspunkte;

○- Zusammensetzung der Oberphase aus Phasengleichgewichtsmessungen;

$\diamond$ - Zusammensetzung der Oberphase (über 5 Stunden);

$\triangle$ - Zusammensetzung der Oberphase (unter 5 Stunden)

Literaturergebnisse für das System Lysozym - $\mathrm{Na}_{2} \mathrm{SO}_{4}-$ Wasser bei $20{ }^{\circ} \mathrm{C}$ und pH=7,8: + -Zusammensetzung der Feedlösung mit Kristallbildung [51]

Zusätzlich sind in der Abbildung 4.4 weitere Ergebnisse für die Löslichkeit gezeigt. Die durch leere Dreiecke gekennzeichneten Zusammensetzungen der Oberphase wurden bei Versuchen mit Wartezeiten unter 5 Stunden gemessen. Die Ergebnisse der Löslichkeitsmessungen mit Wartezeiten über 5 Stunden sind durch leere Rhomben markiert. Die Zusammensetzung der koexistierenden proteinreichen Phasen wurde dabei nicht analysiert.

Die Differenz zwischen Löslichkeitsgrenze und Trübungskurve nimmt mit steigender Lysozymkonzentration zu. Die höchste in der vorliegenden Arbeit gemessene Löslichkeit von Lysozym beträgt etwa 2,8 Massen-\% bei etwa 3 Massen- $\%$ Natriumsulfat. Bei einer Salzkonzentration von etwa 21 Massen-\% beträgt die Löslichkeit von Lysozym noch etwa 0,03 Massen-\%. 
Wenn die proteinarme Phase weniger als 5 Massen-\% Ammoniumsulfat enthält, führt bereits eine geringe Temperatursenkung zur Proteinkristallisation. Deshalb wurden Proben der proteinarmen Phase sofort nach der Phasentrennung verdünnt.

Die experimentellen Ergebnisse für das System Lysozym - $\mathrm{Na}_{2} \mathrm{SO}_{4}-$ Wasser legen für ein stabiles Gleichgewicht folgende Vorstellung nahe (vgl. Abb. 4.5). Die Punkte $\mathrm{L}_{1}$ und $\mathrm{L}_{2}$ markieren die Löslichkeiten von Lysozym und Natriumsulfat in reinem Wasser bei $25{ }^{\circ} \mathrm{C}$. Die Löslichkeitskurve von Lysozym in salzhaltigen wässrigen Lösungen wird durch die Linie $\mathrm{L}_{2}{ }^{*}$ $-\mathrm{L}_{3}-\mathrm{L}_{1}$ festgelegt. Die Linie $\mathrm{L}_{2}-\mathrm{L}_{2}{ }^{*}$ trennt den Bereich der homogenen flüssigen Phase von dem Bereich ab, in dem Natriumsulfat als Dekahydrat $\left(\mathrm{Na}_{2} \mathrm{SO}_{4} \bullet 10 \mathrm{H}_{2} \mathrm{O}\right)$ (Feststoff $\mathrm{S}_{3}$ ) ausfällt. Die Linie $\mathrm{L}_{2}{ }^{*}-\mathrm{L}_{3}$ trennt den homogenen Bereich von einem Zweiphasengebiet $\left(\mathrm{L}_{2}{ }^{*}\right.$ $-\mathrm{L}_{3}-\mathrm{S}_{2}$ ). Dort wird das Ausfallen eines Komplexes aus Lysozym, Natriumsulfat und Wasser $\left(\mathrm{S}_{2}\right)$ beobachtet. In einem weiteren Zweiphasengebiet $\left(\mathrm{L}_{3}-\mathrm{L}_{1}-\mathrm{S}_{1}\right)$ wird das Ausfallen von hydratisiertem Lysozym als Feststoff $\mathrm{S}_{1}$ beobachtet.

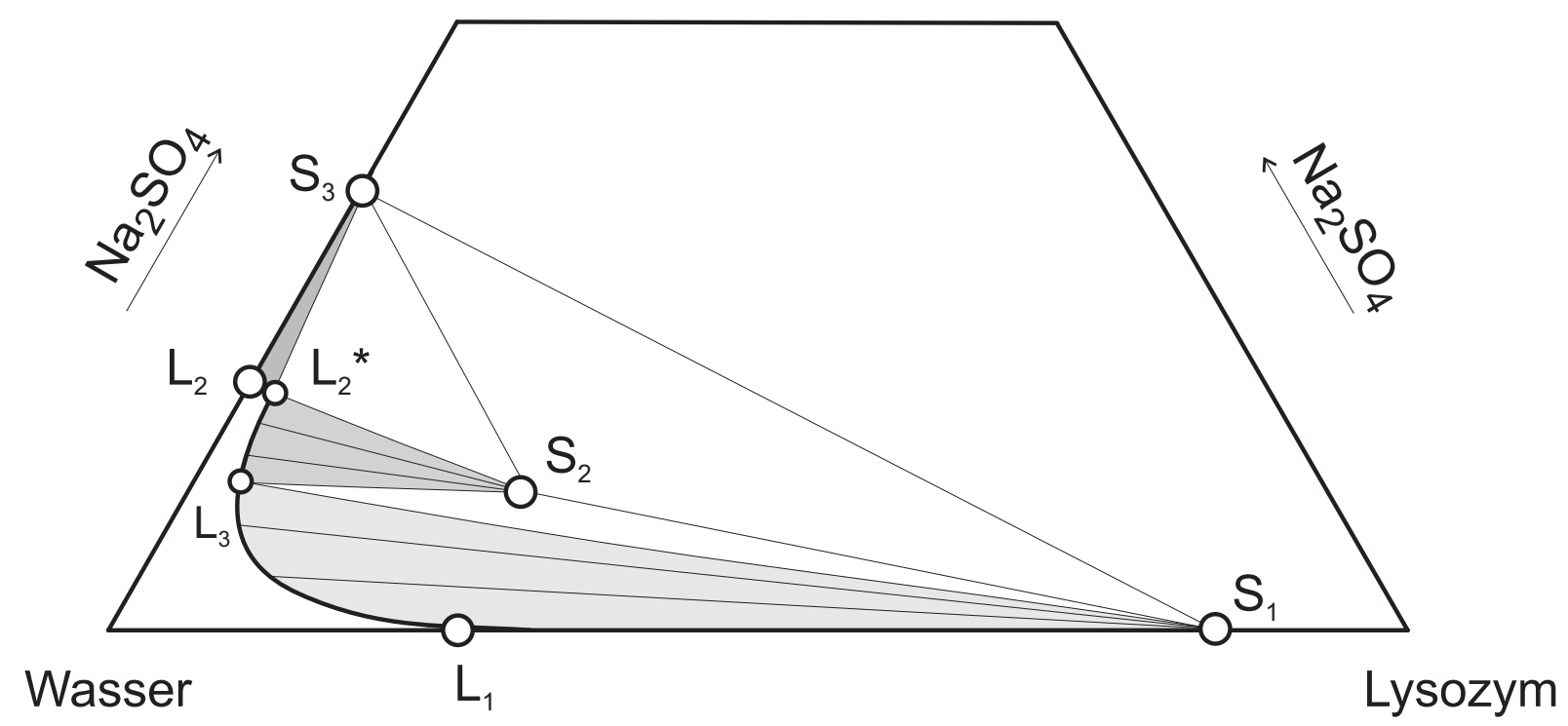

Abb. $4.5 \quad$ Vorschlag für das Phasendiagramm des Systems Lysozym $-\mathrm{Na}_{2} \mathrm{SO}_{4}-\mathrm{Wasser}$ bei $25^{\circ} \mathrm{C}$ und $\mathrm{pH}=7$

Darüber hinaus weist das Diagramm bei vergleichsweise hoher Wasserkonzentration (über 66 Massen-\%) drei Dreiphasengebiete auf. In zwei Gebieten $\left(\mathrm{S}_{2}-\mathrm{L}_{3}-\mathrm{S}_{1}\right.$ und $\left.\mathrm{S}_{3}-\mathrm{L}_{2}{ }^{*}-\mathrm{S}_{2}\right)$ befinden sich zwei feste Phasen mit einer flüssigen Phase im Gleichgewicht. Im Bereich $\mathrm{S}_{3}-$ $\mathrm{S}_{2}-\mathrm{S}_{1}$ koexistieren drei Feststoffe mit unterschiedlicher Zusammensetzung.

Wie bereits erwähnt, können Proteinkristalle bis zu 43 Massen-\% Wasser enthalten. Steinrauf [95] hat Lysozym aus wässrigen Natriumsulfatlösungen kristallisiert (monokline Form) und durch Röntgenstrukturanalyse einen Wassergehalt von 24 Massen- $\%$ ermittelt. In der 
vorliegenden Arbeit beträgt die für den Schnittpunkt $\mathrm{S}_{1}$ gefundene Wasserkonzentration etwa 17 Massen-\%.

\subsubsection{Lysozym - $\left(\mathrm{NH}_{4}\right)_{2} \mathrm{SO}_{4}-\mathrm{H}_{2} \mathrm{O}$}

Die Abbildung 4.6 zeigt die experimentellen Ergebnisse für die Trübungskurve des Systems Lysozym $-\left(\mathrm{NH}_{4}\right)_{2} \mathrm{SO}_{4}-$ Wasser bei $25^{\circ} \mathrm{C}$ und $\mathrm{pH}=6$.

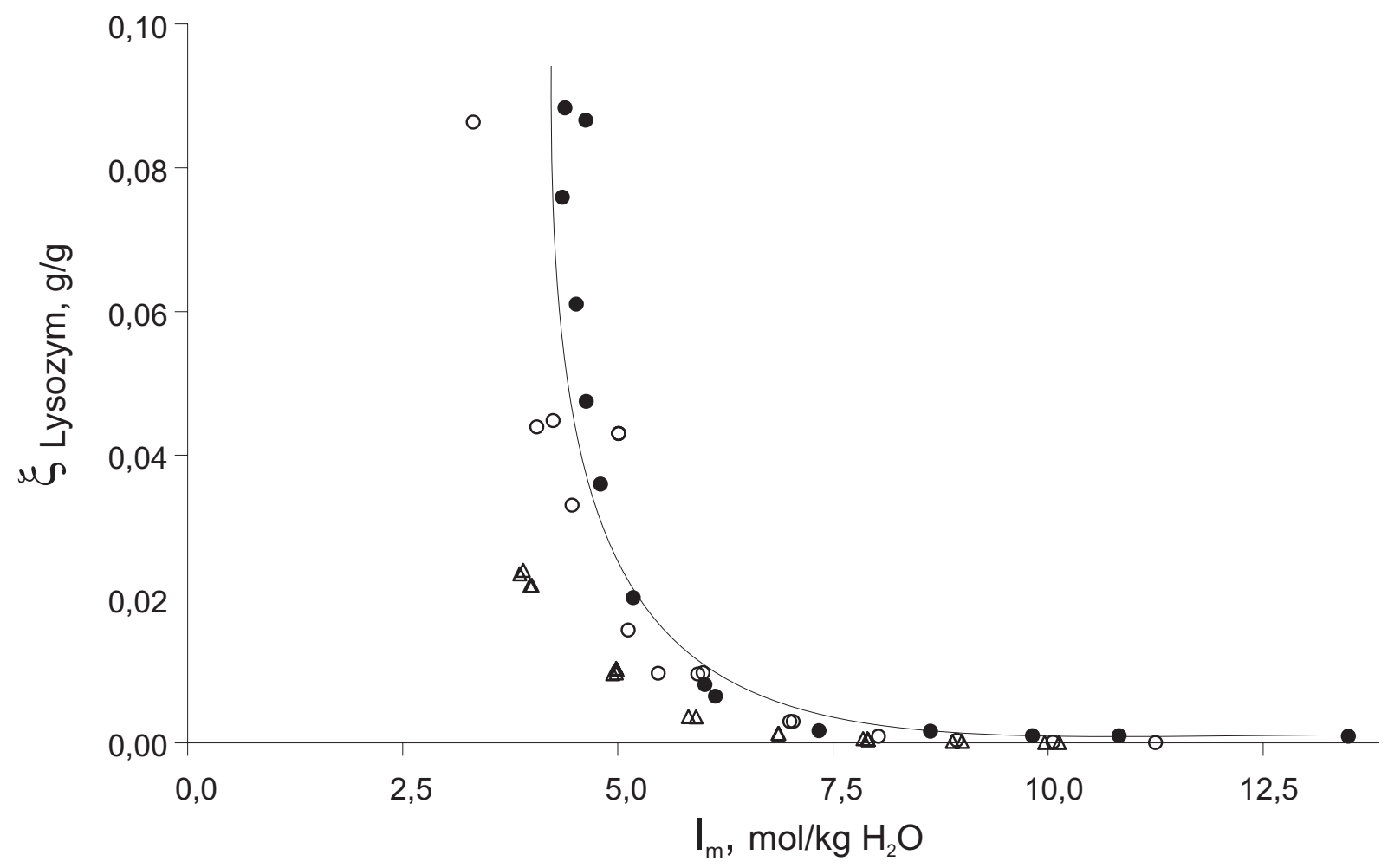

Abb.4.6 Experimentelle Ergebnisse für das System Lysozym - $\left(\mathrm{NH}_{4}\right)_{2} \mathrm{SO}_{4}-$ Wasser bei $25^{\circ} \mathrm{C}$ : - Trübungskurvenmessungen, $\mathrm{pH}=6$ (diese Arbeit);

$\bigcirc$ - Zusammensetzung der proteinarmen Phase ( $\mathrm{pH}=8)$;

$\triangle$ - Zusammensetzung der proteinarmen Phase ( $\mathrm{pH}=4$ ) [19]

Wie in der Abb. 4.1 ist dabei der Massenanteil von Lysozym über der Ionenstärke der Lösung aufgetragen. Die Ionenstärke wird stets allein aus der Salzkonzentration berechnet. Die schwarzen Punkte kennzeichnen die in der vorliegenden Arbeit experimentell bestimmten Trübungspunkte. Die Größe eines Symbols entspricht ungefähr der Messgenauigkeit. Die Konzentrationen der Stammlösungen von Lysozym lagen zwischen etwa 2 und 18 Massen-\%. Die Messungen wurden auf Salzkonzentrationen bis etwa 40 Massen-\% (durch die Salzlöslichkeit bedingt) beschränkt. Die experimentell bestimmte Trübungskurve liegt im 
Konzentrationsbereich bis zu 9 Massen-\% Lysozym und bis zu 37 Massen-\% Ammoniumsulfat. Der Einfluss von Ammoniumsulfat auf den Verlauf der Trübungskurve ist dem Einfluss von Natriumsulfat ähnlich. Die Trübungskurve im System mit Ammoniumsulfat ist jedoch zu höheren Salzkonzentrationen hinverlagert. Es werden ungefähr 15 Massen-\% Ammoniumsulfat benötigt, um eine Trübung bei der höchsten untersuchten Lysozymkonzentration (ca. 8,8 Massen-\%) zu verursachen.

Die Abb. 4.6 zeigt die Ergebnisse von Moretti et al. [19] für das gleiche System bei den pHWerten 4 und 8. Leere Dreiecke und Kreise kennzeichnen die von Moretti et al. angegebene Zusammensetzung der proteinarmen Phase, die zusammen mit einem amorphen, proteinreichen Niederschlag vorliegt (s. auch Abschnitt 2.2.4).

Die experimentell bestimmten Zusammensetzungen der koexistierenden Phasen im System Lysozym - $\left(\mathrm{NH}_{4}\right)_{2} \mathrm{SO}_{4}-$ Wasser bei $25^{\circ} \mathrm{C}$ und $\mathrm{pH}=6$ sind in der Abb. 4.7 dargestellt. Die entsprechenden Zahlenwerte sind im Anhang C tabelliert. Die gefüllten Kreise markieren die Trübungskurve. Leere Quadrate kennzeichnen die Zusammensetzungen der Unterphase (proteinreiche Phase) und leere Kreise kennzeichnen die Zusammensetzungen der Oberphase (proteinarme Phase). Die Zusammensetzungen der Feedlösungen liegen im Rahmen der Messgenauigkeit auf den Linien, die die entsprechenden Zusammensetzungen von Ober- und Unterphase verbinden. Die Feedpunkte wurden zur besseren Überblick nicht eingetragen.

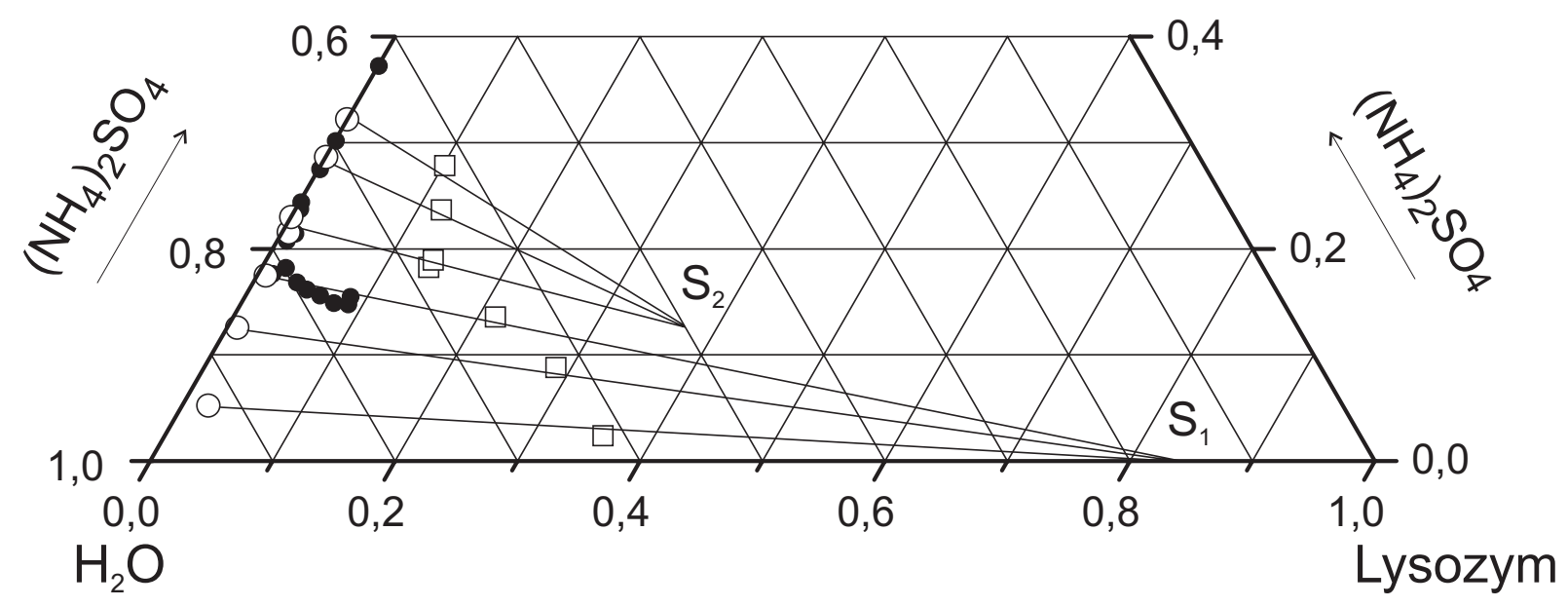

Abb. 4.7 Experimentelle Ergebnisse für das Phasengleichgewicht des Systems Lysozym - $\left(\mathrm{NH}_{4}\right)_{2} \mathrm{SO}_{4}-$ Wasser bei $25^{\circ} \mathrm{C}$ und $\mathrm{pH}=6$ : - Trübungskurve;

$\bigcirc$ - Zusammensetzung der proteinarmen Phase; $\square$ - Zusammensetzung der proteinreichen Phase 
Bei der Vorbereitung der Feedlösungen wurde - wie in System mit Natriumsulfat beobachtet, dass bei Feedpunkten, deren Zusammensetzung innerhalb der gemessenen Trübungskurve lag, ein sofortiger Phasenzerfall auftrat. Bei den Feedlösungen, die weniger als 8 (Natriumsulfat) bzw. 14 Massen-\% (Ammoniumsulfat) des Salzes enthielten, trat der Phasenzerfall erst nach einigen Stunden (in der Regel zwischen 2 und 5 Stunden) auf. Manche Proben mit Salzkonzentrationen unter 4 Massen-\% wurden sogar erst nach einigen Tagen trüb.

Auch in diesem System konnte durch Zentrifugieren keine vollständige Trennung der Phasen erreicht werden. Die Verbindungslinien zwischen entsprechenden Punkten der beiden Phasen verlaufen nicht parallel. Bei der Verlängerung dieser Verbindungslinien treten ebenfalls zwei Schnittpunkte $S_{1}$ und $S_{2}$ auf. Der Punkt $S_{1}$ liegt bei etwa 84 Massen-\% Lysozym und enthält kein Salz. Der Punkt $\mathrm{S}_{2}$ liegt bei etwa 36 Massen-\% Lysozym und etwa 14 Massen-\% Salz.

Einige typische mikroskopische Aufnahmen von Proben der Unterphase unterschiedlicher Zusammensetzung sind in der Abbildung 4.8 dargestellt. Eine Kristallbildung wurde nur bei einer Feedlösung beobachtet (Abb. 4.7a). Die Zusammensetzung dieser Feedlösung lag bei etwa 5 Massen-\% Lysozym und 25 Massen-\% Salz. Bei höheren (Abb. 4.8b) sowie bei niedrigeren (Abb. 4.8c) Salzkonzentrationen bildeten sich wasserlösliche proteinreiche Aggregate. Lysozym wurde aus wässrigen Lösungen von Ammoniumsulfat von Forsythe et al. kristallisiert [55]. In der Regel bringt zwar Ammoniumsulfat ein Protein zum Ausfällen, eine Kristallisation wird jedoch nicht beobachtet.

In der Abbildung 4.9 ist die Zusammensetzung der proteinarmen Phase (Oberphase, d. h. die Löslichkeitsgrenze) mit der Trübungskurve verglichen. 
a)

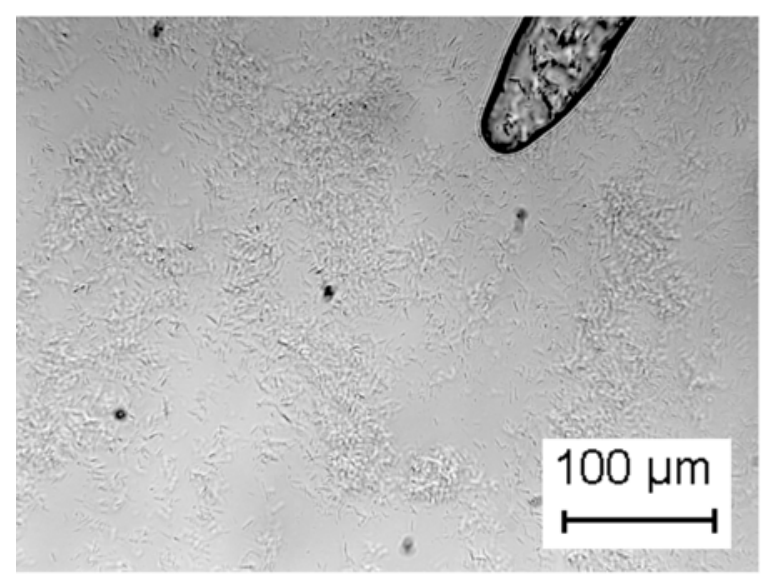

c)

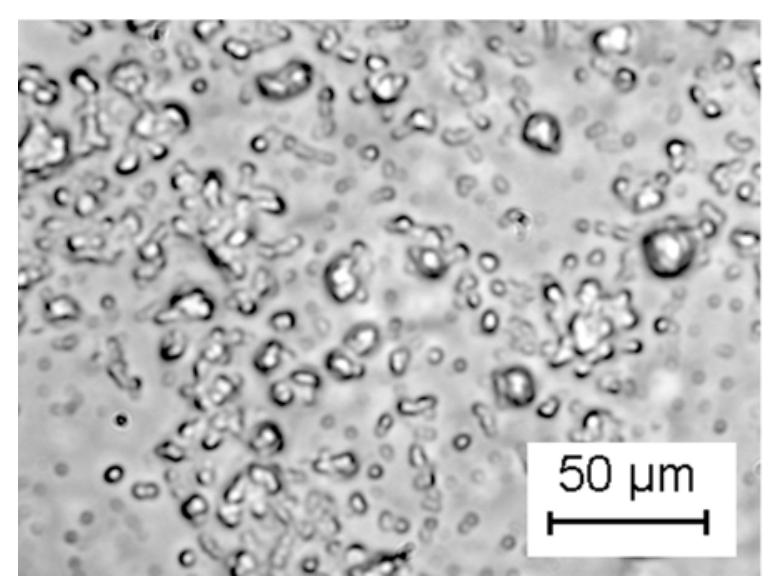

Abb. 4.8 System Lysozym - $\left(\mathrm{NH}_{4}\right)_{2} \mathrm{SO}_{4}-$ Wasser bei $25{ }^{\circ} \mathrm{C}$ und $\mathrm{pH}=6$. Mikroskopische Aufnahmen von Proben der Unterphase:

a) Zusammensetzung der Feedlösung ( $\xi_{P}=0,0563 ; \xi_{S}=0,2521 ; \xi_{W}=0,6917$ );

b) Zusammensetzung der Feedlösung ( $\left.\xi_{P}=0,0551 ; \xi_{S}=0,3500 ; \xi_{W}=0,5949\right)$;

c) Zusammensetzung der Feedlösung ( $\left.\xi_{P}=0,1009 ; \xi_{S}=0,0280 ; \xi_{W}=0,8711\right)$ 


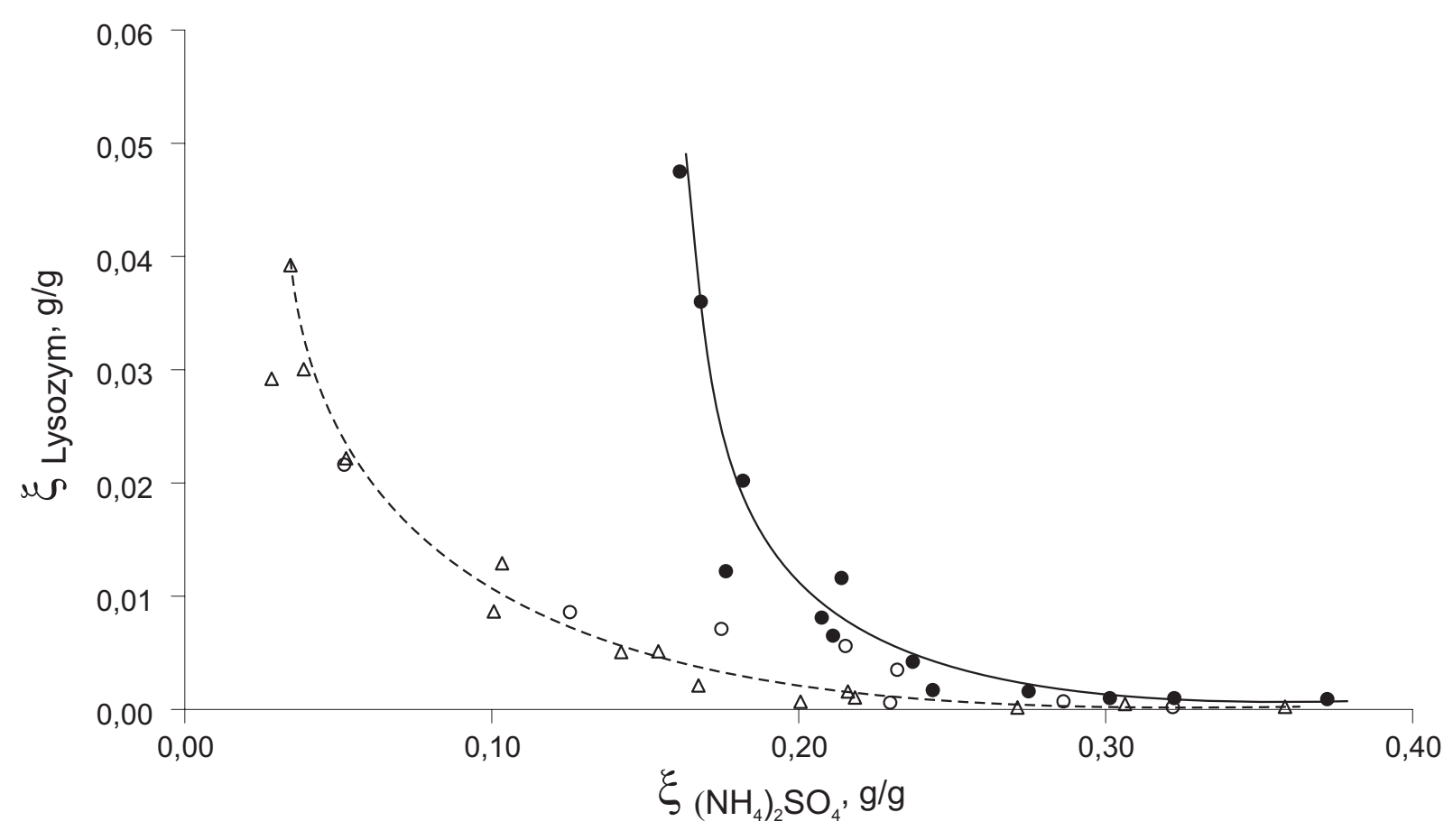

Abb.4.9 Vergleich von Löslichkeits- und Trübungskurve im System Lysozym $\left(\mathrm{NH}_{4}\right)_{2} \mathrm{SO}_{4}$ - Wasser bei $25^{\circ} \mathrm{C}$ und $\mathrm{pH}=6$ : $\bullet-$ Trübungspunkte;

$\bigcirc$ - Zusammensetzung der Oberphase aus Phasengleichgewichtsmessungen;

$\triangle$ - Zusammensetzung der proteinarmen Phase (ohne Bestimmung der Zusammensetzung der Unterphase)

Die experimentell bestimmte Trübungskurve liegt im Zweiphasengebiet. Bei höheren Salzkonzentrationen laufen die Löslichkeitskurve und die Trübungskurve zusammen. Eine ternäre Lösung, deren Zusammensetzung im Bereich zwischen die Löslichkeitskurve (---) und Trübungskurve (-) liegt, kann über längere Zeiten einphasig bleiben. In einigen Fällen wurde eine ausgeprägte Kristallbildung (Kristallgröße ca. $5 \mathrm{~mm}$ ) oder eine Gelbildung beobachtet. In der Tabelle 8 sind die Zusammensetzungen der Feedlösungen angegeben, in denen eine Gelbildung auftrat. Dabei hat sich eine Gelphase ausgebildet, die mit einer vergleichbar geringen Menge an flüssiger Phase koexistierte.

Tabelle $8 \quad$ Gelbildung im System Lysozym - $\left(\mathrm{NH}_{4}\right)_{2} \mathrm{SO}_{4}-$ Wasser bei $25{ }^{\circ} \mathrm{C}$ und $\mathrm{pH}=6$ : Zusammensetzungen der Feedpunkte

\begin{tabular}{|c|c|c|}
\hline$\xi_{P}$ & $\xi_{S}$ & $\xi_{W}$ \\
\hline 0,1023 & 0,1667 & 0,7310 \\
\hline 0,1372 & 0,1099 & 0,7529 \\
\hline
\end{tabular}


In der Abbildung 4.10 ist ein Vorschlag für das Phasendiagramm im System Lysozym $\left(\mathrm{NH}_{4}\right)_{2} \mathrm{SO}_{4}-$ Wasser bei $25{ }^{\circ} \mathrm{C}$ und $\mathrm{pH}=6$ gezeigt. Dieses System weist das gleiche Phasenverhalten wie das System mit Natriumsulfat auf. Die Punkte $L_{1}$ und $L_{2}$ entsprechen den Löslichkeitsgrenzen von Lysozym bzw. Ammoniumsulfat in reinem Wasser. Man erkennt ein einphasiges Gebiet, das durch die Löslichkeitskurve $\mathrm{L}_{2}-\mathrm{L}_{2}{ }^{*}-\mathrm{L}_{3}-\mathrm{L}_{1}$ vom Mehrphasengebiet abgetrennt ist, drei Fest-Flüssig-Zweiphasengebiete, in denen eine der Feststoffe $\mathrm{S}_{1}, \mathrm{~S}_{2}$ bzw. $\mathrm{S}_{3}$ mit einer Flüssigkeit im Gleichgewicht steht, und mehrere Dreiphasengebiete. Bei Salzkonzentrationen über 14 Massen-\% bildet sich ein kristalliner Komplex aus Lysozym, Ammniumsulfat und Wasser $\left(\mathrm{S}_{2}\right)$. Im Rahmen der Messgenauigkeit enthält der (vermutlich amorphe) Feststoff $\mathrm{S}_{1}$ kein Salz und besteht damit lediglich aus Lysozym und Wasser.

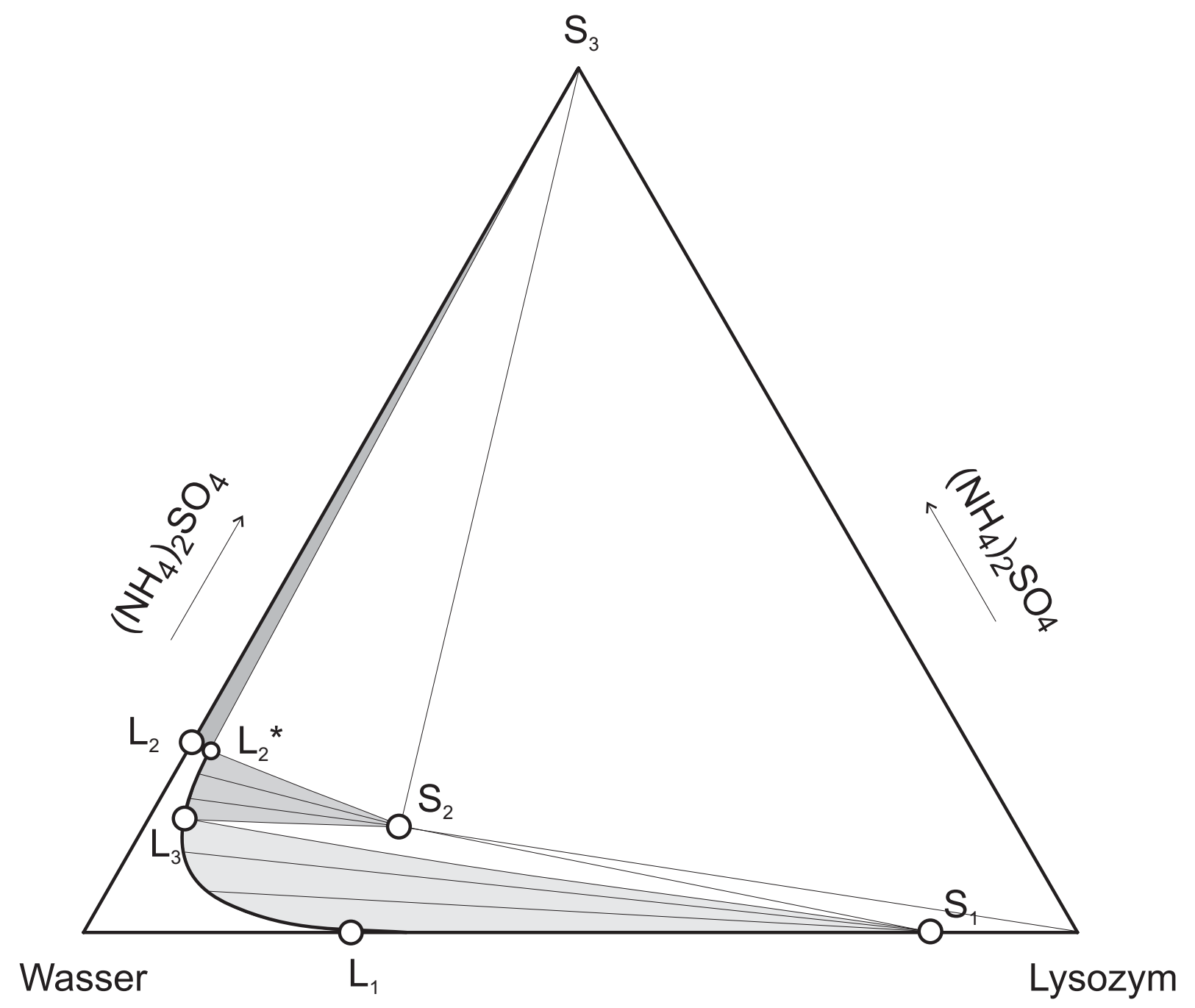

Abb. 4.10 Vorschlag für das Phasendiagramm des Systems Lysozym - $\left(\mathrm{NH}_{4}\right)_{2} \mathrm{SO}_{4}-$ Wasser bei $25^{\circ} \mathrm{C}$ und $\mathrm{pH}=6$ 
In der Arbeit von Moretti et al. [19] wurde das Phasenverhalten des Systems Lysozym Ammoniumsulfat - Wasser bei zwei unterschiedlichen $\mathrm{pH}$-Werten experimentell untersucht (s. Kapitel 2, Abschnitt 2.2.4). In beiden Fällen konnte man zwei Gebiete unterscheiden, in denen sich der Verlauf der Konoden unterscheidet. Der Verlauf dieser Konoden stimmt mit den in der vorliegenden Arbeit erhaltenen Ergebnissen überein. Moretti et al. haben allerdings keine mikroskopische Untersuchungen der proteinreichen Phase durchgeführt. Es ist nicht unüblich, dass ein mikrokristalliner Niederschlag mit einem amorphen Niederschlag verwechselt wird. In einer weitergehenden Arbeit von Cheng Yu-Chia et al. [96] wurde festgestellt, dass Lysozym in konzentrierten Lösungen von Ammoniumsulfat unter bestimmten Bedingungen kristallisiert werden kann. Es wurden kinetische und thermodynamische Aspekte der Lysozymkristallisation diskutiert.

\subsubsection{Lysozym - Flüchtiges Salz $-\mathrm{H}_{2} \mathrm{O}$}

Die Abbildung 4.11 zeigt die experimentellen Ergebnisse für die Trübungskurve des Systems Lysozym $-\mathrm{NH}_{2} \mathrm{COONH}_{4}-$ Wasser bei $25{ }^{\circ} \mathrm{C}$ und $\mathrm{pH}=9$, dabei ist der Massenanteil von Lysozym über der Ionenstärke der Lösung (Molalitätskala) aufgetragen. Die Ionenstärke wird stets allein aus der Salzkonzentration berechnet. Gefüllte Kreise markieren die experimentell bestimmten Trübungspunkte.

Die Konzentrationen der Stammlösungen von Lysozym lagen zwischen 1 und 21 Massen-\%. Die Konzentrationen der Stammlösungen des Salzes lagen zwischen 2 und 30 Massen-\%. Die experimentell bestimmte Trübungskurve befindet sich im Konzentrationsbereich bis zu 20 Massen-\% Lysozym und bis zu 29 Massen-\% Ammoniumcarbamat. Es werden ungefähr 0,5 Massen-\% Ammoniumcarbamat benötigt, um eine Trübung bei der höchsten untersuchten Lysozymkonzentration (20 Massen-\%) zu verursachen. Im Vergleich zu konventionellen Salzen (Natriumsulfat und Ammoniumsulfat) tritt die Trübung im Allgemeinen bei einer viel niedrigerer Salzkonzentration auf.

Die experimentell bestimmten Zusammensetzungen der koexistierenden Phasen im System Lysozym $-\mathrm{NH}_{2} \mathrm{COONH}_{4}-$ Wasser bei $25^{\circ} \mathrm{C}$ und $\mathrm{pH}=9$ sind in der Abb. 4.12 dargestellt und im Anhang $\mathrm{C}$ zusammengestellt. Dabei markieren die gefüllten Kreise die Trübungskurve. Die Zusammensetzungen der Unterphase (proteinreiche Phase) sind durch leere Quadrate, die Zusammensetzungen der Oberphase (proteinarme Phase) durch leere Kreise und die Zusammensetzungen der Feedpunkte durch leere Dreiecke gekennzeichnet. 


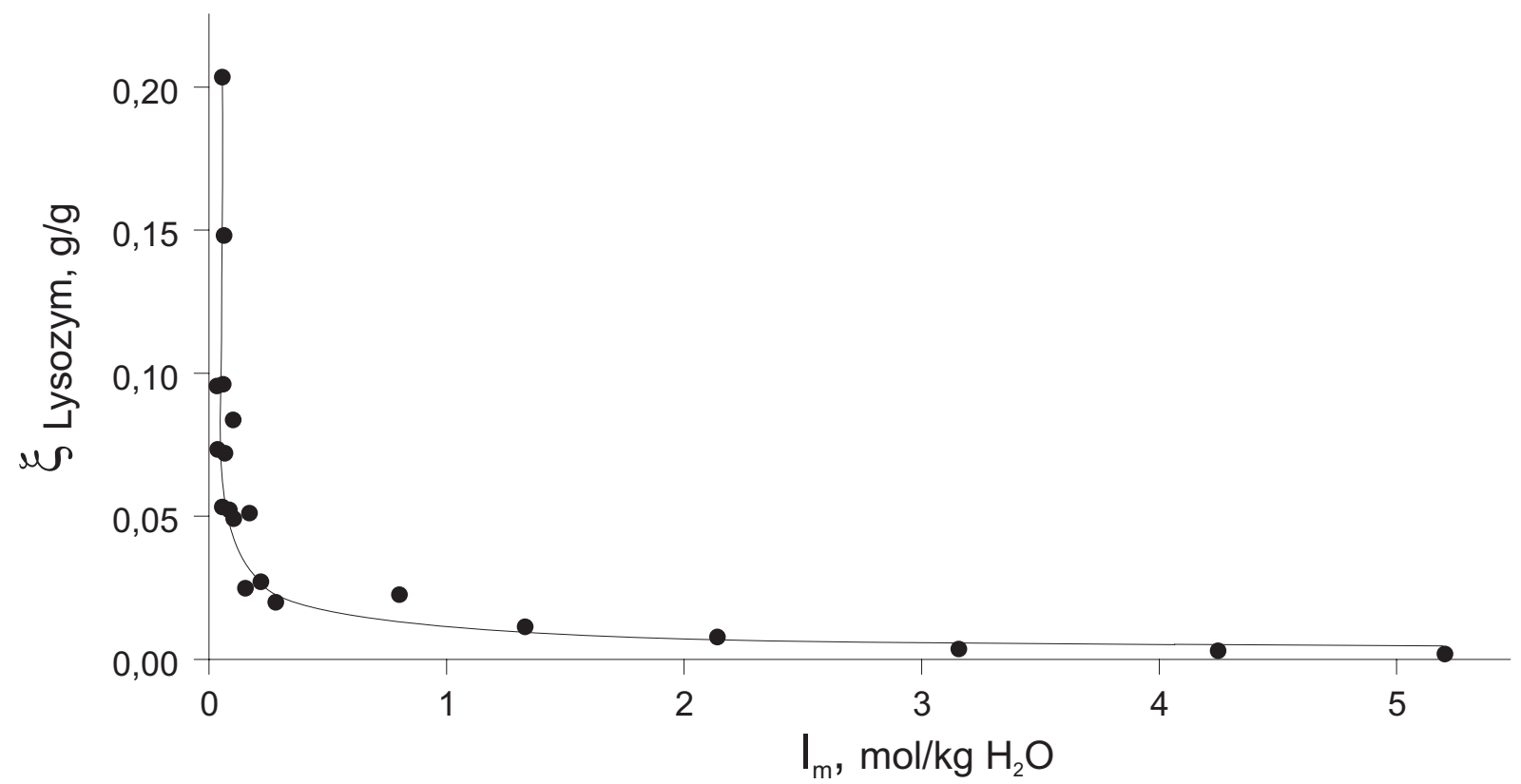

Abb.4.11 Experimentelle Ergebnisse für die Trübungskurve des Systems Lysozym $\mathrm{NH}_{2} \mathrm{COONH}_{4}-$ Wasser bei $25^{\circ} \mathrm{C}$ und $\mathrm{pH}=9$

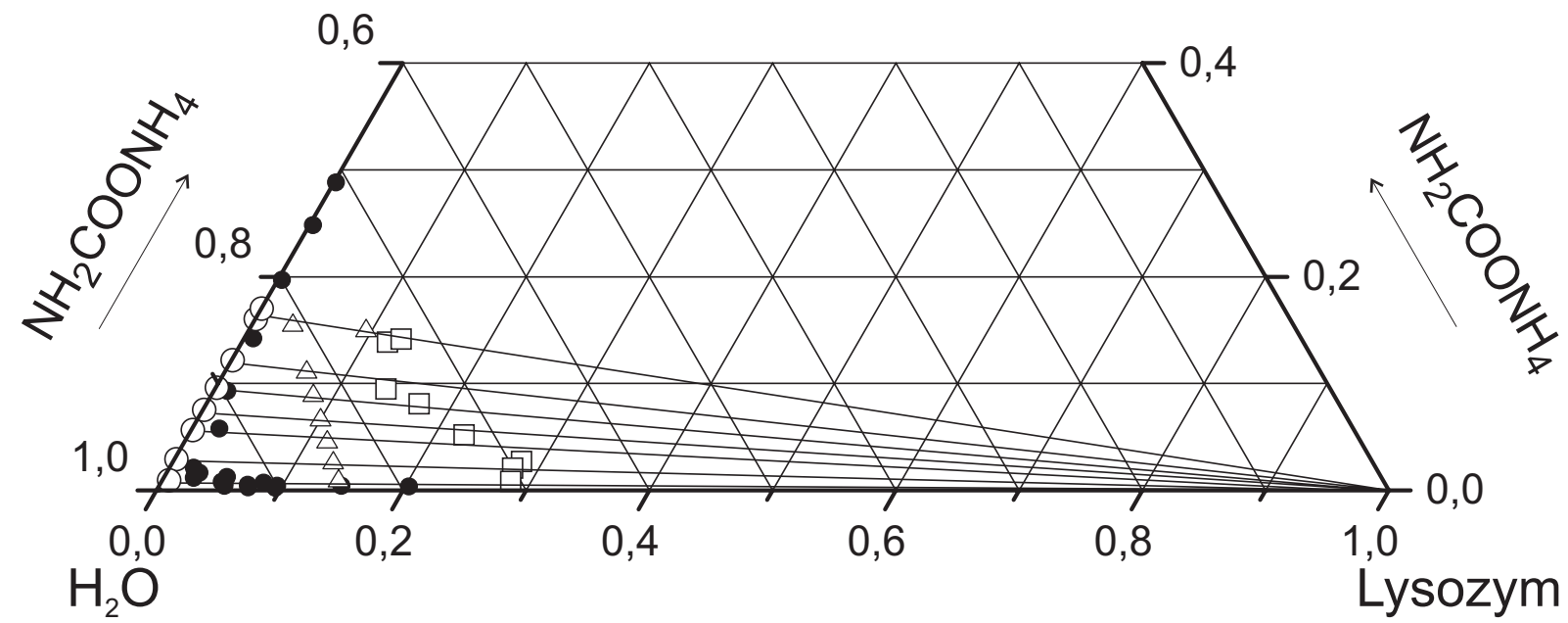

Abb.4.12 Experimentelle Ergebnisse für das Phasengleichgewicht des Systems Lysozym - $\mathrm{NH}_{2} \mathrm{COONH}_{4}-$ Wasser bei $25{ }^{\circ} \mathrm{C}$ und $\mathrm{pH}=9$ : - Trübungskurve;

$\bigcirc$ - Zusammensetzung der proteinarmen Phase; $\square$ - Zusammensetzung der proteinreichen Phase; $\triangle$ - Zusammensetzung der Feedpunkte

Wegen des Einflusses von Ammoniumcarbamat auf die UV-Analyse des Proteingehalts (vgl. Abschnitt 3.5.3) wurden die Messungen auf Salzkonzentrationen unter 20 Massen-\% beschränkt. Die Zusammensetzung der Unterphase wurde aus dem Lysozymgehalt in der Unterphase (analysiert durch Gefriertrocknung) und aus der Zusammensetzung der Oberphase berechnet. 
Da eine vollständige Phasentrennung durch Zentrifugieren nicht erreicht werden konnte, enthält die Unterphase noch die proteinarme Phase. Bei der Verlängerung der Verbindungslinien der Analyseergebnisse für die Ober- und Unterphase zeigt sich ein Schnittpunkt, der dem reinen Protein entspricht. Die mikroskopischen Untersuchungen ergaben, dass beim Ausfällen Kristalle gebildet werden. In der Abbildung 4.13 sind mikroskopische Aufnahmen einiger Proben der Unterphase gezeigt. Auf beiden Bildern sind die Proteinkristalle deutlich zu erkennen. Im linken Teil der Abbildung weisen die Kristalle eine Stäbchenform auf. Die Größe der Kristalle beträgt ungefähr $20 \mu \mathrm{m}$. Die rechte Aufnahme stammt aus den Untersuchungen mit einem Elektronenmikroskop und liefert eine vergrößerte Abbildung eines Kristalls. Der Proteinkristall weist eine unregelmäßige Form auf und ist etwa $5 \mu \mathrm{m}$ groß.

a)

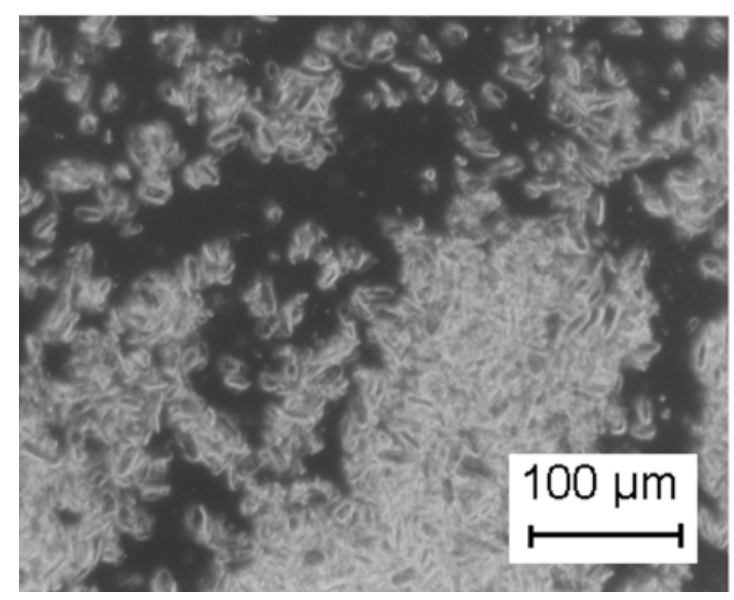

b)

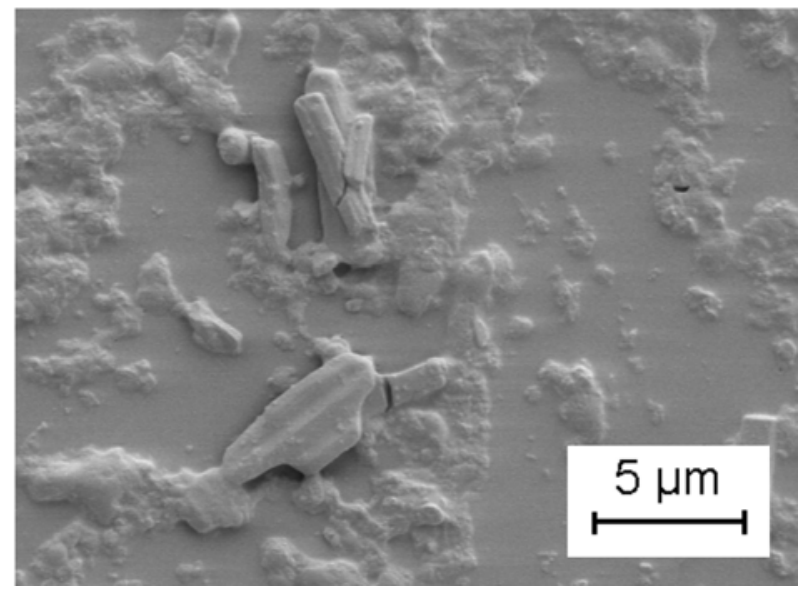

Abb.4.13 System Lysozym $-\mathrm{NH}_{2} \mathrm{COONH}_{4}$ - Wasser bei $25{ }^{\circ} \mathrm{C}$ und $\mathrm{pH}=9$. Mikroskopische Aufnahmen einer Probe aus der Unterphase:

a) Zusammensetzung der Feedlösung ( $\left.\xi_{P}=0,1194 ; \xi_{S}=0,0363 ; \xi_{W}=0,8443\right)$;

b) Zusammensetzung der Feedlösung ( $\xi_{P}=0,1309 ; \xi_{S}=0,0264 ; \xi_{W}=0,8428$ ).

In der Abbildung 4.14 ist die Zusammensetzung der proteinarmen Phase (die Löslichkeitsgrenze) zusammen mit einigen Trübungspunkten aufgetragen. Bei etwa 20 Massen- $\%$ Ammoniumcarbamat beträgt die Löslichkeit von Lysozym etwa $6 \times 10^{-3}$ Massen-\%. Die Löslichkeit steigt mit abnehmender Salzkonzentration und erreicht ungefähr 0,5 Massen- $\%$ bei 1 Massen- $\%$ Ammoniumcarbamat. 
Die Trübungskurve liegt innerhalb des Fest-Flüssig-Zweiphasengebiets. Die Differenz zwischen der Löslichkeitsgrenze und der Trübungskurve nimmt mit steigender Lysozymkonzentration zu.

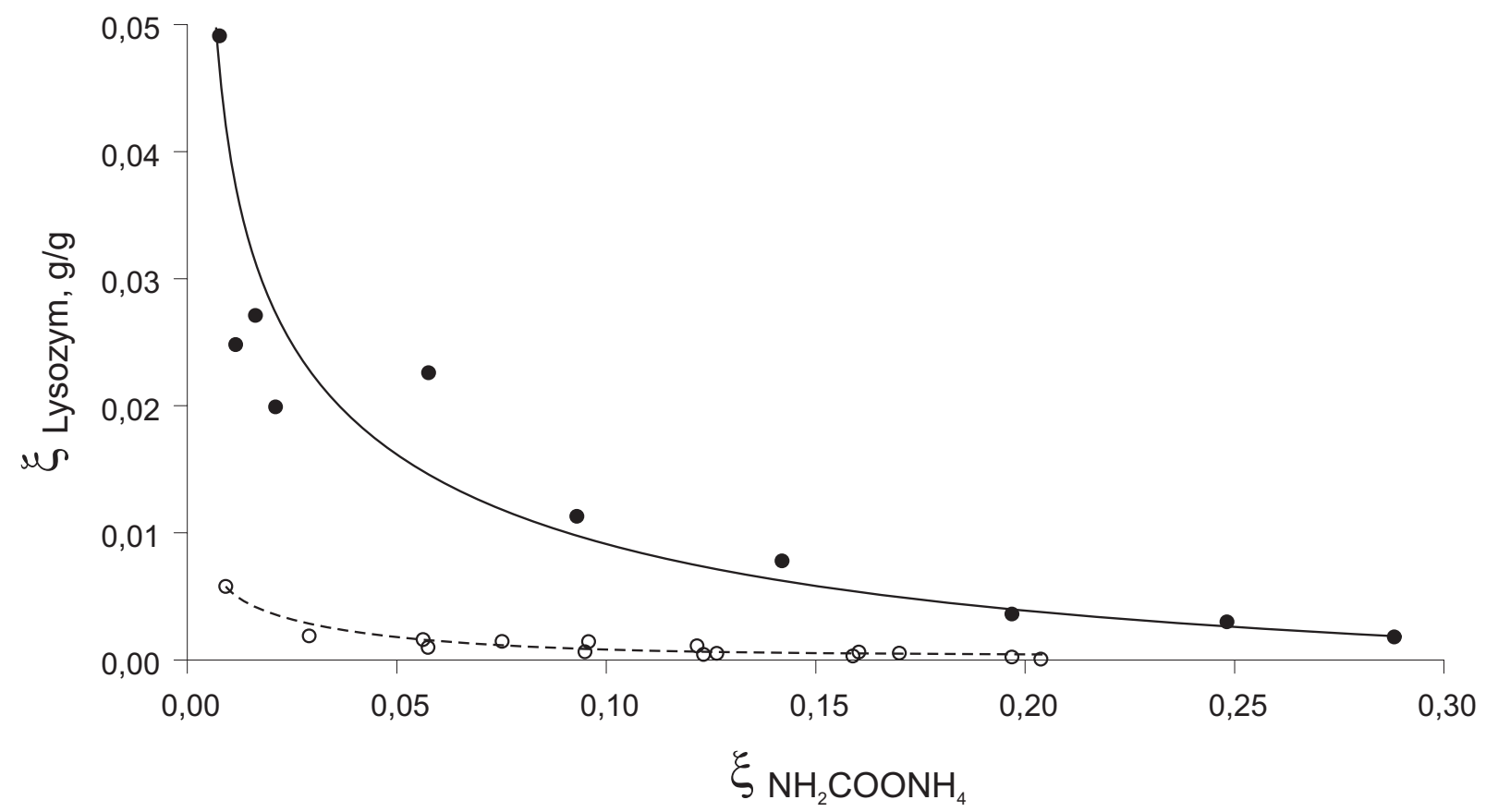

Abb.4.14 Vergleich von Löslichkeits- und Trübungskurve in System Lysozym $\mathrm{NH}_{2} \mathrm{COONH}_{4}$ - Wasser bei $25{ }^{\circ} \mathrm{C}$ und $\mathrm{pH}=9$ : - Trübungspunkte; $\bigcirc$ Zusammensetzung der Oberphase aus Phasengleichgewichtsmessungen

Aus den experimentellen Untersuchungen ergab sich für das System Lysozym $\mathrm{NH}_{2} \mathrm{COONH}_{4}-$ Wasser das in der Abb. 4.15 gezeigte Phasendiagramm. Die Punkte $\mathrm{L}_{1}$ und $\mathrm{L}_{2}$ markieren die Löslichkeiten von Lysozym und Ammoniumcarbamat in reinem Wasser. Die Löslichkeitskurve von Lysozym in salzhaltigen wässrigen Lösungen wird durch die Linie $\mathrm{L}_{2}{ }^{*}$ $-\mathrm{L}_{1}$ festgelegt. Die Linie $\mathrm{L}_{2}-\mathrm{L}_{2}{ }^{*}$ trennt den Bereich der homogenen flüssigen Phase vom Bereich, in dem Ammoniumcarbamat als Feststoff $\mathrm{S}_{2}$ ausfällt. Die Linie $\mathrm{L}_{2}{ }^{*}-\mathrm{L}_{1}$ trennt den homogenen Bereich vom Zweiphasengebiet $\left(\mathrm{L}_{2}{ }^{*}-\mathrm{L}_{1}-\mathrm{S}_{1}\right)$. Dort wird das Ausfallen vom reinen Lysozym $\left(\mathrm{S}_{1}\right)$ beobachtet. Das Diagramm weist keine weiteren Zweiphasengebiete auf. Das Dampf-Flüssig-Gleichgewicht wird in diesem Diagramm nicht berücksichtigt. Es wird davon ausgegangen, dass bei Umgebungstemperatur die Partialdrücke von Ammoniak und Kohlendioxid vernachlässigbar gering sind. 


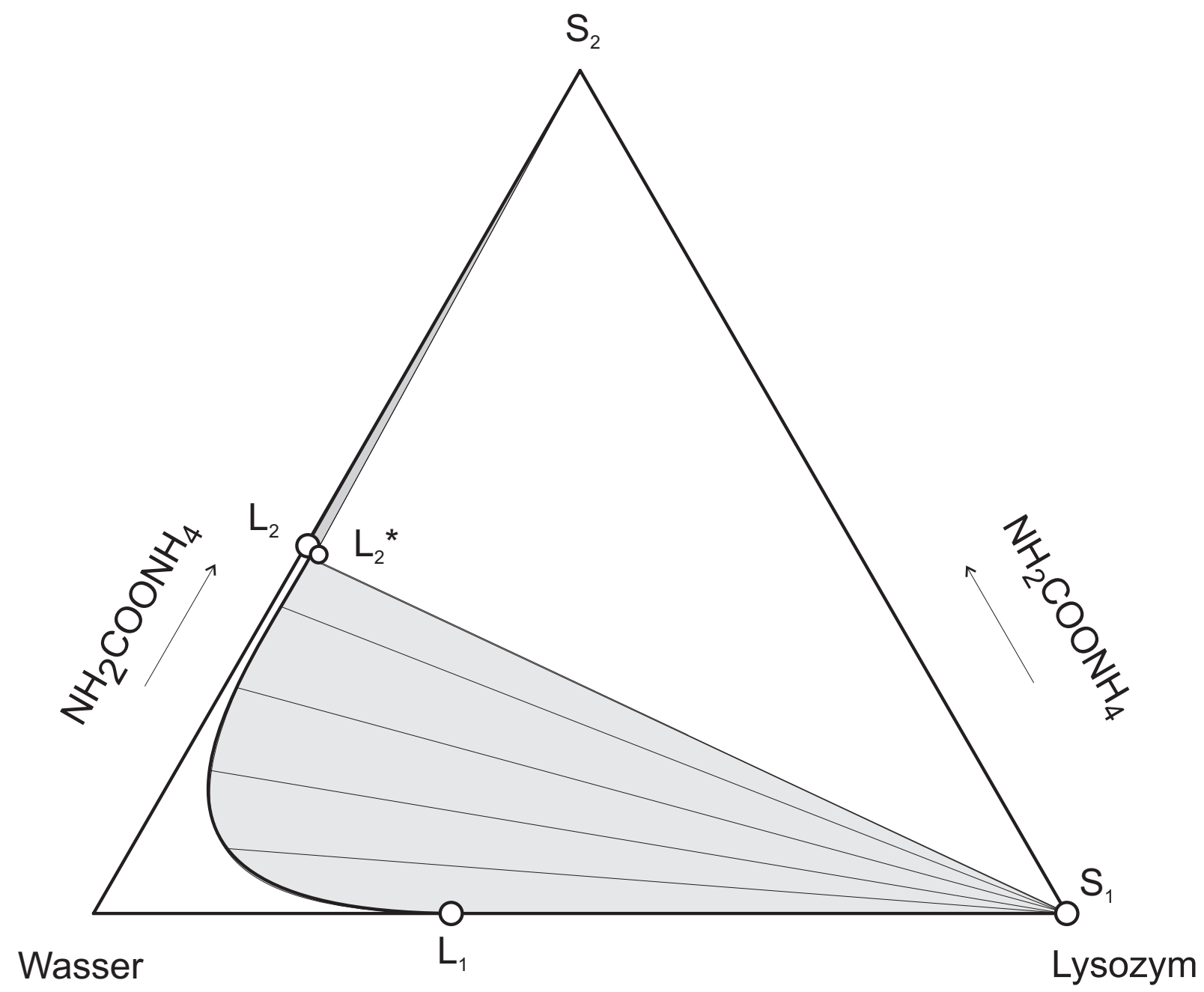

Abb.4.15 Vorschlag für das Phasendiagramm des Systems Lysozym $-\mathrm{NH}_{2} \mathrm{COONH}_{4}-$ Wasser bei $25^{\circ} \mathrm{C}$ und $\mathrm{pH}=9$ 
Die Abbildung 4.16 zeigt die experimentellen Ergebnisse für die Trübungskurve des Systems Lysozym $-\mathrm{NH}_{4} \mathrm{HCO}_{3}-$ Wasser bei $25{ }^{\circ} \mathrm{C}$ und $\mathrm{pH}=8$.

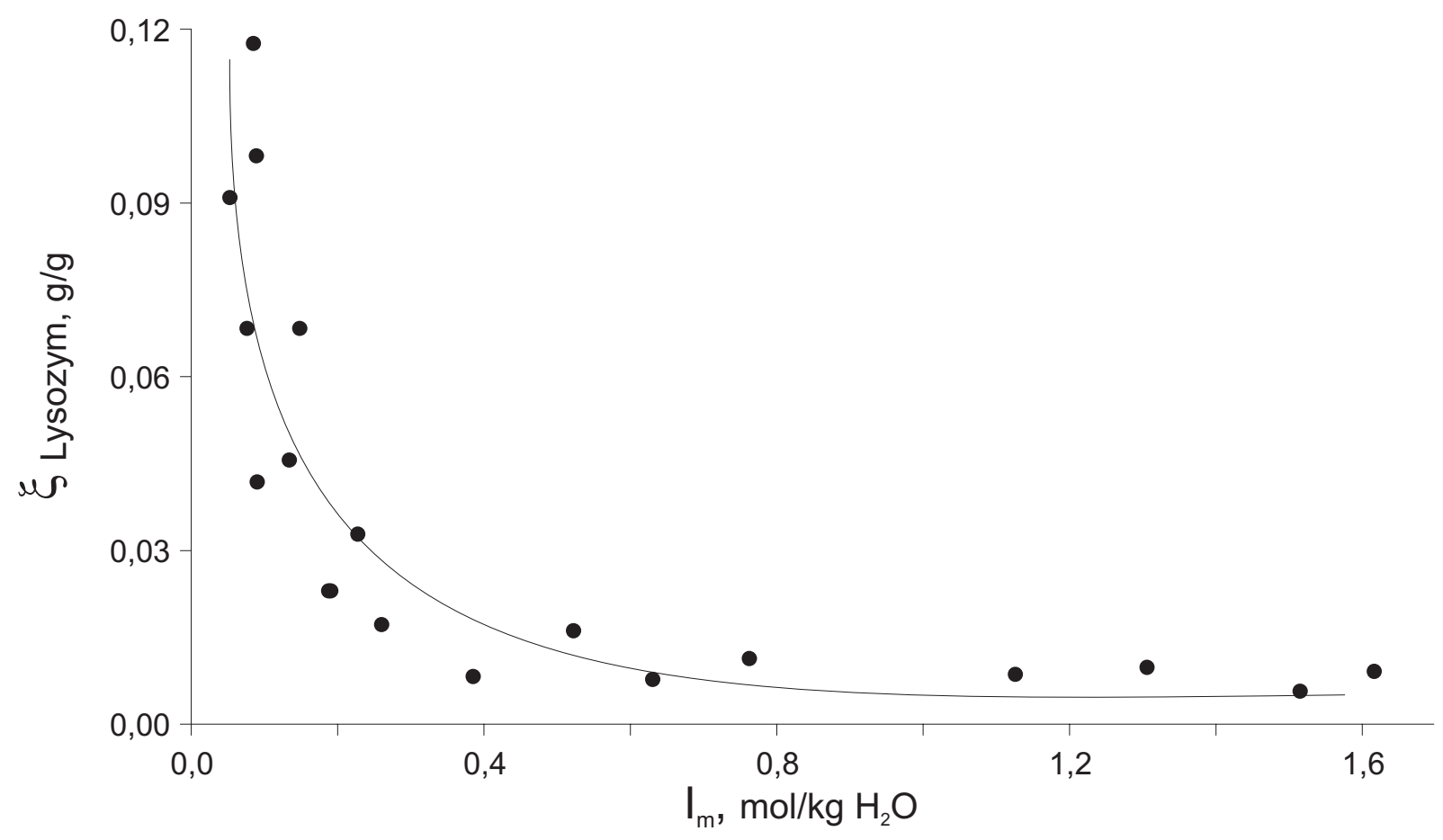

Abb.4.16 Experimentelle Ergebnisse für die Trübungskurve des Systems Lysozym $\mathrm{NH}_{4} \mathrm{HCO}_{3}-$ Wasser bei $25^{\circ} \mathrm{C}$ und $\mathrm{pH}=8$

In dem Diagramm ist der Massenanteil von Lysozym in Abhängigkeit von der Ionenstärke der Lösung aufgetragen. Die Ionenstärke wird stets allein aus der Salzkonzentration berechnet. Schwarze Kreise markieren die experimentell bestimmten Trübungspunkte.

Die Konzentrationen der Stammlösungen von Lysozym lagen zwischen etwa 1 und 12 Massen-\%. Die Messungen wurden auf Salzkonzentration von etwa 12 Massen-\% (wegen der geringeren Salzlöslichkeit) beschränkt. Die experimentell bestimmte Trübungskurve liegt deshalb im Konzentrationsbereich bis zu 12 Massen-\% Lysozym und bis zu 11 Massen-\% Ammoniumbicarbonat. Der Einfluss von Ammoniumbicarbonat auf den Verlauf der Trübungskurve ist mit dem Einfluss von Ammoniumcarbamat vergleichbar. Es werden ungefähr 0,6 Massen-\% Ammoniumbicarbonats benötigt, um eine Trübung bei der höchsten untersuchten Lysozymkonzentration in der Mischung (11,8 Massen-\%) zu verursachen (bei Ammoniumcarbamat betragen die entsprechenden Werte 0,4 Massen- $\%$ und 12 Massen- $\%$ ).

Die experimentell bestimmten Zusammensetzungen der koexistierenden Phasen im System Lysozym $-\mathrm{NH}_{4} \mathrm{HCO}_{3}-$ Wasser bei $25^{\circ} \mathrm{C}$ und $\mathrm{pH}=8$ sind in der Abb. 4.17 dargestellt. Die entsprechenden Zahlenwerte sind im Anhang C tabelliert. Schwarze Kreise markieren die 
Trübungskurve. Die Zusammensetzung der Unterphase (proteinreiche Phase) ist durch leere Quadrate, die Zusammensetzung der Oberphase (proteinarme Phase) durch leere Kreise und die Zusammensetzungen der Feedpunkte durch leere Dreiecke gekennzeichnet.

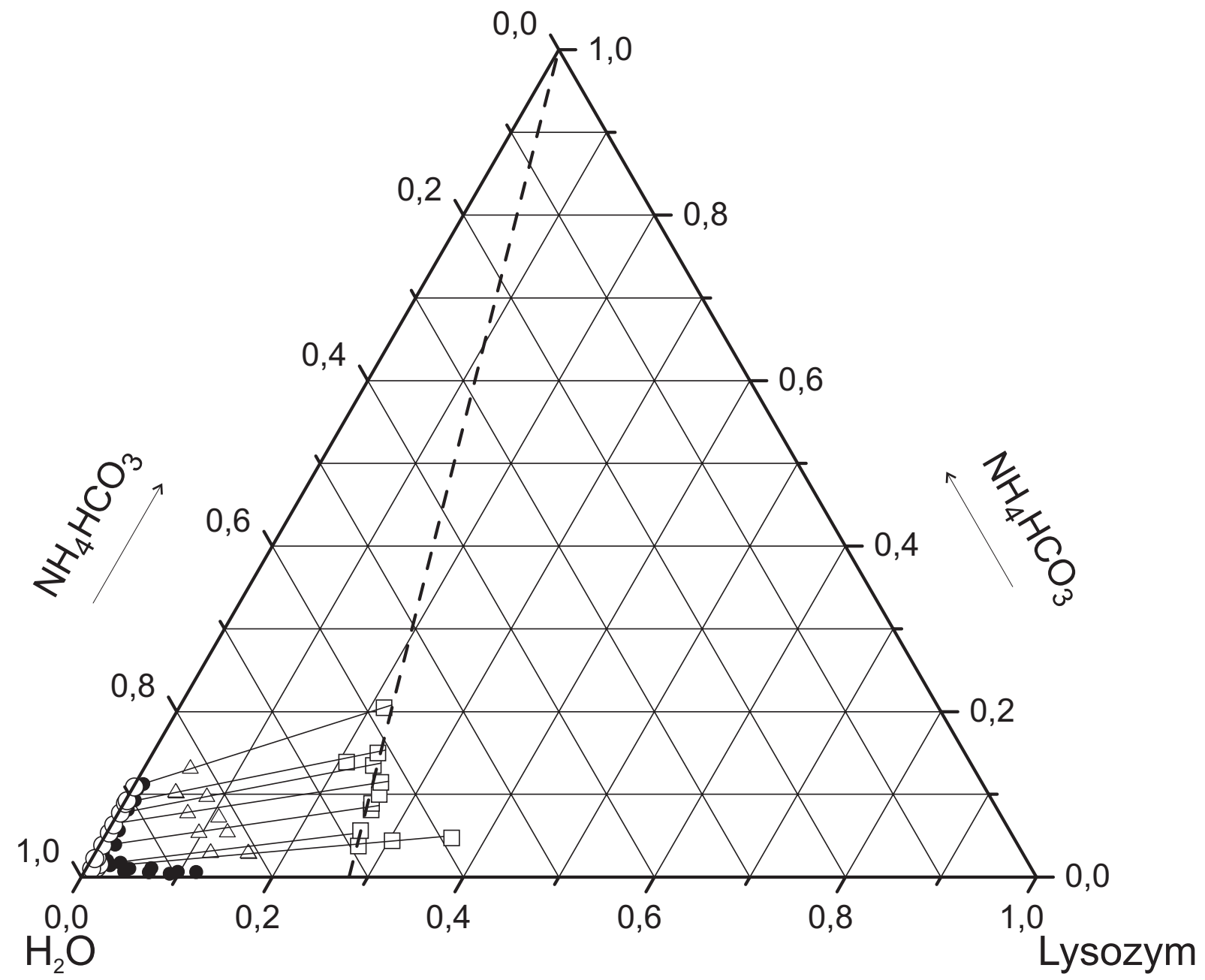

Abb.4.17 Experimentelle Ergebnisse für das Phasengleichgewicht des Systems Lysozym - $\mathrm{NH}_{4} \mathrm{HCO}_{3}-$ Wasser bei $25^{\circ} \mathrm{C}$ und $\mathrm{pH}=8$ : - Trübungskurve;

$\bigcirc$ - Zusammensetzung der proteinarmen Phase; $\square$ - Zusammensetzung der proteinreichen Phase; $\triangle$ - Zusammensetzung der Feedpunkte

Die Messungen wurden auf Salzkonzentrationen bis zu 12 Massen-\% beschränkt. Die Zusammensetzung der Unterphase wurde aus dem Lysozymgehalt der Unterphase (analysiert durch Gefriertrocknung) und aus der Zusammensetzung der Oberphase berechnet.

Der Salzgehalt in der Oberphase ist im Gegensatz zu den früher untersuchten Systemen niedriger als in der Unterphase. Bei einer genaueren Betrachtung stellt sich heraus, dass die Zusammensetzungen der Unterphase sich in Rahmen der Messgenauigkeit auf der Linie 
befinden, die die Löslichkeitsgrenze vom Lysozym in Wasser mit Ammoniumbicarbonat verbindet.

Bei den mikroskopischen Untersuchungen wurde in allen untersuchten Proben die Bildung stäbchenformiger Kristalle nachgewiesen. In der Abbildung 4.18 sind typische Beispiele für die mikroskopischen Aufnahmen von Proben der proteinreichen Phase dargestellt. Auf beiden Bildern sind die Proteinkristalle zu erkennen. Die Größe der Kristalle ist von Probe zu Probe unterschiedlich. Der linke Teil der Abbildung 4.18 zeigt sehr kleine Kristalle, deren Form nur bei größerer Vergrößerung zu erkennen ist. Im rechten Teil der Abbildung sind stäbchenformige Kristalle zu sehen, deren Größe ungefähr $5 \mu \mathrm{m}$ beträgt.

In der Abbildung 4.19 ist die Zusammensetzung der proteinarmen Phase (die Löslichkeitsgrenze) im Vergleich zur experimentell bestimmten Trübungskurve aufgetragen.

Bei etwa 11 Massen-\% Ammoniumbicarbonat beträgt die Löslichkeit von Lysozym etwa 0,2 Massen-\%. Die Löslichkeit steigt mit abnehmender Salzkonzentration und erreicht ungefähr 0,6 Massen-\% bei 1 Massen-\% Salz. Die gemessene Trübungskurve stimmt in Rahmen der Messgenauigkeit mit der Löslichkeitskurve überein. Die Differenz zwischen beiden Kurven bleibt im untersuchten Salzkonzentrationenbereich überall nahezu konstant.

Das Phasenverhalten des Systems Lysozym - $\mathrm{NH}_{4} \mathrm{HCO}_{3}$ - Wasser kann durch die Bildung einer festen metastabilen Phase erklärt werden. Unter Umständen kann diese kristalline Phase in reines Ammoniumbicarbonat und eine gesättigte wässrige Lysozymlösung zerfallen.

a)

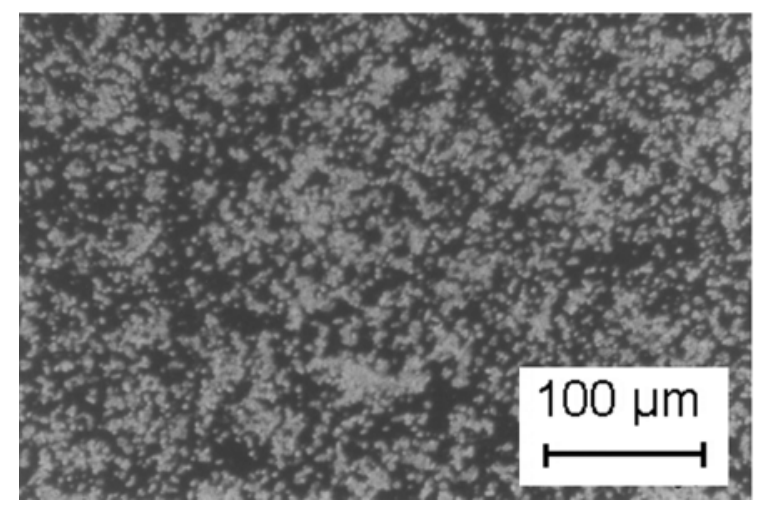

b)

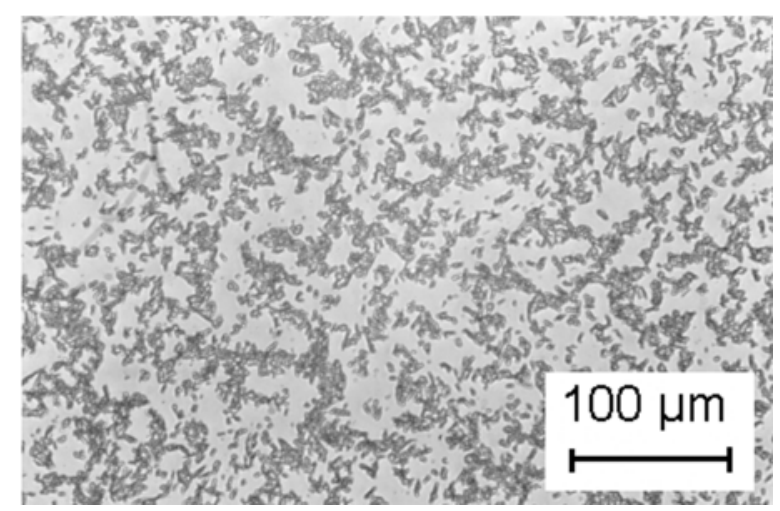

Abb.4.18 System Lysozym $-\mathrm{NH}_{4} \mathrm{HCO}_{3}-$ Wasser bei $25{ }^{\circ} \mathrm{C}$ und $\mathrm{pH}=8$. Mikroskopische Aufnahmen von Probe der Unterphase:

a) Zusammensetzung der Feedlösung ( $\xi_{P}=0,0483 ; \xi_{S}=0,0969 ; \xi_{W}=0,8547$ );

b) Zusammensetzung der Feedlösung ( $\left.\xi_{P}=0,0483 ; \xi_{S}=0,0987 ; \xi_{W}=0,8531\right)$ 


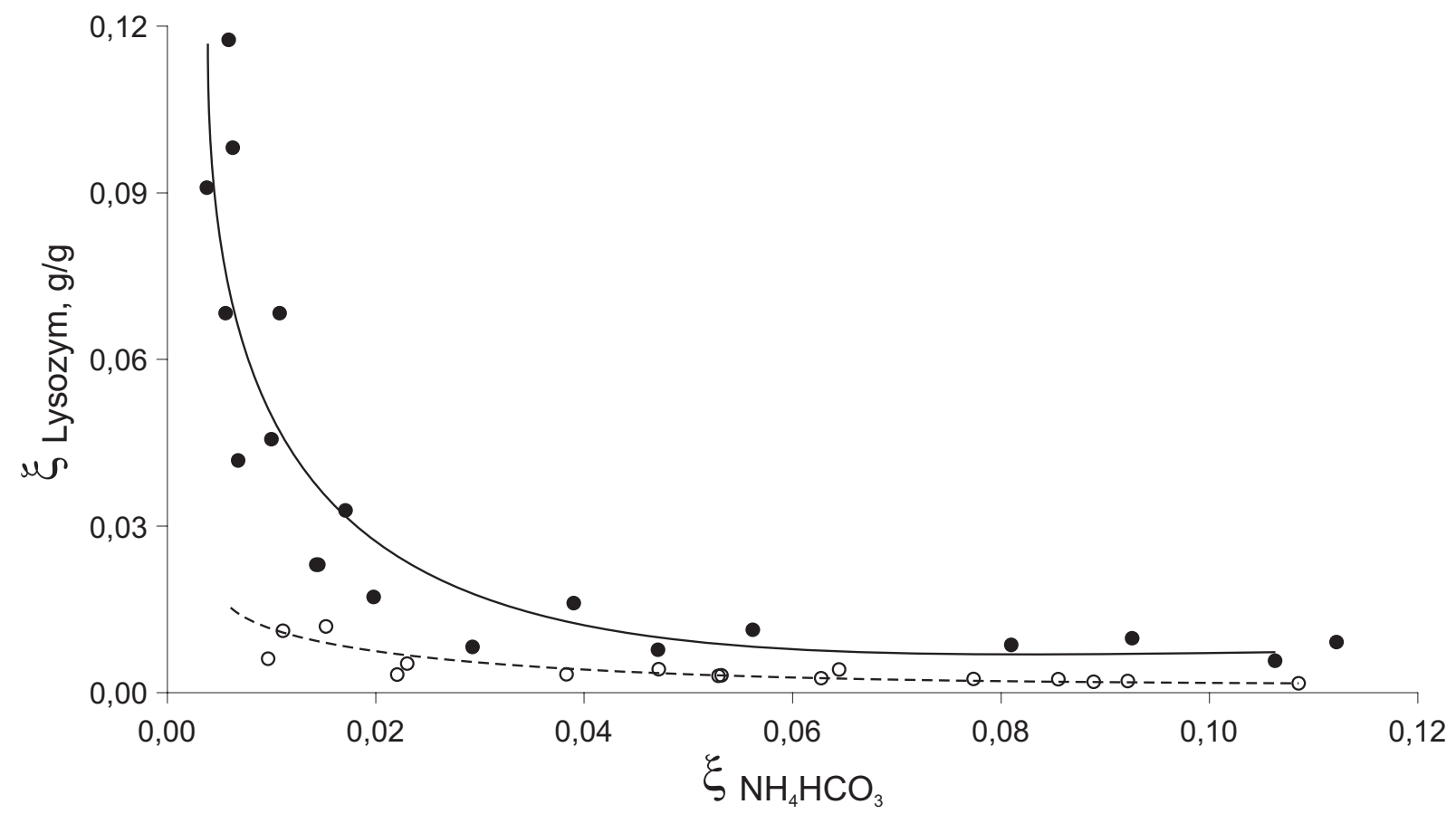

Abb. $4.19 \quad$ Vergleich der Löslichkeits- und Trübungskurve in System Lysozym - $\mathrm{NH}_{4} \mathrm{HCO}_{3}$ - Wasser bei $25{ }^{\circ} \mathrm{C}$ und $\mathrm{pH}=8$ : - Trübungspunkte; $\bigcirc$ - Zusammensetzung der Oberphase aus Phasengleichgewichtsmessungen 


\subsection{Bovin Serum Albumin}

\subsection{1 $\mathrm{BSA}-\left(\mathrm{NH}_{4}\right)_{2} \mathrm{SO}_{4}-\mathrm{H}_{2} \mathrm{O}$}

Die Abbildung 4.20 zeigt die experimentellen Ergebnisse für die Trübungskurve des Systems BSA $-\left(\mathrm{NH}_{4}\right)_{2} \mathrm{SO}_{4}-$ Wasser bei $25^{\circ} \mathrm{C}$ und $\mathrm{pH}=6$.

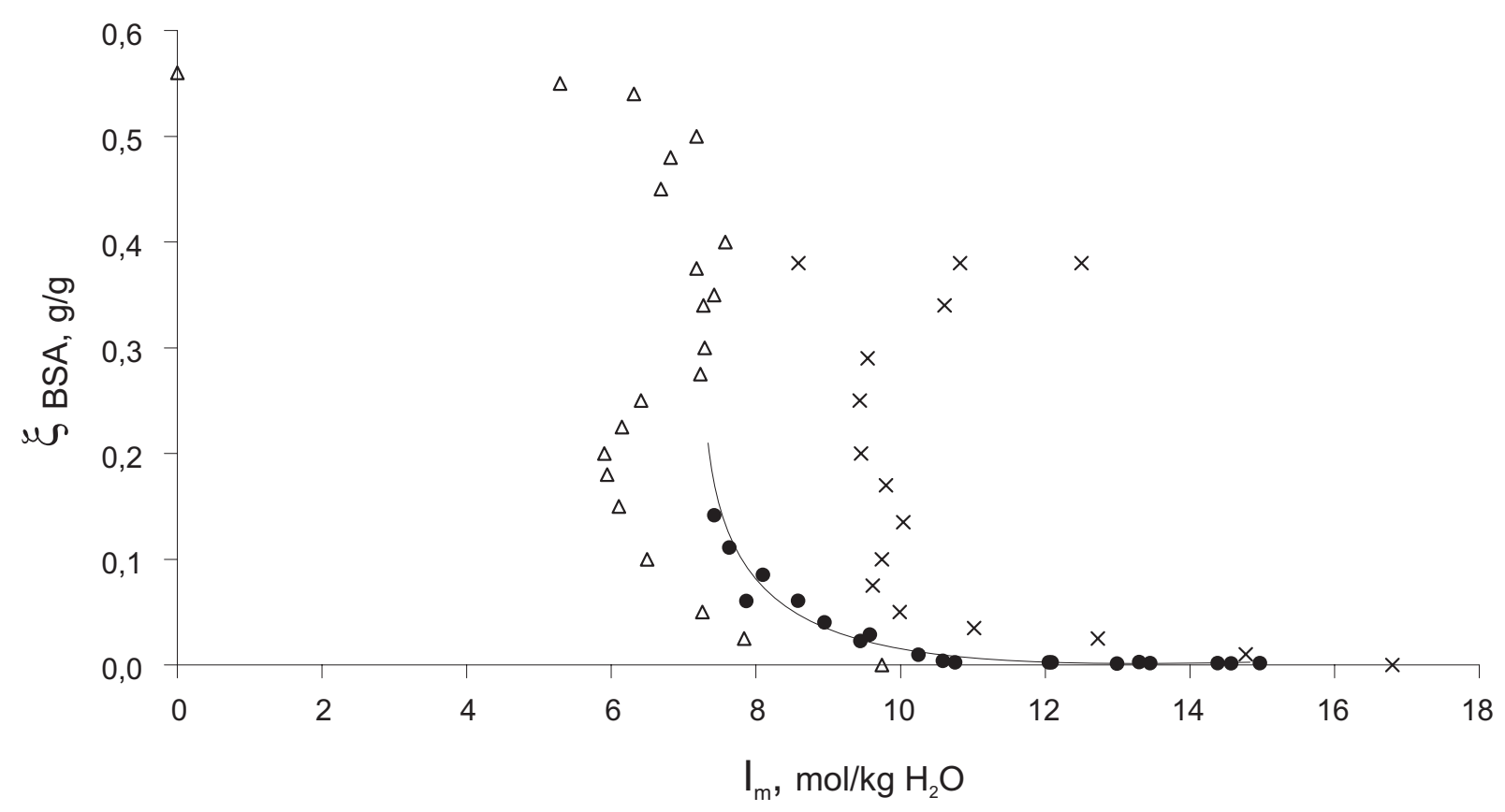

Abb. $4.20 \quad$ Experimentelle Ergebnisse für die Trübungskurve des Systems Bovin Serum Albumin - $\left(\mathrm{NH}_{4}\right)_{2} \mathrm{SO}_{4}$ - Wasser: - Trübungskurvenmessungen bei $25{ }^{\circ} \mathrm{C}$ und pH=6 (diese Arbeit); Phasengrenzen nach Angabe von Elysee-Collen et al. [92] bei $20{ }^{\circ} \mathrm{C}$ und $\mathrm{pH}=7: \triangle$ - Phasengrenze 1, $\times$ - Phasengrenze 2

In dem Diagramm ist der Massenanteil von Bovin Serum Albumin über der Ionenstärke der Lösung aufgetragen. Die Ionenstärke wird stets allein aus der Salzkonzentration berechnet. Die schwarzen Punkte markieren die in der vorliegenden Arbeit experimentell bestimmten Trübungspunkte. Die Größe der Symbole entspricht ungefähr der Messgenauigkeit.

Die Konzentrationen der Stammlösungen von BSA lagen zwischen etwa 1 und 30 Massen-\%. Stammlösungen mit höherem Proteingehalt wurden nicht verwendet, da die erhöhte Viskosität der Lösung die Einstellung der Trübung stark verzögert bzw. deren Beobachtung erschwert. Die Messungen wurden auf Salzkonzentrationen bis etwa 40 Massen-\% (durch die Salzlöslichkeit limitiert) beschränkt. Die experimentell bestimmte Trübungskurve liegt im Konzentrationsbereich bis zu 14 Massen-\% BSA und bis zu 40 Massen-\% Ammoniumsulfat. 
Es werden ungefähr 21 Massen-\% Ammoniumsulfat benötigt, um eine Trübung bei den höchsten untersuchten Konzentration von Bovin Serum Albumin in der Lösung (14 Massen-\%) zu verursachen.

Elysee-Collen et al. [92] haben das Phasenverhalten des Systems BSA - $\left(\mathrm{NH}_{4}\right)_{2} \mathrm{SO}_{4}-\mathrm{H}_{2} \mathrm{O}$ im Temperaturbereich von 20 bis $90{ }^{\circ} \mathrm{C}$ bei $\mathrm{pH}=7$ untersucht. In der Abbildung 4.20 sind diese Literaturangaben gezeigt. Leere Dreiecke markieren die Grenze zwischen einem Einphasengebiet und einem Zweiphasengebiet, in dem eine Flüssigkeit mit einem wasserlöslichen, amorphen Niederschlag vorliegt (Grenze 1). Kreuze kennzeichnen die Grenze, die ein Zweiphasen- von einem Dreiphasengebiet trennt (Grenze 2). In diesem Dreiphasengebiet koexisiert eine Flüssigkeit mit einem wasserlöslichen amorphen Niederschlag und Ammoniumsulfatkristallen. Die in der vorliegenden Arbeit bei den Trübungskurvenmessungen bestimmten Zusammensetzungen liegen zwischen diesen beiden „Grenzen“.

Die in der vorliegenden Arbeit experimentell bestimmten Zusammensetzungen der koexistierenden Phasen im System Bovin Serum Albumin - $\left(\mathrm{NH}_{4}\right)_{2} \mathrm{SO}_{4}-$ Wasser bei $25{ }^{\circ} \mathrm{C}$ und $\mathrm{pH}=6$ sind in der Abb. 4.21 dargestellt. Die entsprechenden Zahlenwerte sind im Anhang C tabelliert.

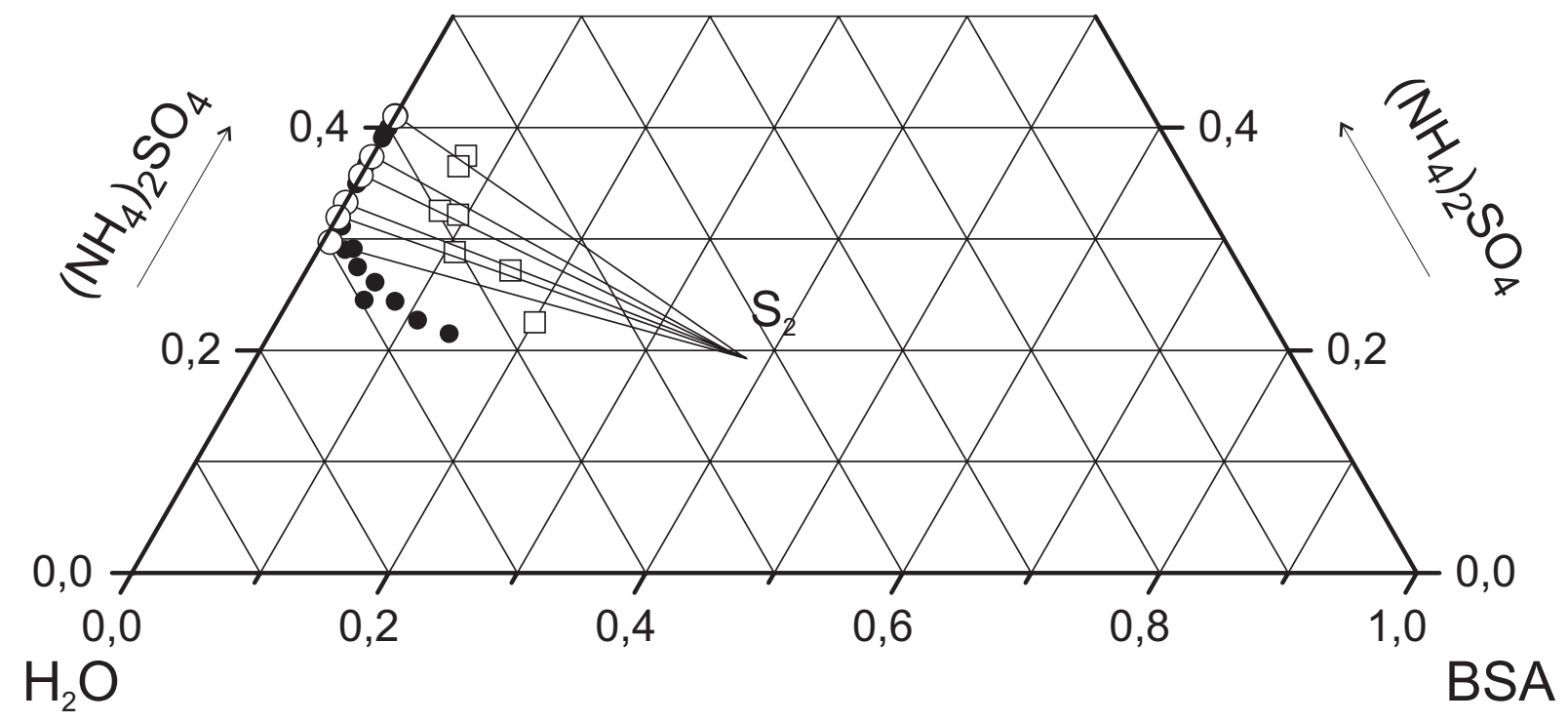

Abb.4.21 Experimentelle Ergebnisse für das Phasengleichgewicht des Systems BSA $\left(\mathrm{NH}_{4}\right)_{2} \mathrm{SO}_{4}-$ Wasser bei $25{ }^{\circ} \mathrm{C}$ und $\mathrm{pH}=6$ : - Trübungskurve;

$\bigcirc$ - Zusammensetzung der proteinarmen Phase; $\square$ - Zusammensetzung der proteinreichen Phase 
Schwarze Kreise markieren Punkte auf der Trübungskurve. Die an BSA angereicherte Phase bildet in diesem System die Unterphase, die proteinarme Phase die Oberphase. Die Zusammensetzung der Unterphase ist durch leere Quadrate und die Zusammensetzung der Oberphase durch leere Kreise gekennzeichnet. Die Feedpunkte werden zum besseren Überblick in der Abb. 4.21 nicht gezeigt. Die Zusammensetzungen der Feedlösungen liegen im Rahmen der Messgenauigkeit auf den Verbindungslinien zwischen der experimentell bestimmten Zusammensetzungen der koexistierenden Phasen.

Die Verlängerungen dieser Verbindungslinien treffen sich in einem Schnittpunkt $\left(\mathrm{S}_{2}\right)$, der einen Komplex kennzeichnet. Die Zusammensetzung des Komplexes $\mathrm{S}_{2}$ beträgt etwa 37 Massen-\% BSA und etwa 20 Massen-\% Ammoniumsulfat.

Mikroskopische Aufnahmen von Proben der proteinreichen Phase sind in der Abbildung 4.22 dargestellt. Es wurden keine Kristalle, sondern proteinreiche, amorphe Aggregate beobachtet.

a)

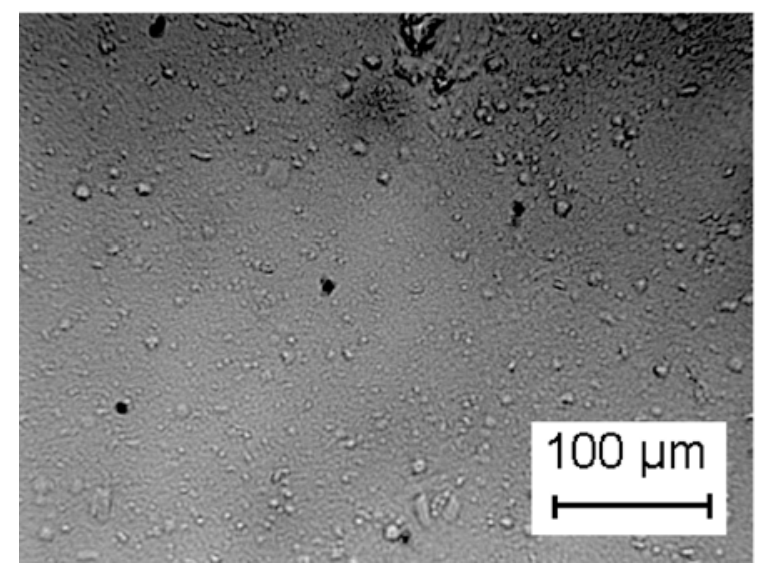

b)

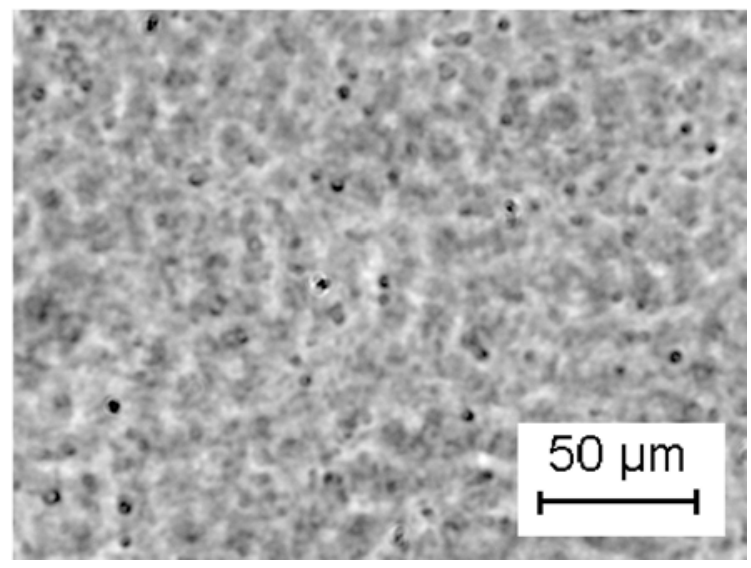

Abb.4.22 System BSA - $\left(\mathrm{NH}_{4}\right)_{2} \mathrm{SO}_{4}-$ Wasser bei $25{ }^{\circ} \mathrm{C}$ und $\mathrm{pH}=6$. Mikroskopische Aufnahmen von Proben der Unterphase:

a) Zusammensetzung der Feedlösung ( $\left.\xi_{P}=0,0302 ; \xi_{S}=0,3598 ; \xi_{W}=0,6100\right)$;

b) Zusammensetzung der Feedlösung ( $\xi_{P}=0,0635 ; \xi_{S}=0,3142 ; \xi_{W}=0,6223$ ) 
In der Abbildung 4.23 sind die experimentellen Ergebnisse für die Zusammensetzung der proteinarmen Phase (die Löslichkeitsgrenze) mit einigen Trübungspunkten verglichen.

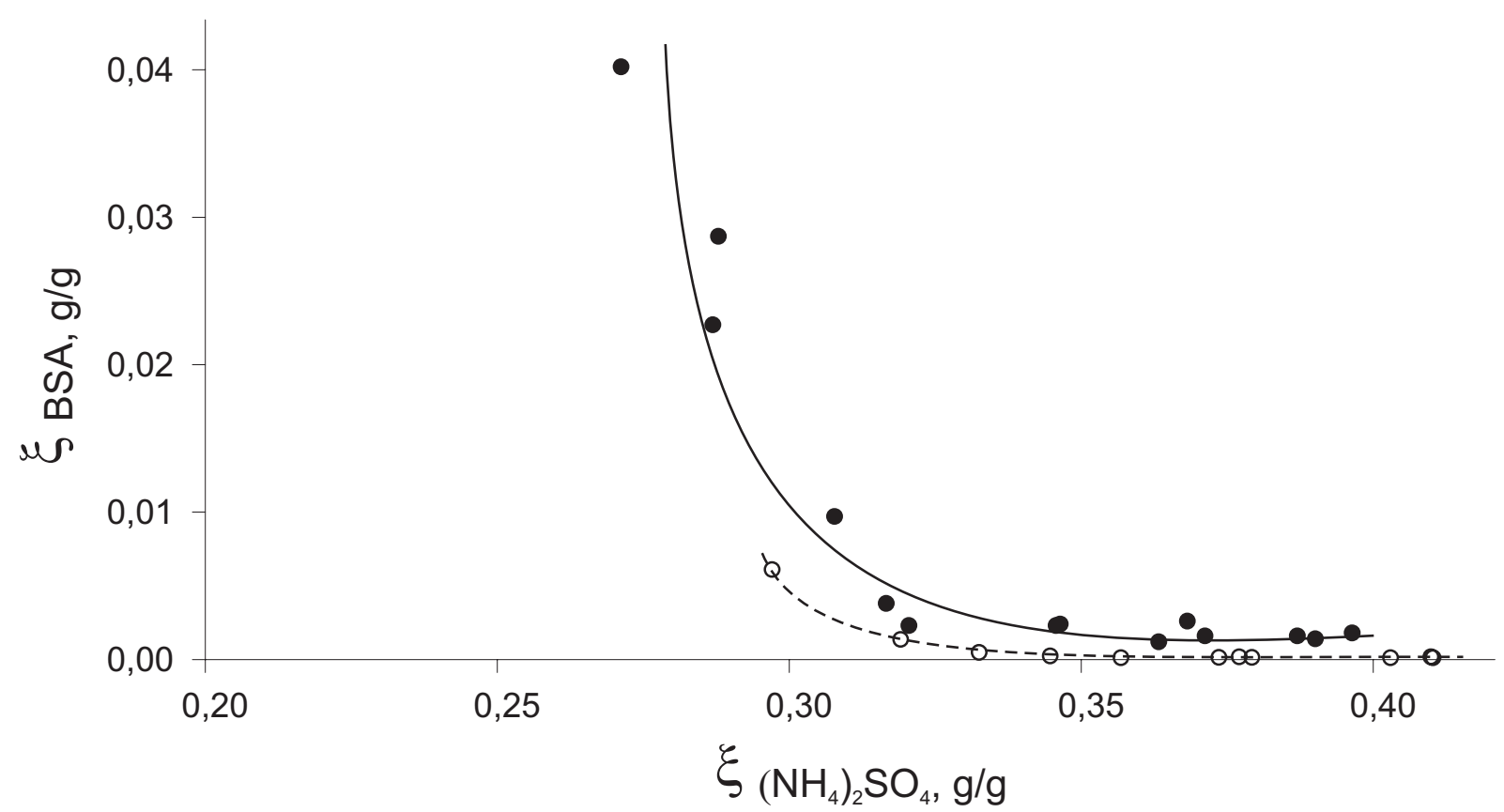

Abb. $4.23 \quad$ Vergleich von Löslichkeits- und Trübungskurve in System BSA - $\left(\mathrm{NH}_{4}\right)_{2} \mathrm{SO}_{4}-$ Wasser bei $25^{\circ} \mathrm{C}$ und $\mathrm{pH}=6$ : $\bigcirc$ - Trübungspunkte; $\bigcirc$ - Zusammensetzung der Oberphase aus Phasengleichgewichtsmessungen

Die Löslichkeit von BSA bei der höchsten untersuchten Salzkonzentration (etwa 40 Massen-\%) beträgt 0,01 Massen-\%. Die Löslichkeit nimmt mit steigender Salzkonzentration ab (d. h. es wird ein „Aussalzen“ beobachtet). Die experimentell ermittelte Trübungskurve liegt auch bei diesem System innerhalb der Löslichkeitskurve. Im Vergleich zum System Lysozym - $\left(\mathrm{NH}_{4}\right)_{2} \mathrm{SO}_{4}$ - Wasser sind die beiden Kurven zu höheren Salzkonzentrationen hinverlagert.

In der Abb. 4.24 sind die Ergebnisse für die Löslichkeit zusammen mit der entsprechenden Kurve nach Gleichung (1) (Cohn Gleichung) sowie die Literaturergebnisse dargestellt. Dabei ist der Logarithmus der Proteinkonzentration (in $\mathrm{mg} / \mathrm{ml}$ ) gegen die Ionenstärke der Lösung (Molalitätskala) aufgetragen. Die experimentellen Ergebnisse der Löslichkeitsmessungen in System BSA - $\left(\mathrm{NH}_{4}\right)_{2} \mathrm{SO}_{4}-\mathrm{H}_{2} \mathrm{O}$ bei $25{ }^{\circ} \mathrm{C}$ und $\mathrm{pH}=7$ von Qasim et al. [14] sind durch leere Dreiecke gekennzeichnet, die eigenen Ergebnisse durch leere Kreise. Beide Linien weisen ungefähr die gleiche Steigung auf $\left(K_{s}\right.$ (aus Gl. (1)) = 0,73 für die Literaturdaten bzw. 0,64 für die Daten der vorliegenden Arbeit). Sie sind jedoch parallel verschoben. Der Parameter $\beta$ (vgl. Gl. (1)) beträgt 6,0 und 6,8. Bei hohen Ionenstärken (über 13 mol/1000 g Wasser) lassen 
sich die Messwerte der vorliegenden Arbeit nicht mit der Cohn Gleichung beschreiben. Dieser Befund deutet auf das Ausfällen einer anderen Phase (vermutlich Ammoniumsulfatkristallen).

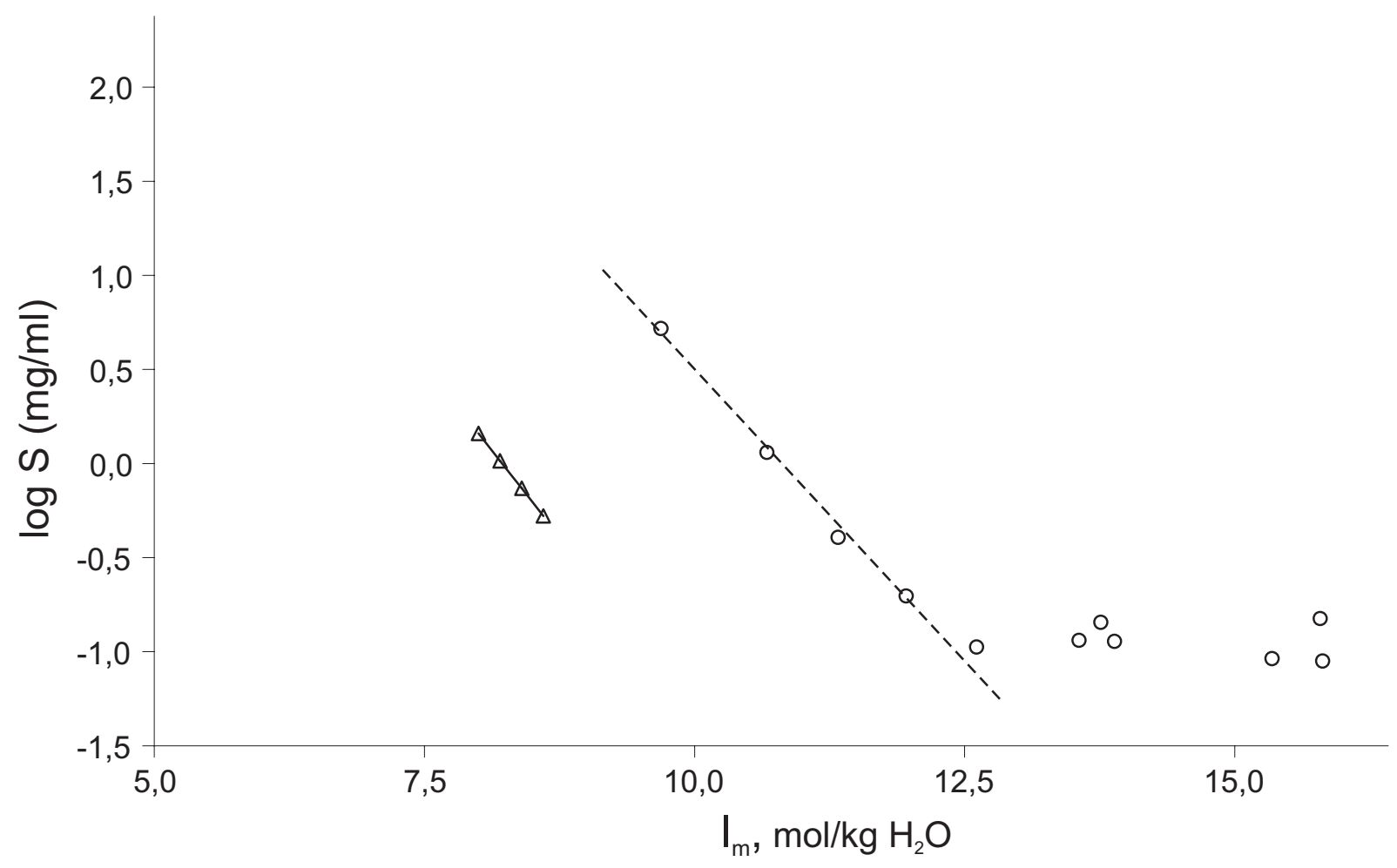

Abb. $4.24 \quad$ Vergleich von Löslichkeitskurven in System BSA - $\left(\mathrm{NH}_{4}\right)_{2} \mathrm{SO}_{4}-$ Wasser bei $25{ }^{\circ} \mathrm{C}$ und $\mathrm{pH}=6: \triangle$ - Löslichkeit von Bovine Serum Albumin [14];

$\bigcirc$ - Zusammensetzung der Oberphase (diese Arbeit)

In der Abbildung 4.25 ist ein Vorschlag für das Phasendiagramm des Systems BSA $\left(\mathrm{NH}_{4}\right)_{2} \mathrm{SO}_{4}$ - Wasser bei $25{ }^{\circ} \mathrm{C}$ und $\mathrm{pH}=6$ gezeigt. Die Punkte $\mathrm{L}_{1}$ und $\mathrm{L}_{2}$ entsprechen den Löslichkeitsgrenzen von Bovin Serum Albumin bzw. Ammoniumsulfat in reinem Wasser. Man erkennt ein einphasiges Gebiet, das durch die Löslichkeitskurve $\mathrm{L}_{2}-\mathrm{L}_{2}{ }^{*}-\mathrm{L}_{3}-\mathrm{L}_{1}$ vom Mehrphasengebiet getrennt ist, drei Fest-Flüssig-Zweiphasengebiete, in denen einer der Feststoffe $S_{1}, S_{2}$ bzw. $S_{3}$ mit einer Flüssigkeit im Gleichgewicht steht und mehrere Dreiphasengebiete. Bei Salzkonzentrationen über 20 Massen-\% bildet sich ein amorpher Komplex aus BSA, Ammoniumsulfat und Wasser $\left(\mathrm{S}_{2}\right)$. Der Feststoff $\mathrm{S}_{1}$ entspricht reinem, kristallinem BSA. 


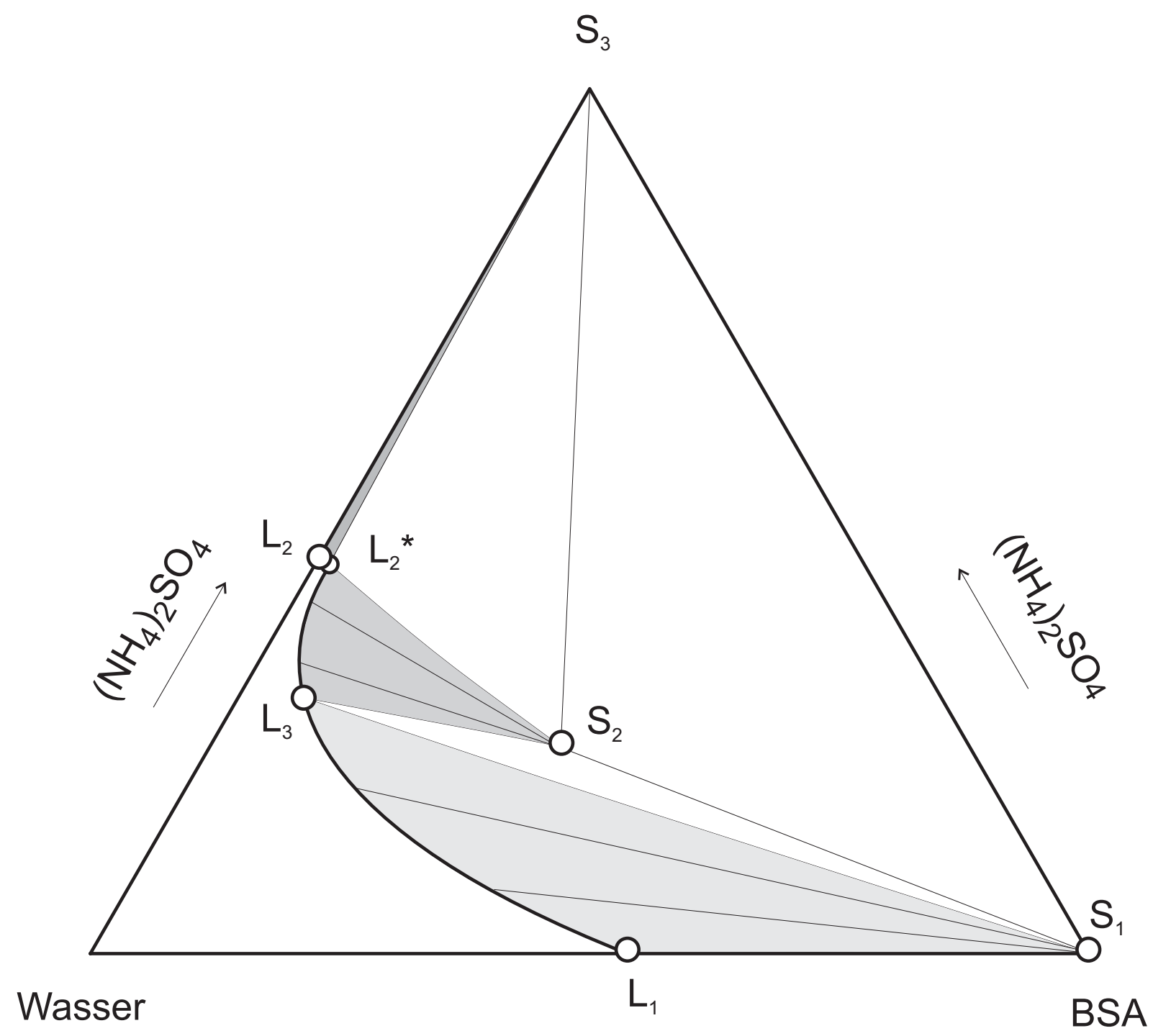

Abb.4.25 Vorschlag für das Phasendiagramm des Systems $\mathrm{BSA}-\left(\mathrm{NH}_{4}\right)_{2} \mathrm{SO}_{4}-$ Wasser bei $25^{\circ} \mathrm{C}$ und $\mathrm{pH}=6$ 


\subsection{2 $\mathrm{BSA}-\mathrm{Na}_{2} \mathrm{SO}_{4}-\mathrm{H}_{2} \mathrm{O}$}

Die Abbildung 4.26 zeigt die Ergebnisse der experimentellen Untersuchungen zur Bestimmung der Trübungskurve des Systems Bovin Serum Albumin - $\mathrm{Na}_{2} \mathrm{SO}_{4}-$ Wasser bei $25^{\circ} \mathrm{C}$ und $\mathrm{pH}=7$.

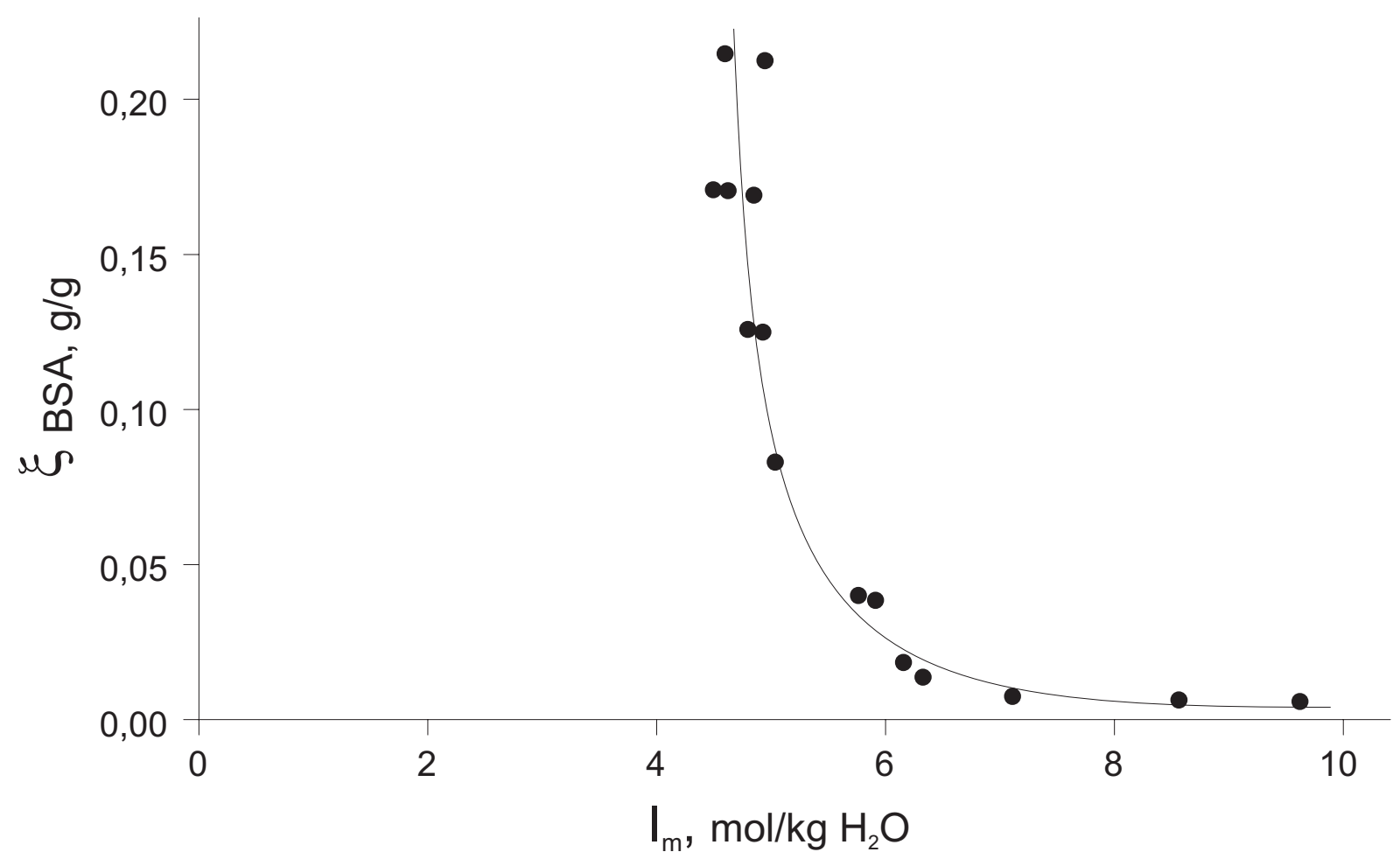

Abb.4.26 Experimentelle Ergebnisse für die Trübungskurve des Systems $\mathrm{BSA}-\mathrm{Na}_{2} \mathrm{SO}_{4}-$ Wasser bei $25^{\circ} \mathrm{C}$ und $\mathrm{pH}=7$

Dabei ist der Massenanteil von BSA über der Ionenstärke aufgetragen. Die Ionenstärke wird stets allein aus der Salzkonzentration berechnet. Die schwarzen Kreise markieren die experimentell bestimmten Trübungspunkte. Die Größe der Symbole entspricht ungefähr der Messgenauigkeit. Die Konzentration der Stammlösungen von Bovin Serum Albumin lagen zwischen 4 und 25 Massen-\%. Durch Zugabe einer gesättigten wässrigen Stammlösung von Natriumsulfat zur wässrigen Stammlösung von Bovine Serum Albumin konnte keine Trübung verursacht werden. Deshalb wurde in weiteren Experimenten die wässrige Salzlösung durch reines wasserfreies Natriumsulfat ersetzt. Bei der Bestimmung der Trübungspunkte im proteinarmen Konzentrationsbereich wurden übersättigte Natriumsulfatlösungen mit Konzentrationen zwischen 20 und 30 Massen-\% verwendet. Diese wurden durch Abkühlen der bei höheren Temperaturen hergestellten Natriumsulfatlösungen vorbereitet. Es wurde 
keine Trübung bei niedrigeren Salzkonzentrationen beobachtet. Die experimentell bestimmte Trübungskurve liegt im Konzentrationsbereich bis zu 21 Massen-\% BSA und bis zu 30 Massen-\% Natriumsulfat. Dieser Bereich befindet sich teilweise oberhalb der Löslichkeitsgrenze des Natriumsulfatdekahydrates. Es werden ungefähr 14 Massen-\% Natriumsulfat benötigt, um eine Trübung bei der höchsten untersuchten Konzentration von Bovin Serum Albumin (22 Massen-\%) zu verursachen. Die für die Trübung einer wässrigen Lösung mit 1 Massen-\% BSA benötigte Natriumsulfatkonzentration beträgt ungefähr 22 Massen-\%.

Die experimentell bestimmte Zusammensetzung der koexistierenden Phasen im System BSA $-\mathrm{Na}_{2} \mathrm{SO}_{4}-$ Wasser bei $25{ }^{\circ} \mathrm{C}$ und $\mathrm{pH}=7$ ist in der $\mathrm{Abb} .4 .27$ aufgetragen. Die entsprechenden Zahlenwerte sind im Anhang C tabelliert.

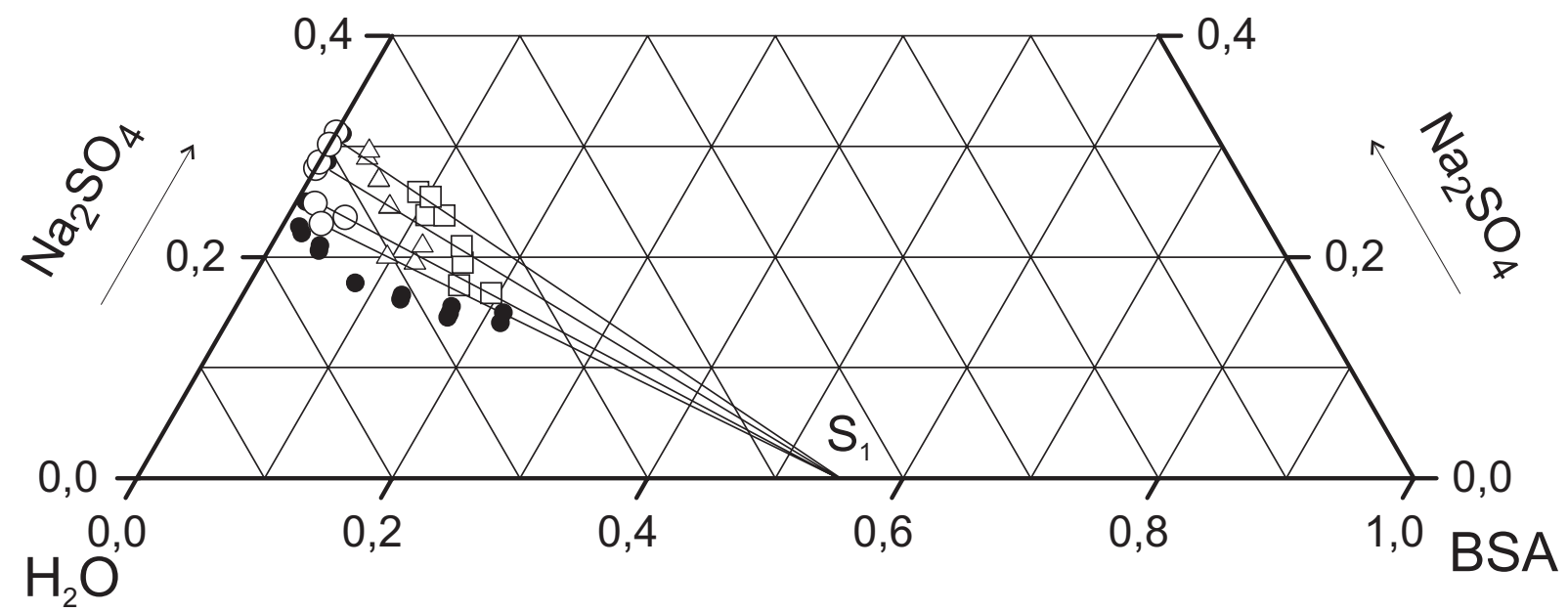

Abb. 4.27 Experimentelle Ergebnisse für das Phasengleichgewicht des Systems BSA $\mathrm{Na}_{2} \mathrm{SO}_{4}$ - Wasser bei $25{ }^{\circ} \mathrm{C}$ und $\mathrm{pH}=7$ : Trübungskurve;

$\bigcirc$ - Zusammensetzung der proteinarmen Phase; $\square$ - Zusammensetzung der proteinreichen Phase

Die an Bovin Serum Albumin angereicherte Phase bildet in diesem System die Oberphase, die proteinarme Phase die Unterphase, d. h. salzreiche wässrige Phasen haben eine höhere Dichte als proteinreiche wässrige Phasen. Da der Salzgehalt in der proteinarmen Phase hoch ist, ist diese Phase schwerer als der proteinreiche Niederschlag. Die Zusammensetzungen der Oberphasen sind in der Abb. 4.27 durch leere Quadrate und die Zusammensetzungen der Unterphasen durch leere Kreise gekennzeichnet. Die Zusammensetzungen der Feedlösungen (leere Dreiecke) liegen in Rahmen der Messgenauigkeit auf den Linien, welche die Zusammensetzungen der koexistierenden Phasen verbindet (d. h. die Massenbilanz ist erfüllt). 
Die Verlängerungen der Verbindungslinien von koexistierenden Ober- und Unterphasen treffen sich lediglich in einem Punkt $\left(\mathrm{S}_{1}\right)$. Der Punkt $\mathrm{S}_{1}$ stimmt im Rahmen der Messgenauigkeit mit der Literaturangabe für Löslichkeit von Bovin Serum Albumin in reinem Wasser [92] überein.

Die mikroskopischen Untersuchungen haben gezeigt, dass die proteinreiche Phase keine kristalline Struktur aufweist. Es handelt sich vermutlich um einen amorphen Niederschlag, der noch einen Teil der proteinarmen Phase enthält. Die Abbildung 4.28 zeigt eine Aufnahme einer der untersuchten Proben.

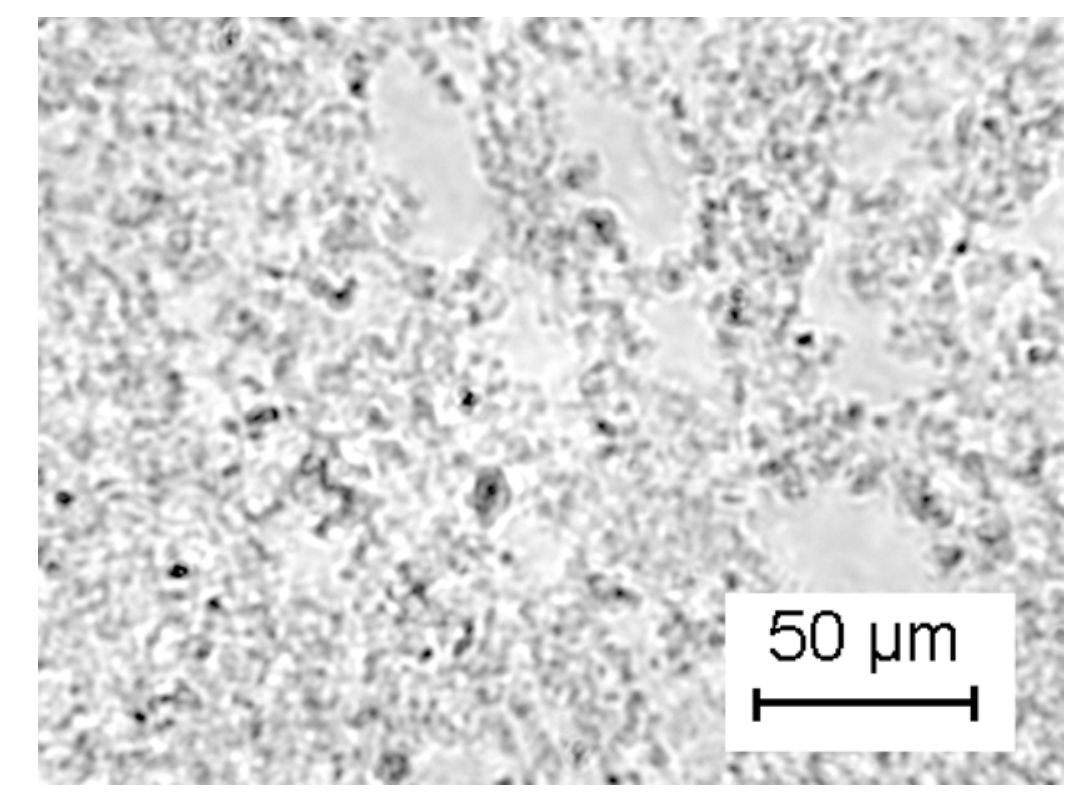

Abb.4.28 System BSA - $\mathrm{Na}_{2} \mathrm{SO}_{4}-$ Wasser bei $25{ }^{\circ} \mathrm{C}$ und $\mathrm{pH}=7$. Mikroskopische Aufnahmen von einer Probe der proteinreichen Phase, Zusammensetzung der Feedlösung ( $\left.\xi_{P}=0,0744 ; \xi_{S}=0,2544 ; \xi_{W}=0,6711\right)$ 
In der Abbildung 4.29 sind die in der vorliegenden Arbeit bestimmten Zusammensetzungen der proteinarmen Phase (die mit einem Präzipitat koexistierte, d. h. Löslichkeitsgrenze) mit den Ergebnissen für die Trübungskurve verglichen.

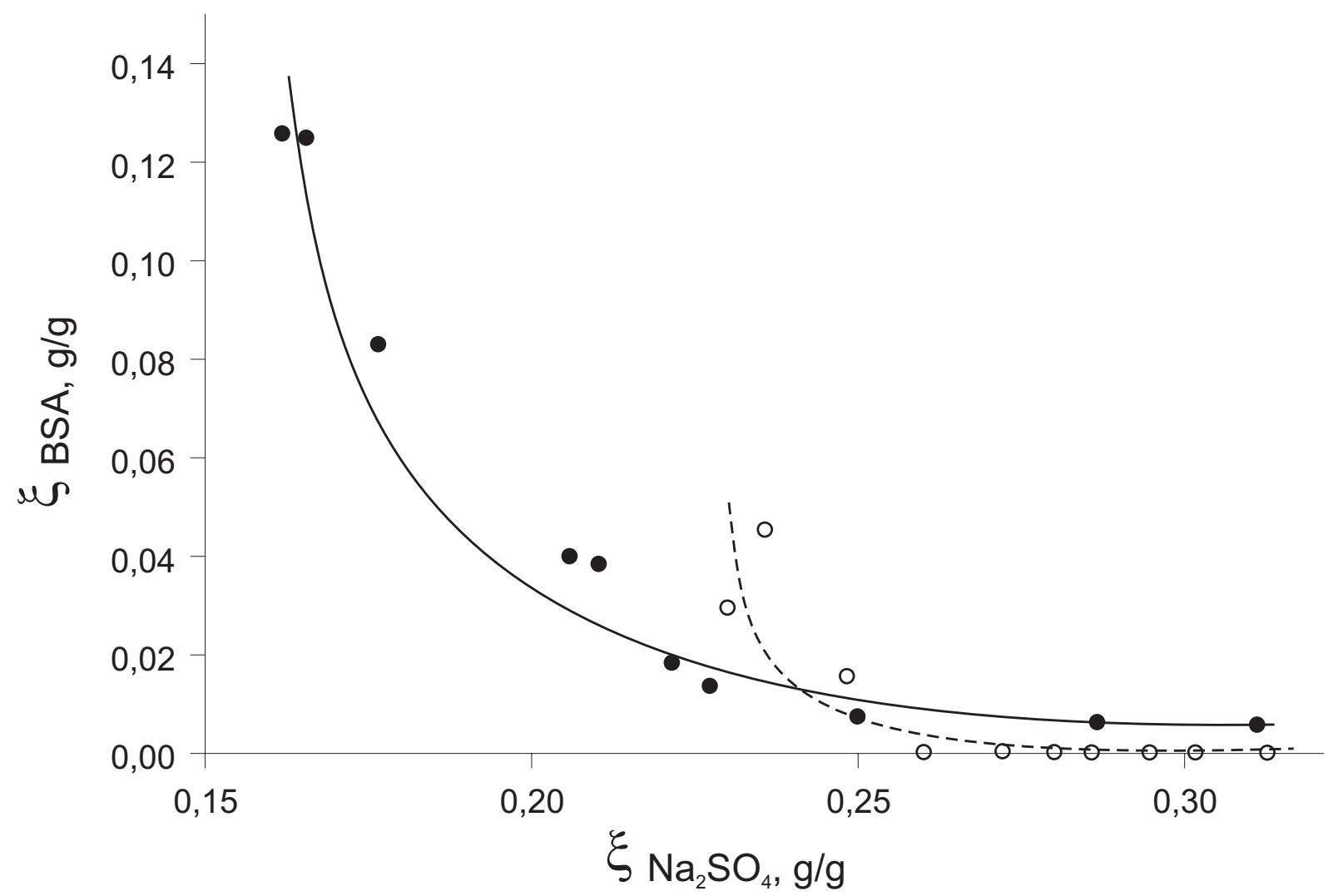

Abb. 4.29 Vergleich von Löslichkeits- und Trübungskurve in System $\mathrm{BSA}-\mathrm{Na}_{2} \mathrm{SO}_{4}-$ Wasser bei $25^{\circ} \mathrm{C}$ und $\mathrm{pH}=7:-$ - Trübungspunkte; $\bigcirc$ - Zusammensetzung der Oberphase aus Phasengleichgewichtsmessungen

Hier ist der Massenanteil von BSA über dem Massenanteil des Salzes aufgetragen. Im Konzentrationsbereich über 25 Massen-\% Natriumsulfat ist die Proteinlöslichkeit sehr gering (ca. 0,02 Massen-\% BSA) und im Rahmen der Messgenauigkeit von der Salzkonzentration unabhängig. Bei Salzkonzentrationen unter 25 Massen-\% steigt die Proteinkonzentration mit abnehmender Salzkonzentration stark an. Die Konzentration von BSA beträgt bei 23 Massen-\% Natriumsulfat ungefähr 4,5 Massen-\%. Die Löslichkeitskurve liegt teilweise bei höheren Proteinkonzentrationen als die gemessene Trübungskurve. Dies deutet darauf hin, dass die Trübung nicht durch das Ausfällen von Bovine Serum Albumin verursacht wurde, sondern möglicherweise durch das Ausfällen von makromolekularen Verunreinigungen (vgl. Abschnitt 3.4.2). 
Bei den experimentellen Untersuchungen wurde neben einem Zweiphasengleichgewicht auch ein Dreiphasengleichgewicht beobachtet. Eine von zwei Feedlösungen mit gleicher Zusammensetzung wurde bei längerem Rühren dreiphasig. Die obere flüssige proteinarme Phase koexistierte mit Salzkristallen und einer dritten sehr viskosen Phase. Die proteinarme Phase konnte beim Zentrifugieren abgetrennt werden. Die Analyse ergab folgende Zusammensetzung: 9,8 Massen-\% BSA, 14,9 Massen-\% Natriumsulfat. Die hochviskose „dritte“ Phase konnte nicht von den Salzkristallen getrennt werden. In der Mischung aus beiden Phasen ergab die Analyse 9,3 Massen-\% BSA und 29,4 Massen-\% Salz.

Ausgehend von diesen Beobachtungen kann man sich für das System BSA $-\mathrm{Na}_{2} \mathrm{SO}_{4}-$ Wasser das in der Abb. 4.30 gezeigte Phasenverhalten vorstellen. Im Fall eines stabilen Phasengleichgewichtes erhält man das im linken Teil der Abbildung 4.30 dargestellte Phasenverhalten. Die Punkte $\mathrm{L}_{1}$ bzw. $\mathrm{L}_{2}$ markieren die Löslichkeiten von BSA bzw. Natriumsulfat in reinem Wasser bei $25^{\circ} \mathrm{C}$. Man erkennt ein einphasiges Gebiet, zwei FestFlüssig- Zweiphasengebiete - in denen ein ausgefälltes Protein bzw. Salzkristalle mit einer flüssigen Phase im Gleichgewicht stehen - und zwei Dreiphasengebiete. Im Dreiphasengebiet $\mathrm{S}_{2}-\mathrm{L}_{2}{ }^{*}-\mathrm{S}_{1}$ liegen die Feststoffe $\mathrm{S}_{2}\left(\mathrm{Na}_{2} \mathrm{SO}_{4} \bullet 10 \mathrm{H}_{2} \mathrm{O}\right)$ und $\mathrm{S}_{1}$ (Bovin Serum Albumin) mit einer an Natriumsulfat und BSA gesättigten Flüssigkeit im Gleichgewicht vor. Die Löslichkeitskurve von BSA wird durch die Linie $\mathrm{L}_{2}-\mathrm{L}_{2} *-\mathrm{L}_{1}$ beschrieben.
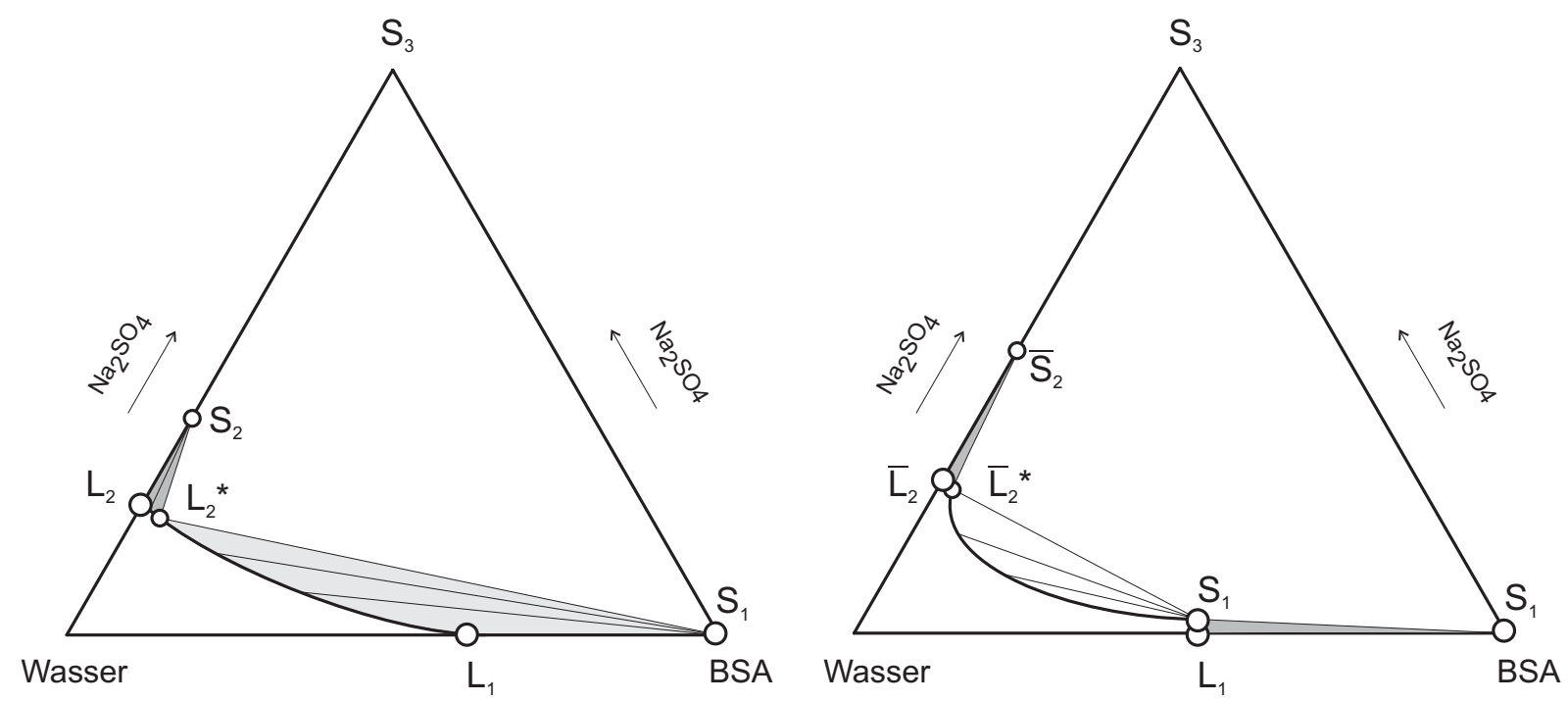

Abb.4.30 Vorschlag für das Phasendiagramm des Systems $\mathrm{BSA}-\mathrm{Na}_{2} \mathrm{SO}_{4}-$ Wasser bei $25^{\circ} \mathrm{C}$ und $\mathrm{pH}=7$ 
Im rechten Teil der Abbildung 4.30 ist ein metastabiles Phasengleichgewicht dargestellt, das dem beobachteten Phasenverhalten entspricht. Die Punkte $L_{1}$ und $\overline{L_{2}}$ markieren die Löslichkeit von BSA und die metastabile Löslichkeit von Natriumsulfat (ca. 35 Massen-\%) in reinem Wasser bei $25^{\circ} \mathrm{C}$ [94]. Man erkennt ein einphasiges Gebiet, zwei Fest-FlüssigZweiphasengebiete - in denen ein ausgefälltes Protein bzw. Salzkristalle mit einer flüssigen Phase im Gleichgewicht stehen - und zwei Dreiphasengebiete. Im Dreiphasengebiet $\overline{S_{2}}-$ $\overline{L_{2}} *-S_{1}$ liegen die Feststoffe $\overline{S_{2}}\left(\mathrm{Na}_{2} \mathrm{SO}_{4} \cdot 7 \mathrm{H}_{2} \mathrm{O}\right)$ und $S_{1}$ (Bovin Serum Albumin) mit einer an Natriumsulfat und BSA gesättigten Flüssigkeit im Gleichgewicht vor. 


\subsection{Ovalbumin}

\subsubsection{Ovalbumin - $\left(\mathrm{NH}_{4}\right)_{2} \mathrm{SO}_{4}-\mathrm{H}_{2} \mathrm{O}$}

Die Abbildung 4.32 zeigt die experimentellen Ergebnisse für die Trübungskurve des Systems Ovalbumin $-\left(\mathrm{NH}_{4}\right)_{2} \mathrm{SO}_{4}-$ Wasser bei $25^{\circ} \mathrm{C}$ und $\mathrm{pH}=6$.

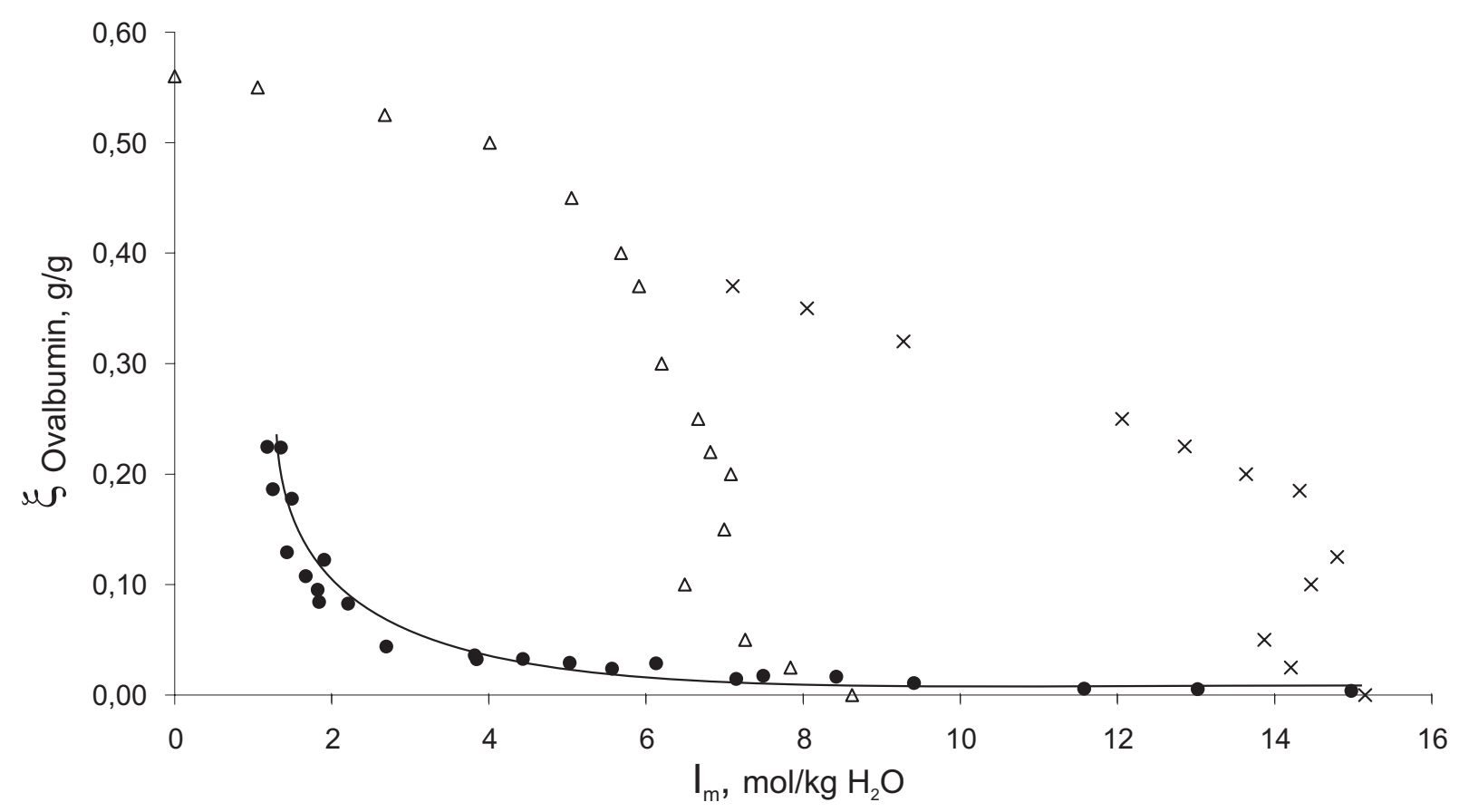

Abb.4.32 Experimentelle Ergebnisse für die Trübungskurve des Systems Ovalbumin $\left(\mathrm{NH}_{4}\right)_{2} \mathrm{SO}_{4}$ - Wasser: • - Trübungskurvenmessungen bei $25{ }^{\circ} \mathrm{C}$ und $\mathrm{pH}=6$ (diese Arbeit); Phasengrenzen nach Angabe von Elysee-Collen et al. bei $20^{\circ} \mathrm{C}$ und $p H=7: \triangle$ - Phasengrenze 1, $\times$ - Phasengrenze 2 [93]

Im Diagramm ist der Massenanteil von Ovalbumin über der Ionenstärke der Lösung aufgetragen. Die Ionenstärke wird stets allein aus der Salzkonzentration berechnet. Die schwarzen Punkte markieren die in der vorliegenden Arbeit experimentell bestimmten Trübungspunkte. Die Größe der Symbole entspricht ungefähr der Messgenauigkeit. Bei höheren Ovalbuminkonzentrationen streuen die Messergebnisse deutlich stärker als die Abschätzung der Messgenauigkeit erwarten lässt. Dies ist durch hohe Zähigkeit dieser Lösungen und die daraus resultierenden Probleme beim Vermischen der Lösungen verursacht. Die Konzentration der Ovalbuminstammlösungen lag zwischen etwa 4 und 30 Massen-\%. Stammlösungen mit höherem Proteingehalt wurden nicht verwendet, da die erhöhte Viskosität der Lösung die Einstellung der Trübung stark verzögert. Die Messungen wurden auf 
Salzkonzentrationen bis etwa 40 Massen-\% (durch die Salzlöslichkeit) beschränkt. Die experimentell bestimmte Trübungskurve liegt im Konzentrationsbereich bis zu 22 Massen-\% Ovalbumin und bis zu 40 Massen-\% Ammoniumsulfat. Es werden ungefähr 4 Massen-\% Ammoniumsulfat benötigt, um eine Trübung bei der höchsten untersuchten Konzentration von Ovalbumin in der Mischung (ca. 22 Massen-\%) zu verursachen.

Elysee-Collen et al. [93] haben das Phasenverhalten des Systems Ovalbumin - $\left(\mathrm{NH}_{4}\right)_{2} \mathrm{SO}_{4}-$ $\mathrm{H}_{2} \mathrm{O}$ im Temperaturbereich zwischen 20 und $90{ }^{\circ} \mathrm{C}$ bei $\mathrm{pH}=7$ untersucht. In der Abbildung 4.32 sind die entsprechenden Literaturangaben für die experimentell bestimmten Phasengrenzen bei $20{ }^{\circ} \mathrm{C}$ gezeigt. Leere Dreiecke markieren die Grenze zwischen einem Einphasengebiet und einem Zweiphasengebiet, in dem eine Flüssigkeit mit einem wasserlöslichen amorphen Niederschlag vorliegt (Grenze 1). Die Kreuze kennzeichnen die Grenze, die ein Zweiphasen- von einem Dreiphasengebiet trennt (Grenze 2). In diesem Dreiphasengebiet koexistiert eine Flüssigkeit mit einem wasserlöslichen amorphen Niederschlag und festem Ammoniumsulfat. Die bei den Trübungskurvenmessungen bestimmten Zusammensetzungen liegen außerhalb der Grenze 1, d. h. im Einphasengebiet. Dies weist auf das Ausfallen von Nebenkomponenten hin.

Die in der vorliegenden Arbeit experimentell bestimmten Zusammensetzungen der koexistierenden Phasen bei $25{ }^{\circ} \mathrm{C}$ und $\mathrm{pH}=6$ sind in der Abb. 4.33 dargestellt. Die entsprechenden Zahlenwerte sind im Anhang C tabelliert.

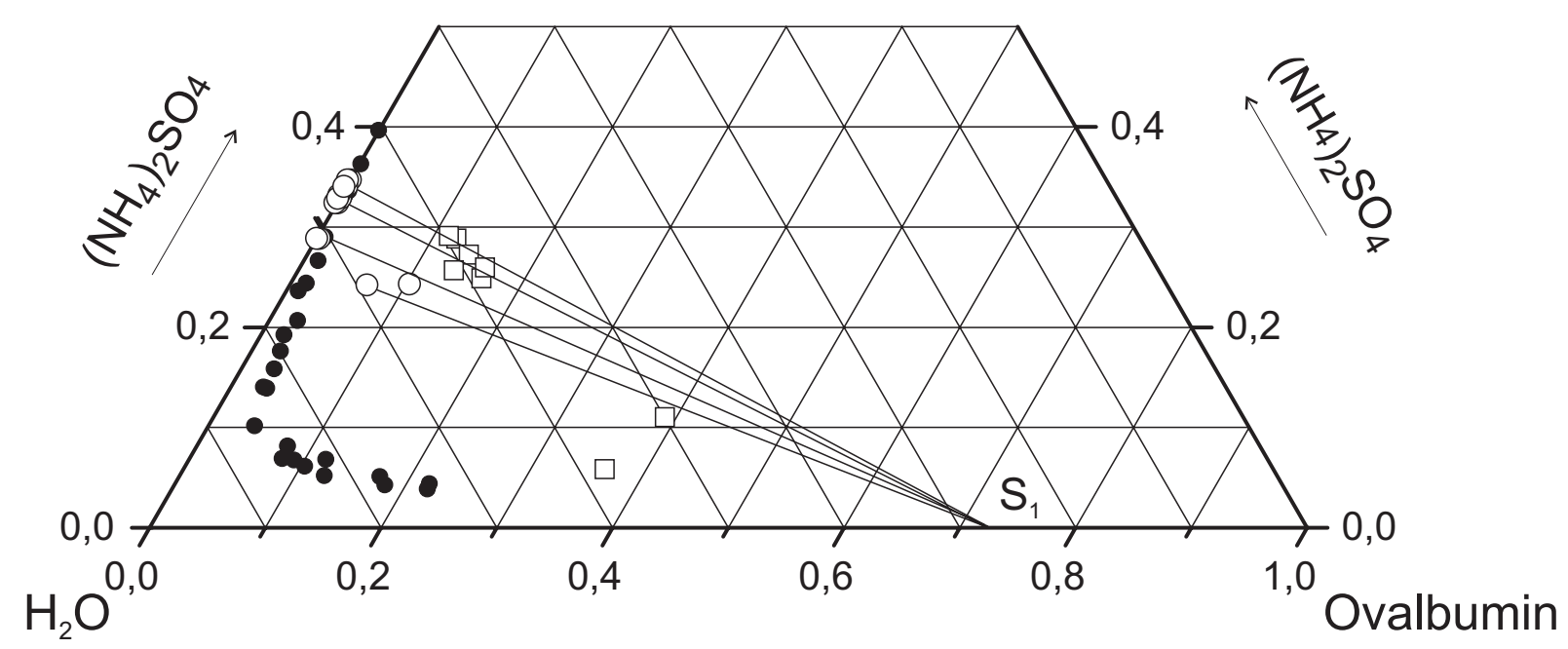

Abb.4.33 Experimentelle Ergebnisse für das Phasengleichgewicht des Systems Ovalbumin - $\left(\mathrm{NH}_{4}\right)_{2} \mathrm{SO}_{4}-$ Wasser bei $25{ }^{\circ} \mathrm{C}$ und $\mathrm{pH}=6$ : - Trübungskurve; $\bigcirc$ - Zusammensetzung der proteinarmen Phase; $\square$ - Zusammensetzung der proteinreichen Phase 
Die schwarzen Kreise markieren die Trübungskurve. Die an Ovalbumin angereicherte Phase bildet in diesem System die Unterphase, die proteinarme (und salzreiche) Phase ist die Oberphase. Die Unterphase ist durch leere Quadrate und die Oberphase durch leere Kreise gekennzeichnet. Die Feedpunkte sind zum besseren Überblick nicht gezeigt. Die Zusammensetzung einer Feedlösung liegt im Rahmen der Messgenauigkeit auf der Verbindungslinie zwischen den koexistierenden Ober- und Unterphasen. Aus der Verlängerung der Verbindungslinien resultiert ein Schnittpunkt $\left(S_{1}\right)$, der entspricht einem salzfreien Feststoff entspricht. Die Zusammensetzung des Feststoffes $\mathrm{S}_{1}$ beträgt etwa 72 Massen-\% Ovalbumin und etwa 28 Massen-\% Wasser.

Mehrere Proben der proteinreichen Unterphase unterschiedlicher Zusammensetzung wurden mikroskopisch untersucht. In allen untersuchten Proben wurden sehr kleine Partikeln festgestellt, deren Form schlecht zu erkennen war. Es ist deshalb nicht ausgeschlossen, dass die proteinreiche Phase eine kristalline Struktur aufweist. Zwei mikroskopische Aufnahmen von Proben der Unterphase sind in der Abbildung 4.34 gezeigt. Auf beiden Aufnahmen sind kleine Aggregate zu erkennen. Im rechten Teil der Abbildung kann man die eingeschlossene Flüssigkeit (die proteinarme Phase) erkennen.

a)

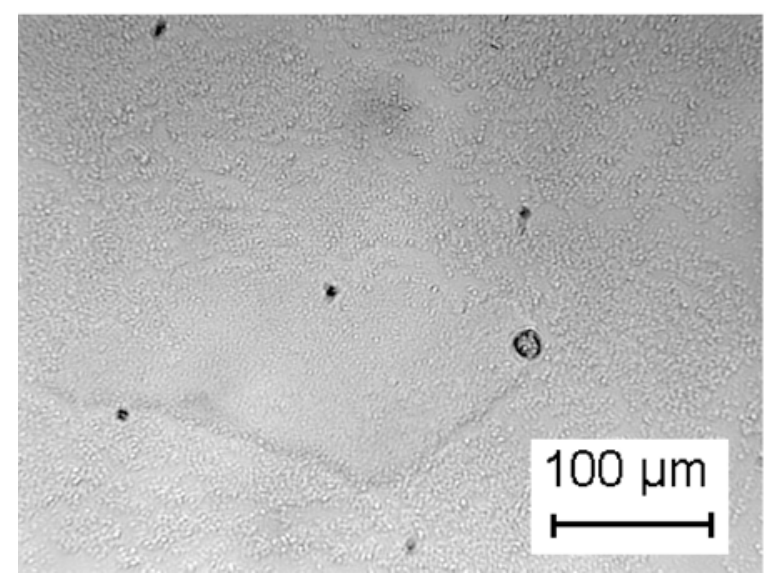

b)

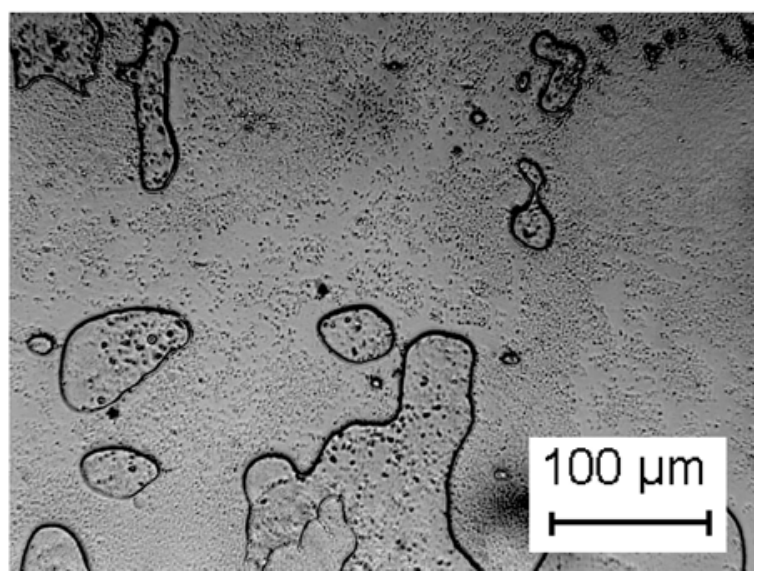

Abb.4.34 System Ovalbumin - $\left(\mathrm{NH}_{4}\right)_{2} \mathrm{SO}_{4}-$ Wasser bei $25{ }^{\circ} \mathrm{C}$ und $\mathrm{pH}=6$. Mikroskopische Aufnahmen von Probe der Unterphase:

a) Zusammensetzung der Feedlösung ( $\xi_{P}=0,0494 ; \xi_{S}=0,3333 ; \xi_{W}=0,6173$ );

b) Zusammensetzung der Feedlösung ( $\left.\xi_{P}=0,1224 ; \xi_{S}=0,2340 ; \xi_{W}=0,6436\right)$ 
In der Abbildung 4.35 ist die Zusammensetzung der proteinarmen Phase (die Löslichkeitsgrenze) zusammen mit einigen Trübungspunkten dargestellt. Die Löslichkeit von Ovalbumin bei der höchsten untersuchten Salzkonzentration (etwa 34 Massen-\%) beträgt ungefähr 0,03 Massen-\%. Die Löslichkeit nimmt mit steigender Salzkonzentration ab („Aussalzen“). Die Proteinlöslichkeit beträgt etwa 10 Massen-\% bei 24 Massen-\% Salz. Wie im System BSA - $\mathrm{Na}_{2} \mathrm{SO}_{4}-\mathrm{H}_{2} \mathrm{O}$ liegt die Löslichkeitskurve im System Ovalbumin$\left(\mathrm{NH}_{4}\right)_{2} \mathrm{SO}_{4}-\mathrm{H}_{2} \mathrm{O}$ teilweise innerhalb der gemessenen Trübungskurve. Die Trübung wird nicht durch das Ausfallen von Ovalbumin, sondern durch das Ausfällen von makromolekularen Verunreinigungen (vgl. Abschnitt 3.4.2) verursacht.

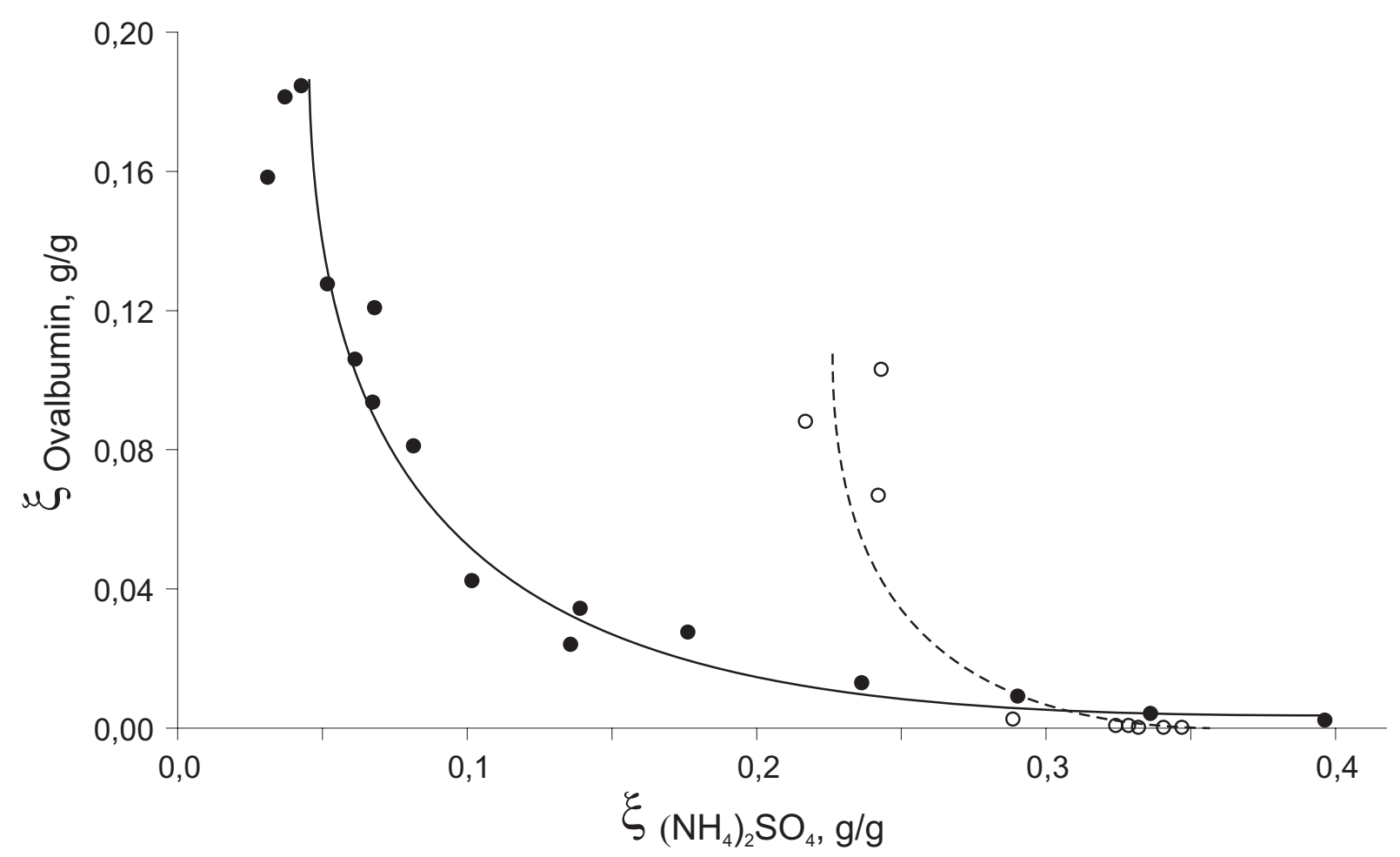

Abb.4.35 Vergleich von Löslichkeits- und Trübungskurve in System Ovalbumin $\left(\mathrm{NH}_{4}\right)_{2} \mathrm{SO}_{4}-$ Wasser bei $25{ }^{\circ} \mathrm{C}$ und $\mathrm{pH}=6$ : - Trübungspunkte;

$\bigcirc$ - Zusammensetzung der Oberphase aus Phasengleichgewichtsmessungen

In der Abbildung 4.36 ist der aus diesen Ergebnissen resultierende Vorschlag für das Phasendiagramm des Systems Ovalbumin - $\left(\mathrm{NH}_{4}\right)_{2} \mathrm{SO}_{4}-$ Wasser bei $25^{\circ} \mathrm{C}$ und $\mathrm{pH}=6$ gezeigt.

Die Punkte $\mathrm{L}_{1}$ bzw. $\mathrm{L}_{2}$ entsprechen den Löslichkeitsgrenzen von Ovalbumin (nach Angaben von Elysee-Collen et al. [93]) bzw. Ammoniumsulfat in reinem Wasser. Man erkennt ein einphasiges Gebiet, das durch die Löslichkeitskurve $\mathrm{L}_{2}-\mathrm{L}_{2}{ }^{*}-\mathrm{L}_{1}$ vom Mehrphasengebiet abgetrennt ist. Das Phasendiagramm weist zwei Fest-Flüssig-Zweiphasengebiete auf, dort 
steht einer der Feststoffe $\mathrm{S}_{1}$ (Komplex aus Ovalbumin und Wasser) bzw. $\mathrm{S}_{3}$ (Ammoniumsulfat) mit einer Flüssigkeit im Gleichgewicht. In einem Dreiphasengebiet koexistiert die Flüssigkeit $\mathrm{L}_{2}{ }^{*}$ mit dem Feststoff $\mathrm{S}_{1}$ und reinem Ovalbumin.

Ovalbumin wurde von Miller et al. [97] aus wässrigen Lösungen kristallisiert. Der Wassergehalt in Ovalbuminkristallen beträgt nach dieser Literaturangabe ca. 18 Massen-\% und ist damit deutlich geringer als der Wassergehalt im Feststoff $\mathrm{S}_{1}$ in der Abbildung 4.33 (ca. 28 Massen-\%).

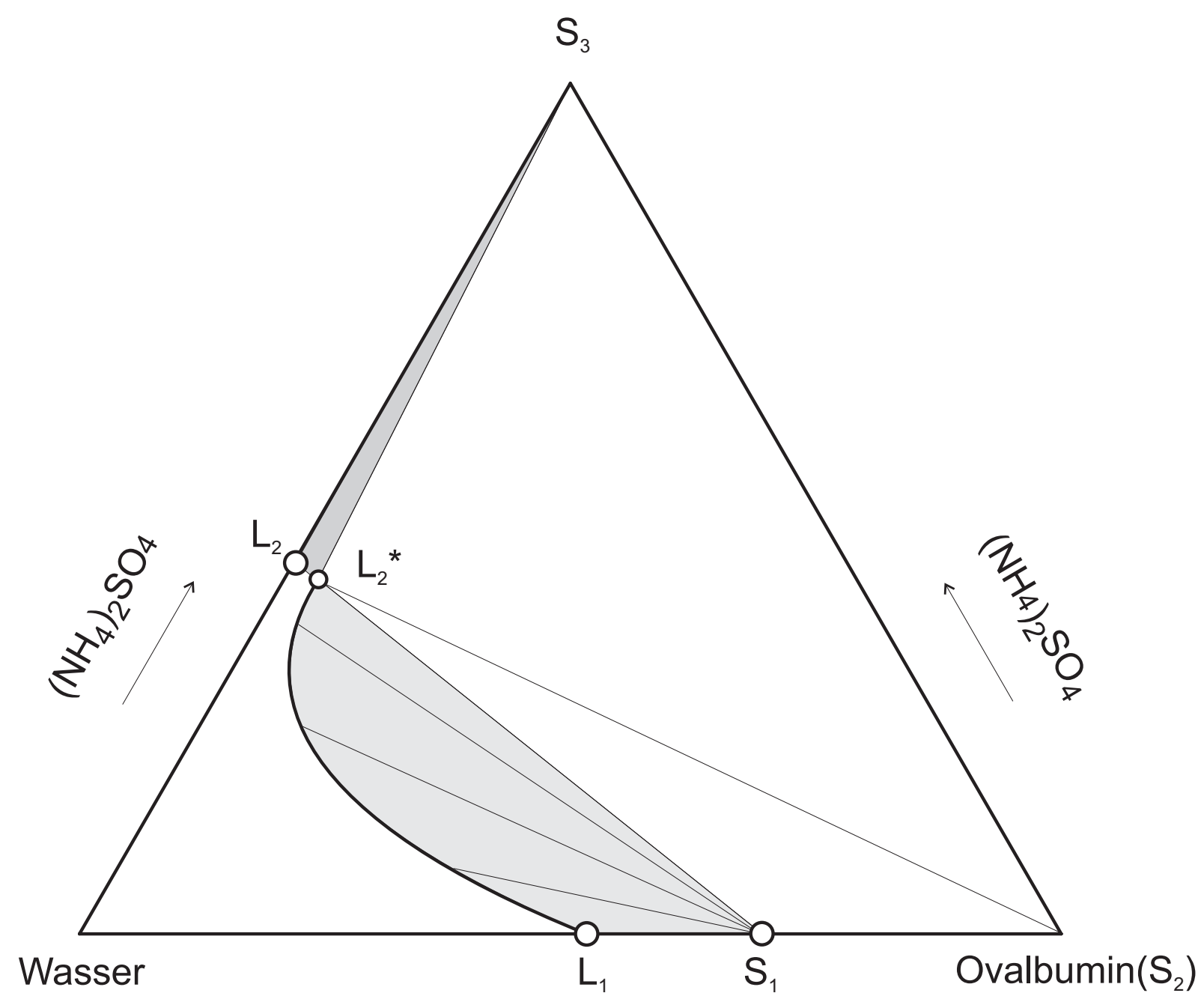

Abb.4.36 Vorschlag für das Phasendiagramm des Systems Ovalbumin - $\left(\mathrm{NH}_{4}\right)_{2} \mathrm{SO}_{4}-$ Wasser bei $25^{\circ} \mathrm{C}$ und $\mathrm{pH}=6$ 


\subsubsection{Ovalbumin $-\mathrm{Na}_{2} \mathrm{SO}_{4}-\mathrm{H}_{2} \mathrm{O}$}

Die Abbildung 4.37 zeigt die experimentellen Ergebnisse für die Trübungskurve des Systems Ovalbumin $-\mathrm{Na}_{2} \mathrm{SO}_{4}-$ Wasser bei $25^{\circ} \mathrm{C}$ und $\mathrm{pH}=7$.

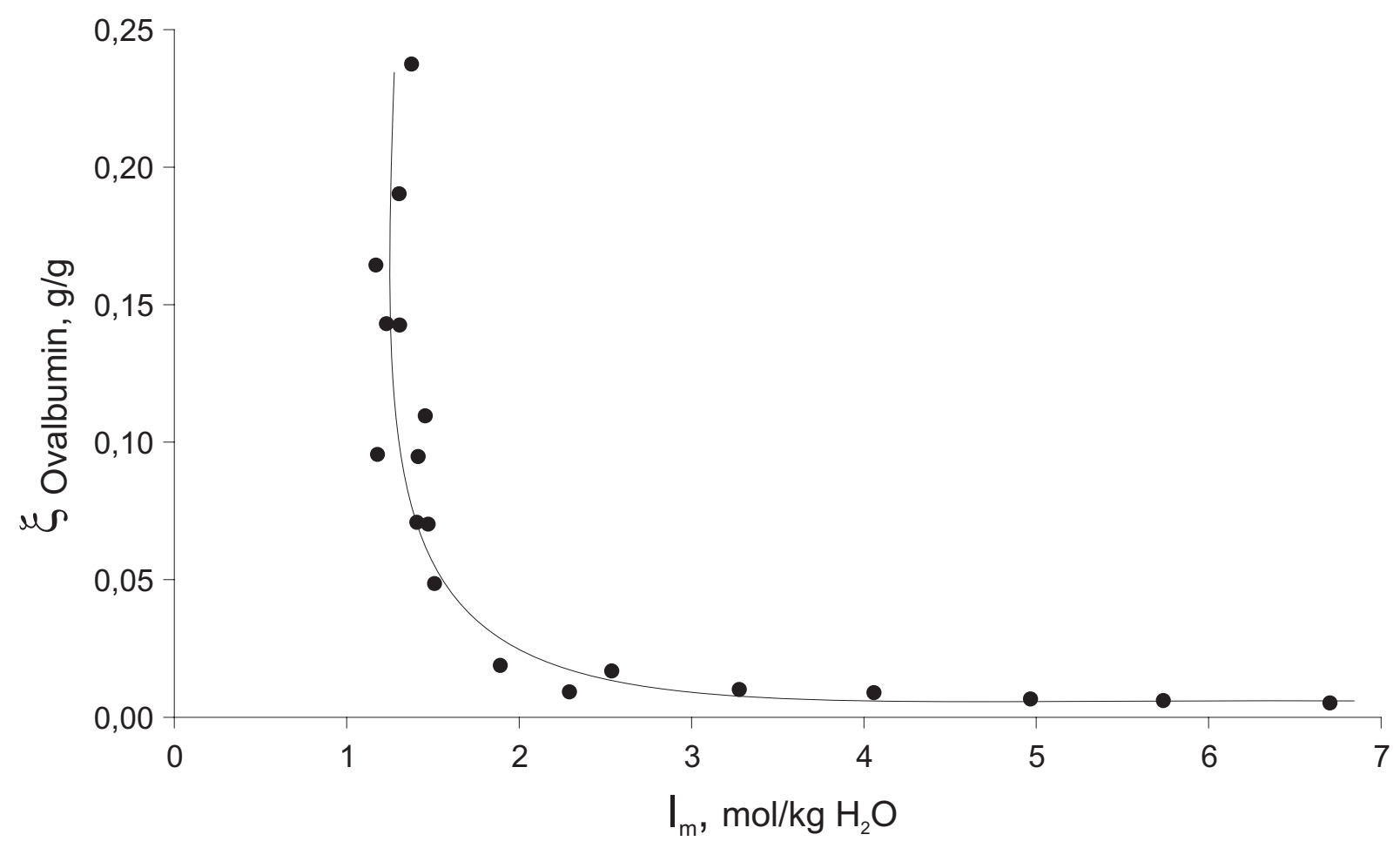

Abb.4.37 Experimentelle Ergebnisse für die Trübungskurve des Systems Ovalbumin $\mathrm{Na}_{2} \mathrm{SO}_{4}-$ Wasser bei $25^{\circ} \mathrm{C}$ und $\mathrm{pH}=7$

Dabei ist der Massenanteil von Ovalbumin über der Ionenstärke der Lösung aufgetragen. Die Ionenstärke wird stets allein aus der Salzkonzentration berechnet. Die schwarzen Kreise markieren die experimentell bestimmten Trübungspunkte. Die Ovalbuminkonzentration der Stammlösungen lagen zwischen 1 und 25 Massen-\%. Die Natriumsulfatkonzentration der Stammlösungen lag zwischen 5 und 22 Massen-\%. Bei der Bestimmung der Trübungspunkte im proteinarmen Konzentrationsbereich wurden übersättigte Salzlösungen verwendet, deren Zusammensetzung zwischen 22 und 25 Massen-\% lag (vgl. System BSA - $\mathrm{Na}_{2} \mathrm{SO}_{4}-\mathrm{H}_{2} \mathrm{O}$ ). Die experimentell bestimmte Trübungskurve liegt im Konzentrationsbereich bis zu 24 Massen-\% Ovalbumin und bis zu 24 Massen-\% Natriumsulfat. Dieser Bereich befindet sich teilweise oberhalb der Löslichkeitsgrenze von Natriumsulfat. Es werden ungefähr 5 Massen-\% Natriumsulfat benötigt, um eine Trübung bei der höchsten untersuchten Ovalbuminkonzentration in der Mischung (ca. 24 Massen-\%) zu verursachen. Die für die 
Trübung einer wässrigen Lösung mit einem Massen-\% Ovalbumin benötigte Konzentration von Natriumsulfat beträgt etwa13 Massen-\%.

Die experimentell bestimmten Zusammensetzungen der koexistierenden Phasen bei $25^{\circ} \mathrm{C}$ und $\mathrm{pH}=7$ sind in der Abb. 4.38 und 4.39 gezeigt. Die entsprechenden Zahlenwerte sind im Anhang $\mathrm{C}$ tabelliert. Die Trübungspunkte sind in beiden Abbildungen nicht aufgetragen. Die Abb. 4.38 zeigt die in der vorliegenden Arbeit beobachteten stabilen Gleichgewichte. Die schwarzen Symbole entsprechen Zuständen im Dreiphasengleichgewicht. Schwarze Kreise kennzeichnen die Zusammensetzungen der proteinarmen Phase (Oberphase), die mit Salzkristallen und einer weiteren festen Phase (Unterphase) koexistiert. Da die festen Phasen nicht getrennt werden konnten, mussten beide Phasen zusammen analysiert werden. Die pauschale Zusammensetzung dieser Mischung ist durch schwarze Quadrate gekennzeichnet. Schwarze Dreiecke markieren Zusammensetzungen der Feedpunkte. Der Mittelwert der analysierten Zusammensetzungen der proteinarmen Phasen beträgt 1,5 Massen-\% Ovalbumin, 20,4 Massen-\% Natriumsulfat und 78,1 Massen-\% Wasser.

Die leeren Symbole in der Abb. 4.38 entsprechen Zweiphasengleichgewichten. Die leeren Kreise kennzeichnen die proteinarme Phase (Oberphase), die leeren Quadrate - die proteinreiche Phase (Unterphase) und die leeren Dreiecke - die entsprechenden Feedpunkte. Der Mittelwert der analysierten Zusammensetzungen der proteinarmen Phasen beträgt 0,8 Massen-\% Ovalbumin, 20,5 Massen-\% Natriumsulfat und 78,7 Massen-\% Wasser und stimmt damit im Rahmen der Messgenauigkeit mit der Zusammensetzung der proteinarmen Phase im Bereich des Dreiphasengleichgewichtes.

Die Abb. 4.39 zeigt die im untersuchten System beobachteten metastabilen Gleichgewichte. Bei diesen Versuchen lag die Konzentration von Natriumsulfat über der Löslichkeitsgrenze (21,9 Massen-\%). Die an Ovalbumin angereicherte Phase bildet die Oberphase, die proteinarme Phase die Unterphase. Die Zusammensetzung der Oberphase ist durch leere Quadrate und die Zusammensetzung der proteinarmen Unterphase durch leere Kreise gekennzeichnet. Die Feedlösungen (leere Dreiecke) liegen auf den Linien, welche die koexistierenden Phasen verbindet. Werden die Verbindungslinien zwischen Ober- und Unterphasen verlängert, treffen sie sich in einem Schnittpunkt. Der Schnittpunkt entspricht reinem Ovalbumin. 


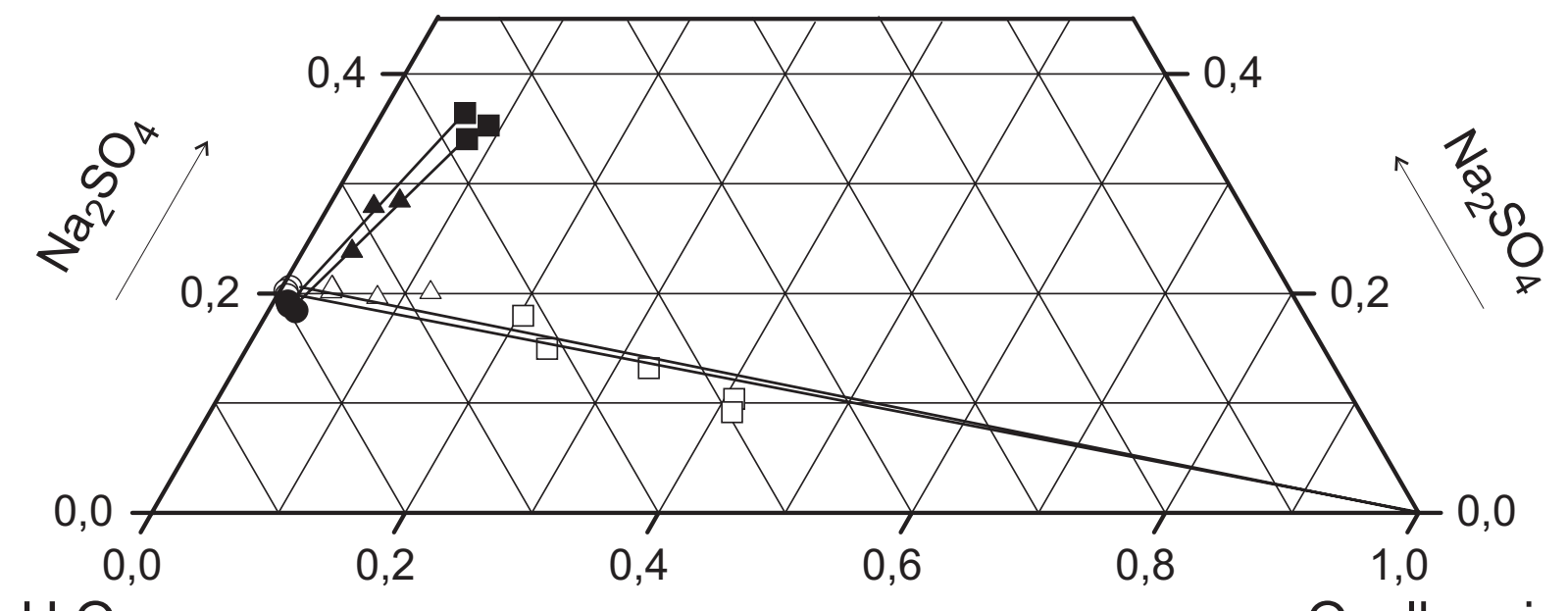

$\mathrm{H}_{2} \mathrm{O}$

Ovalbumin

Abb.4.38 Experimentelle Ergebnisse für das Phasengleichgewicht des Systems Ovalbumin - $\mathrm{Na}_{2} \mathrm{SO}_{4}$ - Wasser bei $25{ }^{\circ} \mathrm{C}$ und $\mathrm{pH}=7$. Stabiles Dreiphasengleichgewicht: -Zusammensetzung der proteinarmen Phase,

- Zusammensetzung der proteinreichen Phase, $\boldsymbol{\Delta}$ - Zusammensetzung der Feedlösung; Stabiles Zweiphasengleichgewicht: $\bigcirc$ - Zusammensetzung der proteinarmen Phase; $\square$ - Zusammensetzung der proteinreichen Phase,

$\triangle$ - Zusammensetzung der Feedlösung

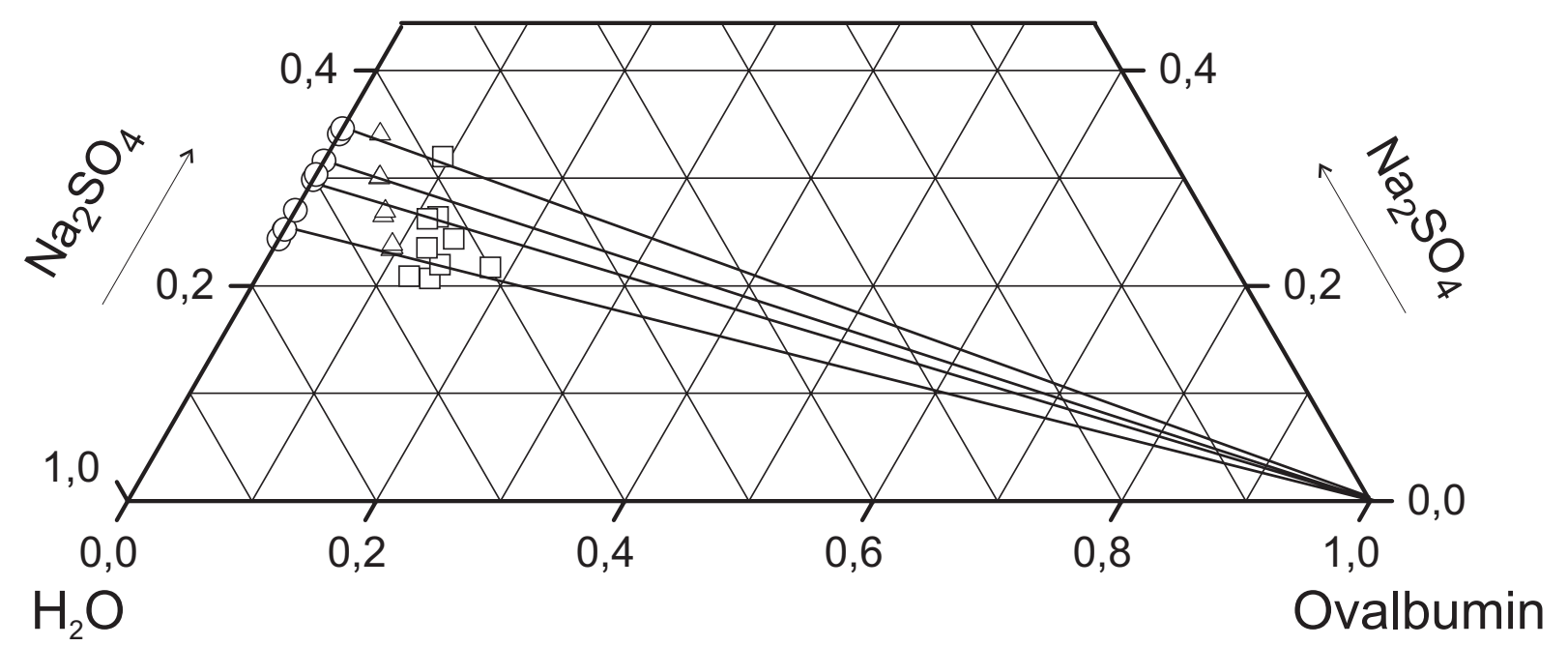

Abb.4.39 Experimentelle Ergebnisse für das Phasengleichgewicht des Systems Ovalbumin - $\mathrm{Na}_{2} \mathrm{SO}_{4}$ - Wasser bei $25{ }^{\circ} \mathrm{C}$ und $\mathrm{pH}=7$. Metastabiles Zweiphasengleichgewicht: $\bigcirc$ - Zusammensetzung der proteinarmen Phase;

$\square$ - Zusammensetzung der proteinreichen Phase, $\triangle$ - Zusammensetzung der Feedlösung 
Es wurden zwei Proben der proteinreichen Phasen mikroskopisch untersucht. In der Abbildung 4.40 sind die Aufnahmen gezeigt. Die Zusammensetzung der Feedlösung der ersten Probe (Abb. 4.40a) lag über die Löslichkeitsgrenze von Natriumsulfat. Trotz der eindeutigen Trennung der Feedlösung in zwei Phasen wurden in der Probe der proteinreichen Phase neben Proteinaggregaten auch Salzkristalle beobachtet (vgl. mikroskopische Aufnahmen von Salzkristallen im Anhang D). Da teilweise das Austrocknen der Proben bei den mikroskopischen Untersuchungen nicht ausgeschlossen werden kann, wird angenommen, dass das Salz nach der Phasentrennung aus der Lösung kristallisiert. Die mikroskopischen Untersuchungen der zweiten Probe (Abb. 4.40b) zeigen, dass die proteinreiche Phase vermutlich eine kristalline Struktur aufweist.

a)

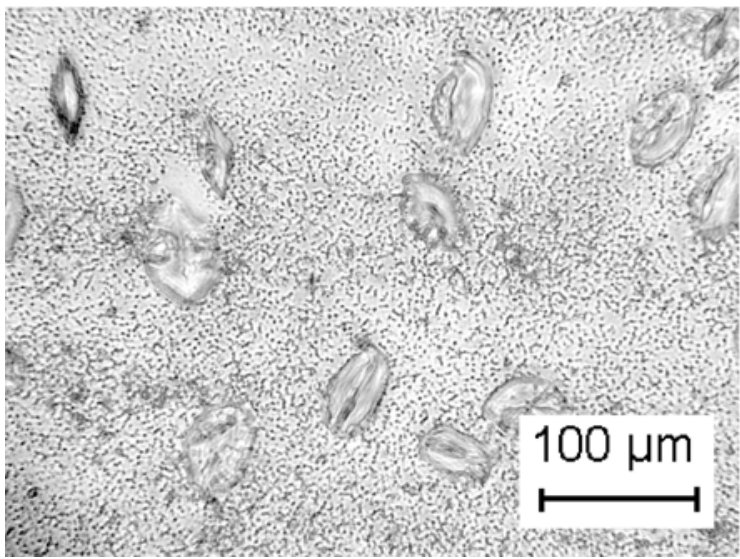

b)

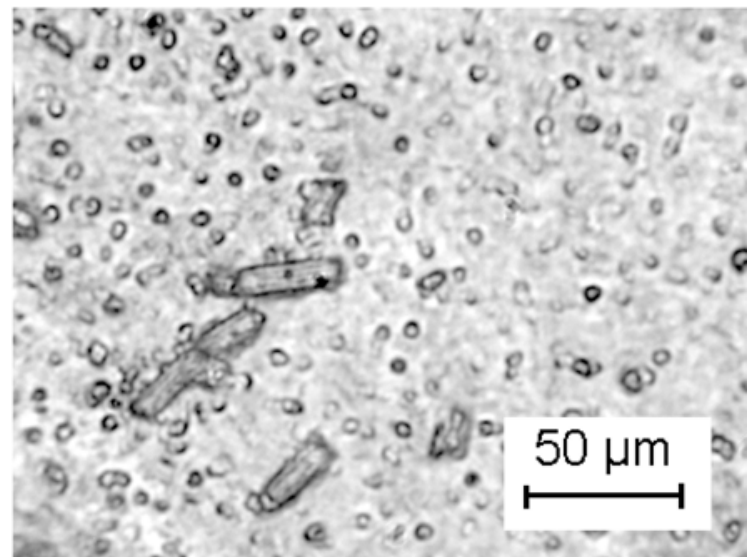

Abb. 4.40 System Ovalbumin $-\mathrm{Na}_{2} \mathrm{SO}_{4}-$ Wasser bei $25{ }^{\circ} \mathrm{C}$ und $\mathrm{pH}=7$. Mikroskopische Aufnahmen von Probe der proteinreichen Unterphase:

a) Zusammensetzung der Feedlösung ( $\left.\xi_{P}=0,0719 ; \xi_{S}=0,2623 ; \xi_{W}=0,6658\right)$;

b) Zusammensetzung der Feedlösung ( $\xi_{P}=0,0829 ; \xi_{S}=0,2083 ; \xi_{W}=0,7088$ ) 
In der Abbildung 4.41 ist die Zusammensetzung der proteinarmen Phase (die Löslichkeitsgrenze) zusammen mit einigen Trübungspunkten dargestellt. Die Proteinlöslichkeit steigt mit abnehmender Salzkonzentration stark an. Die Konzentration von Ovalbumin in einer salzreichen Phase mit 20 Massen-\% Natriumsulfat beträgt ungefähr 1 Massen-\%.

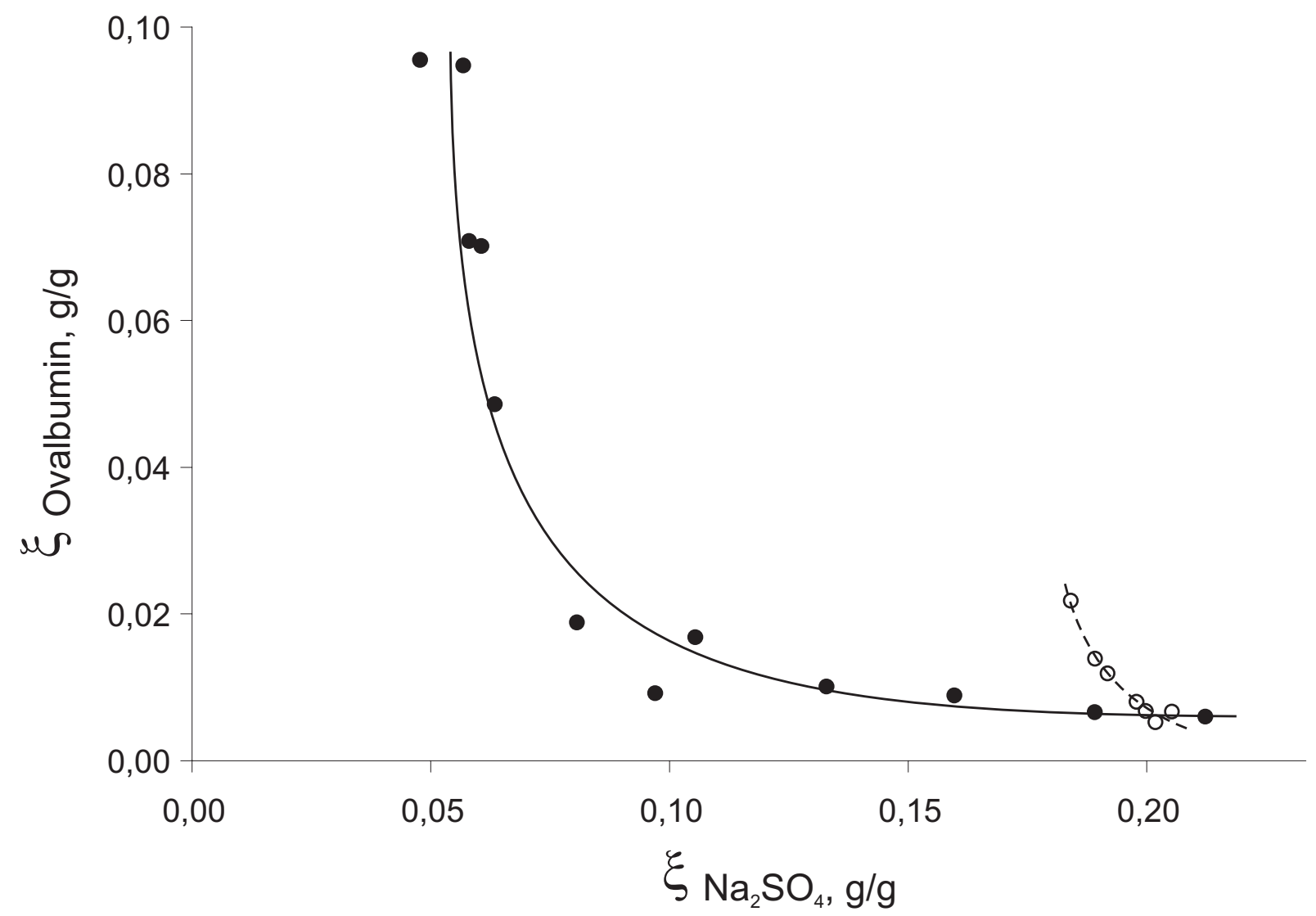

Abb. $4.41 \quad$ Vergleich von Löslichkeits- und Trübungskurve in System Ovalbumin - $\mathrm{Na}_{2} \mathrm{SO}_{4}$ - Wasser bei $25^{\circ} \mathrm{C}$ und $\mathrm{pH}=7$. Stabiles Zweiphasengleichgewicht:

- - Trübungspunkte; $\bigcirc$ - Zusammensetzung der Oberphase aus Phasengleichgewichtsmessungen

Man erkennt wiederum, dass die Trübung (bei festgehaltener Salzkonzentration) schon bei niedrigeren Salzkonzentrationen im Vergleich zu Löslichkeitskurve auftritt. Dies weist darauf hin, dass die Trübung möglicherweise durch das Ausfallen von Nebenkomponenten verursacht wurde. 
Die Abb. 4.42 zeigt die Abhängigkeit der Proteinlöslichkeit von der Konzentration des Salzes, wie sie in den Phasengleichgewichtsmessungen im Fall des metastabilen Phasengleichgewichts bestimmt wurde. Im Konzentrationsbereich über 25 Massen-\% Natriumsulfat ist die Proteinlöslichkeit von der Salzkonzentration im Rahmen der Messgenauigkeit unabhängig. Der Mittelwert beträgt ungefähr 0,025 Massen-\% Ovalbumin.

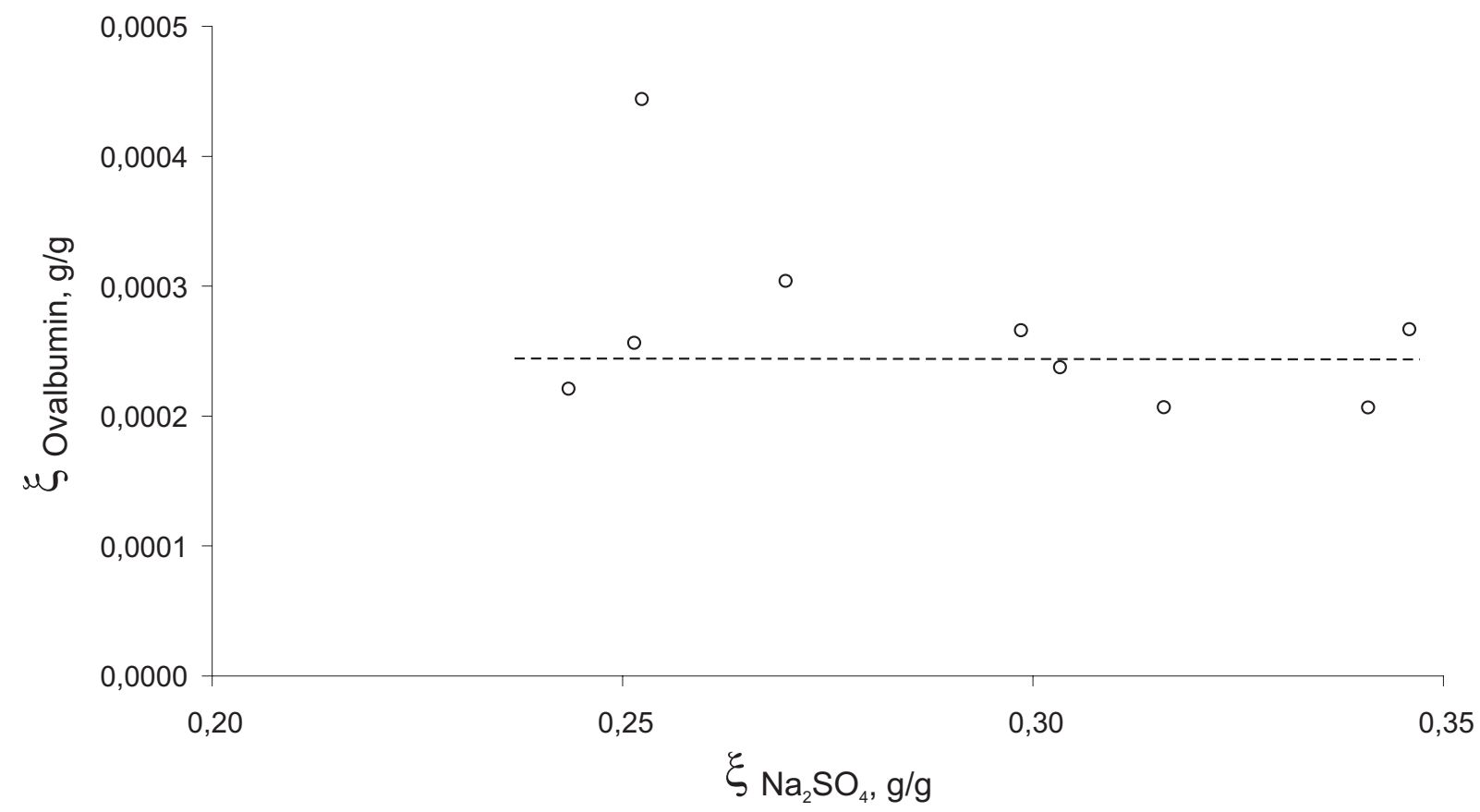

Abb. 4.42 Löslichkeit in System Ovalbumin - $\mathrm{Na}_{2} \mathrm{SO}_{4}-$ Wasser bei $25^{\circ} \mathrm{C}$ und $\mathrm{pH}=7$.

Metastabiles Phasengleichgewicht.

Ausgehend von diesen Beobachtungen kann man sich für das System Ovalbumin $-\mathrm{Na}_{2} \mathrm{SO}_{4}-$ Wasser das in der Abb. 4.43 gezeigte Phasendiagramm vorstellen.

Im Fall des stabilen Phasengleichgewichtes erhält man das im linken Teil der Abbildung 4.43 dargestellte Phasenverhalten. Die Punkte $\mathrm{L}_{1}$ und $\mathrm{L}_{2}$ markieren die Löslichkeiten von Ovalbumin und Natriumsulfat in reinem Wasser bei $25{ }^{\circ} \mathrm{C}$. Man erkennt ein einphasiges Gebiet, zwei Fest-Flüssig-Zweiphasengebiete - in denen ein ausgefälltes Protein bzw. Salzkristalle mit einer flüssigen Phase im Gleichgewicht stehen - und zwei Dreiphasengebiete. Im Dreiphasengebiet $\mathrm{S}_{2}-\mathrm{L}_{2}{ }^{*}-\mathrm{S}_{1}$ liegen die Feststoffe $\mathrm{S}_{2}$ $\left(\mathrm{Na}_{2} \mathrm{SO}_{4} \bullet 10 \mathrm{H}_{2} \mathrm{O}\right)$ und $\mathrm{S}_{1}$ (Ovalbumin) mit einer an Natriumsulfat und Ovalbumin gesättigten Flüssigkeit im Gleichgewicht vor. Die Löslichkeitskurve von Ovalbumin in salzhaltigen wässrigen Lösungen wird durch die Linie $\mathrm{L}_{2}-\mathrm{L}_{2} *-\mathrm{L}_{1}$ festgelegt. 
Im rechten Teil der Abbildung 4.43 ist ein metastabiles Phasengleichgewicht dargestellt, das dem beobachteten Phasenverhalten entspricht. Die Punkte $L_{1}$ und $\overline{L_{2}}$ markieren die Löslichkeit von Ovalbumin und die metastabile Löslichkeit von Natriumsulfat (ca. 35 Massen-\% [94]) in reinem Wasser bei $25{ }^{\circ} \mathrm{C}$. Man erkennt ein einphasiges Gebiet, zwei Fest-Flüssig-Zweiphasengebiete - in denen ein ausgefälltes Protein bzw. Salzkristalle mit einer flüssigen Phase im Gleichgewicht stehen - und zwei Dreiphasengebiete. Im Dreiphasengebiet $\overline{S_{2}}-\overline{L_{2}} *-S_{1}$ liegen die Feststoffe $\overline{S_{2}}\left(\mathrm{Na}_{2} \mathrm{SO}_{4} \cdot 7 \mathrm{H}_{2} \mathrm{O}\right)$ und $S_{1}$ (Ovalbumin) mit einer an Natriumsulfat und Ovalbumin gesättigten Flüssigkeit im Gleichgewicht vor.

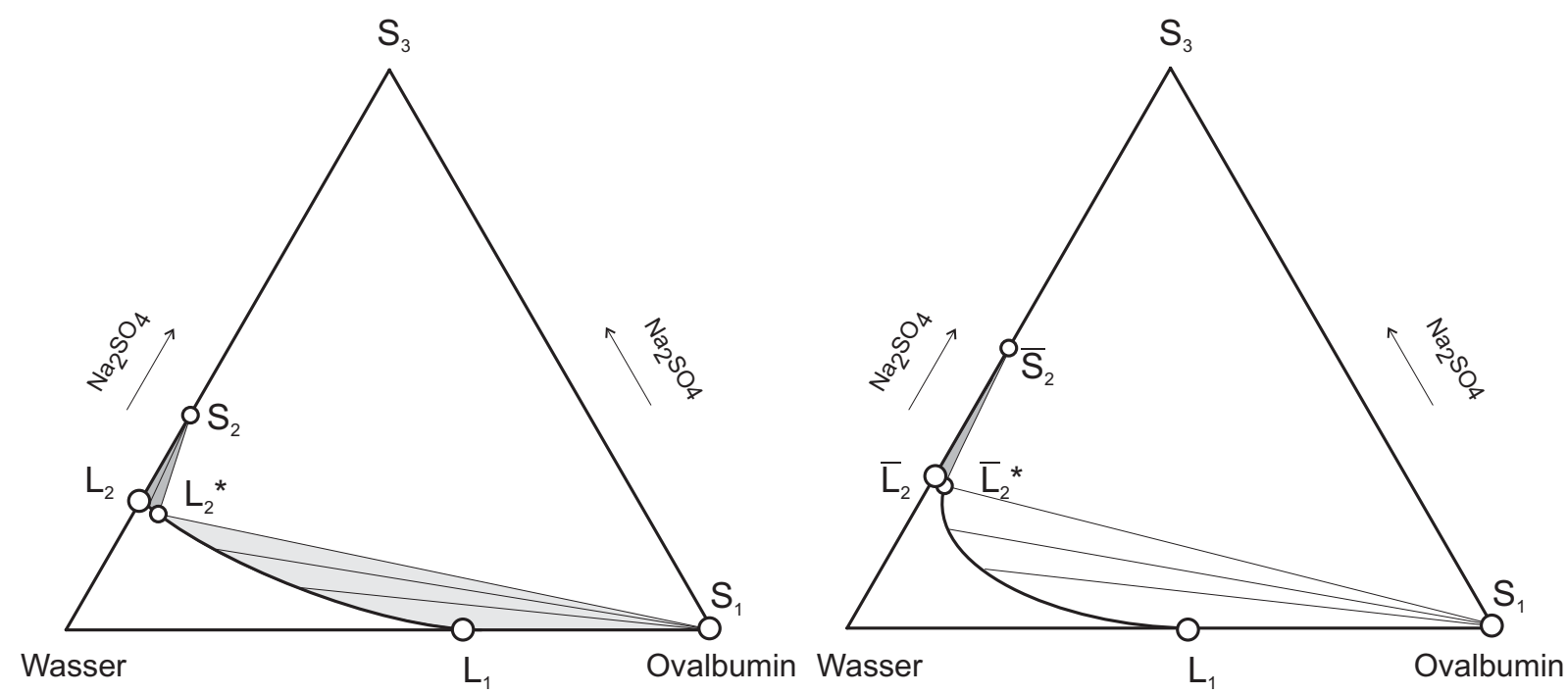

Abb. 4.43 Phasendiagramm für das System Ovalbumin $-\mathrm{Na}_{2} \mathrm{SO}_{4}-$ Wasser bei $25{ }^{\circ} \mathrm{C}$ und $p H=7$ 


\subsection{Trypsin}

\subsubsection{Trypsin - $\left(\mathrm{NH}_{4}\right)_{2} \mathrm{SO}_{4}-\mathrm{H}_{2} \mathrm{O}$}

Die Abbildung 4.44 zeigt die experimentellen Ergebnisse für die Trübungskurve des Systems Trypsin $-\left(\mathrm{NH}_{4}\right)_{2} \mathrm{SO}_{4}-$ Wasser bei $25^{\circ} \mathrm{C}$ und $\mathrm{pH}=5$.

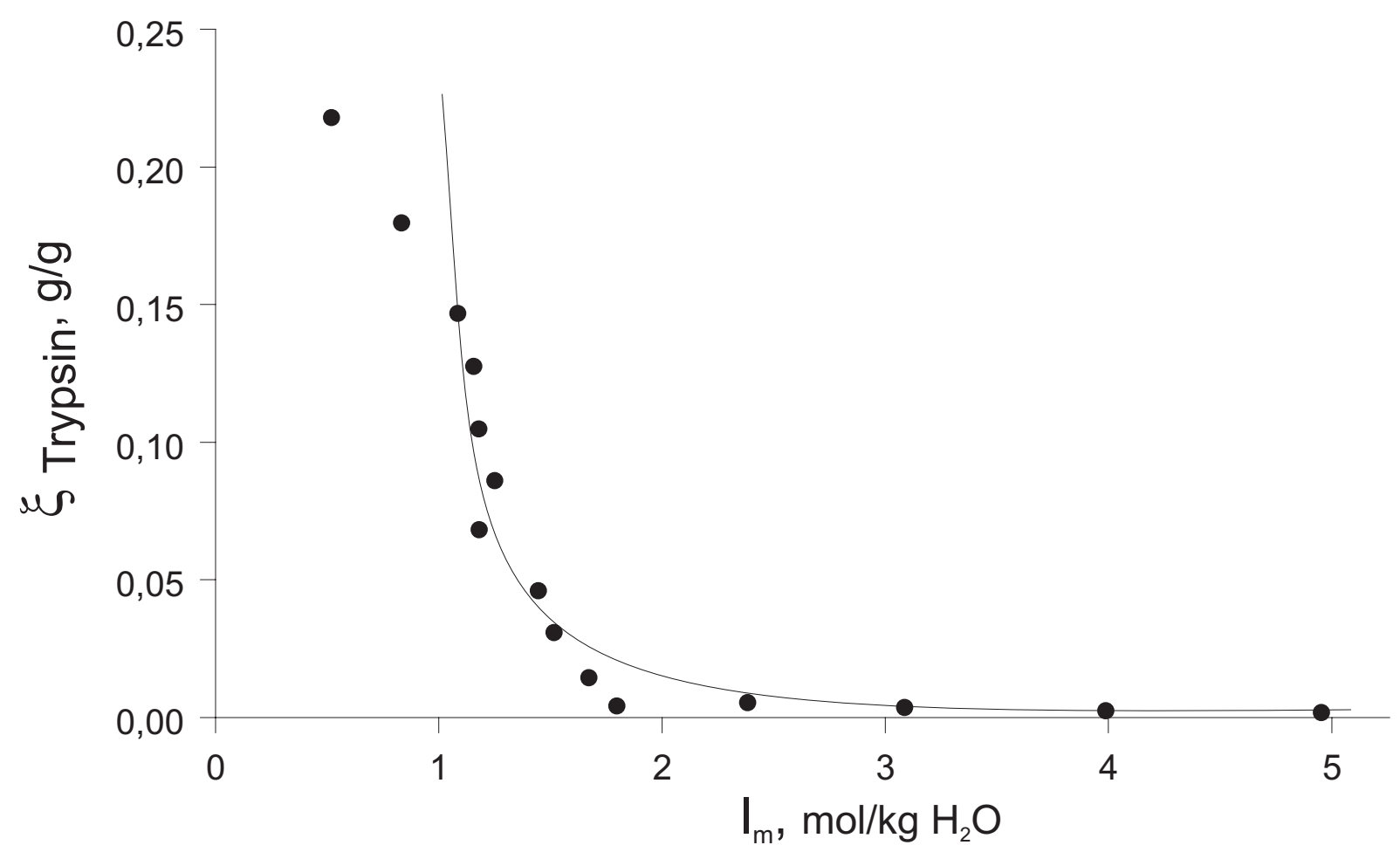

Abb.4.44 Experimentelle Ergebnisse für die Trübungskurve des Systems Trypsin $\left(\mathrm{NH}_{4}\right)_{2} \mathrm{SO}_{4}-$ Wasser bei $25{ }^{\circ} \mathrm{C}$ und $\mathrm{pH}=5$

Dabei ist der Massenanteil von Trypsin über der Ionenstärke der Lösung aufgetragen. Die Ionenstärke wird stets allein aus der Salzkonzentration berechnet. Die schwarzen Punkte markieren die experimentell bestimmten Trübungspunkte. Die Konzentrationen von Trypsin in den Stammlösungen lagen zwischen etwa 2 und 25 Massen-\%. Die Messungen wurden auf Salzkonzentrationen bis etwa 40 Massen-\% (durch die Salzlöslichkeit) beschränkt. Die experimentell bestimmte Trübungskurve liegt im Konzentrationsbereich bis zu 22 Massen-\% Trypsin und bis zu 39 Massen-\% Ammoniumsulfat. Es werden ungefähr 5 Massen-\% Ammoniumsulfat benötigt, um eine Trübung bei der höchsten untersuchten Trypsinkonzentration (ca. 22 Massen-\%) zu verursachen. Auffällig ist bei hoher Trypsinkonzentration ein „Knick“ in einer Vielzahl der Trübungspunkte. Dieser Knick kann z. B. durch den Übergang zu einem anderen Phasengleichgewichtstyp, aber auch durch 
experimentelle Probleme (hohe Zähigkeit der proteinhaltigen Lösungen oder Verunreinigungen) verursacht sein.

Die experimentell bestimmten Zusammensetzungen der koexistierenden Phasen im System Trypsin $-\left(\mathrm{NH}_{4}\right)_{2} \mathrm{SO}_{4}-$ Wasser bei $25^{\circ} \mathrm{C}$ und $\mathrm{pH}=5$ sind in der Abb. 4.45 dargestellt. Die entsprechenden Zahlenwerte sind im Anhang C tabelliert. Die gefüllten Kreise markieren die Trübungskurve. Leere Quadrate kennzeichnen die Unterphase (proteinreiche Phase) und leere Kreise kennzeichnen die Oberphase (proteinarme Phase). Die Zusammensetzung der Feedlösungen (leere Dreiecke) liegen im Rahmen der Messgenauigkeit auf den Linien, die entsprechende Zusammensetzungen der koexistierenden Ober- und Unterphase verbinden.

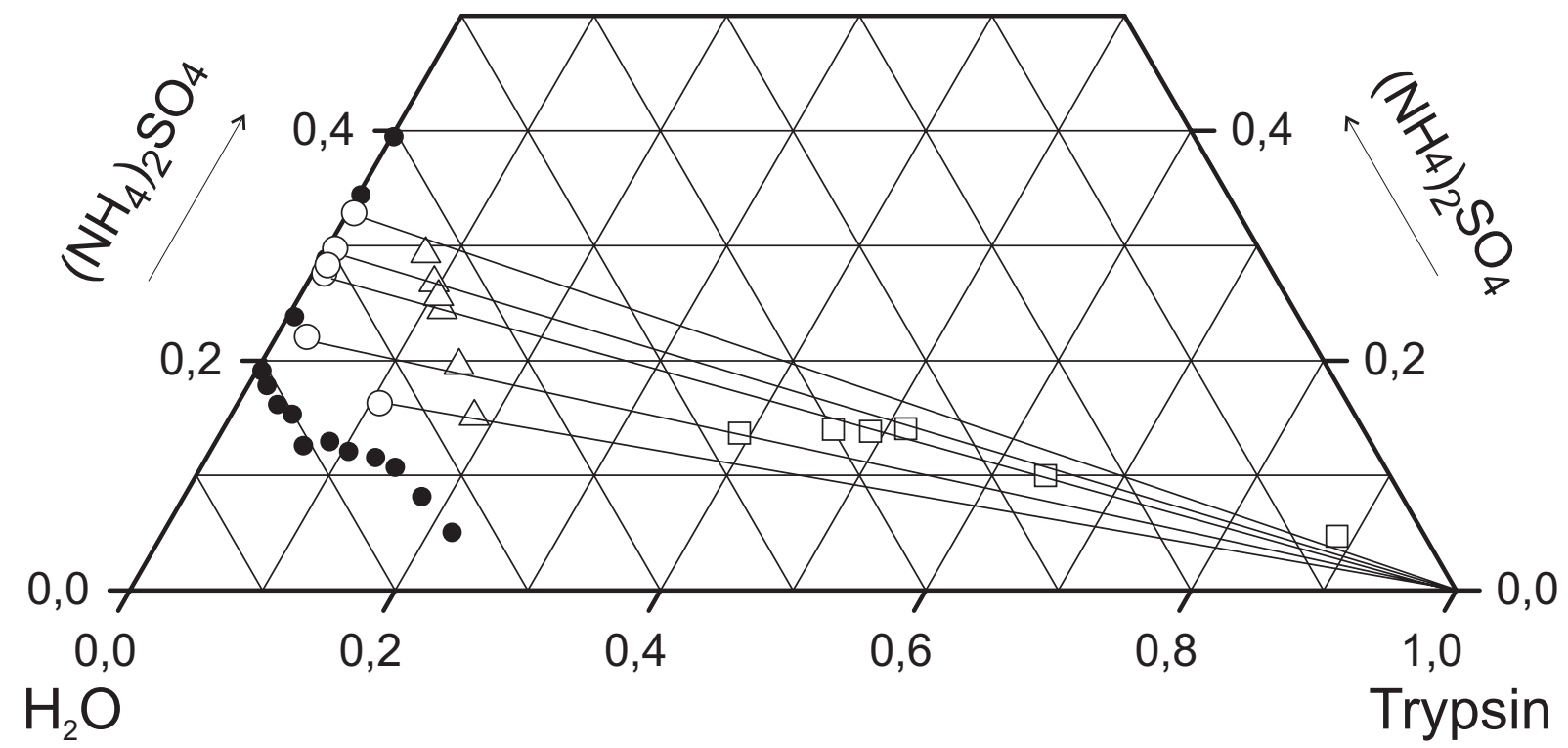

Abb.4.45 Experimentelle Ergebnisse für das Phasengleichgewicht des Systems Trypsin$\left(\mathrm{NH}_{4}\right)_{2} \mathrm{SO}_{4}-$ Wasser bei $25^{\circ} \mathrm{C}$ und $\mathrm{pH}=5$ : - Trübungskurve;

$\bigcirc$ - Zusammensetzung der proteinarmen Phase; $\square$ - Zusammensetzung der proteinreichen Phase

Bei den experimentellen Untersuchungen konnte durch Zentrifugieren keine vollständige Trennung der Phasen erreicht werden. Die Verbindungslinien zwischen Punkten, die die koexistierenden Phasen verbinden, treffen sich in einem Schnittpunkt. Dieser Schnittpunkt entspricht reinem Trypsin.

Einige typische mikroskopische Aufnahmen von Proben der Unterphase unterschiedlicher Zusammensetzung sind in der Abbildung 4.46 gezeigt. Es wurde in allen untersuchten Proben die Bildung wasserlöslicher, proteinreicher Aggregate beobachtet. Im linken Teil der Abbildung (aus einem Versuch mit höherer Salzkonzentration) sind einzelne Kristalle zu erkennen. 
In der Abbildung 4.47 ist die Zusammensetzung der proteinarmen Phase (Oberphase, d. h. die Löslichkeitsgrenze) mit der Trübungskurve verglichen. Die Löslichkeit von Trypsin bei der höchsten untersuchten Salzkonzentration (etwa 33 Massen-\%) beträgt ungefähr 0,4 Massen-\%. Die Löslichkeit nimmt mit steigender Salzkonzentration ab („Aussalzen“). Die Proteinlöslichkeit beträgt etwa 11 Massen-\% bei 17 Massen-\% Ammoniumsulfat. Die experimentell bestimmte Trübungskurve liegt außerhalb des Zweiphasengebiets. Bei höheren Salzkonzentrationen laufen die Löslichkeitskurve und die Trübungskurve zusammen. Dies kann darauf hindeuten, dass die Trübung nicht durch das Ausfällen von Trypsin verursacht wurde, sondern durch das Ausfällen von makromolekularen Verunreinigungen (vgl. Abschnitt 3.4.2).

a)

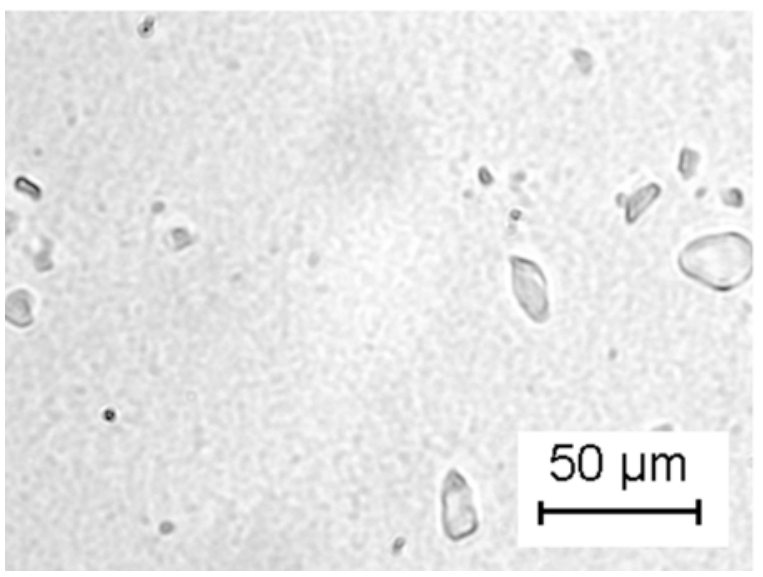

b)

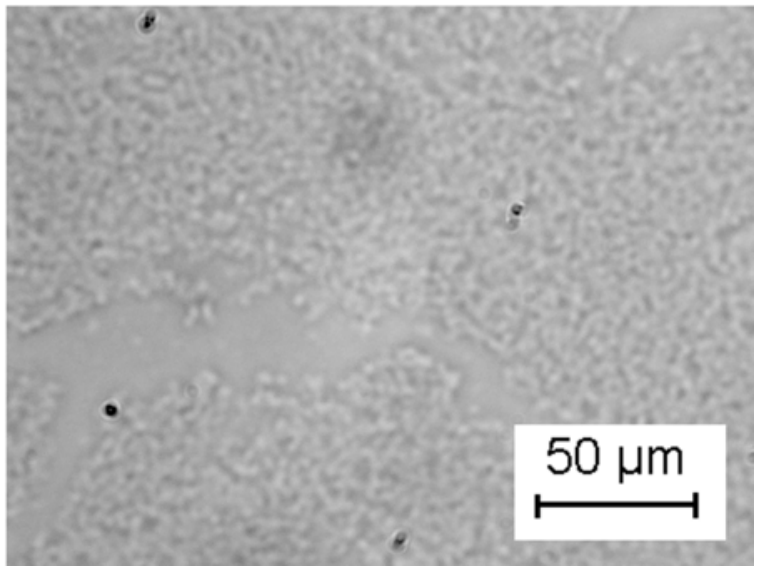

Abb.4.46 System Trypsin - $\left(\mathrm{NH}_{4}\right)_{2} \mathrm{SO}_{4}-$ Wasser bei $25{ }^{\circ} \mathrm{C}$ und $\mathrm{pH}=5$. Mikroskopische Aufnahmen von Proben der Unterphase:

a) Zusammensetzung der Feedlösung ( $\xi_{P}=0,0518 ; \xi_{S}=0,3274 ; \xi_{W}=0,6208$ );

b) Zusammensetzung der Feedlösung $\left(\xi_{P}=0,1513 ; \xi_{S}=0,1962 ; \xi_{W}=0,6525\right)$ 


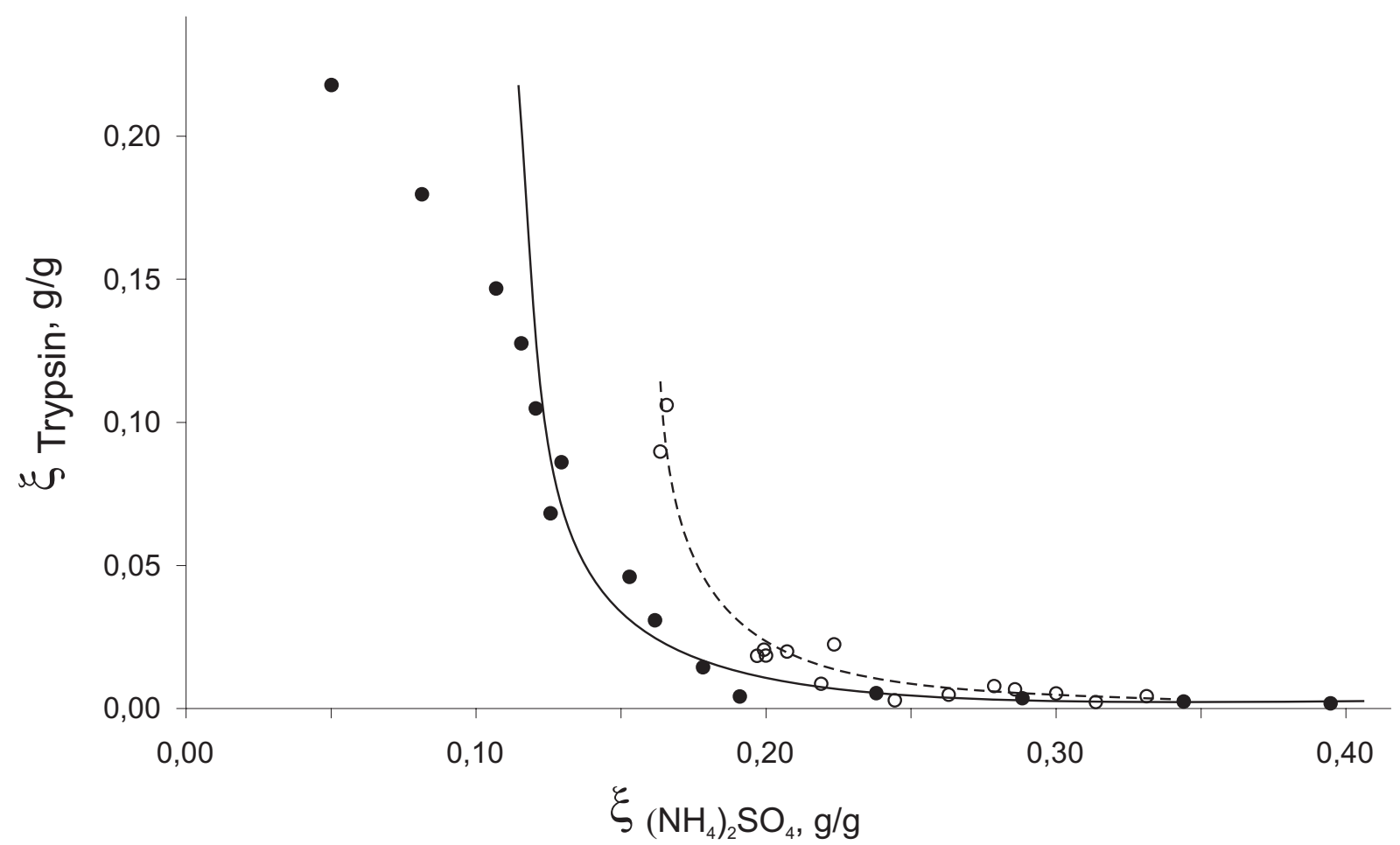

Abb. $4.47 \quad$ Vergleich von Löslichkeits- und Trübungskurve in System Trypsin - $\left(\mathrm{NH}_{4}\right)_{2} \mathrm{SO}_{4}$

- Wasser bei $25{ }^{\circ} \mathrm{C}$ und $\mathrm{pH}=5$ : - Trübungspunkte; $\bigcirc$ - Zusammensetzung der Oberphase aus Phasengleichgewichtsmessungen

Die Abbildung 4.43 zeigt einen Vorschlag für das Phasenverhalten des Systems Trypsin $\left(\mathrm{NH}_{4}\right)_{2} \mathrm{SO}_{4}-$ Wasser bei $25^{\circ} \mathrm{C}$ und $\mathrm{pH}=5$. Die Punkte $\mathrm{L}_{1}$ und $\mathrm{L}_{2}$ markieren die Löslichkeiten von Trypsin und Ammoniumsulfat in reinem Wasser bei $25^{\circ} \mathrm{C}$. Die Löslichkeitsgrenze von Trypsin in salzhaltigen wässrigen Lösungen wird durch die Linie $\mathrm{L}_{2}-\mathrm{L}_{2}{ }^{*}-\mathrm{L}_{1}$ festgelegt. Man erkennt ein einphasiges Gebiet, zwei Fest-Flüssig-Zweiphasengebiete - in denen ein ausgefälltes Protein bzw. Salzkristalle mit einer flüssigen Phase im Gleichgewicht stehen und ein Dreiphasengebiet. Im Zweiphasengebiet $\mathrm{L}_{1}-\mathrm{L}_{2} *-\mathrm{S}_{1}$ koexistieren ein Feststoff $\mathrm{S}_{1}$ (Trypsin) und eine proteinarme flüssige Phase. 


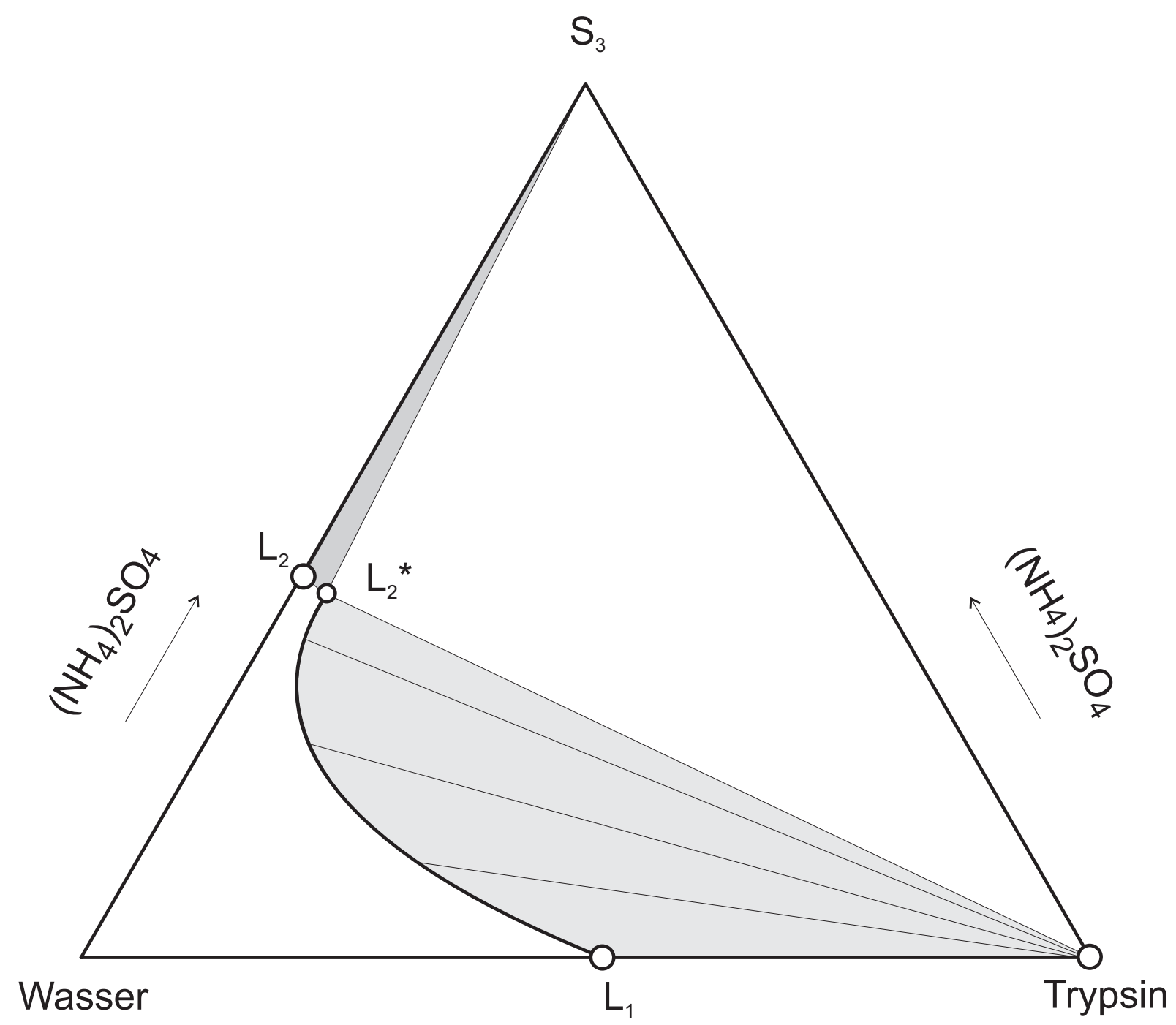

Abb. 4.48 Vorschlag für das Phasendiagramm des Systems Trypsin - $\left(\mathrm{NH}_{4}\right)_{2} \mathrm{SO}_{4}-$ Wasser bei $25^{\circ} \mathrm{C}$ und $\mathrm{pH}=5$ 


\section{Zusammenfassung}

In der biotechnologischen Herstellung von Proteinen ist die Fällung mit Hilfe von Salzen (z. B. Ammoniumsulfat) ein unkompliziertes und verbreitetes Verfahren, wobei die biologischen Eigenschaften der Proteine (meistens) erhalten bleiben. Dieses Verfahren basiert auf dem sogenannten „Aussalzeffekt“. Obwohl das „Aussalzen“ von Proteinen seit langem bekannt ist, ist das Phasenverhalten in Systemen aus Proteinen, Salzen und Wasser weitgehend ungeklärt. Das Phasenverhalten eines proteinhaltigen Systems wird durch eine Vielzahl von Parametern, z. B. Art und Konzentration der Stoffe, Temperatur, pH-Wert und Ionenstärke, beeinflusst. Darüber hinaus können beim Ausfällen der Proteine sowohl stabile als auch metastabile Phasengleichgewichte auftreten.

In der vorliegenden Arbeit wurden experimentelle Untersuchungen zum Phasenverhalten ternärer Systeme (Protein + Salz + Wasser) bei Umgebungstemperatur durchgeführt. Das Ausfällen von Lysozym, Bovin Serum Albumin, Ovalbumin und Trypsin mit Hilfe verschiedener Salze (Ammoniumsulfat, Natriumsulfat und teilweise der flüchtigen Salze Ammoniumcarbamat und Ammoniumbicarbonat) wurde untersucht. Die experimentellen Untersuchungen erfolgten einerseits durch Bestimmung der Trübungskurven und andererseits durch Bestimmung der Zusammensetzung der koexistierenden Phasen. Zusätzlich wurden mikroskopische Untersuchungen durchgeführt, um die Struktur der proteinreichen Phase (amorph, kristallin) aufzuklären.

Die bei den Titrationsversuchen bei konstanter Temperatur beobachtete Trübung in Systemen (Protein + Salz + Wasser) deutet auf die Bildung einer zweiten Phase hin. Allerdings sind weder Struktur noch die thermodynamische Stabilität dieser Phase bekannt. Die Ergebnisse der Trübungskurvenmessungen zeigen, dass die Trübung in der Regel erst dann beobachtet wird, wenn die Grenze zu einem Zweiphasengebiet (d. h. Fest-Flüssig-Gleichgewicht) weit überschritten ist. Tritt die Trübung bereits im Einphasengebiet auf, handelt es sich vermutlich um das Ausfällen makromolekularer Verunreinigungen der Proteine. Die gemessenen Trübungskurven liegen im Konzentrationsbereich bis zu 40 Massen-\% Salz (je nach Salzlöslichkeit) und bis zu 25 Massen-\% Protein. Die Proteinkonzentration, bei der die Trübung eintritt, nimmt mit steigender Salzkonzentration ab.

Die experimentellen Ergebnisse der Trübungskurvenmessungen für die Systeme (Lysozym + Natriumsulfat (Ammoniumsulfat) + Wasser) stimmen mit Literaturangaben für die 
Löslichkeit von amorphem Lysozym überein. Die für die Trübung einer wässrigen einprozentigen Lysozymlösung benötigte Salzkonzentration beträgt bei Verwendung von Natriumsulfat 15 Massen-\%, von Ammoniumsulfat 20 Massen-\%, von Ammoniumcarbamat 9 Massen- $\%$ und von Ammoniumbicarbonat 6 Massen-\%.

Wässrige Lösungen von Bovin Serum Albumin und Ovalbumin lassen sich mit wässrigen Ammoniumsulfatlösungen eintrüben. Dabei wird eine Salzkonzentration von etwa 30 Massen-\% bei einer einprozentigen Proteinlösung benötigt. Durch Zugabe einer gesättigten wässrigen Lösung von Natriumsulfat zu wässrigen Lösungen von Bovine Serum Albumin bzw. Ovalbumin konnte keine Trübung verursacht werden. Die Zugabe einer wässrigen Lösung eines flüchtigen Salz zu einer wässrigen Lösung von Bovin Serum Albumin bzw. Ovalbumin führt zur Bildung von Gasen (Ammoniak bzw. Kohlendioxid).

Bei den Untersuchungen zur Bestimmung der Zusammensetzungen der koexistierenden Phasen wurden Zweiphasengleichgewichte mit einer proteinarmen und einer proteinreichen Phase beobachtet. In den Systemen (Bovin Serum Albumin bzw. Ovalbumin + Natriumsulfat + Wasser) wurde in einigen Untersuchungen ein Dreiphasengleichgewicht festgestellt. In der Regel konnte durch Zentrifugieren keine vollständige Phasentrennung erreicht werden.

Bei den Untersuchungen mit Lysozym zeigte die proteinreiche Phase eine kristalline Struktur. Bei niedrigen Salzkonzentrationen bilden sich in der Regel salzfreie Lysozymkristalle. Die Zusammensetzung dieser Kristalle beträgt ungefähr 16 Massen-\% Wasser und 84 Massen-\% Lysozym. Dieses Ergebnis ist in guter Übereinstimmung mit Literaturangaben. Bei höheren Salzkonzentrationen bilden sich Kristalle, die bis zu 15 Massen-\% Salz enthalten.

In der weitergehenden Arbeit von Watanabe [100] wurde der pH-Einfluss auf das Phasenverhalten in Systemen mit Lysozym und Ammoniumsulfat bzw. Natriumsulfat untersucht. Die Zusammensetzung der salzfreien Lysozymkristallen erwies sich im Rahmen der Messgenauigkeit als pH-Wert unabhängig.

Die zurückbleibende proteinarme Phase, die mit Lysozymkristallen koexistiert, kann je nach Salzkonzentration bis zu 12 Massen-\% Protein enthalten. In den Lösungen flüchtiger Salze ist die Lysozymlöslichkeit deutlich niedriger, was bei der Aufarbeitung wässriger Proteinlösungen von Vorteil ist. Darüber hinaus kann bei Verwendung flüchtiger Salze sowohl die proteinarme als auch die proteinreiche Phase weitgehend entsalzt werden.

In Systemen aus Bovin Serum Albumin bzw. Ovalbumin mit Ammoniumsulfat wurde keine Proteinkristallbildung, sondern die Bildung wasserlöslicher proteinreicher Aggregate 
beobachtet. Diese Aggregate können bis zu 20 Massen-\% Salz enthalten. Die Löslichkeit von Bovin Serum Albumin bzw. Ovalbumin ist größer als die von Lysozym.

Beim „Aussalzen“ dieser Proteine mit Natriumsulfat kann ein metastabiles Zweiphasengleichgewicht auftreten. Dabei ist die Proteinkonzentration in der proteinarmen Phase sehr gering und von der Salzkonzentration unabhängig. Im Fall eines stabilen Dreiphasengleichgewichtes koexistiert eine proteinarme Phase mit Kristallen aus Natriumsulfatdekahydrat und einer sehr viskosen, proteinreichen Phase.

Im System (Trypsin + Ammoniumsulfat + Wasser) wurde ein Gleichgewicht zwischen amorphen Aggregaten und einer proteinarmen Phase beobachtet. Bei der Auswahl des Salzes muss beachtet werden, dass Trypsin lediglich bei niedrigem $\mathrm{pH}-$ Wert stabil ist.

Die vorliegende Arbeit trägt zur Aufklärung der das Ausfällen von Proteinen verursachenden physikalisch-chemischen Effekte am Beispiel einiger Modellsysteme bei. Es wurde gezeigt, dass flüchtige Salze (d. h. die Salze auf Basis von Ammoniak und Kohlendioxid) erfolgreich für die Aufarbeitung der wässrigen Proteinlösungen eingesetzt werden können. Die Ergebnisse der experimentellen Untersuchungen sollen die Grundlage für eine in weiterführenden Arbeiten vorgesehene Modellierung solcher Phasengleichgewichte bilden. 


\section{Literaturverzeichnis}

[1] Scopes R. K., Protein purification: Principles and Practice, 3. Edition, New York, Springer Verlag, 1994

[2] Grigsby J. J., Blanch H. W., Prausnitz J. M., Cloud-point temperatures for lysozyme in electrolyte solutions: effect of salt type, salt concentration and $\mathrm{pH}$. Biophys. Chem. 91 (2001) 231-243

[3] Broide M. L., Berland C. R. Pande J., Ogun O., and Benedek G. B., Binary-liquid phase separation of lens protein solutions. Proc. Natl. Acad. Sci. 88 (1991) 5660-5664

[4] Berland C. R., Thurston G. M., Kondo M., Broide M. L., Pande J., Ogun O., and Benedek G. B., Solid-liquid phase boundaries of lens protein solutions. Proc. Natl. Acad. Sci. 89 (1992) 1214-1218

[5] Broide M. L., Tominc T. M., Saxowsky M. D., Using phase transitions to investigate the effect of salts on protein interactions. Phys. Rev. E 53 (1996) 6325-6335

[6] Liu C. W., Lomakin A., Thurston G. M., Hayden D., Pande A., Pande J., Ogun O., Asherie N., Benedek G. B., Phase separation in multicomponent aqueous protein solutions. J. Phys. Chem. 99 (1995) 454-461

[7] Muschol M., Rosenberger F., Liquid-liquid phase separation in supersaturated lysozyme solutions an associated precipitate formation/crystallization. J. Chem. Phys. 107 (1997) 1953-1962

[8] Taratuta V.G., Holschbach A., Thurston G. M., Blankschtein D., Benedek G. B., Liquid-liquid phase separation of aqueous lysozyme solutions: effect of $\mathrm{pH}$ and salt identity. J. Phys. Chem. 94 (1990) 2140-2144

[9] Foster P. R., Dunnill P., Lilly M. D., Salting-out of enzymes with ammonium sulfate. Biotech. Bioeng. 13 (1971) 713-718

[10] Shih Y. C., Prausnitz J. M., Blanch H. W., Some characteristics of protein precipitation by salts. Biotech. Bioeng. 40 (1992) 1155-1164

[11] Shiau K.-S., Chen T.-L., Initial protein concentration effects on precipitation by salt. Biotech. Bioeng. 53 (1997) 202-206

[12] Coen C. J., Blanch H. W., Prausnitz, J. M., Salting out of aqueous proteins: phase equilibrium and intermolecular potentials. AICHE J. 41 (1995) 996-1004

[13] Coen C. J., Prausnitz J. M., Blanch H. W., Protein salting-out: phase equilibrium in two-protein systems. Biotech. Bioeng. 53 (1997) 567-574 
[14] Qasim M. A., Salahuddin A., Sibghatullah, Solubility of serum albumins in ammonium sulfate solution with special reference to its dependence on protein conformation. Indian J. Biochem. Biophys. 18 (1981) 15-21

[15] Ducruix A. F., Ries-Kautt M. M., Solubility diagram analysis and the relative effectiveness of different ions on protein crystal growth. Methods: A companion to Methods in Enzymology, 1 (1990) 25-30

[16] Rosenberger F., Protein crystallisazion. J. Cryst. Growth, 166 (1996) 40-54

[17] Rosenberger F., Vekilov P. G., Muschol M., Thomas B. R., Nucleation and crystallization of globular proteins - What we know and what is missing. J. Cryst. Growth, 168 (1996) 1-27

[18] Durbin S. D., Feher G., Protein crystallization. Ann. Rev. Phys. Chem. 47 (1996) $171-204$

[19] Moretti J. J., Sandler S. I., Lenhoff A. M., Phase equilibria in the lysozymeammonium sulfate-water system. Biotech. Bioeng. 70 (2000) 498-506

[20] Asherie N., Protein crystallization and phase diagrams. Methods 34 (2004) 266-272

[21] Prausnitz J. M., Molecular thermodynamics for some applications in biotechnology. Pure and Applied Chem. 75 (2003) 859-873

[22] Melander W., Horvath C., Salt effects on hydrophobic interactions in precipitation and chromatography of proteins - interpretation of lyotropic series. Arch. Biochem. Biophys. 183 (1977) 200-215

[23] Tanford C., Wagner M. L., Hydrogen ion equilibria of lysozyme. J. Am. Chem. Soc. 76 (1954) 3331-3336

[24] Retailleau P., Ries-Kautt M. M., Ducruix A. F., No salting-in of lysozyme chloride observed at high ionic strength over a large range of pH. Biophys. J. 73 (1997) 21562163

[25] Timasheff S. N., Lee J. C., Pittz E. P., Tweedy N., Interactions of tubulin and other proteins with structure-stabilizing solvents. J. Coll. Interf. Sci. 55 (1976) 658-663

[26] Arakawa T., Timasheff S. N., Preferential interactions of proteins with salts in concentrated solutions. Biochemistry 21 (1982) 6545-6552

[27] Arakawa T., Timasheff S. N., Mechanism of protein salting-in and salting-out by divalent cation salts: balance between hydration and salt binding. Biochemistry 23 (1984), 5912-5923

[28] Arakawa T., Timasheff S. N., Abnormal solubility behavior of $\beta$ - lactoglobulin: Salting-in by glycine and NaCl. Biochemistry 26 (1987) 5147-5163 
[29] Timasheff S. N., Arakawa T., Mechanism of protein precipitation and stabilization by co-solvents. J. Cryst. Growth 90 (1988) 39-46

[30] Hofmeister F., Zur Lehre von der Wirkung der Salze. II. Arch. Exp. Pathol. Pharmakol. 24 (1888) 247-260

[31] Collins K. D., Washabaugh M. W., The Hofmeister effect and the behavior of water at interfaces. Quart. Rev. Biophys. 18 (1985) 323-422

[32] Cacace M. G., Landau E. M., Ramsden J. J., The Hofmeister series: salt and solvent effects on interfacial phenomena. Quart. Rev. Biophys. 30 (1997) 241-277

[33] Cohn E. J., Edsall J. T., Proteins, amino acids and peptides. Reinhold, New York, 1943

[34] Howard S. B., Twigg P. J., Baird J. K., Meehan E. J., The solubility of hen egg-white lysozyme. J. Cryst. Growth 90 (1988) 94-104

[35] Carter C. W., Efficient Factorial Designs and the Analysis of Macromolecular Crystal Growth Conditions. Methods: A Companion to Methods in Enzymology, 1 (1990) $12-24$

[36] Ducruix A. F., Giege R., Crystallization of Nucleic Acids and Proteins: A practical approach, Oxford: IRL/Oxford University Press, 1991

[37] Wyckoff H. W., Hirs C. H. W., Timascheff S. N. (eds.), Methods in Enzymology 114, Diffraction Methods for Biological Macromolecules: Part A, New York: Academic, 1985

[38] Blundell T. L., Johnson L. N., Protein crystallography. New York, Academic, 1976

[39] McPherson A., The Preparation and Analysis of Protein Crystals. New York, Wiley, 1982

[40] Hünefeld F. L., Der Chemismus in den tierischen Organismen. Leipzig, Brockhaus, 1840

[41] McPherson A., A brief history of protein crystal growth. J. Cryst. Growth 110 (1991) $1-10$

[42] Gilliland G. L., The Biological Macromolecule Crystallization Database. Methods in Enzymology 277 (1997) 546-556

[43] Chernov A. A., Komatsu H., in: Science and Technology of Crystal Growth, Eds. J. P. van der Eerden and O.S.L. Bruinsma, Kluwer, Dordrecht (1995) 329-353

[44] Frey M., Water-structure associated with proteins and its role in crystallization. Acta Cryst. D 50 (1994) 663-666 
[45] Salunke D., Veerapandian R., Vijayan M., Water-Mediated Transformation in Protein crystals. Acta Cryst. B41 (1985) 431-436

[46] Schoenborn B. P., Solvent effect in protein crystals. A neutron diffraction analysis of solvent and ion density. J. Mol. Biol. 201 (1988) 741-749

[47] Carugo O., Bordo D., How many water molecules can be detected by protein crystallography? Acta Cryst. D55(1999) 479-483

[48] Ataka M., Tanaka S., The growth of large single crystals of lysozyme. Biopolymers 25 (1986) 337-350

[49] Ries-Kautt M. M., Ducruix A. F., Vandorsselaer A., Crystallization of previously desalted lysozyme in the presence of sulfate ions. Acta Cryst. D50 (1994) 366-369

[50] Guillotea J. P., Ries-Kautt M. M., Ducruix A. F. Variation of lysozyme solubility as a function of temperature in the presence of organic and inorganic salts. J. Cryst. Growth 122 (1992) 223-230

[51] Forsythe E. L., Snell E. H., Malone C. C, Pusey M. L., Crystallization of chicken egg white lysozyme from assorted sulfate salts. J. Cryst. Growth 196 (1999) 332-343

[52] Judge R. A., Johns M. R., White E. T., Protein purification by bulk crystallization: The Recovery of ovalbumin, Biotech. Bioeng. 48 (1995) 316-323

[53] Cacioppo E. and Pusey M. L., The Solubility of the tetragonal form of hen egg white lysozyme from pH 4.0 to 5.4. J. Crystal Growth 114 (1992) 286-292.

[54] Ewing F., Forsythe E., Pusey M. L., Orthorhombic lysozyme solubility. Acta Cryst. D50 (1994) 424-428

[55] Forsythe E., Snell E. H., and Pusey M. L, Crystallisation of chicken egg white lysozyme from ammonium sulfate. Acta Cryst., D53 (1997) 795-797

[56] Forsythe E. L, Judge R. A, Pusey M. L., Tetragonal chicken egg white lysozyme solubility in sodium chloride solutions. J. Chem. Eng. Data 44 (1999) 637-640

[57] Broutin I., Ries-Kautt M. M., Ducruix A. F., Lysozyme solubility in $\mathrm{H}_{2} \mathrm{O}$ and $\mathrm{D}_{2} \mathrm{O}$ solutions as a function of sodium chloride. J. Appl. Cryst. 28 (1995) 614-617

[58] Ries-Kautt M. M., Ducruix A. F., Relative effectiveness of various ions on the solubility and crystal growth of lysozyme. J. Biol. Chem., 264(1989) 745-748

[59] Green A. A., Studies on the physical chemistry of proteins. VIII. The solubility of hemoglobin in concentrated salt solutions. A study of the salting out of proteins. J. Biol. Chem. 93 (1931) 495-516 
[60] Green A. A., Studies in the physical chemistry of the proteins. X. The solubility of hemoglobin in solutions of chlorides and sulfates of varying concentrations. J. Biol. Chem. 95 (1932) 47-66

[61] Judge R. A., Johns M. R., White E. T., Solubility of ovalbumin in ammonium sulfate solutions. J. Chem. Eng. Data 41 (1996) 422-424

[62] DeMattei R. C., Feigelson R. S., The solubility dependence of canavalin on $\mathrm{pH}$ and temperature. J. Cryst. Growth, 110 (1991) 34-40

[63] Foltmann B., Studies on rennin. III. Solubility of rennin. Acta Chem. Scand. 13 (1959) 1936-42

[64] Carbonnaux C., Ries-Kautt M. M., Ducruix A. F., Relative effectiveness of various anions on the solubility of acidic Hypoderma lineatum collagenase at pH 7.2. Protein Science 4 (1995) 2123-2128

[65] Mikol V., Giege R., Phase diagram of a crystalline protein: Determination of the solubility of concanavalin A by a microquantitation assay. J. Cryst. Growth 97 (1989) 324-332

[66] Lafont S., Veesler S., Astier J. P., Boistelle R., Solubility and prenucleation of aprotinin (BPTI) molecules in sodium chloride solutions. J. Cryst. Growth 143 (1994) $249-55$

[67] Vaney M. C., Broutin I., Retailleau P., Douangamath A., Lafont S., Hamiaux C., Prange T., Ducruix A. F., Ries-Kautt M. M., Structural effects of monovalent anions on polymorphic lysozyme crystals. Acta Cryst. D57 (2001) 929-940

[68] Ishimoto C., Tanaka T., Critical behavior of a binary mixture of protein and saltwater. Phys. Rev. Lett. 39 (1977) 474-477

[69] Kuznetsov Y. G., Malkin A. J., McPherson A., The liquid protein phase in crystallization: a case study - intact immunoglobulins. J. Cryst. Growth 232 (2001) $30-39$

[70] Vilker V. L., Colton C. K., Smith K. A., The osmotic pressure of concentrated protein solutions - effect of concentration and $\mathrm{pH}$ in saline solutions of bovine serum albumin. J. Coll. Int. Sci. 79 (1981) 548-566

[71] Haynes C. A., Tamura K., Korfer H. R., Blanch H. W., Prausnitz J. M., Thermodynamic properties of aqueous alpha-chymotrypsin solutions from membrane osmometry measurements. J. Phys. Chem. 96 (1992) 905-912

[72] Lomakin A., Asherie N., Benedek G. B., Monte Carlo study of phase separation in aqueous protein solutions. J. Chem. Phys. 104 (1996) 1646-1656 
[73] ten Wolde P. R., Frenkel D., Enhancement of protein crystal nucleation by critical density fluctuations. Science 77 (1997) 1975-1977

[74] Lutsko J. F., Nicolis G., The effect of the range of interaction on the phase diagram of a globular protein - art. no. 244907. J. Chem. Phys. 122 (2005) 244907-1-8

[75] Pagan D. L., Gracheva M. E., Gunton J. D., A finite-size scaling study of a model of globular proteins. J. Chem. Phys. 120 (2004) 8292-8298

[76] Thomson J. A., Schurtenberger P., Thurston G. M., Benedek G. B., Binary liquid phase separation and critical phenomena in a protein water solution. Proc. Nat. Acad. Sci. 84 (1987) 7079-7083

[77] ten Wolde P. R., Frenkel D., Enhanced protein crystallization around the metastable critical point, Theor. Chem. Acc. 101 (1999) 205-208

[78] Rosenbaum D., Zamora P. C., Zukoski C. F., Phase behavior of small attractive colloidal particles. Phys. Rev. Lett. 76 (1996) 150-153

[79] Verwey E. J. W., Overbeek J. T. G., Theory of the stability of lyophobic colloids, Elsevier, Amsterdam, 1948

[80] McMillan W. G., Mayer J. E., The statistical thermodynamics of multicomponent systems. J. Chem. Phys. 13 (1945) 276

[81] Muschol M., Rosenberger F., Interactions in undersaturated and supersaturated lysozyme solutions: Static and dynamic light scattering results. J. Chem. Phys. 103 (1995) 10424-10432

[82] Grimson M. J., Small-angle scattering from colloidal dispersions. J. Chem. Soc.Farad. Trans. II 79 (1983) 817-832

[83] Tombs M. P., Newsom B. G., Wilding P., Protein solubility - phase separation in arachnin-salt-water systems. Int. J. Pept. Protein Res. 6 (1974) 253-277

[84] George A., Chiang Y., Guo B., Arabshani A., Cai Z., Wilson W. W., Second virial coefficient as predictor in protein crystal growth. Methods in Enzymology, 276 (1997) 100-110

[85] Bonnete F., Finet S., Tardieu A., Second virial coefficient: variations with lysozyme crystallization conditions. J. Cryst. Growth 196 (1999) 403-414

[86] Guo B., Kao S., McDonald H., Asanov A., Combs L. L., Wilson W. W., Correlation of second virial coefficients and solubilities useful in protein crystal growth. J. Cryst. Growth 196 (1999) 424-433 
[87] Hitscherich C., Kaplan J., Allaman M., Wiencek J., Loll P. J., Static light scattering studies of OmpF porin: Implications for integral membrane protein crystallization. Protein Sci. 9 (2000) 1559-1566

[88] Tavares F. W., Sandler S. I., Phase equilibria for the mean force potential of globular protein solutions. AICHE J. 43 (1997) 218-231

[89] Wu J. Z., Prausnitz J. M., Osmotic pressures of aqueous bovine serum albumin solutions at high ionic strength. Fluid Phase Equil. 155 (1999) 139-154

[90] Hino T., Prausnitz J. M., Solid-liquid equilibria for solutions of binary globular protein mixtures. AICHE J. 45 (1999) 622-632

[91] Rabinovich W. A., Havin Z. Y., Kratkij himicheskij spravochnik, Izd. "Himiya”, Sankt-Peterburg, 1994

[92] Elysee-Collen B., Lencki R. W., Effect of ethanol, ammonium sulfate, fatty acids, and temperature on the solution behavior of Bovin Serum Albumin. Biotechnol. Prog. 13 (1997) 849-856

[93] Elysee-Collen B., Lencki R. W., Protein ternary phase diagrams. 2. Effect of ethanol, ammonium sulfate, and temperature on the phase behavior of (S)-ovalbumin. J. Agric. Food Chem. 44 (1996) 1658-1663

[94] Landolt H., Börnstein R., Roth W. A., Physikalisch-chemische Tabellen, Springer Verlag, Berlin, 1923

[95] Steinrauf L. K., Preliminary X-ray data for new some crystalline forms of Blactoglobulin and hen egg-white Lysozyme. Acta Cryst. 12 (1959) 77

[96] Cheng Y.-C., Lobo R. F., Sandler S. I., Lenhoff A. M., Kinetics and equilibria of lysozyme precipitation and crystallization in concentrated ammonium sulfate solutions. Biotech. Bioeng. 94 (2006) 177-188

[97] Miller M., Weinstein J. N., Wlodawers A., Preliminary X-ray Analysis of Single Crystals of Ovalbumin and Plakalbumin, J. Biol. Chem. 258 (1983) 5864-5866

[98] Bloomfield V., The structure of bovine serum albumin at low pH. Biochemistry 5 (1966) 684-689

[99] Cunningham L., Molecular-kinetic properties of crystalline diisopropyl Phosphoryl Trypsin. J. Biol. Chem. 13 (1954) 211

[100] Watanabe Otah E., Dissertation an der Universidade Estadual de Campinas UNICAMP, Campinas / Brasilien, in Vorbereitung 


\section{Anhang}

\section{A Versuchsapparatur}

Zur Durchführung der Experimente wurden die folgenden Geräte verwendet:

- Thermostatisierbarer Doppelmantelbehälter aus Kupfer (Eigenbau, Prinzipskizze s. Abbildung A.1)

- Tischzentrifuge (Fa. Heraeus Sepatech, Osterode, Model Labofuge A)

- Analysewaage (Fa. Mettler Toledo, Gießen, Model AG 204)

- Kryostate (Fa. Julabo, Seelbach, Model MP F25 und HC F10)

- Karl-Fischer Titration - Gerät (Fa. Metrohm, Model 701 KF Titrino mit 703 TiStand)

- Gefriertrockner (Fa. Amsco/Finn-Aqua, Hürth, Typ Lyovac GT2)

- Muffelofen (Fa. Heraeus, Berlin, Model T16A)

- $\quad$ H-Meter (Fa. WTW, Weilheim, Model pMX 3000)

- UV/VIS Spektrophotometer (Fa. Hewlett Packard, Palo Alto, USA, Model 8452A)

- Rasterelektronenmikroskop (Fa. JEOL, Eching, Deutschland, Modell JSM-6400F)

- Ionenchromatograph (Abb. A.3) und Analysenbedingungen:

1) Eluent: 18,5 g Borsäure, 0,249 g Phthalsäure und 0,171 g Tris(hydroxymethyl)aminomethan pro $1 l$ Chromatographie-Wasser

2) Entgaser (Fa. ERC, Tokio, Japan, Model ERC-3315)

3) HPLC-Pumpe (Fa. Shimadzu, Duisburg, Model LP-6A), Eluentflussrate 0,7$0,8 \mathrm{ml} / \mathrm{min}$

4) Autoinjektor (Fa. Shimadzu, Duisburg, Model SIL-10AD $D_{\mathrm{VP}}$ ), Probenvolumen $0,5-10 \mu l$

5) Säulenofen (Fa. Shimadzu, Duisburg, Model HIC-6A), $\mathrm{t}=40^{\circ} \mathrm{C}$

6) Leitfähigkeitsdetektor (Fa. Shimadzu, Duisburg, Model CDD-6A)

7) Integrator (Fa. Shimadzu, Duisburg, Model CR-6A) 


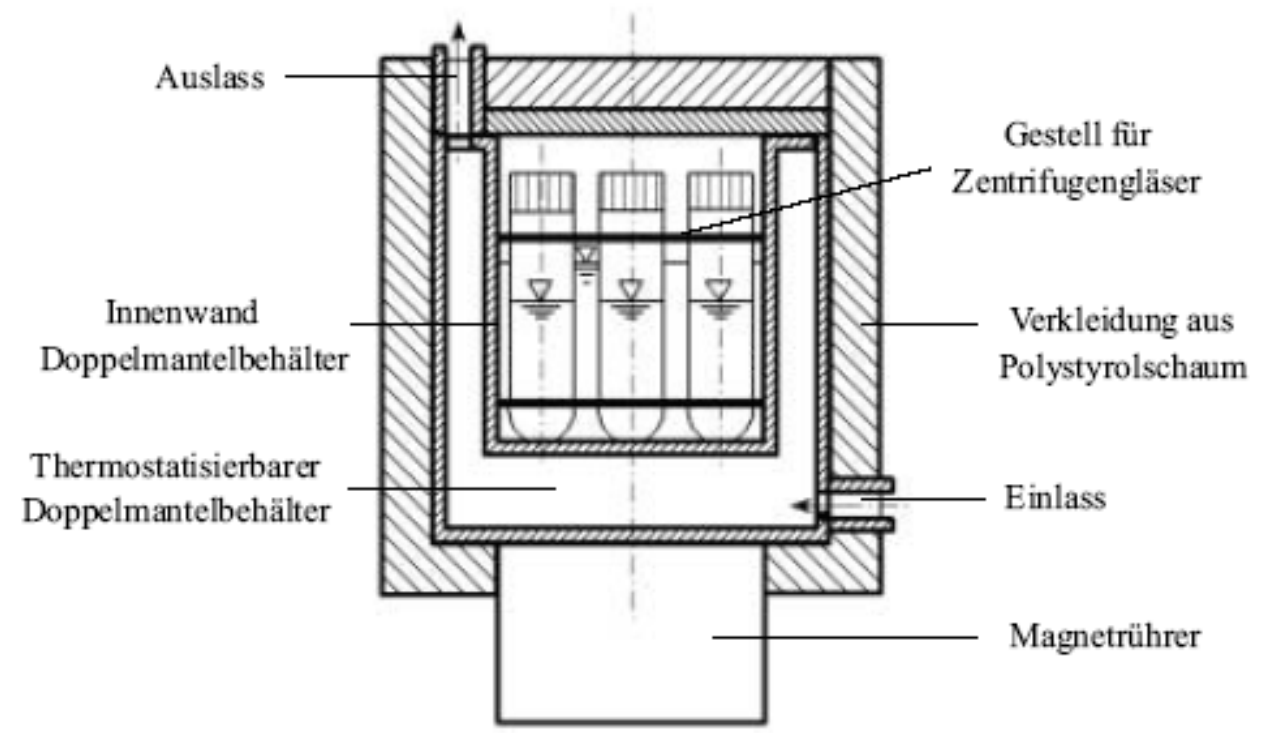

Abb. A.1 Doppelmantelbehälter zum Thermostatisieren der Probengläser

Monochromator

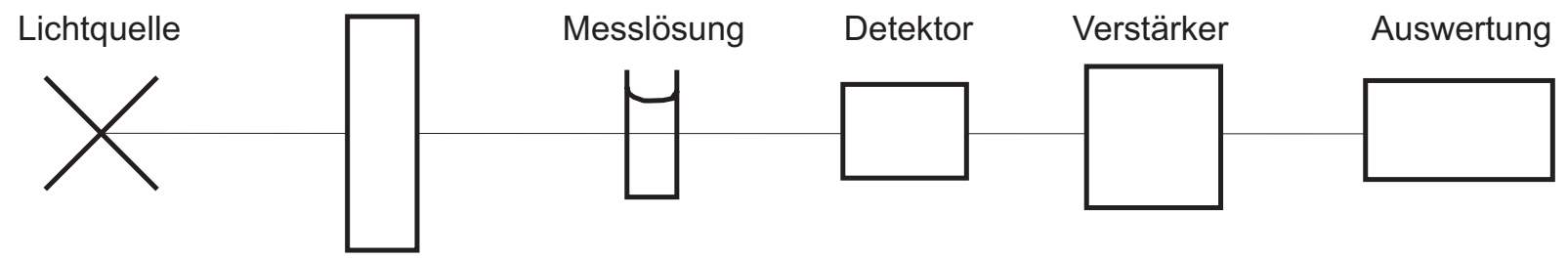

Abb. A.2. Schema eines Einlichtstrahl-Spektrometers

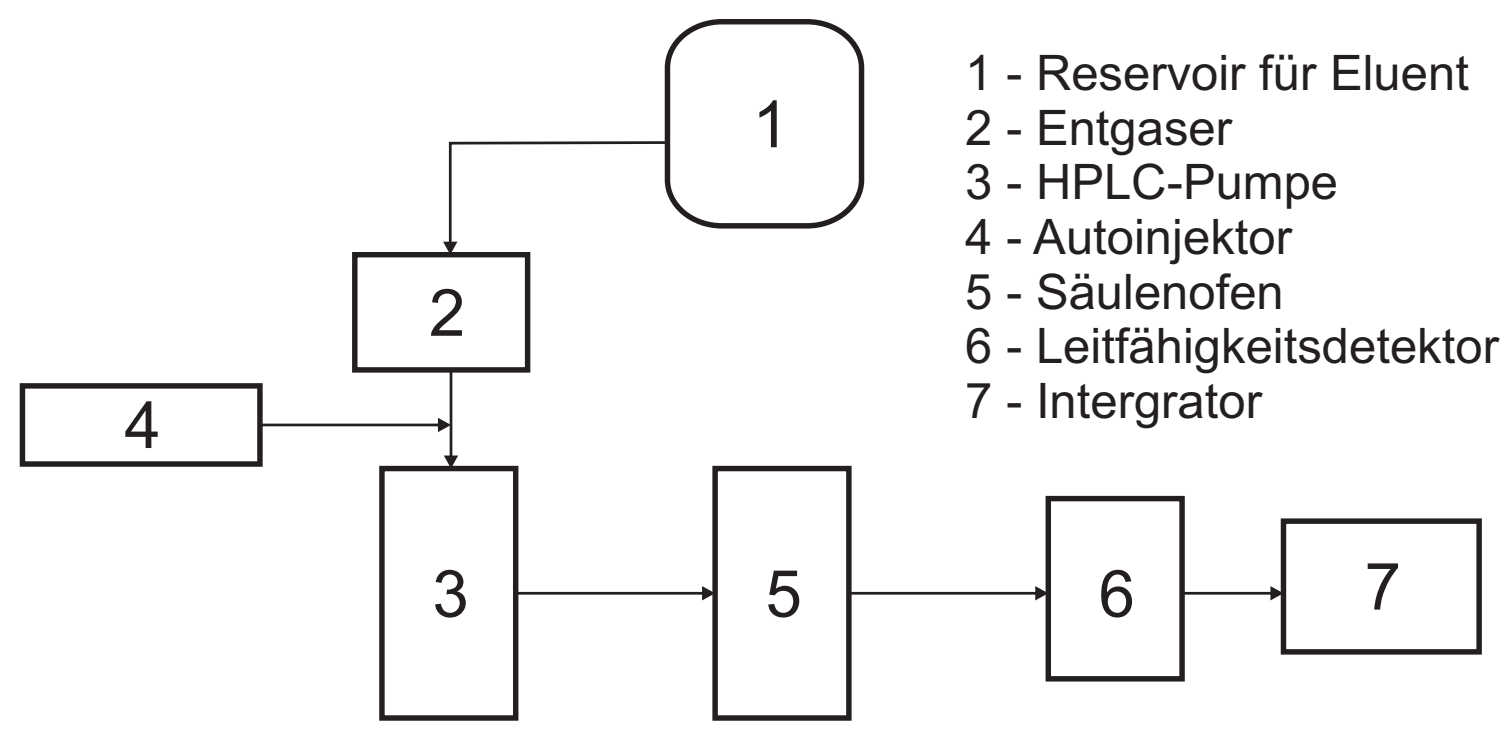

Abb. A.3. Schema einer chromatographischen Anlage zur Bestimmung der Salzkonzentration 


\section{B Ergebnisse der experimentellen Untersuchungen zur Bestimmung der Trübungskurven}

In den folgenden Tabellen sind die im Rahmen der vorliegenden Arbeit ermittelten Messwerte zusammengestellt. Die Zusammensetzung der einzelnen Trübungspunkte wurde aus den Massen der Protein- und Salzlösungen errechnet (vgl. Abschnitt 3.4.1).

Tabelle B.1 Messwerte für das System Lysozym $+\mathrm{Na}_{2} \mathrm{SO}_{4}+\mathrm{H}_{2} \mathrm{O}$ bei $25^{\circ} \mathrm{C}$

\begin{tabular}{|c|c|c|}
\hline \multicolumn{3}{|c|}{ Lysozym $+\mathrm{Na}_{2} \mathrm{SO}_{4}+\mathrm{H}_{2} \mathrm{O}$} \\
\hline$\xi_{P}$ & $\xi_{S}$ & $\xi_{W}$ \\
\hline 0,0036 & 0,1542 & 0,8422 \\
\hline 0,0037 & 0,1746 & 0,8216 \\
\hline 0,0043 & 0,1653 & 0,8303 \\
\hline 0,0061 & 0,1906 & 0,8033 \\
\hline 0,0074 & 0,1751 & 0,8175 \\
\hline 0,0076 & 0,1511 & 0,8413 \\
\hline 0,0136 & 0,1355 & 0,8509 \\
\hline 0,0139 & 0,1351 & 0,8510 \\
\hline 0,0149 & 0,1172 & 0,8680 \\
\hline 0,0182 & 0,1294 & 0,8524 \\
\hline 0,0238 & 0,1228 & 0,8534 \\
\hline 0,0296 & 0,1153 & 0,8551 \\
\hline 0,0323 & 0,1158 & 0,8520 \\
\hline 0,0327 & 0,1151 & 0,8523 \\
\hline 0,0359 & 0,1116 & 0,8524 \\
\hline 0,0424 & 0,1066 & 0,8510 \\
\hline 0,0504 & 0,0977 & 0,8519 \\
\hline 0,0615 & 0,0949 & 0,8436 \\
\hline 0,0697 & 0,0920 & 0,8383 \\
\hline 0,0828 & 0,0864 & 0,8308 \\
\hline 0,0986 & 0,0836 & 0,8178 \\
\hline 0,1013 & 0,0812 & 0,8176 \\
\hline 0,1172 & 0,0715 & 0,8113 \\
\hline 0,1481 & 0,0549 & 0,7970 \\
\hline
\end{tabular}


Tabelle B.2 Messwerte für das System Lysozym $+\left(\mathrm{NH}_{4}\right)_{2} \mathrm{SO}_{4}+\mathrm{H}_{2} \mathrm{O}$ bei $25^{\circ} \mathrm{C}$

\begin{tabular}{|c|c|c||}
\hline \multicolumn{3}{|c|}{ Lysozym $+\left(\mathrm{NH}_{4}\right)_{2} \mathrm{SO} 4+\mathrm{H}_{2} \mathrm{O}$} \\
\hline \hline$\xi_{P}$ & $\xi_{S}$ & $\xi_{W}$ \\
\hline 0,0009 & 0,3722 & 0,6269 \\
\hline 0,0010 & 0,3224 & 0,6767 \\
\hline 0,0010 & 0,3014 & 0,6975 \\
\hline 0,0016 & 0,2749 & 0,7235 \\
\hline 0,0017 & 0,2437 & 0,7546 \\
\hline 0,0042 & 0,2372 & 0,7586 \\
\hline 0,0065 & 0,2112 & 0,7823 \\
\hline 0,0081 & 0,2075 & 0,7844 \\
\hline 0,0116 & 0,2140 & 0,7744 \\
\hline 0,0122 & 0,1763 & 0,8115 \\
\hline 0,0202 & 0,1819 & 0,7980 \\
\hline 0,0360 & 0,1681 & 0,7959 \\
\hline 0,0475 & 0,1613 & 0,7912 \\
\hline 0,0610 & 0,1557 & 0,7832 \\
\hline 0,0759 & 0,1486 & 0,7755 \\
\hline 0,0866 & 0,1545 & 0,7589 \\
\hline 0,0883 & 0,1475 & 0,7642 \\
\hline
\end{tabular}


Tabelle B.3 Messwerte für das System Lysozym $+\mathrm{NH}_{2} \mathrm{COONH}_{4}+\mathrm{H}_{2} \mathrm{O}$ bei $25^{\circ} \mathrm{C}$

\begin{tabular}{|c|c|c|}
\hline \multicolumn{3}{|c|}{ Lysozym $+\mathrm{NH}_{2} \mathrm{COONH}_{4}+\mathrm{H}_{2} \mathrm{O}$} \\
\hline$\xi_{P}$ & $\xi_{S}$ & $\bar{\xi}_{W}$ \\
\hline 0,0018 & 0,2882 & 0,7100 \\
\hline 0,0030 & 0,2482 & 0,7489 \\
\hline 0,0036 & 0,1969 & 0,7996 \\
\hline 0,0078 & 0,1420 & 0,8502 \\
\hline 0,0113 & 0,0930 & 0,8957 \\
\hline 0,0199 & 0,0211 & 0,9590 \\
\hline 0,0226 & 0,0576 & 0,9198 \\
\hline 0,0248 & 0,0116 & 0,9636 \\
\hline 0,0271 & 0,0163 & 0,9566 \\
\hline 0,0491 & 0,0077 & 0,9432 \\
\hline 0,0511 & 0,0125 & 0,9364 \\
\hline 0,0522 & 0,0063 & 0,9415 \\
\hline 0,0532 & 0,0042 & 0,9426 \\
\hline 0,0720 & 0,0049 & 0,9231 \\
\hline 0,0733 & 0,0027 & 0,9239 \\
\hline 0,0836 & 0,0072 & 0,9092 \\
\hline 0,0955 & 0,0024 & 0,9021 \\
\hline 0,0961 & 0,0042 & 0,8997 \\
\hline 0,1481 & 0,0042 & 0,8477 \\
\hline 0,2034 & 0,0035 & 0,7931 \\
\hline
\end{tabular}


Tabelle B.4 Messwerte für das System Lysozym $+\mathrm{NH}_{4} \mathrm{HCO}_{3}+\mathrm{H}_{2} \mathrm{O}$ bei $25{ }^{\circ} \mathrm{C}$

\begin{tabular}{||c|c|c||}
\hline \multicolumn{3}{|c|}{ Lysozym $+\mathrm{NH}_{4} \mathrm{HCO}_{3}+\mathrm{H}_{2} \mathrm{O}$} \\
\hline \hline$\xi_{P}$ & $\xi_{S}$ & $\xi_{W}$ \\
\hline \hline 0,0057 & 0,1063 & 0,8880 \\
\hline 0,0077 & 0,0471 & 0,9452 \\
\hline 0,0082 & 0,0293 & 0,9626 \\
\hline 0,0086 & 0,0810 & 0,9105 \\
\hline 0,0091 & 0,1122 & 0,8787 \\
\hline 0,0098 & 0,0926 & 0,8976 \\
\hline 0,0113 & 0,0562 & 0,9325 \\
\hline 0,0161 & 0,0390 & 0,9449 \\
\hline 0,0172 & 0,0198 & 0,9630 \\
\hline 0,0230 & 0,0143 & 0,9627 \\
\hline 0,0230 & 0,0145 & 0,9624 \\
\hline 0,0328 & 0,0171 & 0,9501 \\
\hline 0,0418 & 0,0068 & 0,9514 \\
\hline 0,0456 & 0,0100 & 0,9444 \\
\hline 0,0683 & 0,0056 & 0,9261 \\
\hline 0,0683 & 0,0108 & 0,9208 \\
\hline 0,0909 & 0,0038 & 0,9053 \\
\hline 0,0981 & 0,0063 & 0,8957 \\
\hline 0,1175 & 0,0059 & 0,8766 \\
\hline
\end{tabular}


Tabelle B.5 Messwerte für das System BSA $+\mathrm{Na}_{2} \mathrm{SO}_{4}+\mathrm{H}_{2} \mathrm{O}$ bei $25^{\circ} \mathrm{C}$

\begin{tabular}{|c|c|c||}
\hline \multicolumn{3}{|c|}{$\mathrm{BSA}+\mathrm{Na}_{2} \mathrm{SO}_{4}+\mathrm{H}_{2} \mathrm{O}$} \\
\hline \hline$\xi_{P}$ & $\xi_{S}$ & $\xi_{W}$ \\
\hline \hline 0,0058 & 0,3111 & 0,6831 \\
\hline 0,0063 & 0,2866 & 0,7071 \\
\hline 0,0075 & 0,2499 & 0,7426 \\
\hline 0,0137 & 0,2273 & 0,7590 \\
\hline 0,0184 & 0,2215 & 0,7601 \\
\hline 0,0384 & 0,2103 & 0,7513 \\
\hline 0,0400 & 0,2058 & 0,7542 \\
\hline 0,0830 & 0,1765 & 0,7404 \\
\hline 0,1249 & 0,1655 & 0,7095 \\
\hline 0,1258 & 0,1618 & 0,7124 \\
\hline 0,1691 & 0,1551 & 0,6757 \\
\hline 0,1705 & 0,1490 & 0,6805 \\
\hline 0,1708 & 0,1455 & 0,6837 \\
\hline 0,2124 & 0,1494 & 0,6381 \\
\hline 0,2147 & 0,1404 & 0,6449 \\
\hline
\end{tabular}


Tabelle B.6 Messwerte für das System BSA $+\left(\mathrm{NH}_{4}\right)_{2} \mathrm{SO}_{4}+\mathrm{H}_{2} \mathrm{O}$ bei $25{ }^{\circ} \mathrm{C}$

\begin{tabular}{||c|c|c||}
\hline \multicolumn{3}{|c|}{$\mathrm{BSA}+\left(\mathrm{NH}_{4}\right)_{2} \mathrm{SO}_{4}+\mathrm{H}_{2} \mathrm{O}$} \\
\hline \hline$\xi_{P}$ & $\xi_{S}$ & $\xi_{W}$ \\
\hline \hline 0,0012 & 0,3633 & 0,6355 \\
\hline 0,0014 & 0,3901 & 0,6084 \\
\hline 0,0016 & 0,3712 & 0,6272 \\
\hline 0,0016 & 0,3870 & 0,6114 \\
\hline 0,0018 & 0,3964 & 0,6018 \\
\hline 0,0023 & 0,3457 & 0,6520 \\
\hline 0,0023 & 0,3205 & 0,6772 \\
\hline 0,0024 & 0,3464 & 0,6512 \\
\hline 0,0026 & 0,3862 & 0,6292 \\
\hline 0,0038 & 0,3166 & 0,6797 \\
\hline 0,0097 & 0,3078 & 0,6825 \\
\hline 0,0227 & 0,2869 & 0,6904 \\
\hline 0,0287 & 0,2879 & 0,6834 \\
\hline 0,0402 & 0,2712 & 0,6887 \\
\hline 0,0603 & 0,2417 & 0,6981 \\
\hline 0,0607 & 0,2575 & 0,6818 \\
\hline 0,0851 & 0,2403 & 0,6746 \\
\hline 0,1109 & 0,2235 & 0,6656 \\
\hline 0,1414 & 0,2114 & 0,6472 \\
\hline
\end{tabular}


Tabelle B.7 Messwerte für das System Ovalbumin $+\mathrm{Na}_{2} \mathrm{SO}_{4}+\mathrm{H}_{2} \mathrm{O}$ bei $25^{\circ} \mathrm{C}$

\begin{tabular}{|c|c|c|}
\hline \multicolumn{3}{|c|}{ Ovalbumin $+\mathrm{Na}_{2} \mathrm{SO}_{4}+\mathrm{H}_{2} \mathrm{O}$} \\
\hline$\xi_{P}$ & $\xi_{S}$ & $\xi_{W}$ \\
\hline 0,0052 & 0,2396 & 0,7552 \\
\hline 0,0060 & 0,2123 & 0,7817 \\
\hline 0,0066 & 0,1891 & 0,8043 \\
\hline 0,0089 & 0,1597 & 0,8314 \\
\hline 0,0092 & 0,0970 & 0,8938 \\
\hline 0,0101 & 0,1329 & 0,8570 \\
\hline 0,0168 & 0,1054 & 0,8777 \\
\hline 0,0188 & 0,0806 & 0,9005 \\
\hline 0,0486 & 0,0635 & 0,8879 \\
\hline 0,0701 & 0,606 & 0,8692 \\
\hline 0,0708 & 0,0580 & 0,8711 \\
\hline 0,0948 & 0,0568 & 0,8484 \\
\hline 0,0955 & 0,0478 & 0,8567 \\
\hline 0,1095 & 0,0574 & 0,8330 \\
\hline 0,1426 & 0,0500 & 0,8074 \\
\hline 0,1430 & 0,0472 & 0,8098 \\
\hline 0,1644 & 0,0439 & 0,7917 \\
\hline 0,1903 & 0,0471 & 0,7626 \\
\hline 0,2374 & 0,0467 & 0,7159 \\
\hline
\end{tabular}


Tabelle B.8 Messwerte für das System Ovalbumin $+\left(\mathrm{NH}_{4}\right)_{2} \mathrm{SO}_{4}+\mathrm{H}_{2} \mathrm{O}$ bei $25^{\circ} \mathrm{C}$

\begin{tabular}{|c|c|c|}
\hline \multicolumn{3}{|c|}{ Ovalbumin $+\left(\mathrm{NH}_{4}\right)_{2} \mathrm{SO}_{4}+\mathrm{H}_{2} \mathrm{O}$} \\
\hline$\xi_{P}$ & $\xi_{S}$ & $\xi_{W}$ \\
\hline 0,0023 & 0,3963 & 0,6014 \\
\hline 0,0036 & 0,3630 & 0,6334 \\
\hline 0,0042 & 0,3361 & 0,6597 \\
\hline 0,0058 & 0,3295 & 0,6647 \\
\hline 0,0092 & 0,2902 & 0,7006 \\
\hline 0,0130 & 0,2363 & 0,7507 \\
\hline 0,0150 & 0,2664 & 0,7186 \\
\hline 0,0158 & 0,2441 & 0,7401 \\
\hline 0,0224 & 0,1925 & 0,7852 \\
\hline 0,0271 & 0,2068 & 0,7662 \\
\hline 0,0276 & 0,1763 & 0,7961 \\
\hline 0,0309 & 0,1404 & 0,8287 \\
\hline 0,0311 & 0,1583 & 0,8106 \\
\hline 0,0344 & 0,1391 & 0,8265 \\
\hline 0,0424 & 0,1017 & 0,8559 \\
\hline 0,0811 & 0,0815 & 0,8374 \\
\hline 0,0827 & 0,0689 & 0,8484 \\
\hline 0,0937 & 0,0674 & 0,8389 \\
\hline 0,1060 & 0,0613 & 0,8327 \\
\hline 0,1208 & 0,0681 & 0,8110 \\
\hline 0,1276 & 0,0518 & 0,8206 \\
\hline 0,1761 & 0,0509 & 0,7730 \\
\hline 0,1846 & 0,0427 & 0,7727 \\
\hline 0,2225 & 0,0438 & 0,7338 \\
\hline 0,2232 & 0,0385 & 0,7383 \\
\hline
\end{tabular}


Tabelle B.9 Messwerte für das System Trypsin $+\left(\mathrm{NH}_{4}\right)_{2} \mathrm{SO}_{4}+\mathrm{H}_{2} \mathrm{O}$ bei $25^{\circ} \mathrm{C}$

\begin{tabular}{|c|c|c||}
\hline \multicolumn{3}{|c|}{ Trypsin $+\left(\mathrm{NH}_{4}\right)_{2} \mathrm{SO}_{4}+\mathrm{H}_{2} \mathrm{O}$} \\
\hline \hline$\xi_{P}$ & $\xi_{S}$ & $\xi_{W}$ \\
\hline 0,0018 & 0,3947 & 0,6035 \\
\hline 0,0024 & 0,3441 & 0,6535 \\
\hline 0,0036 & 0,2885 & 0,7079 \\
\hline 0,0042 & 0,1910 & 0,8048 \\
\hline 0,0053 & 0,2381 & 0,7566 \\
\hline 0,0144 & 0,1783 & 0,8073 \\
\hline 0,0308 & 0,1617 & 0,8074 \\
\hline 0,0460 & 0,1530 & 0,8010 \\
\hline 0,0682 & 0,1257 & 0,8061 \\
\hline 0,0860 & 0,1295 & 0,7844 \\
\hline 0,1048 & 0,1207 & 0,7745 \\
\hline 0,1276 & 0,1156 & 0,7568 \\
\hline 0,1467 & 0,1070 & 0,7462 \\
\hline 0,1797 & 0,0814 & 0,7390 \\
\hline 0,2179 & 0,0502 & 0,7319 \\
\hline
\end{tabular}




\section{Ergebnisse der Gleichgewichtsmessungen}

In den folgenden Tabellen sind die im Rahmen der vorliegenden Arbeit ermittelten Messwerte zusammengestellt. Die Zusammensetzungen der Feedpunkte wurde aus der Einwaage der Stammlosungen von Protein und Salz errechnet (vgl. Abschnitt 3.5.1). Die proteinarme Phase ist stets als Phase 1 und die proteinreiche Phase als Phase 2 bezeichnet.

Tabelle C.1 Messwerte für das System Lysozym $+\mathrm{Na}_{2} \mathrm{SO}_{4}+\mathrm{H}_{2} \mathrm{O}$ bei $25^{\circ} \mathrm{C}$

\begin{tabular}{||c|c|c||c|c|c||c|c|c||}
\hline \multicolumn{3}{|c||}{ Feedpunkt } & \multicolumn{3}{c||}{ Phase 1 } & \multicolumn{3}{c|}{ Phase 2 } \\
\hline \hline$\xi_{P}$ & $\xi_{S}$ & $\xi_{W}$ & $\xi_{P}$ & $\xi_{S}$ & $\xi_{W}$ & $\xi_{P}$ & $\xi_{S}$ & $\xi_{W}$ \\
\hline \hline 0,1806 & 0,0262 & 0,7932 & 0,0276 & 0,0295 & 0,9428 & 0,4325 & 0,0137 & 0,5539 \\
\hline 0,1184 & 0,0462 & 0,8355 & 0,0213 & 0,0458 & 0,9329 & 0,3773 & 0,0268 & 0,5959 \\
\hline 0,1338 & 0,0665 & 0,7997 & 0,0106 & 0,0715 & 0,9179 & 0,2888 & 0,0643 & 0,6469 \\
\hline 0,1333 & 0,0768 & 0,7899 & 0,0089 & 0,0926 & 0,8986 & 0,3391 & 0,0494 & 0,6116 \\
\hline 0,0253 & 0,1434 & 0,8313 & 0,0014 & 0,1460 & 0,8526 & 0,1775 & 0,1039 & 0,7186 \\
\hline 0,0583 & 0,1573 & 0,7844 & 0,0011 & 0,1769 & 0,8221 & 0,2250 & 0,1212 & 0,6537 \\
\hline 0,0401 & 0,1976 & 0,7623 & 0,00032 & 0,2091 & 0,7905 & 0,0733 & 0,1802 & 0,7406 \\
\hline 0,0387 & 0,2285 & 0,7327 & 0,00007 & 0,2483 & 0,7516 & 0,0715 & 0,2025 & 0,7307 \\
\hline 0,0375 & 0,2516 & 0,7109 & 0,00009 & 0,2841 & 0,7158 & 0,0733 & 0,2454 & 0,6813 \\
\hline 0,0351 & 0,2965 & 0,6683 & 0,00013 & 0,3114 & 0,6884 & 0,0583 & 0,2775 & 0,6600 \\
\hline \hline
\end{tabular}


Tabelle C.2 Messwerte für das System Lysozym $+\left(\mathrm{NH}_{4}\right)_{2} \mathrm{SO}_{4}+\mathrm{H}_{2} \mathrm{O}$ bei $25^{\circ} \mathrm{C}$

\begin{tabular}{||c|c|c||c|c|c||c|c|c||}
\hline \multicolumn{3}{|c||}{ Feedpunkt } & \multicolumn{3}{c||}{ Phase 1 } & \multicolumn{3}{c||}{ Phase 2 } \\
\hline \hline$\xi_{P}$ & $\xi_{S}$ & $\xi_{W}$ & $\xi_{P}$ & $\xi_{S}$ & $\xi_{W}$ & $\xi_{P}$ & $\xi_{S}$ & $\xi_{W}$ \\
\hline \hline 0,1722 & 0,0389 & 0,7889 & 0,1261 & 0,0450 & 0,8289 & 0,4752 & 0,0025 & 0,5224 \\
\hline 0,1750 & 0,0516 & 0,7735 & 0,0216 & 0,0520 & 0,9265 & 0,3581 & 0,0237 & 0,6182 \\
\hline 0,1500 & 0,1017 & 0,7483 & 0,0086 & 0,1255 & 0,8659 & 0,2876 & 0,0878 & 0,6246 \\
\hline 0,1253 & 0,1512 & 0,7235 & 0,0071 & 0,1748 & 0,8181 & 0,2143 & 0,1356 & 0,6501 \\
\hline 0,0674 & 0,1997 & 0,7329 & 0,0056 & 0,2153 & 0,7791 & 0,1366 & 0,1823 & 0,6812 \\
\hline 0,1006 & 0,2007 & 0,6987 & 0,0035 & 0,2321 & 0,7644 & 0,1366 & 0,1893 & 0,6741 \\
\hline 0,0697 & 0,2198 & 0,7105 & 0,0006 & 0,2298 & 0,7696 & 0,1606 & 0,2066 & 0,6328 \\
\hline 0,0752 & 0,2516 & 0,6732 & 0,0007 & 0,2863 & 0,7130 & 0,1198 & 0,2365 & 0,6436 \\
\hline 0,0506 & 0,3009 & 0,6485 & 0,0002 & 0,3219 & 0,6779 & 0,1016 & 0,2784 & 0,6200 \\
\hline \hline
\end{tabular}

Tabelle C.3 Messwerte für das System Lysozym $+\mathrm{NH}_{2} \mathrm{COONH}_{4}+\mathrm{H}_{2} \mathrm{O}$ bei $25^{\circ} \mathrm{C}$

\begin{tabular}{||c|c|c||c|c|c||c|c|c||}
\hline \hline \multicolumn{3}{|c||}{ Feedpunkt } & \multicolumn{3}{c||}{ Phase 1 } & \multicolumn{3}{c||}{ Phase 2 } \\
\hline \hline$\xi_{P}$ & $\xi_{S}$ & $\xi_{W}$ & $\xi_{P}$ & $\xi_{S}$ & $\xi_{W}$ & $\xi_{P}$ & $\xi_{S}$ & $\xi_{W}$ \\
\hline \hline 0,1435 & 0,0087 & 0,8478 & 0,0058 & 0,0092 & 0,9850 & 0,2837 & 0,0082 & 0,7081 \\
\hline 0,1309 & 0,0254 & 0,8437 & 0,0019 & 0,0291 & 0,9690 & 0,2789 & 0,0206 & 0,7005 \\
\hline 0,1162 & 0,0449 & 0,8390 & 0,0016 & 0,0563 & 0,9421 & 0,2828 & 0,270 & 0,6902 \\
\hline 0,1005 & 0,0656 & 0,8339 & 0,0014 & 0,0752 & 0,9234 & 0,2239 & 0,0519 & 0,7242 \\
\hline 0,0832 & 0,0886 & 0,8282 & 0,0014 & 0,0958 & 0,9028 & 0,1730 & 0,0808 & 0,7462 \\
\hline 0,0668 & 0,1103 & 0,8229 & 0,0011 & 0,1217 & 0,8772 & 0,1391 & 0,0948 & 0,7661 \\
\hline 0,0956 & 0,1493 & 0,7551 & 0,0005 & 0,1700 & 0,8295 & 0,1280 & 0,1416 & 0,7304 \\
\hline 0,0336 & 0,1542 & 0,8122 & 0,0006 & 0,1603 & 0,8391 & 0,1183 & 0,1387 & 0,7430 \\
\hline \hline
\end{tabular}


Tabelle C.4 Messwerte für das System Lysozym $+\mathrm{NH}_{4} \mathrm{HCO}_{3}+\mathrm{H}_{2} \mathrm{O}$ bei $25{ }^{\circ} \mathrm{C}$

\begin{tabular}{||c|c|c||c|c|c||c|c|c||}
\hline \multicolumn{3}{|c||}{ Feedpunkt } & \multicolumn{3}{c||}{ Phase 1 } & \multicolumn{3}{c||}{ Phase 2 } \\
\hline \hline$\xi_{P}$ & $\xi_{S}$ & $\xi_{W}$ & $\xi_{P}$ & $\xi_{S}$ & $\xi_{W}$ & $\xi_{P}$ & $\xi_{S}$ & $\xi_{W}$ \\
\hline \hline 0,1616 & 0,0279 & 0,8105 & 0,0111 & 0,0111 & 0,9778 & 0,3037 & 0,0437 & 0,6525 \\
\hline 0,1604 & 0,0287 & 0,8109 & 0,0119 & 0,0152 & 0,9729 & 0,3645 & 0,0471 & 0,5884 \\
\hline 0,1209 & 0,0291 & 0,8500 & 0,0052 & 0,0230 & 0,9717 & 0,2716 & 0,0372 & 0,6912 \\
\hline 0,1209 & 0,0293 & 0,8498 & 0,0061 & 0,0097 & 0,9842 & 0,2647 & 0,0559 & 0,6794 \\
\hline 0,0967 & 0,0534 & 0,8500 & 0,0033 & 0,0383 & 0,9584 & 0,2629 & 0,0812 & 0,6559 \\
\hline 0,1261 & 0,0539 & 0,8201 & 0,0033 & 0,0221 & 0,9747 & 0,2597 & 0,0887 & 0,6516 \\
\hline 0,1080 & 0,0720 & 0,8201 & 0,0030 & 0,0529 & 0,9441 & 0,2622 & 0,0998 & 0,6381 \\
\hline 0,0732 & 0,0769 & 0,8499 & 0,0026 & 0,0628 & 0,9346 & 0,2566 & 0,1143 & 0,6291 \\
\hline 0,0832 & 0,0967 & 0,8201 & 0,0025 & 0,0774 & 0,9202 & 0,2386 & 0,1347 & 0,6267 \\
\hline 0,0494 & 0,1009 & 0,8497 & 0,0019 & 0,0889 & 0,9092 & 0,2357 & 0,1499 & 0,6144 \\
\hline 0,0480 & 0,1020 & 0,8500 & 0,0021 & 0,0922 & 0,9057 & 0,2085 & 0,1390 & 0,6525 \\
\hline 0,0490 & 0,1309 & 0,8201 & 0,0016 & 0,1086 & 0,8898 & 0,2148 & 0,2047 & 0,5804 \\
\hline \hline
\end{tabular}

Tabelle C.5 Messwerte für das System BSA $+\mathrm{Na}_{2} \mathrm{SO}_{4}+\mathrm{H}_{2} \mathrm{O}$ bei $25^{\circ} \mathrm{C}$

\begin{tabular}{||c|c|c||c|c|c||c|c|c||}
\hline \hline \multicolumn{3}{|c||}{ Feedpunkt } & \multicolumn{3}{c||}{ Phase 1 } & \multicolumn{3}{c||}{ Phase 2 } \\
\hline \hline$\xi_{P}$ & $\xi_{S}$ & $\xi_{W}$ & $\xi_{P}$ & $\xi_{S}$ & $\xi_{W}$ & $\xi_{P}$ & $\xi_{S}$ & $\xi_{W}$ \\
\hline \hline 0,1208 & 0,1944 & 0,6848 & 0,0156 & 0,2483 & 0,7361 & 0,1940 & 0,1674 & 0,6387 \\
\hline 0,0961 & 0,2000 & 0,7039 & 0,0975 & 0,1489 & 0,7537 & 0,0928 & 0,2940 & 0,6132 \\
\hline 0,0960 & 0,2000 & 0,7040 & 0,0296 & 0,2300 & 0,7404 & 0,1654 & 0,1745 & 0,6601 \\
\hline 0,1189 & 0,2098 & 0,6713 & 0,0454 & 0,2357 & 0,7189 & 0,1580 & 0,1947 & 0,6472 \\
\hline 0,0756 & 0,2449 & 0,6795 & 0,0003 & 0,2800 & 0,7197 & 0,1497 & 0,2096 & 0,6406 \\
\hline 0,0755 & 0,2455 & 0,6790 & 0,0002 & 0,2601 & 0,7397 & 0,1081 & 0,2378 & 0,6541 \\
\hline 0,0759 & 0,2473 & 0,6768 & 0,0004 & 0,2721 & 0,7275 & 0,1336 & 0,2039 & 0,6625 \\
\hline 0,0549 & 0,2693 & 0,6759 & 0,0002 & 0,2858 & 0,7140 & 0,1223 & 0,2373 & 0,6403 \\
\hline 0,0551 & 0,2693 & 0,6756 & 0,0002 & 0,2947 & 0,7052 & 0,1077 & 0,2401 & 0,6522 \\
\hline 0,0359 & 0,2894 & 0,6747 & 0,0001 & 0,3127 & 0,6872 & 0,0910 & 0,2588 & 0,6502 \\
\hline 0,0342 & 0,2959 & 0,6699 & 0,0002 & 0,3017 & 0,6982 & 0,1030 & 0,2544 & 0,6426 \\
\hline \hline
\end{tabular}


Tabelle C.6 Messwerte für das System BSA $+\left(\mathrm{NH}_{4}\right)_{2} \mathrm{SO}_{4}+\mathrm{H}_{2} \mathrm{O}$ bei $25^{\circ} \mathrm{C}$

\begin{tabular}{||c|c|c||c|c|c||c|c|c||}
\hline \hline \multicolumn{3}{|c||}{ Feedpunkt } & \multicolumn{3}{c||}{ Phase 1 } & \multicolumn{3}{c||}{ Phase 2 } \\
\hline \hline$\xi_{P}$ & $\xi_{S}$ & $\xi_{W}$ & $\xi_{P}$ & $\xi_{S}$ & $\xi_{W}$ & $\xi_{P}$ & $\xi_{S}$ & $\xi_{W}$ \\
\hline \hline 0,1315 & 0,2520 & 0,6166 & 0,0195 & 0,3419 & 0,6386 & 0,2094 & 0,2023 & 0,5883 \\
\hline 0,1501 & 0,2520 & 0,5979 & 0,0061 & 0,2971 & 0,6968 & 0,2014 & 0,2249 & 0,5737 \\
\hline 0,1003 & 0,3022 & 0,5975 & 0,00048 & 0,3325 & 0,6670 & 0,1591 & 0,2715 & 0,5694 \\
\hline 0,0467 & 0,3073 & 0,6459 & 0,0014 & 0,3191 & 0,6796 & 0,1076 & 0,2881 & 0,6043 \\
\hline 0,0622 & 0,3152 & 0,6226 & 0,00024 & 0,3447 & 0,6551 & 0,1130 & 0,2906 & 0,5964 \\
\hline 0,0268 & 0,3472 & 0,6259 & 0,00013 & 0,3568 & 0,6431 & 0,0755 & 0,3251 & 0,5974 \\
\hline 0,0325 & 0,3554 & 0,6121 & 0,00014 & 0,3736 & 0,6263 & 0,0933 & 0,3214 & 0,5853 \\
\hline 0,0309 & 0,3575 & 0,6115 & 0,00017 & 0,3771 & 0,6228 & 0,0976 & 0,3195 & 0,5828 \\
\hline 0,0304 & 0,3593 & 0,6103 & 0,00014 & 0,3792 & 0,6206 & 0,0910 & 0,3207 & 0,5883 \\
\hline 0,0304 & 0,3966 & 0,5730 & 0,00011 & 0,4103 & 0,5896 & 0,0730 & 0,3745 & 0,5525 \\
\hline 0,0304 & 0,3973 & 0,5723 & 0,00019 & 0,4099 & 0,5899 & 0,0717 & 0,3651 & 0,5632 \\
\hline 0,0303 & 0,3974 & 0,5723 & 0,00011 & 0,4030 & 0,5969 & 0,0801 & 0,3529 & 0,5569 \\
\hline \hline
\end{tabular}

Tabelle C.7 Messwerte für das System BSA $+\mathrm{NH}_{2} \mathrm{COONH}_{4}+\mathrm{H}_{2} \mathrm{O}$ bei $25^{\circ} \mathrm{C}$

\begin{tabular}{||c|c|c||c|c|c||c|c|c||}
\hline \hline \multicolumn{3}{|c||}{ Feedpunkt } & \multicolumn{3}{c||}{ Phase 1 } & \multicolumn{3}{c||}{ Phase 2 } \\
\hline \hline$\xi_{P}$ & $\xi_{S}$ & $\xi_{W}$ & $\xi_{P}$ & $\xi_{S}$ & $\xi_{W}$ & $\xi_{P}$ & $\xi_{S}$ & $\xi_{W}$ \\
\hline \hline 0,1315 & 0,2520 & 0,6166 & 0,0195 & 0,3419 & 0,6386 & 0,2094 & 0,2023 & 0,5883 \\
\hline 0,1501 & 0,2520 & 0,5979 & 0,0061 & 0,2971 & 0,6968 & 0,2014 & 0,2249 & 0,5737 \\
\hline 0,1003 & 0,3022 & 0,5975 & 0,00048 & 0,3325 & 0,6670 & 0,1591 & 0,2715 & 0,5694 \\
\hline 0,0304 & 0,3973 & 0,5723 & 0,00019 & 0,4099 & 0,5899 & 0,0717 & 0,3651 & 0,5632 \\
\hline 0,0303 & 0,3974 & 0,5723 & 0,00011 & 0,4030 & 0,5969 & 0,0801 & 0,3529 & 0,5569 \\
\hline
\end{tabular}


Tabelle C.8a Messwerte für das System Ovalbumin $+\mathrm{Na}_{2} \mathrm{SO}_{4}+\mathrm{H}_{2} \mathrm{O}$ bei $25{ }^{\circ} \mathrm{C}$ : Metastabiles Zwei-Phasen-Gleichgewicht

\begin{tabular}{||c|c|c||c|c|c||c|c|c||}
\hline \multicolumn{3}{|c||}{ Feedpunkt } & \multicolumn{3}{c||}{ Phase 1 } & \multicolumn{3}{c||}{ Phase 2 } \\
\hline \hline$\xi_{P}$ & $\xi_{S}$ & $\xi_{W}$ & $\xi_{P}$ & $\xi_{S}$ & $\xi_{W}$ & $\xi_{P}$ & $\xi_{S}$ & $\xi_{W}$ \\
\hline \hline 0,0955 & 0,2335 & 0,6711 & 0,0003 & 0,2514 & 0,7483 & 0,1399 & 0,2067 & 0,6534 \\
\hline 0,0955 & 0,2335 & 0,6709 & 0,0003 & 0,2986 & 0,7012 & 0,1223 & 0,2087 & 0,6689 \\
\hline 0,0956 & 0,2355 & 0,6689 & 0,0002 & 0,2434 & 0,7564 & 0,1836 & 0,2169 & 0,5995 \\
\hline 0,0939 & 0,2382 & 0,6679 & 0,0004 & 0,2523 & 0,7472 & 0,1420 & 0,2193 & 0,6387 \\
\hline 0,0734 & 0,2651 & 0,6615 & 0,0002 & 0,3160 & 0,6838 & 0,1235 & 0,2350 & 0,6414 \\
\hline 0,0729 & 0,2690 & 0,6581 & 0,0003 & 0,2699 & 0,7298 & 0,1408 & 0,2434 & 0,6158 \\
\hline 0,0526 & 0,3001 & 0,6473 & 0,0002 & 0,3408 & 0,6590 & 0,1182 & 0,2638 & 0,6180 \\
\hline 0,0525 & 0,3012 & 0,6464 & 0,0002 & 0,3033 & 0,6965 & 0,1104 & 0,2619 & 0,6277 \\
\hline 0,0330 & 0,3409 & 0,6261 & 0,0003 & 0,3458 & 0,6539 & 0,0940 & 0,3199 & 0,5861 \\
\hline \hline
\end{tabular}

Tabelle C.8b Messwerte für das System Ovalbumin $+\mathrm{Na}_{2} \mathrm{SO}_{4}+\mathrm{H}_{2} \mathrm{O}$ bei $25{ }^{\circ} \mathrm{C}$ : Stabiles Zwei-Phasen-Gleichgewicht

\begin{tabular}{||c|c|c||c|c|c||c|c|c||}
\hline \hline \multicolumn{3}{|c||}{ Feedpunkt } & \multicolumn{3}{c||}{ Phase 1 } & \multicolumn{3}{c||}{ Phase 2 } \\
\hline \hline$\xi_{P}$ & $\xi_{S}$ & $\xi_{W}$ & $\xi_{P}$ & $\xi_{S}$ & $\xi_{W}$ & $\xi_{P}$ & $\xi_{S}$ & $\xi_{W}$ \\
\hline \hline 0,0802 & 0,1963 & 0,7236 & 0,0068 & 0,1998 & 0,7934 & 0,4082 & 0,1036 & 0,4882 \\
\hline 0,1200 & 0,2007 & 0,6794 & 0,0131 & 0,2220 & 0,7650 & 0,2053 & 0,1807 & 0,6216 \\
\hline 0,0412 & 0,2013 & 0,7575 & 0,0067 & 0,2053 & 0,7880 & 0,2376 & 0,1493 & 0,6131 \\
\hline 0,0402 & 0,2053 & 0,7544 & 0,0052 & 0,2018 & 0,7929 & 0,4126 & 0,0915 & 0,4960 \\
\hline 0,0395 & 0,2055 & 0,7550 & 0,0080 & 0,1979 & 0,7941 & 0,3265 & 0,1318 & 0,5416 \\
\hline \hline
\end{tabular}


Tabelle C.8c Messwerte für das System Ovalbumin $+\mathrm{Na}_{2} \mathrm{SO}_{4}+\mathrm{H}_{2} \mathrm{O}$ bei $25{ }^{\circ} \mathrm{C}$ : Stabiles Drei-Phasen-Gleichgewicht

\begin{tabular}{||c|c|c||c|c|c||c|c|c||}
\hline \multicolumn{3}{|c||}{ Feedpunkt } & \multicolumn{3}{c||}{ Phase 1 } & \multicolumn{3}{c||}{ Phase 2+3 } \\
\hline \hline$\xi_{P}$ & $\xi_{S}$ & $\xi_{W}$ & $\xi_{P}$ & $\xi_{S}$ & $\xi_{W}$ & $\xi_{P}$ & $\xi_{S}$ & $\xi_{W}$ \\
\hline \hline 0,0390 & 0,2383 & 0,7226 & 0,0218 & 0,1841 & 0,7941 & 0,0788 & 0,3404 & 0,5808 \\
\hline 0,0570 & 0,2402 & 0,7028 & 0,0117 & 0,2504 & 0,7380 & 0,1319 & 0,2906 & 0,5775 \\
\hline 0,0358 & 0,2793 & 0,6849 & 0,0139 & 0,1892 & 0,7970 & 0,0653 & 0,3642 & 0,5705 \\
\hline 0,0537 & 0,2844 & 0,6620 & 0,0119 & 0,1918 & 0,7963 & 0,0897 & 0,3528 & 0,5575 \\
\hline \hline
\end{tabular}

Tabelle C.9 Messwerte für das System Ovalbumin $+\left(\mathrm{NH}_{4}\right)_{2} \mathrm{SO}_{4}+\mathrm{H}_{2} \mathrm{O}$ bei $25{ }^{\circ} \mathrm{C}$

\begin{tabular}{||c|c|c||c|c|c||c|c|c||}
\hline \hline \multicolumn{3}{|c||}{ Feedpunkt } & \multicolumn{3}{c||}{ Phase 1 } & \multicolumn{3}{c||}{ Phase 2 } \\
\hline \hline$\xi_{P}$ & $\xi_{S}$ & $\xi_{W}$ & $\xi_{P}$ & $\xi_{S}$ & $\xi_{W}$ & $\xi_{P}$ & $\xi_{S}$ & $\xi_{W}$ \\
\hline \hline 0,1508 & 0,2013 & 0,6480 & 0,1013 & 0,2431 & 0,6538 & 0,3641 & 0,0583 & 0,5775 \\
\hline 0,1592 & 0,2033 & 0,6375 & 0,0669 & 0,2421 & 0,6911 & 0,3903 & 0,1100 & 0,4997 \\
\hline 0,0896 & 0,2202 & 0,6902 & 0,0882 & 0,2169 & 0,6949 & 0,0779 & 0,3180 & 0,6042 \\
\hline 0,0620 & 0,2752 & 0,6628 & 0,0026 & 0,2885 & 0,7088 & 0,1347 & 0,2566 & 0,6087 \\
\hline 0,0866 & 0,2906 & 0,6227 & 0,0008 & 0,3286 & 0,6707 & 0,1603 & 0,2596 & 0,5801 \\
\hline 0,0862 & 0,2911 & 0,6226 & 0,0008 & 0,3241 & 0,6752 & 0,1625 & 0,2487 & 0,5887 \\
\hline 0,0512 & 0,3206 & 0,6282 & 0,0002 & 0,3319 & 0,6679 & 0,1396 & 0,2724 & 0,5879 \\
\hline 0,0496 & 0,3226 & 0,6278 & 0,0002 & 0,3470 & 0,6528 & 0,1210 & 0,2885 & 0,5906 \\
\hline 0,0375 & 0,3253 & 0,6373 & 0,0003 & 0,3405 & 0,6592 & 0,1132 & 0,2910 & 0,5958 \\
\hline \hline
\end{tabular}


Tabelle C.10 Messwerte für das System Trypsin $+\left(\mathrm{NH}_{4}\right)_{2} \mathrm{SO}_{4}+\mathrm{H}_{2} \mathrm{O}$ bei $25^{\circ} \mathrm{C}$

\begin{tabular}{|c|c|c||c|c|c||c|c|c||}
\hline \multicolumn{3}{|c||}{ Feedpunkt } & \multicolumn{3}{c||}{ Phase 1 } & \multicolumn{3}{c||}{ Phase 2 } \\
\hline \hline$\xi_{P}$ & $\xi_{S}$ & $\xi_{W}$ & $\xi_{P}$ & $\xi_{S}$ & $\xi_{W}$ & $\xi_{P}$ & $\xi_{S}$ & $\xi_{W}$ \\
\hline \hline 0,1830 & 0,1544 & 0,6626 & 0,1060 & 0,1658 & 0,7282 & 0,8858 & 0,0500 & 0,0643 \\
\hline 0,1494 & 0,1987 & 0,6519 & 0,0224 & 0,2235 & 0,7542 & 0,6396 & 0,1028 & 0,2575 \\
\hline 0,1126 & 0,2472 & 0,6402 & 0,0078 & 0,2787 & 0,7135 & 0,4597 & 0,1429 & 0,3974 \\
\hline 0,0758 & 0,2958 & 0,6284 & 0,0042 & 0,3313 & 0,6645 & 0,3905 & 0,1397 & 0,4698 \\
\hline 0,0948 & 0,2706 & 0,6345 & 0,0053 & 0,3001 & 0,6946 & 0,4884 & 0,1411 & 0,3705 \\
\hline 0,1040 & 0,2585 & 0,6375 & 0,0067 & 0,2859 & 0,7075 & 0,5139 & 0,1435 & 0,3426 \\
\hline \hline
\end{tabular}




\section{Mikroskopische Aufnahmen und Zusammensetzungen der Feedlösungen}

\section{D.1 Lysozym $-\mathrm{Na}_{2} \mathrm{SO}_{4}-\mathrm{H}_{2} \mathrm{O}$}

Tabelle D.1 Zusammensetzung der Feedlösungen für das System Lysozym $-\mathrm{Na}_{2} \mathrm{SO}_{4}-\mathrm{H}_{2} \mathrm{O}$

\begin{tabular}{||c|c|c||c||}
\hline \multicolumn{3}{|c||}{ Feedpunkt } & Abbildung \\
\hline \hline$\xi_{P}$ & $\xi_{S}$ & $\xi_{W}$ & \\
\hline \hline 0,0562 & 0,1385 & 0,8053 & $\mathrm{D} .1$ \\
\hline 0,0563 & 0,1379 & 0,8059 & $\mathrm{D} .2$ \\
\hline 0,1302 & 0,0261 & 0,8437 & $\mathrm{D} .3$ \\
\hline
\end{tabular}
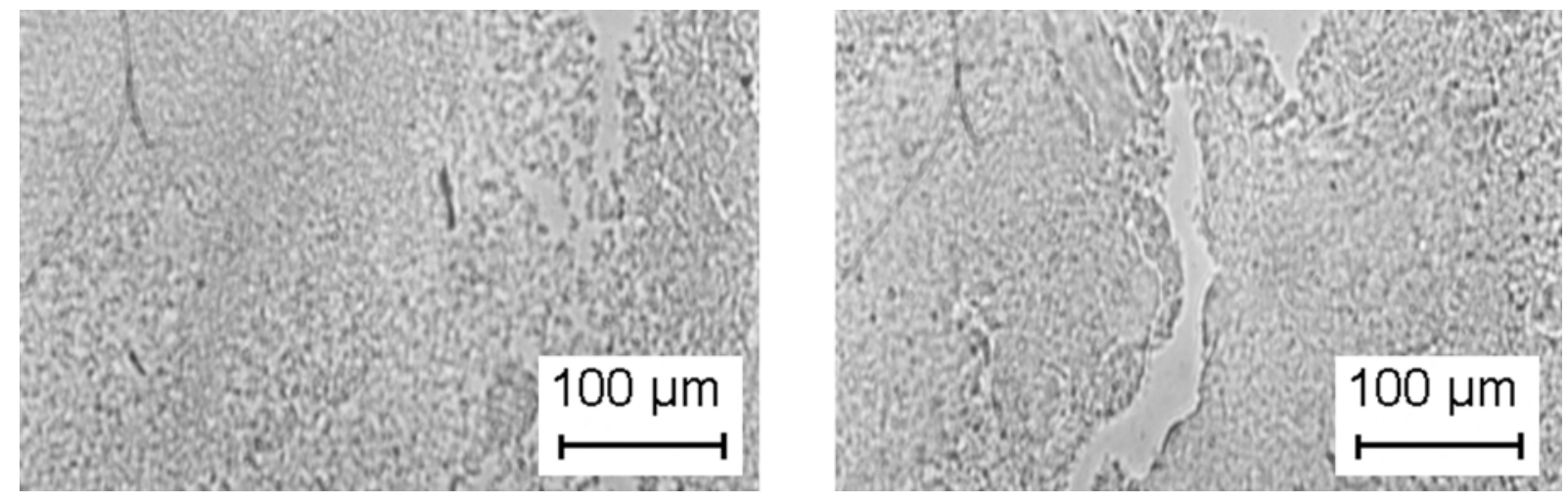

Abb. D.1
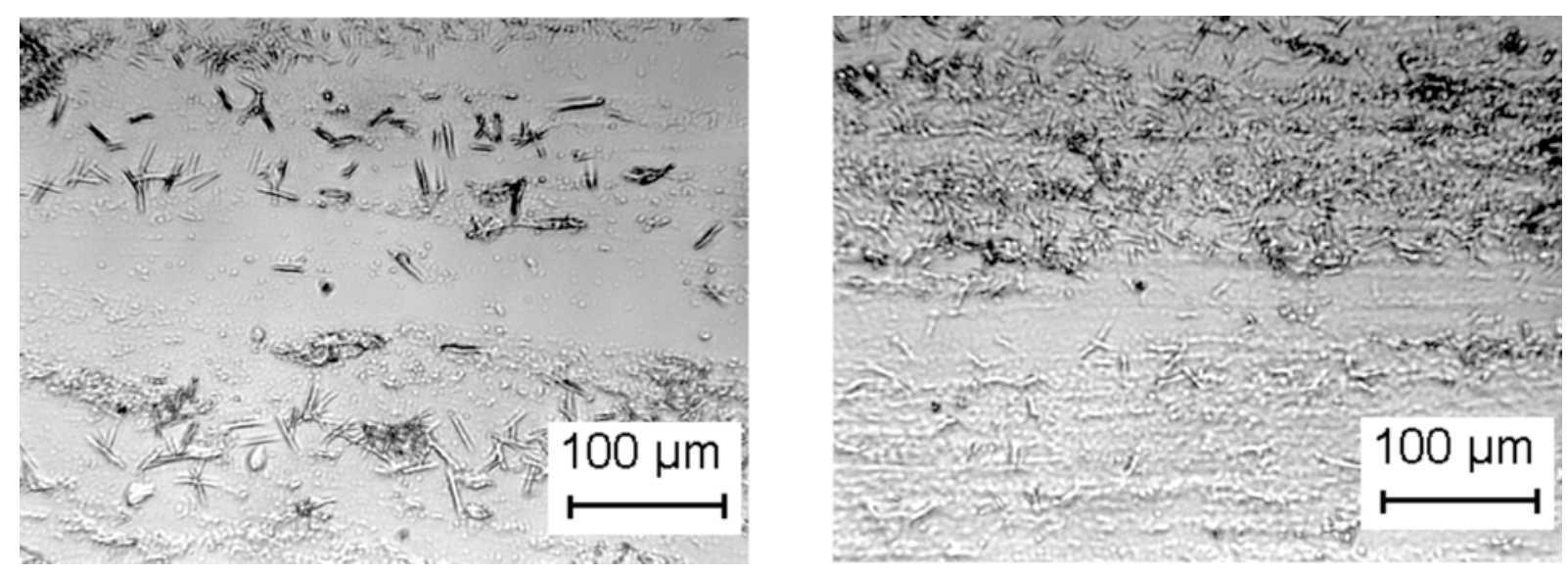

Abb. D.2 

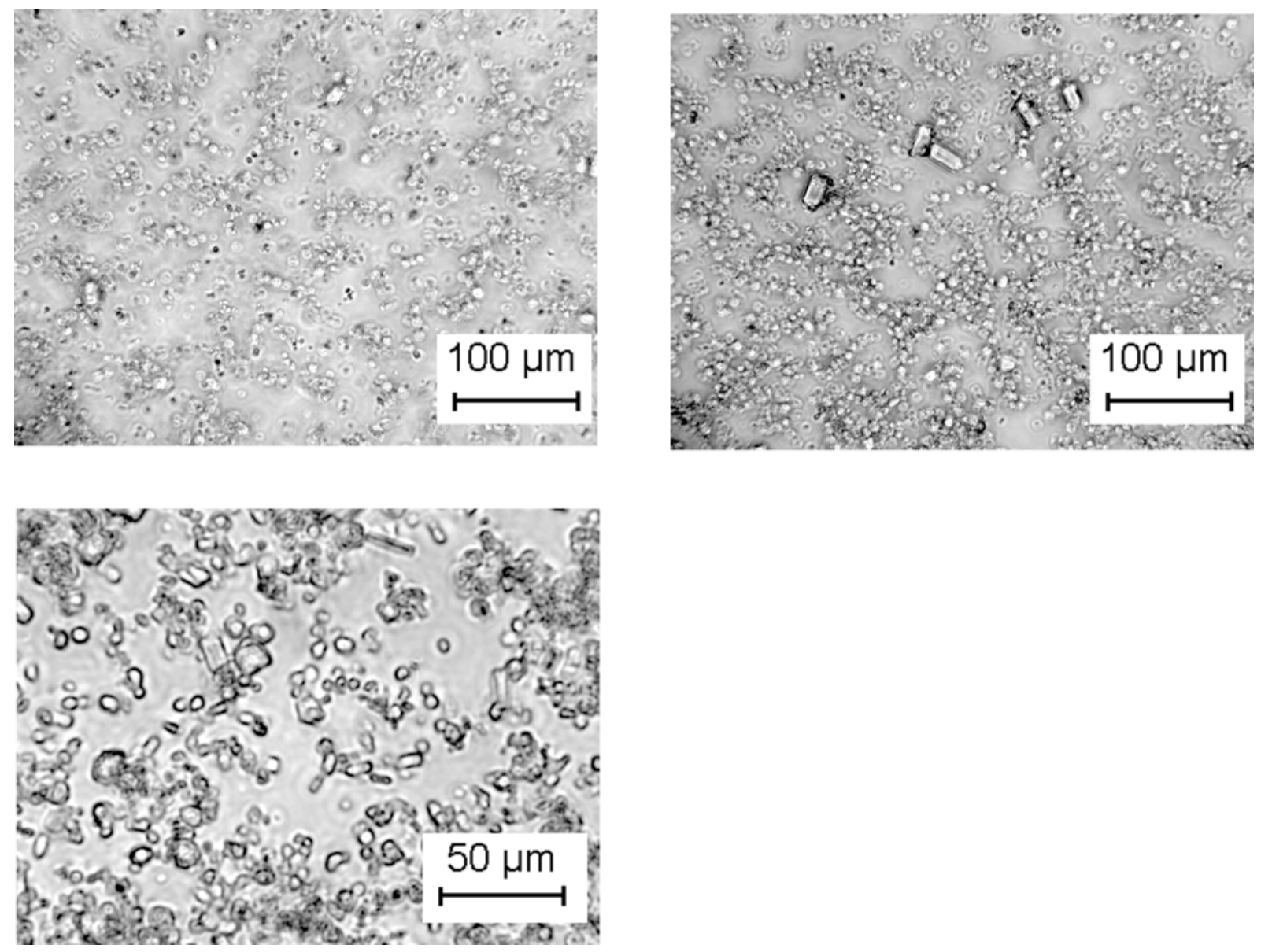

Abb. D.3

\section{D.2 Lysozym - $\left(\mathrm{NH}_{4}\right)_{2} \mathrm{SO}_{4}-\mathrm{H}_{2} \mathrm{O}$}

Tabelle D.2 Zusammensetzung der Feedlösungen für das System Lysozym - $\left(\mathrm{NH}_{4}\right)_{2} \mathrm{SO}_{4}-\mathrm{H}_{2} \mathrm{O}$

\begin{tabular}{||c|c|c||c||}
\hline \multicolumn{3}{|c||}{ Feedpunkt } & Abbildung \\
\hline \hline$\xi_{P}$ & $\xi_{S}$ & $\xi_{W}$ & \\
\hline \hline 0,0563 & 0,2521 & 0,6917 & $\mathrm{D} .4$ \\
\hline 0,0551 & 0,3500 & 0,5949 & $\mathrm{D} .5$ \\
\hline 0,1009 & 0,0280 & 0,8711 & $\mathrm{D} .6$ \\
\hline
\end{tabular}



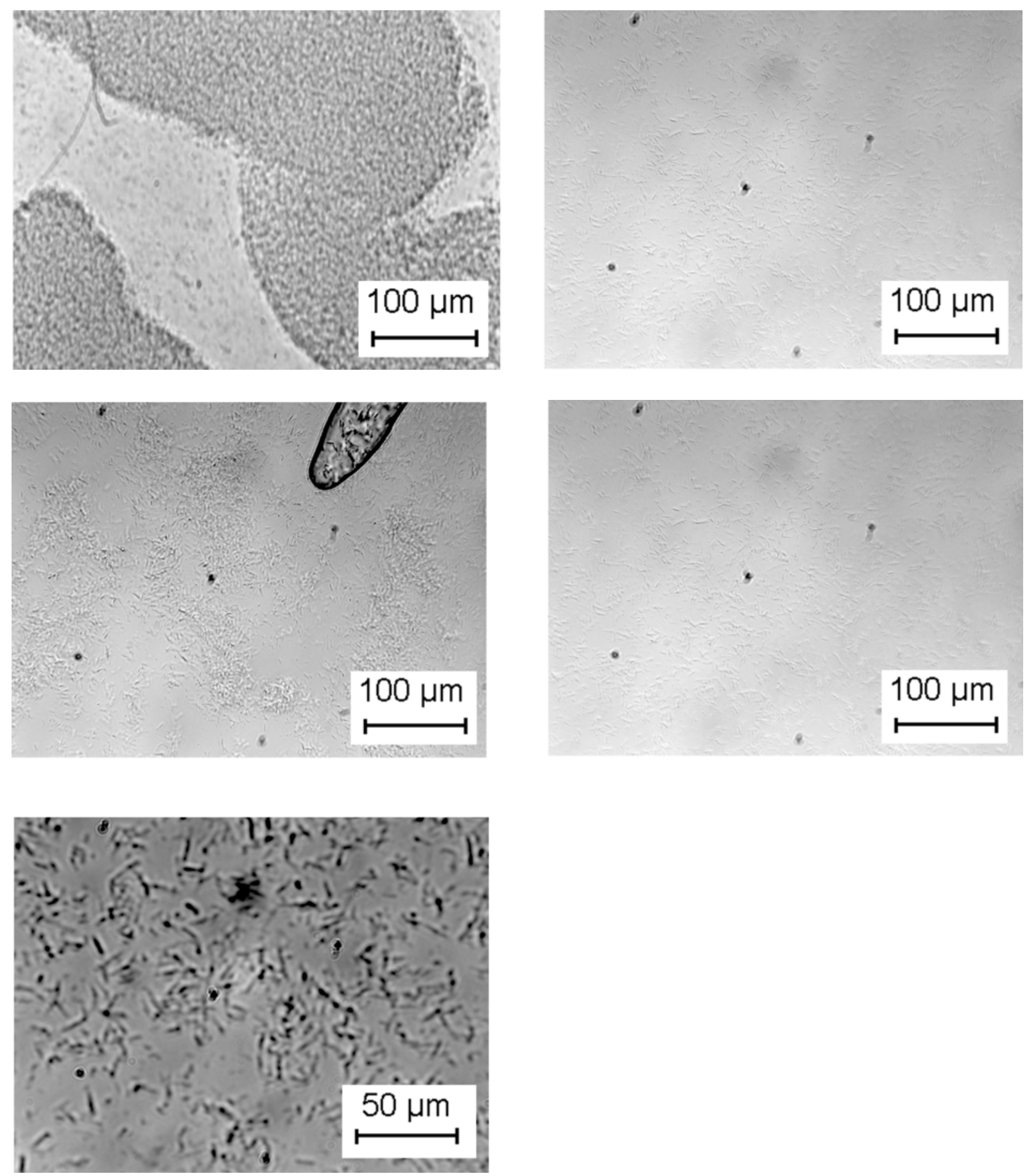

Abb. D.4 

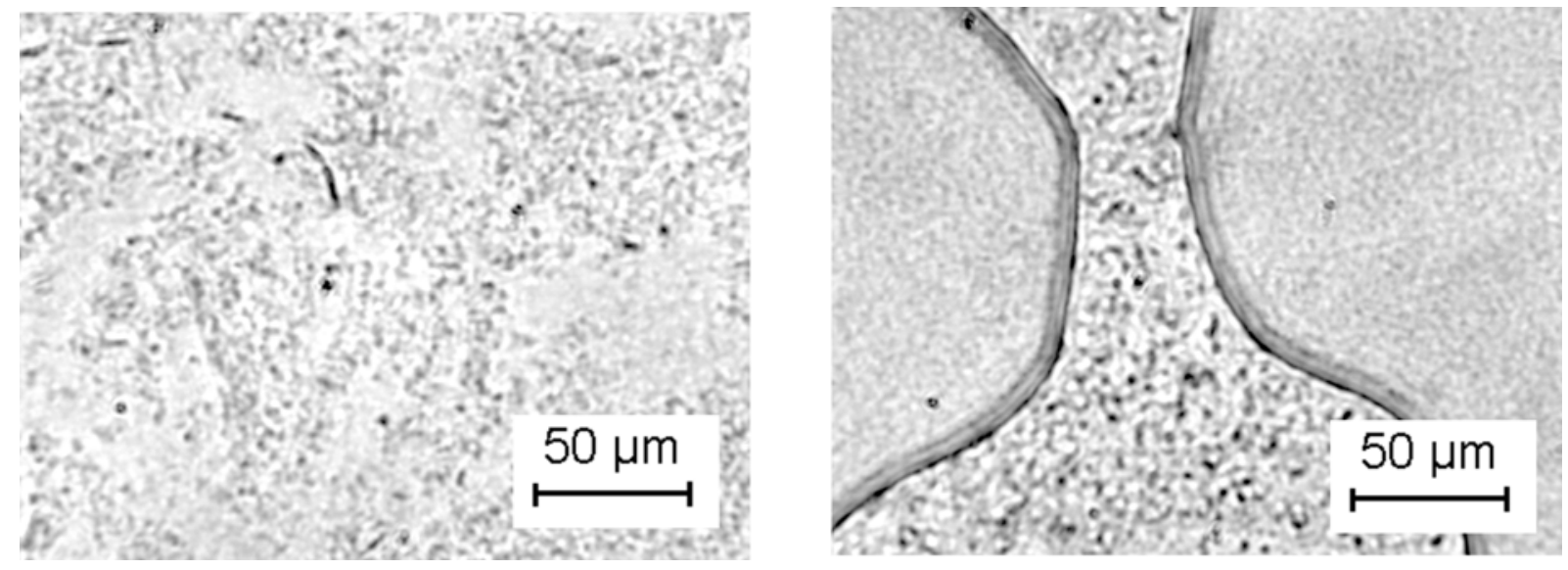

Abb. D.5
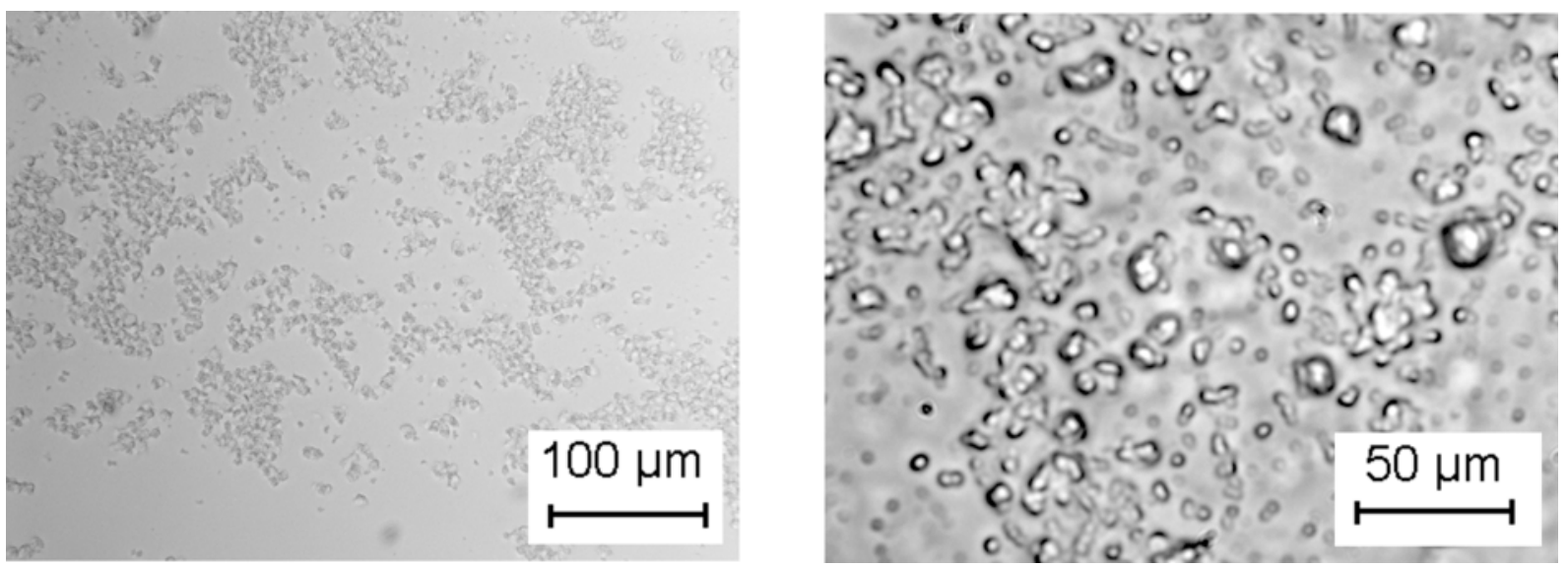

Abb. D.6

\section{D.3 Lysozym $-\mathrm{NH}_{2} \mathrm{COONH}_{4}-\mathrm{H}_{2} \mathrm{O}$}

Tabelle D.3 Zusammensetzung der Feedlösungen für das System Lysozym $-\mathrm{NH}_{2} \mathrm{COONH}_{4}-\mathrm{H}_{2} \mathrm{O}$

\begin{tabular}{||c|c|c||c||}
\hline \multicolumn{3}{|c||}{ Feedpunkt } & \multirow{2}{*||}{ Abbildung } \\
\hline \hline$\xi_{P}$ & $\xi_{S}$ & $\xi_{W}$ & \\
\hline \hline 0,0741 & 0,1049 & 0,8210 & D.7 \\
\hline 0,1194 & 0,0363 & 0,8443 & D. 8 \\
\hline 0,1309 & 0,0264 & 0,8428 & D.9 \\
\hline
\end{tabular}




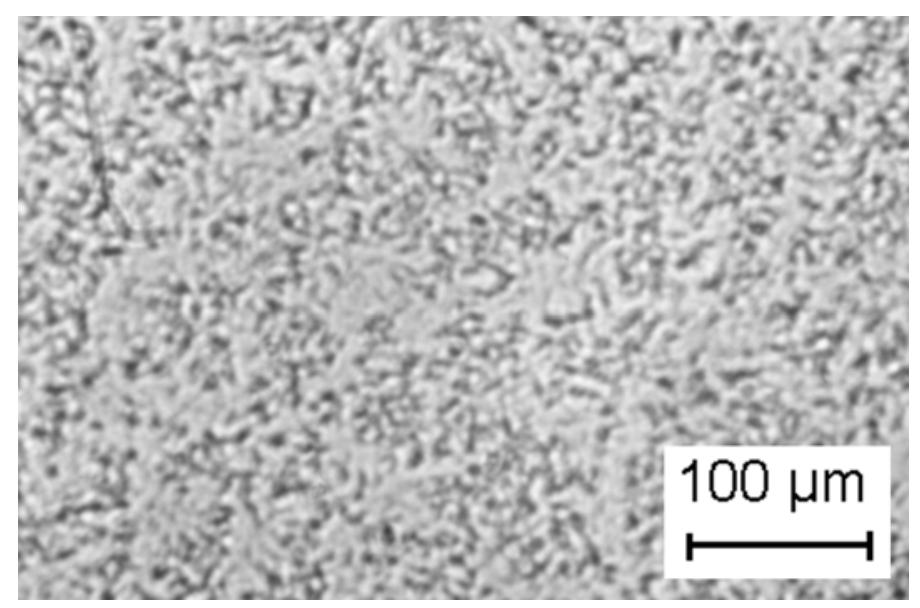

Abb. D.7

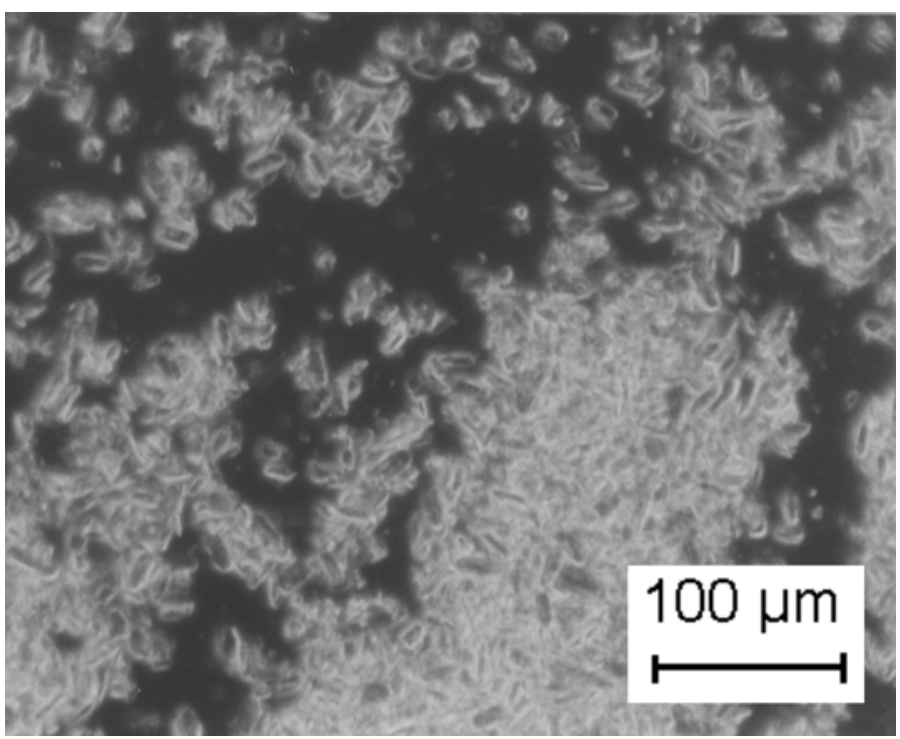

Abb. D.8
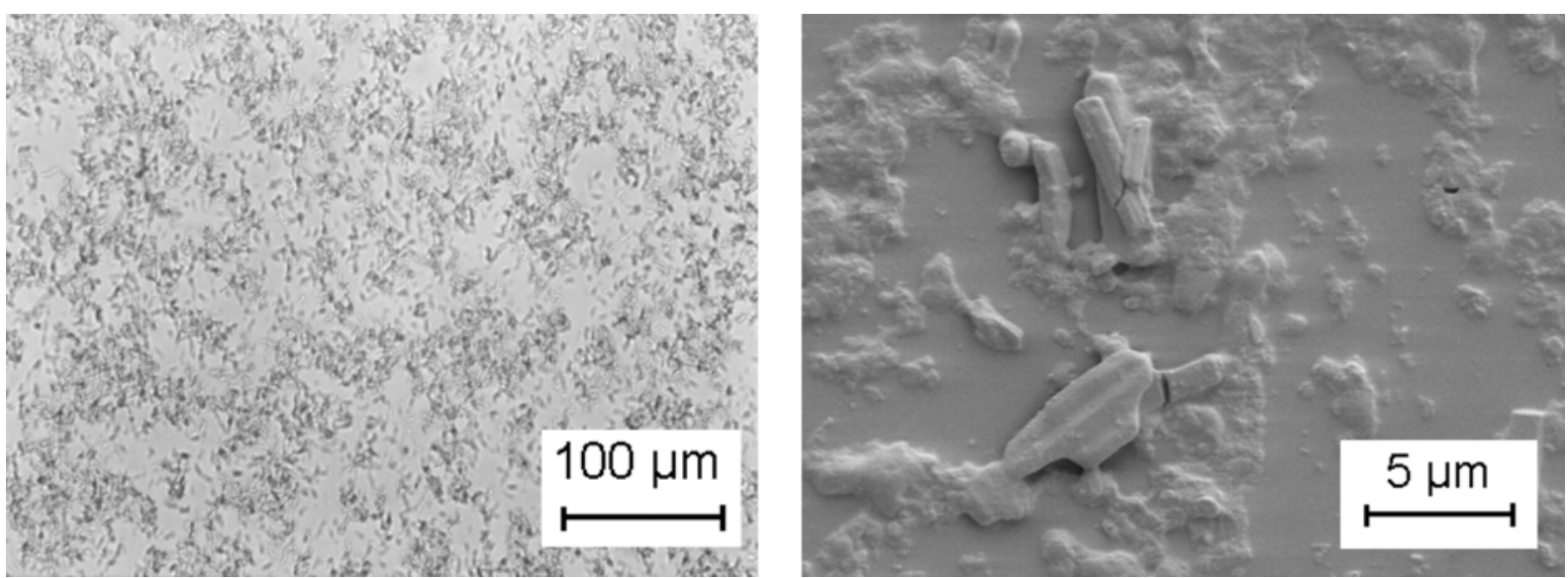

Abb. D.9 


\section{D.4 Lysozym $-\mathrm{NH}_{4} \mathrm{HCO}_{3}-\mathrm{H}_{2} \mathrm{O}$}

Tabelle D.4 Zusammensetzung der Feedlösungen für das System Lysozym $-\mathrm{NH}_{4} \mathrm{HCO}_{3}-\mathrm{H}_{2} \mathrm{O}$

\begin{tabular}{||c|c|c||c||}
\hline \multicolumn{3}{|c||}{ Feedpunkt } & Abbildung \\
\hline \hline$\xi_{P}$ & $\xi_{S}$ & $\xi_{W}$ & D.10 \\
\hline \hline 0,0483 & 0,0987 & 0,8531 & D. 11 \\
\hline 0,0483 & 0,0969 & 0,8547 & D. 12 \\
\hline 0,1179 & 0,0311 & 0,8509 & \\
\hline
\end{tabular}

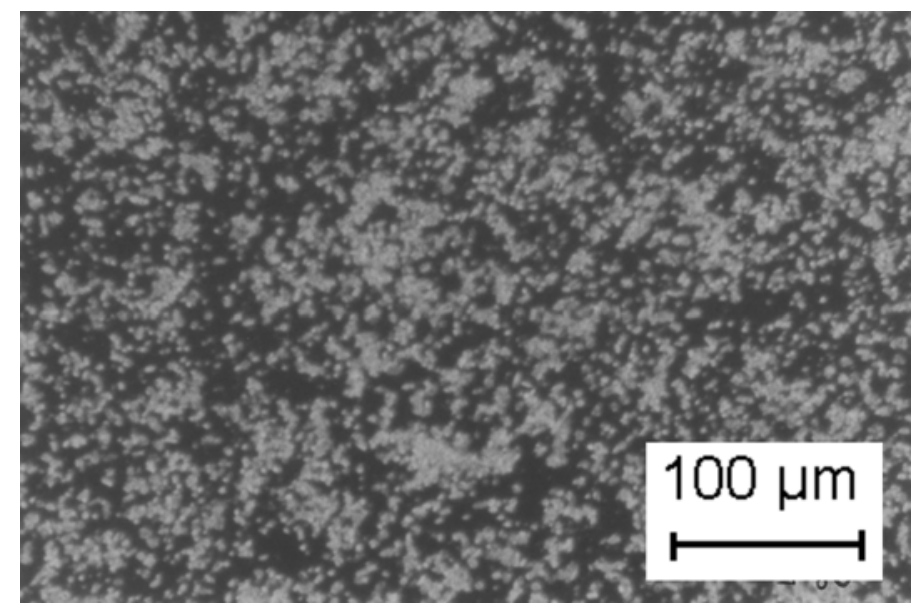

Abb. D.10

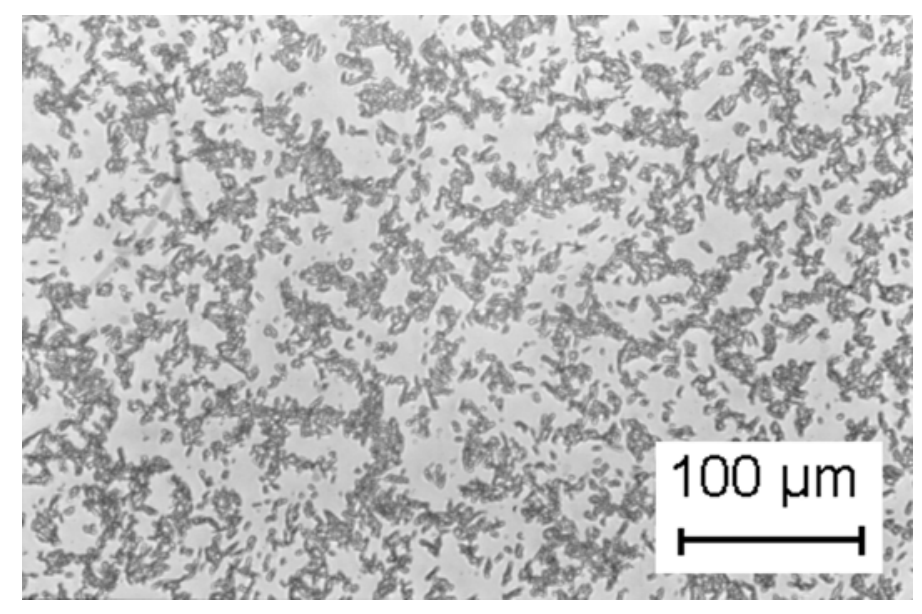

Abb. D.11 

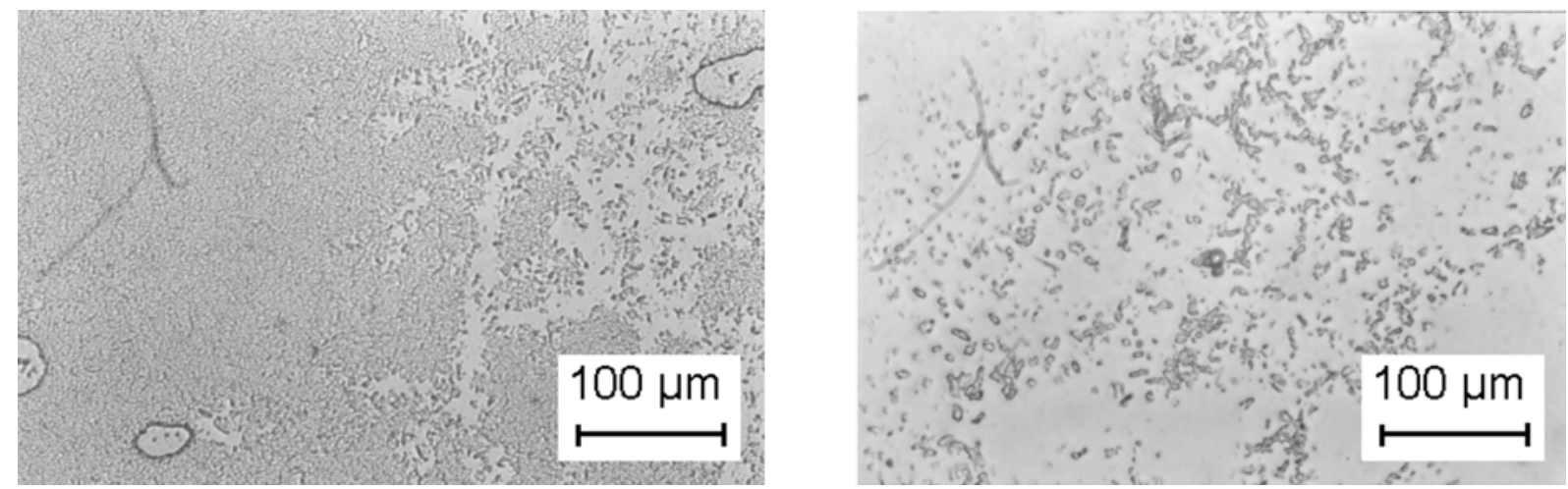

Abb. D.12

\section{D.5 Bovin Serum Albumin - $\left(\mathrm{NH}_{4}\right)_{2} \mathrm{SO}_{4}-\mathrm{H}_{2} \mathrm{O}$}

Tabelle D.5 Zusammensetzung der Feedlösungen für das System BSA $-\left(\mathrm{NH}_{4}\right)_{2} \mathrm{SO}_{4}-\mathrm{H}_{2} \mathrm{O}$

\begin{tabular}{||c|c|c||c||}
\hline \multicolumn{3}{|c||}{ Feedpunkt } & Abbildung \\
\hline \hline$\xi_{P}$ & $\xi_{S}$ & $\xi_{W}$ & \\
\hline \hline 0,0635 & 0,3142 & 0,6223 & $\mathrm{D} .13$ \\
\hline 0,0302 & 0,3598 & 0,6100 & $\mathrm{D} .14$ \\
\hline
\end{tabular}
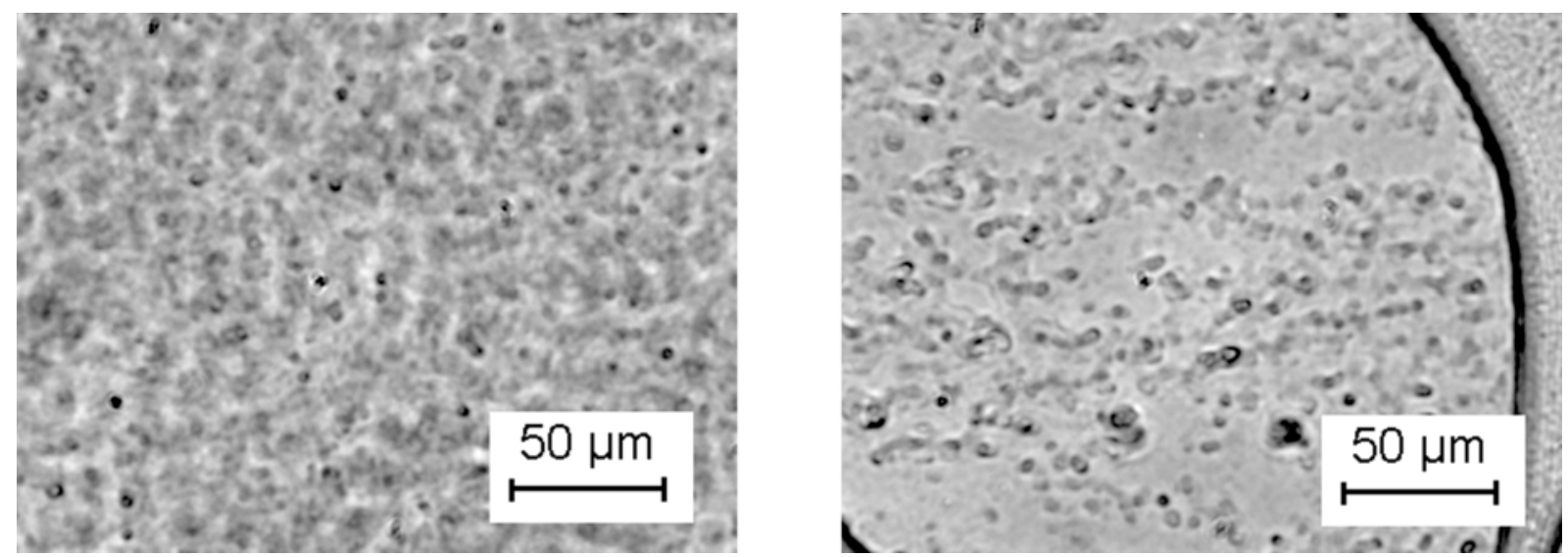

Abb. D.13 

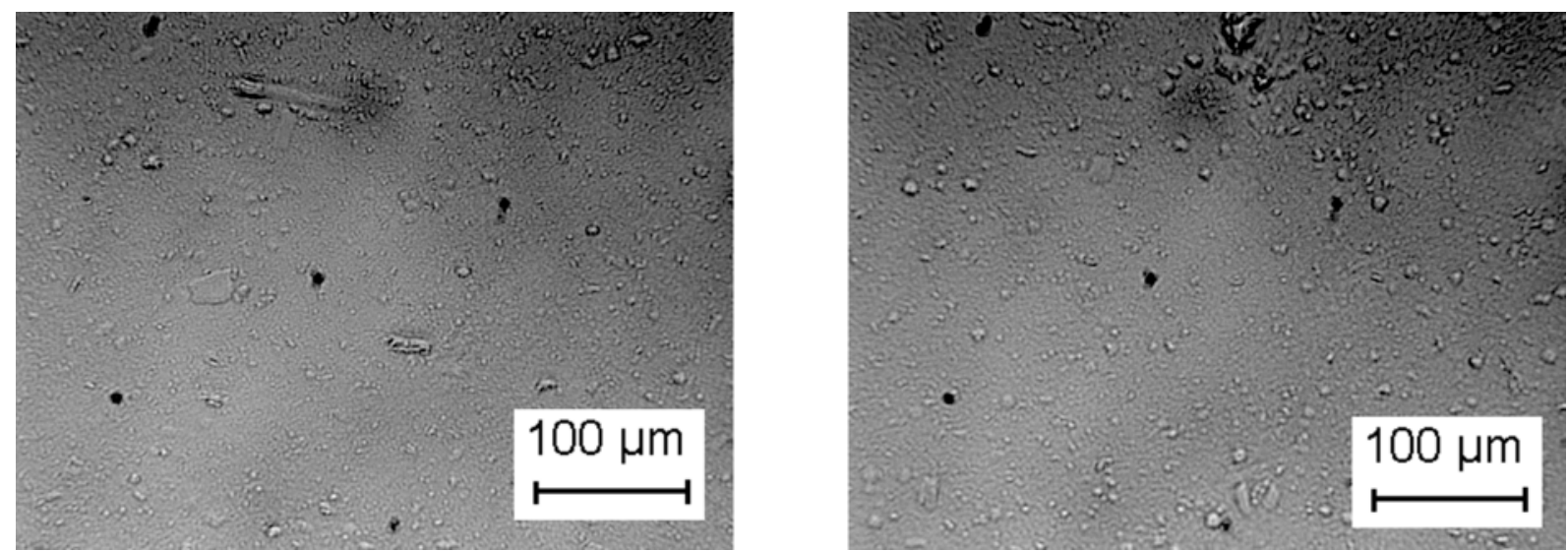

Abb. D.14

\section{D.6 Bovin Serum Albumin - $\mathrm{Na}_{2} \mathrm{SO}_{4}-\mathrm{H}_{2} \mathrm{O}$}

Tabelle D.6 Zusammensetzung der Feedlösungen für das System BSA $-\left(\mathrm{NH}_{4}\right)_{2} \mathrm{SO}_{4}-\mathrm{H}_{2} \mathrm{O}$

\begin{tabular}{||c|c|c||c||}
\hline \multicolumn{3}{|c||}{ Feedpunkt } & Abbildung \\
\hline \hline$\xi_{P}$ & $\xi_{S}$ & $\xi_{W}$ & \\
\hline \hline 0,0744 & 0,2544 & 0,6711 & $\mathrm{D} .15$ \\
\hline
\end{tabular}
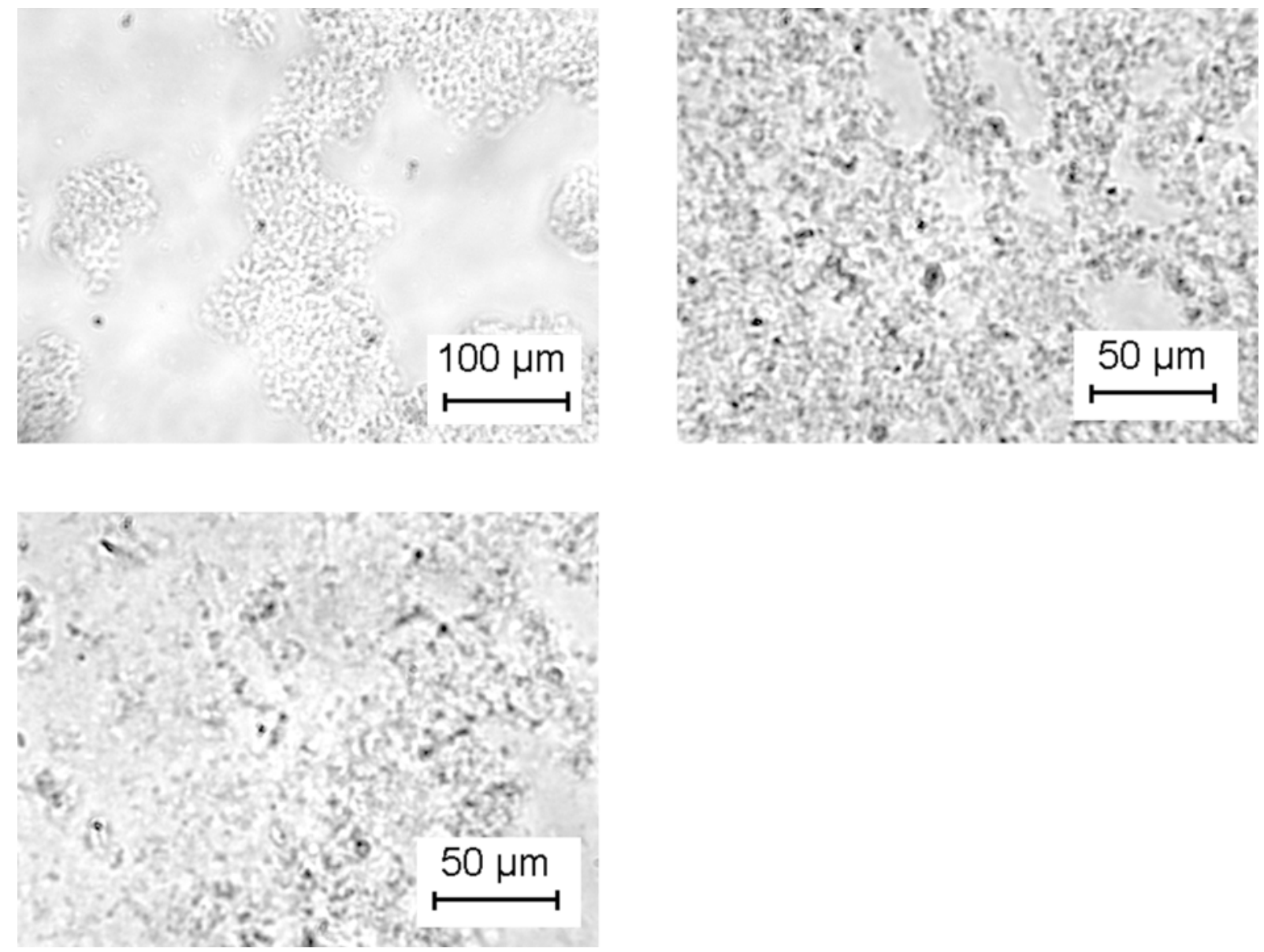
Abb. D.15

\section{D.7 Ovalbumin - $\left(\mathrm{NH}_{4}\right)_{2} \mathrm{SO}_{4}-\mathrm{H}_{2} \mathrm{O}$}

Tabelle D.7 Zusammensetzung der Feedlösungen für das System Ovalbumin $-\left(\mathrm{NH}_{4}\right)_{2} \mathrm{SO}_{4}-\mathrm{H}_{2} \mathrm{O}$

\begin{tabular}{||c|c|c||c||}
\hline \hline \multicolumn{3}{|c||}{ Feedpunkt } & Abbildung \\
\hline \hline$\xi_{P}$ & $\xi_{S}$ & $\xi_{W}$ & \\
\hline \hline 0,1224 & 0,2340 & 0,6436 & D.16 \\
\hline 0,0494 & 0,3333 & 0,6173 & D.17 \\
\hline
\end{tabular}
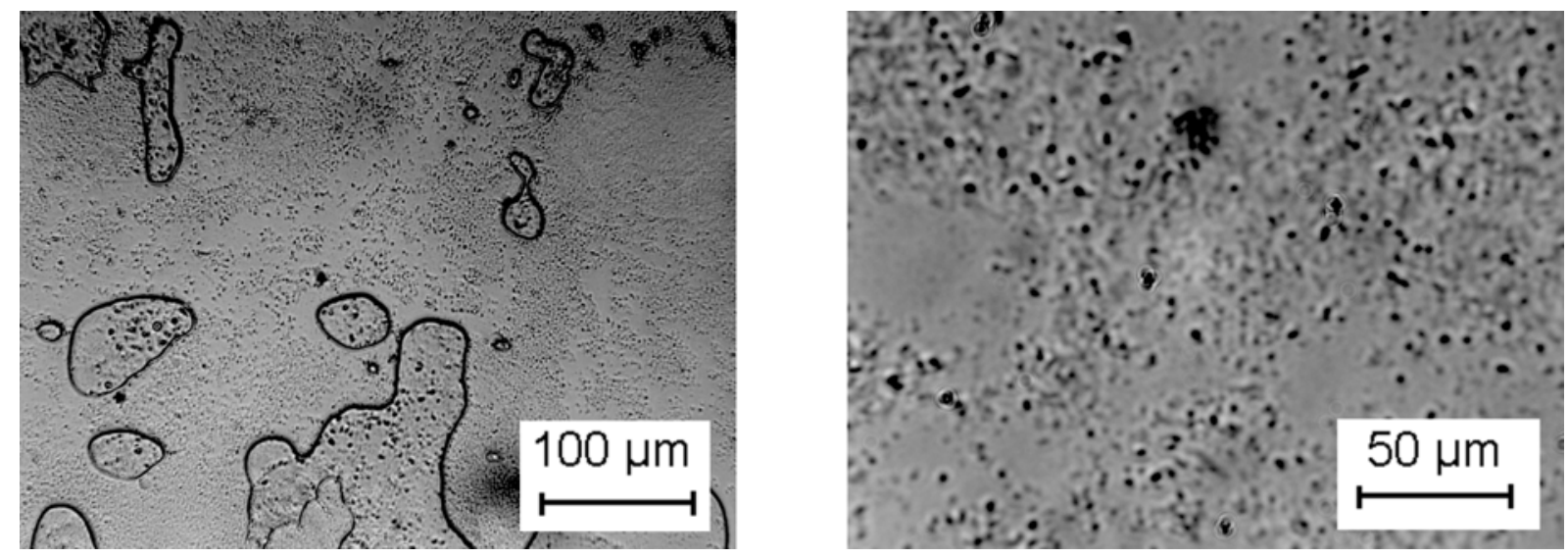

Abb. D.16
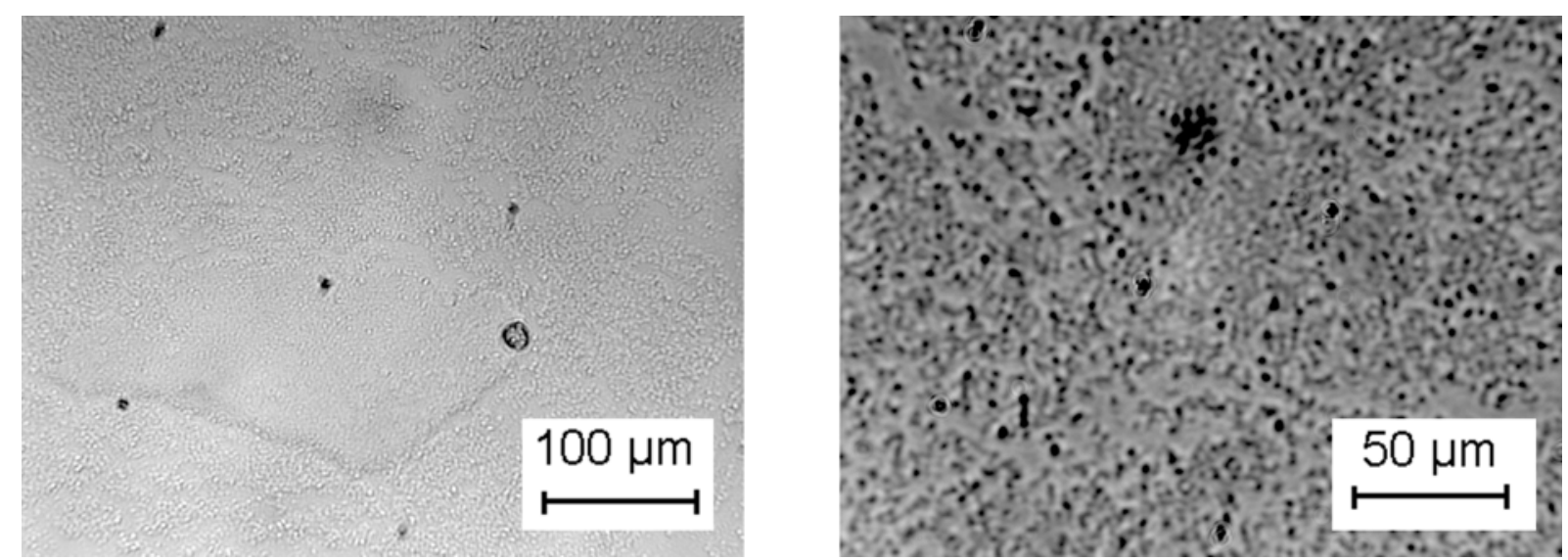

Abb. D.17 


\section{D.8 Ovalbumin $-\mathrm{Na}_{2} \mathrm{SO}_{4}-\mathrm{H}_{2} \mathrm{O}$}

Tabelle D.8 Zusammensetzung der Feedlösungen für das System Ovalbumin $-\left(\mathrm{NH}_{4}\right)_{2} \mathrm{SO}_{4}-\mathrm{H}_{2} \mathrm{O}$

\begin{tabular}{||c|c|c||c||}
\hline \multicolumn{3}{|c||}{ Feedpunkt } & Abbildung \\
\hline \hline$\xi_{P}$ & $\xi_{S}$ & $\xi_{W}$ & \\
\hline \hline 0,0829 & 0,2083 & 0,7088 & D.18 \\
\hline 0,0786 & 0,2492 & 0,6721 & D.19 \\
\hline 0,0719 & 0,2623 & 0,6658 & D. 20 \\
\hline
\end{tabular}
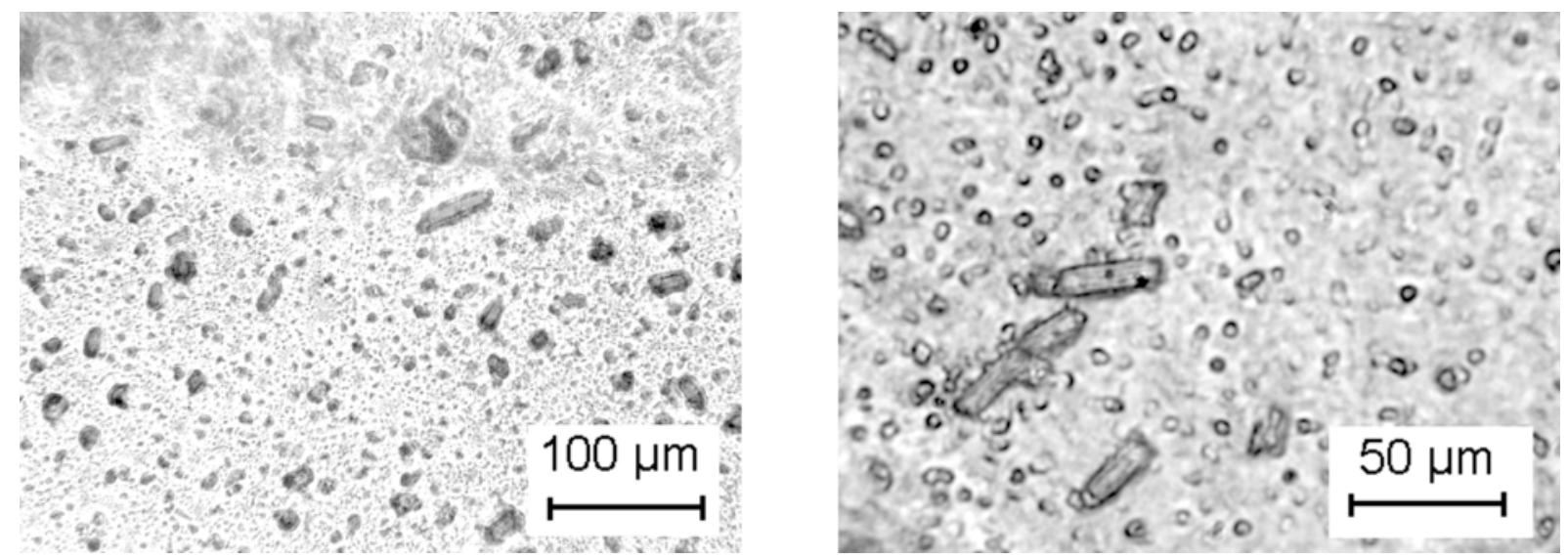

Abb. D.18
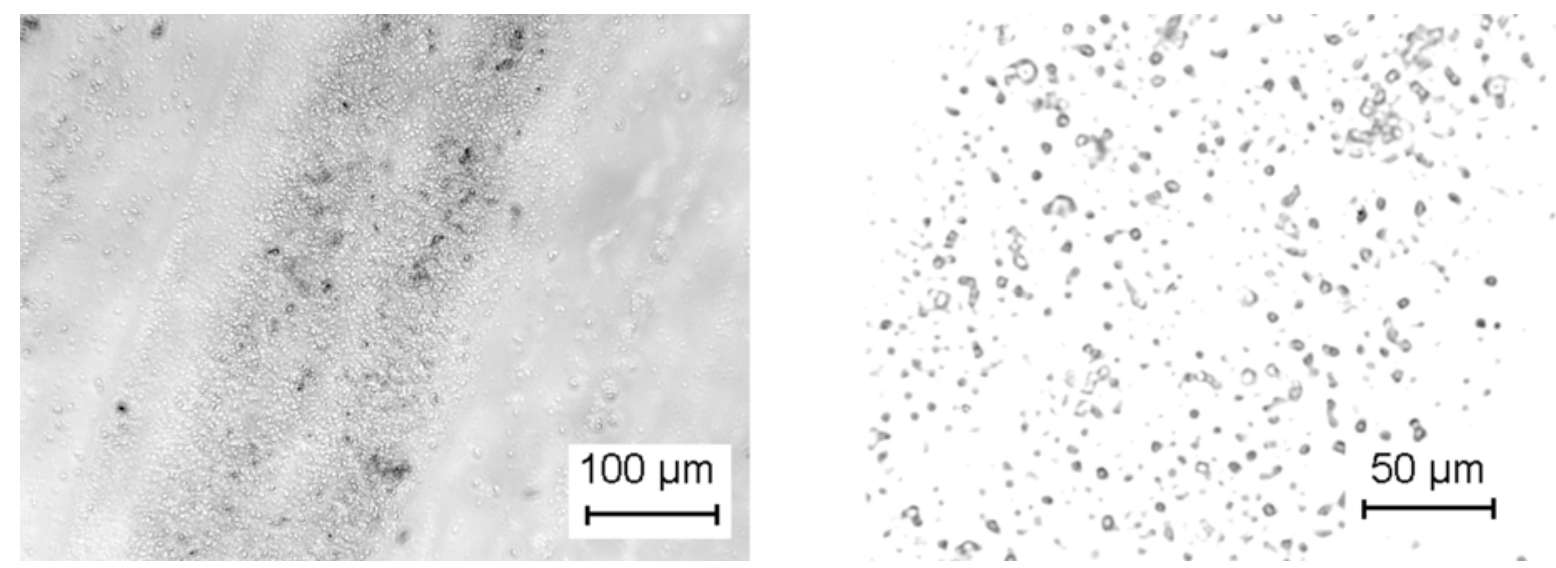

Abb. D.19 

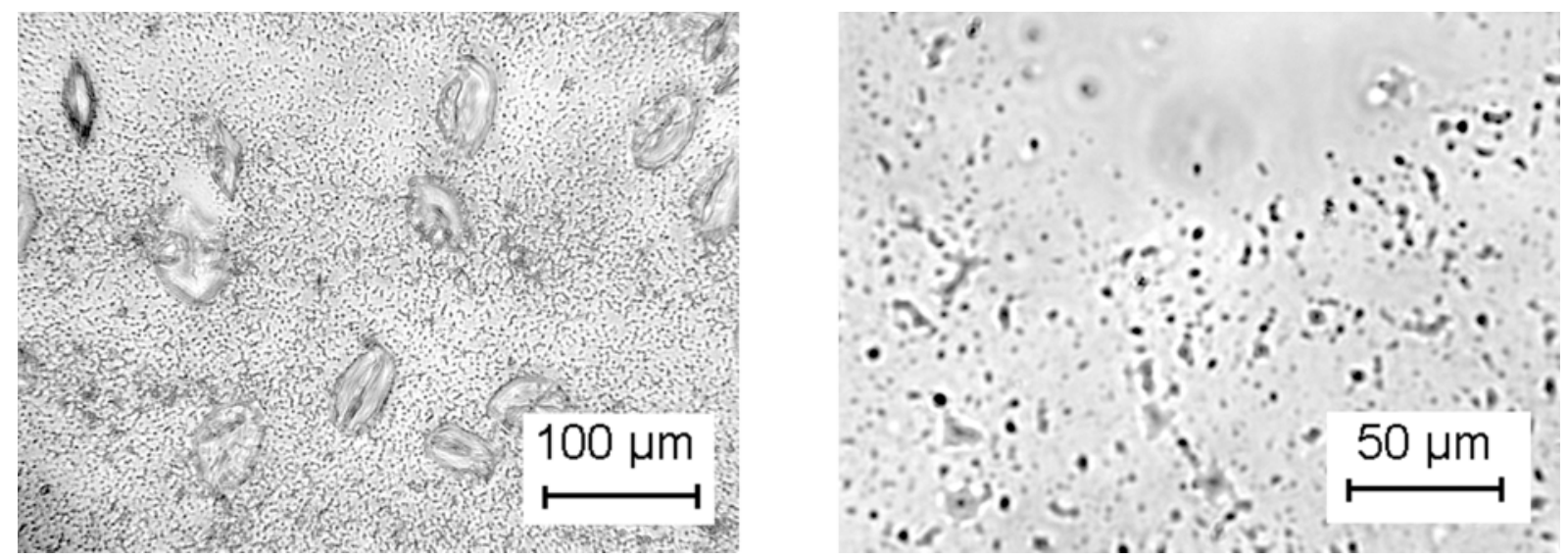

Abb. D.20

\section{D.9 Trypsin - $\left(\mathrm{NH}_{4}\right)_{2} \mathrm{SO}_{4}-\mathrm{H}_{2} \mathrm{O}$}

Tabelle D.7 Zusammensetzung der Feedlösungen für das System Trypsin $-\left(\mathrm{NH}_{4}\right)_{2} \mathrm{SO}_{4}-\mathrm{H}_{2} \mathrm{O}$

\begin{tabular}{||c|c|c||c||}
\hline \multicolumn{3}{|c||}{ Feedpunkt } & Abbildung \\
\hline \hline$\xi_{P}$ & $\xi_{S}$ & $\xi_{W}$ & \\
\hline \hline 0,0518 & 0,3274 & 0,6208 & D.21 \\
\hline 0,1513 & 0,1962 & 0,6525 & D.22 \\
\hline
\end{tabular}
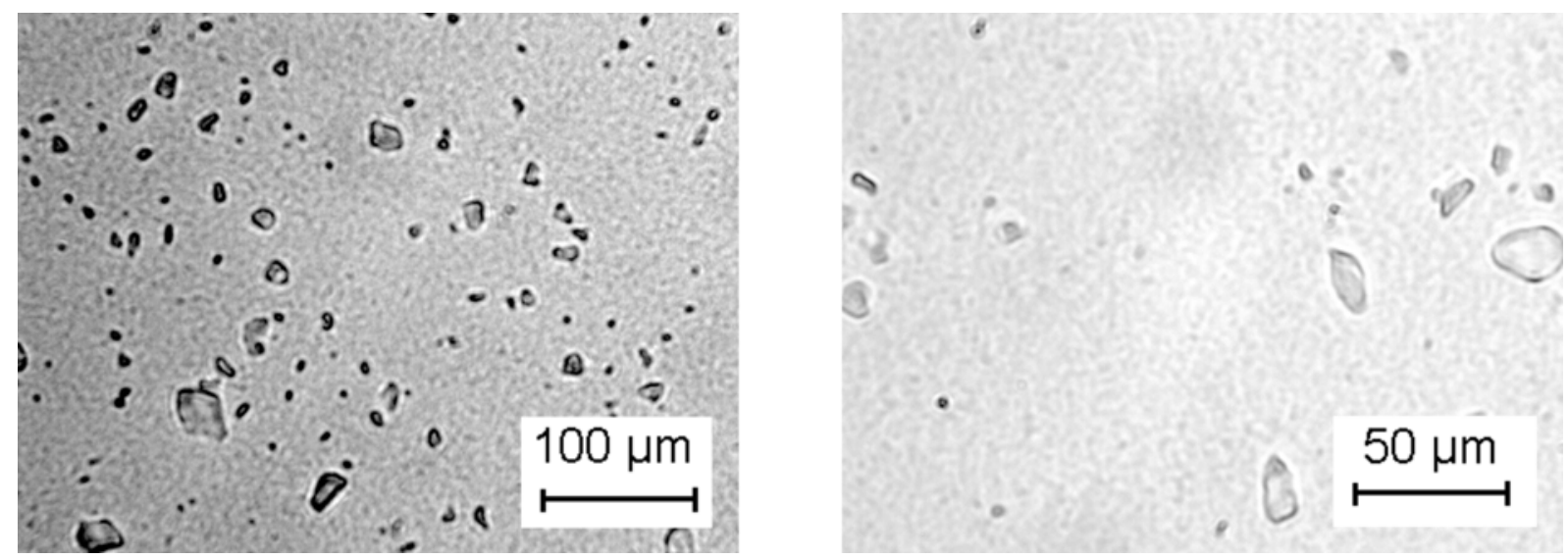

Abb. D.21 

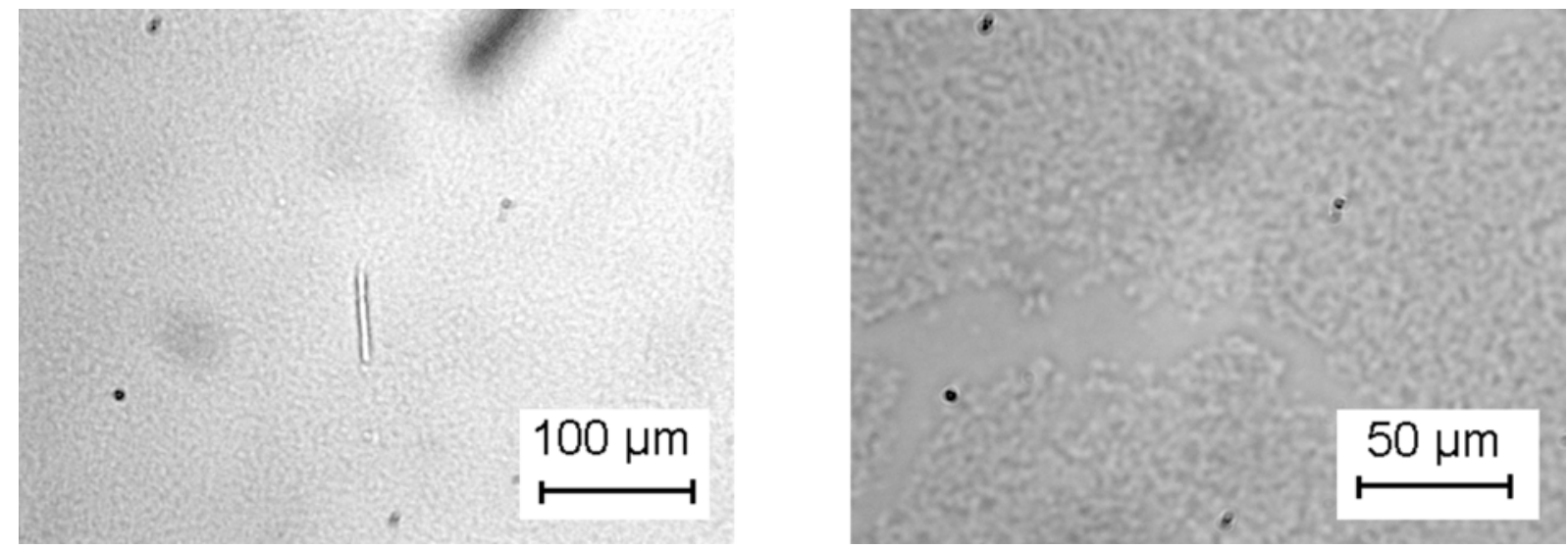

Abb. D.22

\section{D.10 Mikroskopische Aufnahmen von Salzkristallen}

Tabelle D.10

\begin{tabular}{|c||c||}
\hline Salz & Abbildung \\
\hline \hline $\mathrm{Na}_{2} \mathrm{SO}_{4}$ & $\mathrm{D} .23$ \\
\hline$\left(\mathrm{NH}_{4}\right)_{2} \mathrm{SO}_{4}$ & $\mathrm{D} .24$ \\
\hline
\end{tabular}

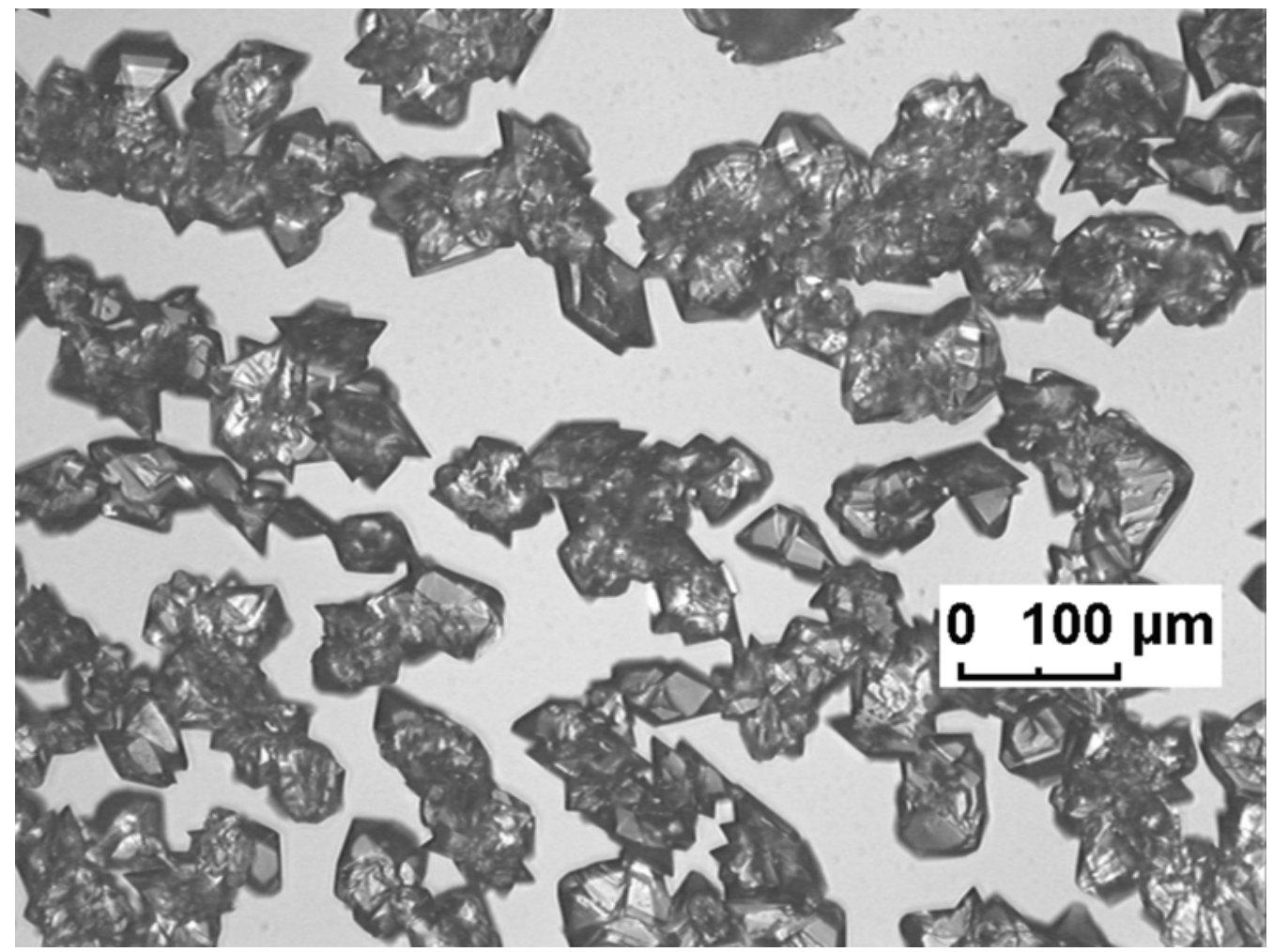

Abb. D.23 


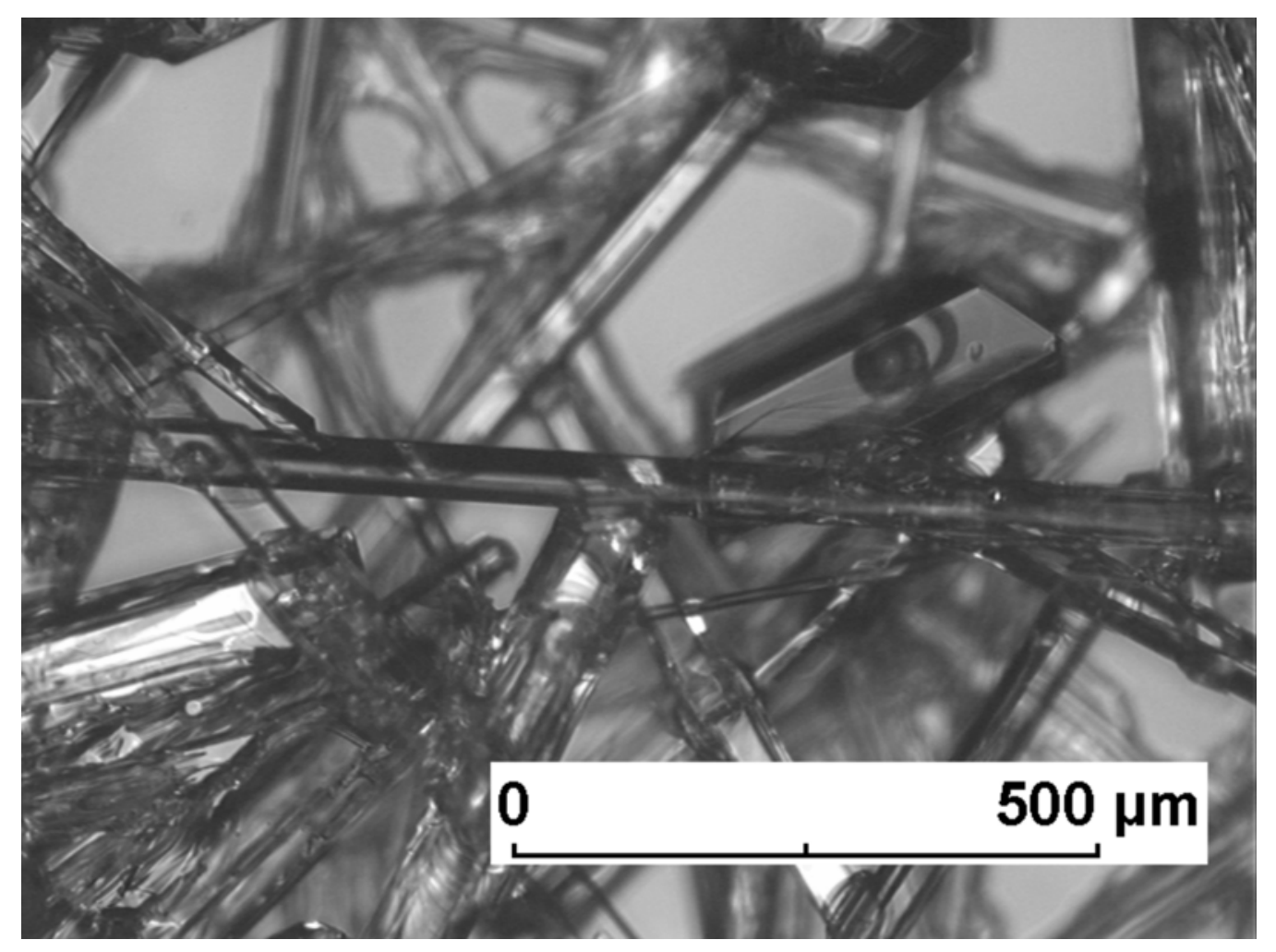

Abb. D. 2 



\section{Lebenslauf}

Geburtsdatum:

Geburtsort:

Familienstand:

Staatangehörigkeit:

\section{Schulbildung:}

1987-1997

\section{Studium:}

$1997-2002$

2002-2006
24. Juni 1980

St. Petersburg, Russische Föderation

ledig

Russische Föderation

\section{Ekaterina Popova}

Grundschule und Akademisches Gymnasium der Staatlichen Universität St. Petersburg, Russische Föderation

Studium an der Staatlichen Universität St. Petersburg, Russische Föderation

Studiengang: Chemie

Vertiefungsrichtung: Physikalische Chemie

Thema der Diplomarbeit: „Untersuchungen des Dampf-Flüssig-

Gleichgewichts in Systemen Polymer (Polyvinylacetat, Polybutylacrylat) - Lösungsmittel (Vinylacetat, Butylacrylat) bei Prof. Dr. N. Smirnova

Promotionsstudium an der Technischen Universität Kaiserslautern Fachbereich Maschinenbau und Verfahrenstechnik

Lehrstuhl für Technische Thermodynamik

Prof. Dr.-Ing. G. Maurer

\section{Berufliche Tätigkeit:}

2002-2006

Wissenschaftliche Mitarbeiterin am Lehrstuhl für Technische Thermodynamik der Technischen Universität Kaiserslautern Prof. Dr.-Ing. G. Maurer

Seit Sept. $2006 \quad$ Laborleiterin bei der BASF AG, Polymertechnologie 